\title{
MECHANISMS OF ACTION FOR ARYL HYDROCARBON RECEPTOR LIGANDS IN THE PLHC-1 CELL LINE
}

\author{
By \\ Eli V. Hestermann \\ Bachelor of Science, Purdue University, 1994 \\ Submitted in partial fulfillment of the requirements for the degree of \\ Doctor of Philosophy \\ at the \\ MASSACHUSETTS INSTITUTE OF TECHNOLOGY \\ and the \\ WOODS HOLE OCEANOGRAPHIC INSTITUTION
}

December 1999

(C) 1999 Eli V. Hestermann

All rights reserved.

The author hereby grants to MIT and WHOI permission to reproduce paper and electronic copies of this thesis in whole or in part and to distribute them publicly.

Signature of Author

Joint Program in Oceanography

Massachusetts Institute of Technology and Woods Hole Oceanographic Institution

December 1999

Certified by

John J. Stegeman

Thesis Supervisor

Accepted by

Mark E. Hahn

Thesis Supervisor and

Chair, Joint Committee for Biological Oceanography

Woods Hole Oceanographic Institution 
Life is short,

The art long,

Opportunity fleeting,

Experiment treacherous,

Judgment difficult.

- Hippocrates

Aphorisms, sec. I, 1 


\section{TABLE OF CONTENTS}

Frontispiece 3

Brief Abstract $\quad 6$

Complete Abstract $\quad 7$

List of Abbreviations $\quad 9$

List of Tables 11

$\begin{array}{ll}\text { List of Figures } & 12\end{array}$

$\begin{array}{ll}\text { Acknowledgements } & 14\end{array}$

CHAPTER 1: Introduction 18

$\begin{array}{ll}\text { Background } & 19\end{array}$

HAH Toxicity 19

Ah Receptor 22

Ah Receptor Signaling Cross-talk 29

Receptor Pharmacology 33

Rationale $\quad 35$

CHAPTER 2: Characterization of Ah Receptor Expression, Proliferation 38 and the Cell Cycle in PLHC-1 Cells
Abstract

Introduction $\quad 40$

Materials and Methods $\quad 42$

Results $\quad 47$

Discussion $\quad 59$

CHAPTER 3: Cell Culture Serum Alters the Uptake and Relative Potencies $\quad 64$

of Halogenated Aromatic Hydrocarbons in PLHC-1 Cells Abstract $\quad 65$

Introduction $\quad 66$

Materials and Methods $\quad 68$

Results $\quad 72$

Discussion $\quad 86$

CHAPTER 4: Stimulus-Response Relationships Demonstrate the 91

Contributions of Affinity and Intrinsic Efficacy toAryl Hydrocarbon

Receptor Ligand Potency

$\begin{array}{ll}\text { Abstract } & 92\end{array}$

Introduction $\quad 93$

Materials and Methods $\quad 95$

Results 101

Discussion $\quad 114$ 
CHAPTER 5: Serum Withdrawal Reduces CYP1A Induction by TCDD in PLHC-1 Cells: A Link Between AHR Expression and Response Abstract Introduction

122

Materials and Methods 123

Results

126

Discussion

CHAPTER 6: Conclusions and Future Directions 139

APPENDIX A: A Primer on Radioligand Binding Assays 147

APPENDIX B: Development of an AHR Binding Assay for PLHC-1 Cells 157

APPENDIX C: Modeling the Effects of Changes in AHR Expression 162 on Responses

APPENDIX D: Predicting AHR Ligand Intrinsic Efficacy in H4IIE 167

$\begin{array}{ll}\text { REFERENCES } & 169\end{array}$ 


\section{BRIEF ABSTRACT}

Aryl hydrocarbon receptor (AHR) expression and activity was characterized in the teleost hepatoma cell line, PLHC-1. This work was carried out in order to gain insights into mechanisms of halogenated aromatic hydrocarbon (HAH) toxicity. The results improve our ability to characterize the risks posed by $\mathrm{HAH}$ exposure as well as further demonstrate the application of cultured cells to questions of AHR function.

Cell proliferation, the cell cycle, and DNA sequences for an AHR2 and $\beta$-actin were all characterized in PLHC-1. Serum withdrawal of early-passage cells reduced AHR expression and consequently TCDD-induced induction of cytochrome P4501A (CYP1A), which is mediated by the AHR.

Serum in cell culture medium was found to reduce bioavailability of AHR agonists and significantly alter relative potencies of CYP1A induction, raising the possibility of artificial differences in measured potencies among cell types and laboratories. A quantitative pharmacological approach was used to show that both AHR binding affinity and intrinsic efficacy of ligands contribute to observed CYP1A induction potencies. These data also demonstrate the existence of "spare receptors" in this system. Non-additive effects of low-efficacy ligands call into question the utility of the "toxic equivalency factor" approach currently used for HAH risk assessment. 


\section{COMPLETE ABSTRACT}

The teleost hepatoma cell line, PLHC-1, was further characterized and used to explore mechanisms of toxicity of halogenated aromatic hydrocarbons (HAH) and function of the aryl hydrocarbon receptor (AHR). This work proceeded along two principle avenues: 1) investigation of interactions among AHR signaling and pathways involved in cell cycle and cell proliferation, and 2) determination of factors contributing to measured response potencies of AHR ligands. These two lines converged to allow use of a quantitative stimulus-response model to correlate a decline in AHR expression with changes in response.

The doubling time, lengths of cell cycle stages, and ability of several cell cycle inhibitors to synchronize populations were determined. The prototypical AHR agonist 2,3,7,8-tetrachlorodibenzo-p-dioxin (TCDD) was found to inhibit PLHC-1 proliferation in a time- and dose-dependent manner in one sub-clone, but not in several others, suggesting heterogeneity exists within the cell line. Identification of partial sequences for an AHR2 and $\beta$-actin were obtained and used to measure AHR mRNA expression. Use of this technique and ligand binding assays demonstrated no change in AHR mRNA or protein levels throughout the cell cycle.

The effect of serum in cell culture medium on the bioavailability of AHR agonists was determined in PLHC-1 cells. The EC50 for AHR-mediated induction of cytochrome P4501A (CYP1A) activity by TCDD was increased 20 -fold when $10 \%$ calf serum was present in the medium as compared to treatment in serum-free medium. The apparent difference in potencies was a result of decreased bioavailability in the presence of serum, effectively reducing the concentration of TCDD within the cells. Induction of CYP1A protein and activity in response to treatment with each of three coplanar polychlorinated biphenyls (PCB congeners 77, 126, and 169) was similarly affected by serum. Relative potencies (calculated as $\mathrm{EC} 50_{\mathrm{TCDD}} / \mathrm{EC} 5 \mathrm{O}_{\mathrm{PCB}}$ ) for CYP1A activity induction by the three $\mathrm{PCBs}$ were significantly higher in the absence of serum.

In order to build quantitative stimulus-response model for the AHR, binding affinities and CYP1A induction potencies were measured in PLHC-1 cells for ten halogenated aromatic hydrocarbons (HAH). From these data, an operational model of AHR action was used to determine intrinsic efficacies of these ligands. TCDD, 2,3,7,8tetrachlorodibenzofuran (TCDF), and non-ortho-substituted PCB congeners 77, 81, 126 and 169 behaved as full agonists and displayed high intrinsic efficacy. In contrast, the mono- and di-ortho substituted PCBs bound to the AHR but displayed lower or no intrinsic efficacy. PCB 156 was a full agonist, but with an intrinsic efficacy 10- to 50fold lower than non-ortho-substituted PCBs. PCB 118 was a very weak partial agonist. PCBs 105 and 128 were shown to be competitive antagonists in this system. In cotreatments, both PCB 156 (a low intrinsic-efficacy agonist) and PCB 128 (a competitive antagonist) inhibited the induction of CYP1A by TCDD. The stimulus-response model also demonstrates the existence of "spare" receptors in this system. These data show that the insensitivity of PLHC-1 cells to ortho-substituted PCBs is due to both reduced affinity and reduced intrinsic efficacy as compared to non-ortho-subsituted PCBs. 
The ability of changes in serum used in cell culture medium to alter expression of the AHR and subsequent induction of CYP1A in PLHC-1 teleost hepatoma cells was tested. Growth in serum-free medium for two days led to a loss of CYP1A inducibility by TCDD. In contrast, growth in medium with $10 \%$ delipidated calf serum increased the inducibility of both CYP1A protein and enzymatic activity, relative to controls grown with $10 \%$ complete calf serum. Measurement of induction of CYP1A in cells grown in serum-free medium for 1 and 2 days demonstrated a progressive loss of inducibility. This loss of response was correlated to a time-dependent loss of AHR protein, as measured by specific binding of ${ }^{3} \mathrm{H}-\mathrm{TCDD}$. Using an operational model for AHR action in PLHC-1, the measured reduction in AHR could be shown to account for the changes in induction of CYP1A. Expression of AHR protein was unaffected by growth in $10 \%$ delipidated serum. These phenotypes were found in only a limited subset of PLHC-1, and only in early-passage cells. Comparison of early- and late-passage cells revealed a 2fold greater rate of proliferation in the latter, suggesting a growth advantage is coincident with loss of controls on expression of AHR. These results provide a quantitative link between changes in receptor expression and a downstream response, pointing the way for future studies of effects on sensitivity to toxic responses in vitro and in vivo.

Taken together, this work further establishes the PLHC-1 cell line as a piscine model of AHR research. Fundamental molecular processes of AHR function have been explored using models of receptor pharmacology. The knowledge gained from these models has been applied not only to specific questions of HAH toxicity in fish, but also to general studies of $\mathrm{HAH}$ risk assessment across the vertebrate subphylum. Extension and continued use of this approach will strengthen the connections among our understanding of AHR activity and $\mathrm{HAH}$ toxicity from the level of the molecule to the environment. 


\section{List of Abbreviations}

$\mathrm{AHH}$

AHR

ARNT

$\mathrm{BaP}$

bHLH

$\mathrm{BNF}$

bp

BSA

CYP1A

DMSO

EC50

ED50

EFEE

ELISA

EROD

FACS

FBS

GR

$\mathrm{HAH}$

HPLC

HSP90

K(D)

$\mathrm{kb}$

LD50

LSC

MEM

MFME

$\mathrm{PAH}$

PAS

PB

PBS

PCB

PI

PKC

PLHC

$\mathrm{RB}$

RT-PCR

$\mathrm{S}_{0}$

$\mathrm{S}_{10}$

$\mathrm{S}_{5}$

SAR aryl hydrocarbon hydroxylase

aryl hydorcarbon receptor, Ah receptor

aryl hydrocarbon nuclear translocator

benzo[a]pyrene

basic helix-loop-helix

beta-naphthoflavone

base pairs

bovine serum albumin

cytochrome P450 1A

dimethyl sulfoxide

dose required to elicit a $50 \%$ maximal response in vitro

dose required to elicit a $50 \%$ maximal response in vivo

ethoxyfluorescein ethyl ester

enzyme-linked immunosorbence assay

ethoxyresorufin O-deethylase

fluorescence-activated cell sorting

fetal bovine serum

glucocorticoid receptor

halogenated aromatic hydrocarbon

high pressure liquid chromatography

90 kilodalton heat shock protein

equilibrium dissociation constant

kilobase pairs

dose lethal to $50 \%$ of the test population

liquid scintillation counting

minimum essential medium

methoxyfluorescein methyl ester

polynuclear aromatic hydrocarbon

PER-ARNT-SIM homology domain

phenobarbital

phosphate-bufferred saline

polychlorinated biphenyl

propidium iodide

protein kinase $\mathrm{C}$

Poeciliopsis lucida hepatocellular carcinoma

retinoblastoma

reverse transcriptase - polymerase chain reaction

serum-free medium

medium containing $10 \%$ bovine calf serum

medium containing $5 \%$ bovine calf serum

structure-activity relationships 
$\mathrm{S}_{\mathrm{DL}}$

TCDD

TCDF

TEF

TGF- $\beta$

XRE

medium containing $10 \%$ delipidated serum

2,3,7,8-tetrachlorodibenzo- -dioxin

2,3,7,8-tetrachlorodibenzofuran

toxic equivalency factor

transforming growth factor beta

xenobiotic response element 


\section{List of Tables}

Chapter 1

Table 1. Names and relative toxic potencies of selected HAH. 23

Table 2. Gene products regulated by ligands of the AHR. 27

Chapter 2

Table 1. PCR primer sequences. $\quad 46$

Table 2. Synchronization of PLHC-1 by chemical treatment. 50

Chapter 3

Table 1. Effect of medium on dose-response relationship parameters $\quad 72$ for EROD rates in PLHC-1 cells treated with TCDD.

Table 2. Fractions of TCDD associated with culture medium, PLHC-1 75 cells, and well surfaces.

Table 3. Effect of serum on CYP1A induction EC50s measured by 83 EROD and ELISA for TCDD and three coplanar PCBs.

Table 4. Effect of serum on determination of induction relative 86 potencies.

Chapter 4

Table 1. Parameters for CYP1A and EROD activity induction and 106 AHR binding for selected HAH.

Table 2. Stimulus-response coupling for AHR agonists. 110

Appendix A

Table 1. Binding data for ${ }^{3} \mathrm{H}-\mathrm{TCDD}$ in PLHC-1 cells. 152

Table 2. Binding coefficients. 154

Table 3. Binding constants for different fitting methods. 156

Appendix C

Table 1. Effect of receptor number on EC50 and maximum response. $\quad 166$

Appendix D

Table 1. Calculating relative efficacies in the rat from relative receptor affinities measured in rat cytosol and induction potencies measured in H4IIE cells. 


\section{List of Figures}

Chapter 1

Figure 1. Representative HAH structures. 20

Figure 2. The Ah receptor signaling pathway. 25

Figure 3. Functional domains of mouse AHR and ARNT. 28

Chapter 2

Figure 1. Proliferation in PLHC-1 cells. 48

Figure 2. Determination of the minimum seeding density. 48

Figure 3. Flow cytometric analysis of DNA content in PLHC-1. 49

Figure 4. Density-dependence of synchronization efficiency. 51

Figure 5. Flow cytometric analysis of CYP1A expression. 52

Figure 6. Effect of TCDD on PLHC-1 proliferation. 54

Figure 7. RT-PCR cloning of PLHC-1 AHR2 and $\beta$-actin. 56

Figure 8. PLHC-1 AHR expression after cell cycle synchronization. $\quad 58$

Chapter 3

Figure 1. Effect of serum on potency of EROD induction by TCDD. 73

Figure 2. Effect of serum on TCDD uptake in PLHC-1 cells. 76

Figure 3. Effect of serum on specific binding of TCDD in PLHC-1 cells. 79

Figure 4. TCDD uptake and EROD induction. 80

Figure 5. Effect of serum on potency for EROD induction by PCBs. $\quad 82$

Figure 6. Effect of serum on potency of CYP1A induction by HAH. 84

\section{Chapter 4}

$\begin{array}{ll}\text { Figure 1. EROD induction by AHR agonists. } & 102\end{array}$

Figure 2. CYP1A induction by AHR agonists. 103

Figure 3. Inhibition of $\left[{ }^{3} \mathrm{H}\right] \mathrm{TCDD}$ binding by AHR ligands. 104

Figure 4. Competitive inhibition of $\left[{ }^{3} \mathrm{H}\right]$ TCDD binding by PCB $105 . \quad 108$

Figure 5. Stimulus-response coupling for AHR agonists. 109

Figure 6. Demonstration of ligand intrinsic efficacy by co-treatment. 112

Figure 7. Schild regression for co-treatments. 113

\section{Chapter 5}

Figure 1. Effect of growth medium on EROD inducibility by TCDD. 127

$\begin{array}{ll}\text { Figure 2. Effect of growth medium on CYP1A protein induction. } & 127\end{array}$

Figure 3. Time course of induction of EROD activity. 129

Figure 4. Effect of 1-2 days of growth in different media. 130

Figure 5. Effect of growth medium and time on AHR expression. 131

Figure 6. Response of early and late passage cells to growth medium. 132

Figure 7. Proliferation in early- and late-passage cells. 132

Figure 8. Influence of receptor number on induction of CYP1A. 134 


\section{Appendix A}

Figure 1. Linear and semi-log plots of binding. $\quad 150$

Figure 2. Non-specific binding. 153

Figure 3. Scatchard plot. 153

Figure 4. Varying Hill coefficient and binding data fit. 154

Figure 5. Total binding determination. 154

Figure 6. Fit of curve predicted from total binding. 155

Figure 7. Simultaneous fitting of specific and non-specific binding. 155

Figure 8. Fits to specific binding using various methods. 156

Appendix B

Figure 1. Binding measured by filtration on GF/A or GF/F filters. 158

Figure 2. Binding measured after exposure in suspended cells. 159

Figure 3. Time course of binding in PLHC-1 cells. 160

$\begin{array}{ll}\text { Figure 4. Binding with increasing cell protein. } & 161\end{array}$

Appendix C

Figure 1. Effect of TCDD and PB on AHR expression. 163

Figure 2. Effect of receptor number on response. 165 


\section{ACKNOWLEDGEMENTS}

If I have the gift of prophecy and can fathom all mysteries and all knowledge... but have not love, I am nothing. $\quad-1$ Corinthians 13:2

I heard this passage at Brenda's wedding last year, and immediately knew it belonged here as well. Readers who know me even moderately well will not be surprised that this is the section of the dissertation I started writing first: not only because I have so many people to thank, but also because I consider it the most fun. I think the relationships we form are more important than the knowledge we acquire.

First there are my committee members. All of them willingly took on the burden of advising a student working to a greater or lesser extent outside their own fields. First Bill Greenlee, who very kindly agreed to assist a second-year student with only the vaguest notion of his research project. Peter Sorger has provided clarity of thought and purpose to this dissertation, which I believe greatly improves the final product you now hold in your hands. Jackie Lees was kind enough to come aboard later in my graduate career, when I started to think that I really needed more help! And, finally, a huge thankyou to Judy McDowell for serving as my proposal defense chair and being willing and able to provide advice, perspective, and countless other valuable services throughout my graduate career.

The members of the Stegeman and Hahn labs have by turns been mentors, friends, motivators, critics, and valued contributors to me these past five plus years. I mention them here in something approximating order of appearance:

- Bruce really is the glue that holds this group together. I hope you realize how much we all need and appreciate your hard work, bad puns and kind nature.

- Michael has been generous with his time, knowledge and resources whenever I've asked for them.

- Renee showed me in my first months here that there is light at the end of the tunnel.

- Connie has been a great inspiration. More than anyone else, she was the student who had already been through everything I was facing and could show me the way through. From experiments to committee meetings to job hunting, we have shared many an hour discussing our lives. I only hope I helped her half as much as she helped me.

- Sibel has shared jokes, molecular biology knowledge, milk for coffee (THANK YOU!) and a joy for life. I think I still owe you a few scares, so look out!

- Margie was everything I could have hoped for in a friend and officemate. Her dedication to science and quiet perseverance were examples I've been hard pressed to follow. I'll always remember our talks and laughs.

- Rachel has been a great example of how to make science fit into one's life, when so many other influences want it to be the other way around.

- Jennifer demonstrated that hard work and dedication to the craft do pay off. Her constant cheerfulness always brightened the lab. I think most graduate students 
consciously or subconsciously measure themselves against their immediate predecessors, and in this case I know I've had a much harder time than most!

- Sue has been by turns my pool buddy, fellow PC user in the Mac wilderness, euchre partner, advisor on binding assays, and guide in the dissertation writing process. What else is there? :)

- Brenda. Ann. Jensen. (Quick! Who was I imitating?) Unless this section is going to be a separate chapter, I'll have to cut this one short! From the day I entered the Joint Program until the day I leave, Brenda's been a constant friend and companion in this adventure called grad school. I don't know what else to say.

- Malin by her example taught me so much about the careful, well-reasoned approach to research that is necessary for success.

- Carolyn has taught me techniques, trusted me with her computer for three stress-filled days, and continually kept me guessing what she'll do next (learn to fly? "stroke" whales? Or, most foolhardy of all, go to grad school?).

- Celine kept me sane in some rough times and has always been a source of support. Unfortunately she also thinks she rules the universe when it's plain to see I do. I let her keep her delusions.

- Shannon and I have shared many hours in cars, more than a few bottles of wine, and a love-hate relationship with our projects! Her drive and compassion are a wonderful combination.

- Agnes came into the lab looking for a 6-week project and ended up coming back for more punishment. Her assistance and friendship at a crucial time in this work and my life will never be forgotten. I feel like I have two sisters now.

- Joanna has now discovered who "we" are and is poised to carry on that fine tradition as well as make her unique mark on this group.

- Heather has continually surprised me. When I lost first Margie and then Agnes I thought my good luck with officemates had run out. Then I thought I had more to teach than to learn with the newer students. Rarely have I enjoyed being proven wrong so much.

- Diana has taught me more than I think either of us realizes. She always seems to have that crucial data or ragent I need (Can I borrow some cells?).

- Wade's presence and example in the lab have improved all of our work. Many times his level-headed outlook has been the reality check I need.

- Hisato and Eun Young have been kind enough to answer my questions about Japan and help me learn the language. Osewa ni narimashita.

- I've enjoyed the tenures of four "glassware specialists", as Bruce would say. Howie, Liz, Justin and Sam have all been helpful and good sports, even when I show up with a dirty beaker just as they finished washing everything else (Would I ever do that, Liz?)

Most of the scientists in Redfield have assisted my education at some point in time. I would like to specifically thank Heidi Sosik for teaching two of the best courses I've ever taken and Lauren Mullineaux for assistance and opportunities in several areas. 
Members of the Olsen, Sosik, Caron, and Anderson labs (proceeding clockwise around the third floor) have all provided assistance with my research at various times. I owe much to Gaspar Taroncher for expert assistance early in my project as well as friendly cynicism and advice throughout. Both he and the staff of the MIT Cell Sorting Facility provided advice on the cell cycle analyses in Chapter 2.

Debby Fripp has become a great friend. Who knew where a casual question, "What were you doing on 495 this morning?" in spring of 1996 would lead? We learned each other's life histories, debated the issues of the times, and critiqued Star Trek episodes in 45-minute intervals every morning and evening. The daily commute will never be the same. Look for our forthcoming book (with co-authors Brenda and Agnes) entitled "Engineers and the Biologists who Love Them."

Several members of WHOI 94 have been crucial to this endeavor. Liz Kujawinski has analyzed my results, explained that magical property called "fugacity", validated my ever-changing career outlooks, and provided invaluable leadership to the Thesis Support Group (a.k.a. "six senior students drinking regularly at the Kidd"). Classmates Brenda, Mike, Nicole, Gabrielle, Becky, and Patrick have shared and commiserated over the ominous "New Curriculum" we beta-tested in our first two years. Hoosier Joe Warren (your secret's out now!) and that wild and crazy guy Steve Jayne have both made this time more enjoyable.

I've also been blessed with friends made over this exploding medium known as the internet. The members of the Heinlein Forum have challenged, supported, and entertained me for almost three years now. Thanks are especially due to Greg Renner and Beatrice Kondo for their graduate student companionship. Elizabeth Moon and Susan Shwartz have set a new paradigm for me: now I read authors whom I've first come to know as good people. These two ladies have provided me with more interesting discussions, helpful advice, and fabulous stories than I can ever repay. Of course I know they'd tell me I have to pay forward, not back.

When we moved here we lived an hour away from anyone we knew. Our brothers and sisters at Lutheran Church of the Way quickly changed that and have helped with support, encouragement, fun, and most of all prayers for the last five and a half years. Special thanks are due to the Dutzmann, Mueller and Giger families for opening their homes and hearts to us and making us feel welcome here. Likewise, the Brighams have been our adoptive family in Massachusetts. Dave and Suzanne are such close friends that it seems impossible we haven't always known them.

Returning to the arena of scientific endeavor, Sean Kennedy, Mike Gallo and Alvaro Puga have all flattered me with their interest in my research and assisted me with their invaluable advice. Though I don't know them personally, the writings of Alan Poland and Terry Kenakin have greatly influenced how I think about my work and the direction it has taken. The entire staff of the WHOI Education Office has been superb at making sure I had the tools necessary to get all this done, and have also provided friendship and support. I must also thank the National Science Foundation for believing in and supporting my potential and the Environmental Protection Agency, National Institutes of Health and Sea Grant for funding this research. 
I can't properly thank John and Mark for all they have done for me. I have to hope my gratitude is evident in my actions: past, present and future. Most students are lucky to have one good advisor, and I've been fortunate enough to have two. They have given me the freedom to pursue my own interests along with the guidance to do it right and make it worthwhile. Their encouragement, support, and advice are in large part responsible for this dissertation; it couldn't have happened without them.

My family also has been a constant source of support and encouragement throughout my graduate career. Parents, siblings, grandparents, aunts, uncles, cousins, in-laws, outlaws, and all the rest have combined to keep me going and properly grounded at many different times. Of course first among them all is Dani. She always makes me a better person. This dissertation and the resultant degree are as much hers as they are mine. I love you, D!

I truly believe that all these wonderful people have been placed in my life by God to reveal His love for me. This work is a demonstration of what it says in Philippians 4:13. Faith does move mountains.

Speaking of mountains, readers who know me even moderately well also will not be surprised to learn that portions of this dissertation were written in crayon on a sheet of notepaper at Greenleaf Hut on the shoulder of Mt. Lafayette.

Funding for this research was provided by the:

National Science Foundation, through a pre-doctoral fellowship

Environmental Protection Agency, through grant R823889

NOAA National Sea Grant College Program Office, under grant NA46RG0470, WHOI

Sea Grant project No. R/B-124

National Institutes of Health, through project ES06272 


\section{Chapter 1: Introduction}

$\begin{array}{ll}\text { Background } & 19\end{array}$

HAH Toxicity 19

Ah Receptor 22

Ah Receptor Signaling Cross-talk 29

Receptor Pharmacology 33

Rationale 35 
Understanding mechanisms and risks of halogenated aromatic hydrocarbon (HAH) toxicity is a continuing goal for human and environmental health. Study of various model organisms and cell systems has proven fruitful in moving toward that goal. The aryl hydrocarbon receptor (Ah receptor, AHR) has been identified as a cellular factor governing the action of many of these compounds, and provides an essential link in the pathway from exposure to response. Quantitative models of AHR action are being developed to provide guidance in HAH risk assessment. Despite these successes, there are substantial deficiencies in our understanding of the mechanisms of toxicity and the predictive power of our models.

\section{BACKGROUND}

\section{HAH Toxicity}

Halogenated aromatic hydrocarbons are persistent environmental contaminants. This class of chemicals includes polychlorinated biphenyls (PCBs), halogenated dibenzodioxins, and halogenated dibenzofurans (Figure 1). These compounds have mostly anthropogenic origins and enter the aquatic environment through wastewater and runoff from terrestrial sources. They are toxic to several groups of organisms, including mammals (reviewed in Vanden Heuvel and Lucier 1993), fish (Peakall 1975), and marine invertebrates (Wassermann et al. 1979). In addition, they are very hydrophobic and accumulate in sediments (Kalmaz and Kalmaz 1979) as well as lipid-rich animal tissues (Ernst et al. 1976).

The hydrophobicity of HAH makes trophic transfer the most common method of uptake, although water- and airborne exposure take place (WHO 1976). Partitioning of HAH to lipid-rich tissues leads to slow excretion and bioaccumulation, and biomagnification through successive trophic levels results. High level consumers, such as fish and marine mammals, can carry burdens of these compounds that greatly exceed their concentration in the environment (Wassermann et al. 1979). In addition, slow excretion can lead to toxic effects after the original source of exposure has been removed. 


\section{PCB}

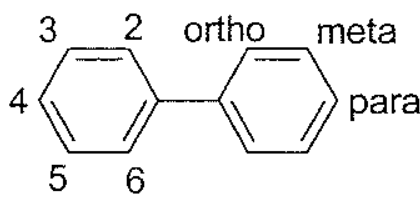<smiles>Clc1ccc(-c2ccc(Cl)c(Cl)c2)cc1Cl</smiles>

3,3',4,4'-tetrachlorobiphenyl (PCB 77)

\section{Chlorinated Dibenzo-p-dioxin}

\section{Chlorinated Dibenzofuran}<smiles>Clc1cc2c(cc1Cl)Oc1cc(Cl)c(Cl)cc1O2</smiles>

2,3,7,8-tetrachlorodibenzo- $p$-dioxin<smiles>Clc1cc2oc3cc(Cl)c(Cl)cc3c2cc1Cl</smiles>

2,3,7,8-tetrachlorodibenzofuran

Figure 1. Representative HAH structures.

Toxicity of HAH has been characterized best with PCBs and 2,3,7,8tetrachlorodibenzo- $p$-dioxin (TCDD). Toxic effects include mortality, liver enlargement and damage, reduced weight gain, carcinogenesis, teratogenesis, and immunosuppression (Wassermann et al. 1979; Poland and Knutson 1982). In mammals, TCDD has also been implicated in chloracne, gastric and urinary tract lesions, and lymphoid involution (Poland et al. 1982). Both lethal and sublethal toxic effects of $\mathrm{HAH}$ have been noted in aquatic and marine organisms including phytoplankton, zooplankton, fish, and marine mammals (Wassermann et al. 1979). Reduced growth rate, vascular defects, thymic involution, fin necrosis, and damage to liver parenchymal cells are among the sublethal effects noted following exposure of fish to TCDD (Spitsbergen et al. 1988).

Several sub-lethal responses to HAH have been characterized as potential biomarkers of sensitivity, exposure and effect (Huggett 1992). Induction of cytochrome P450 1A (CYP1A) isoforms is commonly used due to its sensitivity, ease of 
measurement by enzyme activity or immunoassay, and well-established link to the AHR, which mediates HAH toxicity (see below). CYP1A induction is also important toxicologically, because it metabolizes many AHR ligands, and in the process can create toxic products, such as reactive polynuclear aromatic hydrocarbon $(\mathrm{PAH})$ metabolites (reviewed in Schenkman and Greim 1992) or reactive oxygen (Schlezinger et al. 1999).

Due to the number and severity of HAH toxic effects, elucidating their mechanism(s) of toxicity is a priority for toxicologists. Furthermore, the health risk to humans and wildlife associated with exposure to these compounds has made them the target of governmental regulatory measures designed to limit production at the sources and remediate contamination at the most polluted sites. Several methods for determining maximum safe levels of exposure have been proposed and implemented (reviewed in Kociba 1991), leading to an increased need for a thorough, quantitative understanding of the fundamental mechanisms to choose among these competing methods.

The most striking example of a quantitative difference in HAH toxicity is in the wide range of potencies for the different compounds (Safe 1990), known as structureactivity relationships (SAR). Lethal potencies in a single species can range over 5 orders of magnitude, from $\mu \mathrm{g} / \mathrm{kg}$ doses of TCDD killing half a test population (LD50) to $>10$ $\mathrm{mg} / \mathrm{kg}$ LD50s for some ortho-substituted PCBs (van den Berg et al. 1998). PCBs with two ortho substitutions generally are not toxic. The relative toxic potencies for compounds used in this work are shown in Table 1.

The knowledge that these compounds have a shared mechanism of toxicity involving a receptor protein has led to the proposal that the toxicity of complex mixtures can be considered as a whole, rather than for each compound individually. This has been labeled the toxic, or TCDD, equivalency factor (TEF) concept (Safe 1987). Originally proposed as a quantitative method to relate in vitro bioassay data to expected in vivo effects, the practice has grown to incorporate methods for correlating concentrations of individual compounds with the toxic potential of the entire mixture. The toxic equivalent of a mixture is determined by multiplying the concentration of each compound by its toxicity relative to TCDD (i.e. the values in Table 1), and then summing these individual 
equivalents to find the potential toxicity of the mixture. This approach assumes that the toxicity of individual compounds is additive, which is not always true (see below).

Table 1 reveals another feature of the relationship between compound structure and potency: ortho-substituted PCBs are less toxic than non-ortho substituted PCBs in fish, and are less potent than in mammals. This is a phenomenon that was first described by studying CYP1A induction in vivo (Gooch et al. 1989) and subsequently confirmed by embryotoxicity and in vitro bioassay experiments (Walker and Peterson 1991; Zabel et al. 1995; Hahn and Chandran 1996a; Clemons et al. 1998). The underlying mechanism for this difference in potencies is unclear.

Studies of HAH toxic potency have also sought to explain observed differences among species and strains. For example, there is a $>2500$-fold difference between the LD50s for TCDD in the highly-sensitive guinea pig and the comparatively insensitive hamster (Kociba and Schwetz 1982), and a 5-fold difference in LD50 between the "Ahresponsive" C57BL/6 and "Ah-non-responsive" DBA/2 strains of mice (Poland et al. 1982). Furthermore, potencies for sub-lethal effects are typically greater than acute lethality, but the magnitude of this difference varies among species and endpoints (reviewed in Hahn 1998b). Such differences must be explained before inter-species extrapolation of potencies can be accurately performed.

The desire to promote risk-assessment, regulation, remediation, and prevention based on a detailed understanding of the mechanism of action has been a driving force in the study of $\mathrm{HAH}$ toxicity and, consequently Ah receptor signal transduction, since its inception.

\section{Ah Receptor}

Experiments led by Nebert (Nebert et al. 1972) and Poland (1974) in the early 1970s revealed differences in CYP1A-catalyzed aryl hydrocarbon hydroxylase (AHH) inducibility by PAHs and TCDD between two strains of inbred mice. Work in these laboratories and others over the next decade revealed that this difference was due to a 
Table 1. Names and relative toxic potencies of selected HAH (relative potencies following van den Berg et al. 1998).

\begin{tabular}{|c|c|c|c|}
\hline \multirow[b]{2}{*}{ Short name } & \multirow[b]{2}{*}{ Full name } & \multicolumn{2}{|c|}{ Relative toxic potency } \\
\hline & & Mammals & Fish \\
\hline TCDD & $2,3,7,8$-tetrachlorodibenzo- $p$-dioxin & 1 & 1 \\
\hline TCDF & 2,3,7,8-tetrachlorodibenzofuran & 0.1 & 0.05 \\
\hline Non-ortho PCBs & & & \\
\hline PCB 77 & $3,3^{\prime}, 4,4^{\prime}$-tetrachlorobiphenyl & 0.0001 & 0.0001 \\
\hline PCB 81 & $3,4,4^{\prime}, 5$ - tetrachlorobiphenyl & 0.0001 & 0.0005 \\
\hline PCB 126 & 3,3',4,4',5-pentachlorobiphenyl & 0.1 & 0.005 \\
\hline PCB 169 & $3,3^{\prime}, 4,4^{\prime}, 5,5^{\prime}$-hexachlorobiphenyl & 0.01 & 0.00005 \\
\hline Mono-ortho PCB & & & \\
\hline PCB 105 & $2,3,3^{\prime}, 4,4^{\prime}$ - pentachlorobiphenyl & 0.0001 & $<0.000005$ \\
\hline PCB 118 & $2,3^{\prime}, 4,4^{\prime}, 5$ - pentachlorobiphenyl & 0.0001 & $<0.000005$ \\
\hline PCB 156 & $2,3,3^{\prime}, 4,4^{\prime}, 5$ - hexachlorobiphenyl & 0.0005 & $<0.000005$ \\
\hline Di-ortho PCB & & & \\
\hline PCB 128 & $2,2^{\prime}, 3,3^{\prime}, 4,4^{\prime}-$ hexachlorobiphenyl & 0 & 0 \\
\hline
\end{tabular}

single autosomal dominant gene (Nebert et al. 1972), and Poland (1975) postulated the existence of an "induction receptor".

Synthesis of a high-affinity radioligand allowed for biochemical characterization of a cytosolic receptor responsible for $\mathrm{PAH}$ and $\mathrm{HAH}$ binding, and this receptor was later linked to the genetic studies (Poland et al. 1976; Okey et al. 1979). The gene locus was named ah (later changed to $A H R$ ) for aryl hydrocarbon, and the receptor came to be called the aryl hydrocarbon receptor (Ah receptor or AHR). The binding affinities of several compounds to the AHR matched their relative potencies in eliciting toxicity, suggesting that their primary mechanism of toxicity involves this receptor (reviewed in 
Huff et al. 1994). More recently, it has been shown that AHR-deficient mice are resistant to TCDD toxicity (Fernandez-Salguero et al. 1996).

Purification of the receptor (Bradfield et al. 1991) led to N-terminal amino acid sequence, which was used to clone the corresponding cDNA from mice (Burbach et al. 1992; Ema et al. 1992). Work with cell lines deficient in AHH inducibility had led to the cloning of another protein required for AHR function, the Ah receptor nuclear translocator (ARNT), the year before (Hoffman et al. 1991). These events have led to a rapid increase in our understanding of AHR signal transduction, confirming and extending earlier work (Hankinson 1993).

\section{Signaling Pathway}

The AHR exists in the cytoplasm complexed with two $90 \mathrm{kD}$ heat shock proteins (HSP90; Perdew 1988) and an immunophilin-like protein (Carver and Bradfield 1997; Ma and Whitlock 1997; Meyer et al. 1998). Ah receptor ligands are hydrophobic and diffuse through the cell membrane. Equilibrium dissociation constants $\left(\mathrm{K}_{\mathrm{D}}\right)$ for purified receptor and its high-affinity ligands are on the picomolar order of magnitude, but impurities in preparation usually lead to measured $\mathrm{K}_{\mathrm{D}}$ in the nanomolar range (Bradfield and Poland 1988b). HSP90 is necessary for ligand binding (Whitelaw et al. 1995), and the protein complex translocates to the nucleus and dissociates after ligand has been bound (Figure 2). The process of ligand binding, translocation, complex dissociation, and ARNT dimerization often is referred to as transformation.

Following nuclear translocation, the AHR dimerizes with ARNT (Hoffman et al. 1991; Figure 3). Despite its name, ARNT does not appear to be necessary for nuclear translocation, as ligand-induced nuclear translocation still takes place in ARNT deficient mouse cell lines (Pollenz et al. 1994). However, ARNT does appear to facilitate for dissociation of HSP90 (McGuire et al. 1994). In addition, ARNT is a dimerization partner for other PAS proteins (see below), and competition for ARNT may limit AHR activity (Gradin et al. 1996; Chan et al. 1999) and contribute to HAH toxicity. 


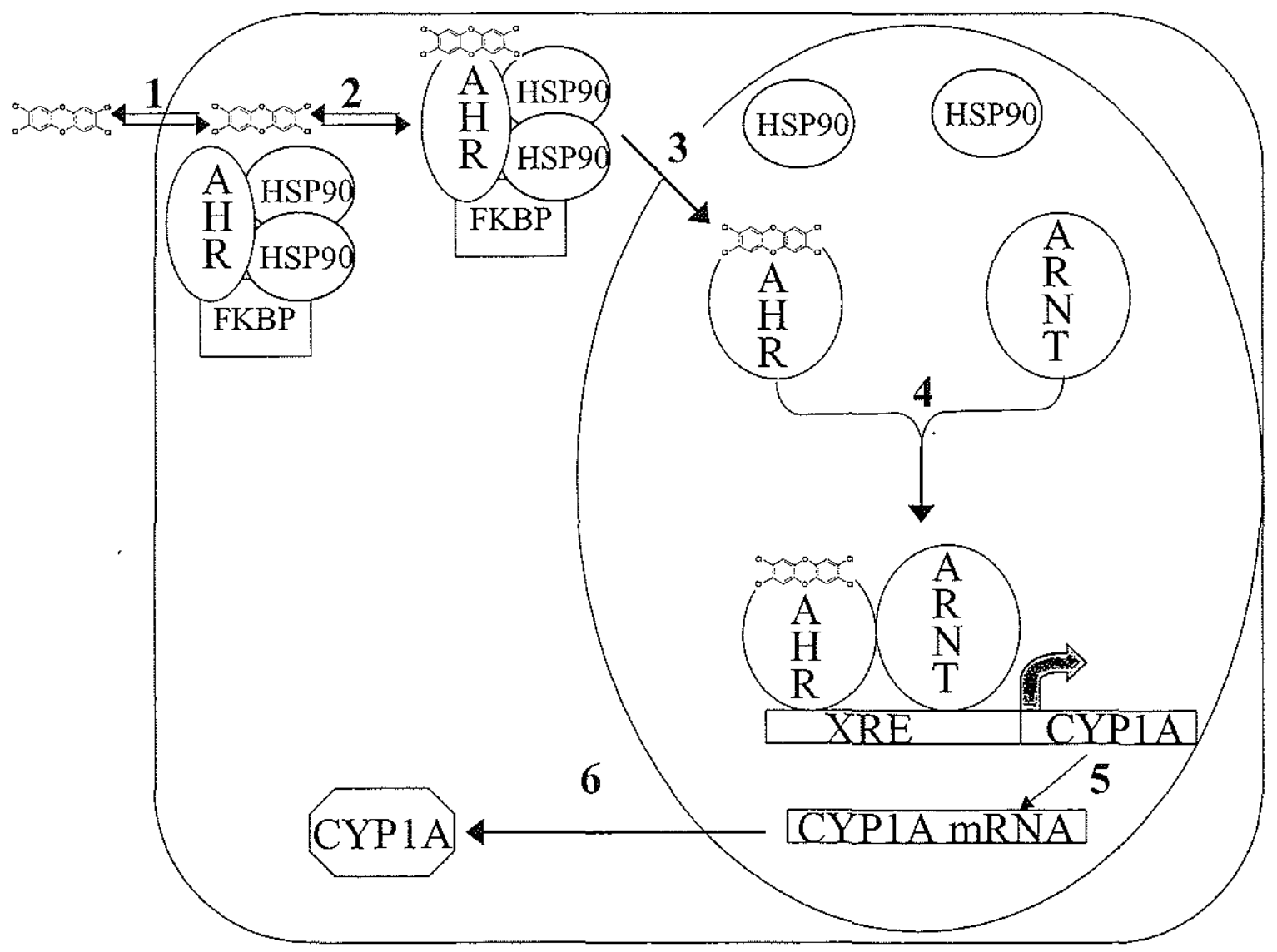

Figure 2. The Ah receptor signaling pathway. Numbered events are: 1) entry of ligand into the cell, 2) binding of ligand to the receptor, 3) transformation of the receptor to an active form and nuclear translocation, 4) dimerization with ARNT and binding to XREs, 5) recruitment of transcriptional cofactors and stimulation of gene transcription, and 6) translation of the protein.

The AHR-ARNT dimer binds to DNA sequences called xeniobiotic, dioxin, or AHR responsive elements (here referred to as XREs; Jones et al. 1986; Denison et al. 1988). The consensus sequence for these sites is 5'TNGCGTG3' (Dolwick et al. 1993; Lusska et al. 1993). An additional, $100 \mathrm{kD}$ protein appears to be involved in the DNAbound complex (Elferink et al. 1990; Swanson et al. 1993). A carboxy-terminal domain 
is required for transcriptional activation (see below), likely by mediating interactions with transcriptional co-activators and the basal transcription machinery.

More than a dozen genes respond to AHR ligands, typically by transcriptional induction (Hankinson 1995, Table 2). Induction of mRNA, protein, and enzyme activity from one of these genes, CYP1A1, is the best characterized, and is used as a diagnostic for AHR signaling.

\section{$\underline{\text { Structure and Expression Patterns }}$}

Functionally significant domains of the AHR have been identified using sequence homology, deletion analysis, receptor chimeras, and site-directed mutagenesis. These domains are shown in Figure 3. The AHR is a member of the basic helix-loop-helix (bHLH) superfamily of transcription factors as well as the emerging PAS family of proteins (named for ARNT and Per and Sim, two Drosophila genes). The bHLH domain is important for dimerization and DNA binding (Reisz-Porszasz et al. 1994). The PAS domain includes two 50 amino acid repeats, labeled PAS A and PAS B. This domain is involved in dimerization as well (Reisz-Porszasz et al. 1994). In addition, the PAS B repeat is within the overlapping sites for HSP90 and ligand binding. A C-terminal glutamine rich domain is necessary for transcriptional activation (Whitelaw et al. 1994). The bHLH, PAS, and transcriptional activation domains are present in ARNT and perform the same functions, with the exceptions of HSP90 and ligand binding.

The AHR and ARNT have been found in most mammalian tissues examined to date (reviewed in Schmidt and Bradfield 1996). With some exceptions, they demonstrate coordinate levels of expression. In mice, AHR and ARNT are expressed by gestational day 10-11, and their levels in various tissues change throughout gestation (Abbott et al. 1995a; Abbott and Probst 1995b). The highest levels of expression were seen in tissues undergoing a high degree of differentiation and proliferation. 
Table 2. Gene products regulated by ligands of the AHR; after Hankinson (1995), with additions. $\uparrow, \downarrow$ : increase or decrease in level or rate; ND: not determined

\begin{tabular}{|c|c|c|c|c|}
\hline Gene product & $\begin{array}{c}\text { AHR and/or ARNT } \\
\text { dependence }\end{array}$ & $\begin{array}{c}\text { mRNA } \\
\text { level }\end{array}$ & Transcription rate & Reference \\
\hline CYP1A1 & Yes & $\uparrow$ & $\uparrow$ & $\begin{array}{l}\text { (Israel and J.P. } \\
\text { Whitlock 1984) }\end{array}$ \\
\hline CYP1A2 & Yes & $\uparrow$ & $\uparrow$ & (Pasco et al. 1993) \\
\hline CYP1B1 & Yes & $\uparrow$ & $\uparrow$ & (Sutter et al. 1991) \\
\hline $\mathrm{NQO}_{1}$ & Yes & $\uparrow$ & $\uparrow$ & $\begin{array}{l}\text { (Favreau and } \\
\text { Pickett 1991) }\end{array}$ \\
\hline GST-Ya & Yes & $\uparrow$ & $\uparrow$ & $\begin{array}{l}\text { (Rushmore and } \\
\text { Pickett 1990) }\end{array}$ \\
\hline Ugt $1 * 06$ & Yes & $\uparrow$ & ND & (Sutter et al. 1991) \\
\hline PAI-2 & $\mathrm{ND}$ & $\uparrow$ & $\uparrow$ & (Sutter et al. 1991) \\
\hline TGF- $\beta_{2}$ & ND & $\uparrow$ & $\uparrow$ & (Gaido et al. 1992) \\
\hline c-fos & No & $\uparrow$ & $\mathrm{ND}$ & $\begin{array}{l}\text { (Puga et al. 1992; } \\
\text { Hoffer et al. 1996) }\end{array}$ \\
\hline FosB & No & $\uparrow$ & ND & $\begin{array}{c}\text { (Hoffer et al. } \\
\text { 1996) }\end{array}$ \\
\hline Jun-B & No & $\uparrow$ & ND & $\begin{array}{l}\text { (Puga et al. 1992; } \\
\text { Hoffer et al. 1996) }\end{array}$ \\
\hline c-jun & Yes & $\uparrow$ & ND & $\begin{array}{l}\text { (Puga et al. 1992; } \\
\text { Hoffer et al. 1996) }\end{array}$ \\
\hline Jun-D & Yes & $\uparrow$ & ND & $\begin{array}{l}\text { (Puga et al. 1992; } \\
\text { Hoffer et al. 1996) }\end{array}$ \\
\hline ALAS & Yes & $\mathrm{ND}$ & ND & $\begin{array}{l}\text { (Poland and } \\
\text { Glover 1973) }\end{array}$ \\
\hline ALDH 3 & Yes & $\uparrow$ & $\uparrow$ & $\begin{array}{c}\text { (Vasiliou et al. } \\
1993 \text { ) }\end{array}$ \\
\hline
\end{tabular}




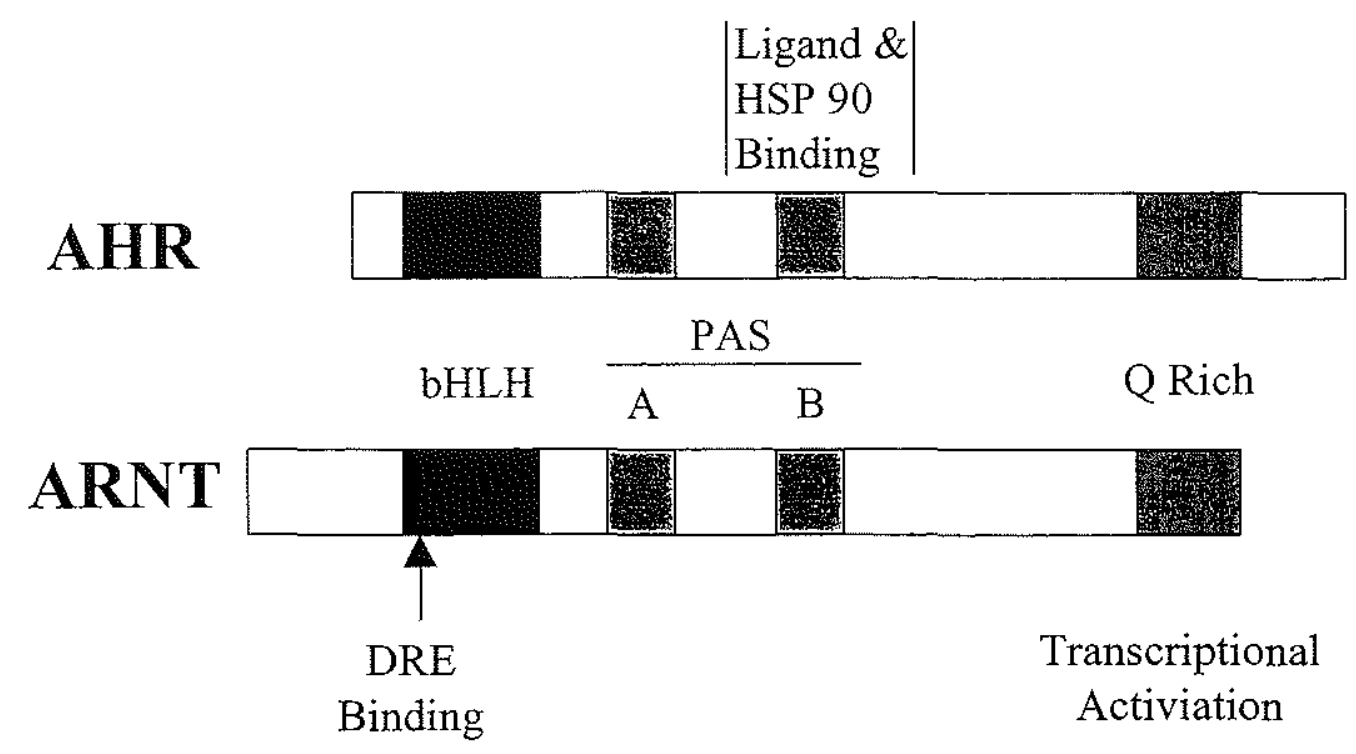

Figure 3. Functional domains of mouse AHR and ARNT; after Hankinson (1995).

Radioligand binding (Lorenzen and Okey 1990), photoaffinity labeling (Hahn et al. 1994), and RT-PCR cloning (Hahn and Karchner 1995; Hahn et al. 1997; Tanguay et al. 1998, Karchner et al 1999) have been used to identify AHR homologues in fish (reviewed in Hahn 1998a). The photoaffinity labeling study found no evidence of AHR in any invertebrate species examined, although a specific binding protein was identified in two out of three cartilaginous fishes and all of the bony fishes studied. Subsequently, AHR homologues have been cloned from C. elegans (Powell-Coffman et al. 1998), Drosophila (Duncan et al. 1998), and primitive vertebrates (Hahn et al. 1997). The C. elegans and lamprey AHRs do not bind TCDD (Powell-Coffman et al. 1998; Karchner et al unpublished). Thus, while AHR homologues occur throughout much of the animal kingdom, the $\mathrm{HAH}$ binding function appears to have emerged early in vertebrate evolution.

Two AHR forms occur in the killifish Fundulus heteroclitus, smooth dogfish (AHR1 and AHR2; Hahn et al. 1997) and rainbow trout (AHR2 $\alpha$ and AHR2 $\beta$; Abnet et al. 1999). Phylogenetic analyses indicate that a duplication event early in vertebrate evolution may have led to the two dogfish and Fundulus forms, suggesting that multiple 
forms may exist in other vertebrate species. The two trout forms are both more closely related to Fundulus AHR2 than AHR1, and are likely the result of a more recent duplication in the salmonid lineage. Both AHR forms in Fundulus and rainbow trout are capable of binding ligand.

\section{Ah Receptor Signaling Cross-Talk}

\section{Cell Cycle}

The cell cycle is divided into four stages: G1 (gap 1), S (DNA synthesis), G2 (gap 2), and $\mathrm{M}$ (mitosis). Transitions from one stage to the next are controlled by the cyclins and the kinases with which they dimerize. Work in yeast, Xenopus, and sea urchin models has uncovered many of the activities and interactions of these proteins (reviewed in Murray and Hunt 1994). Cyclins regulate the activity of their partner kinases, and several such dimers have been identified that act at different stages of the cell cycle.

Such activity is necessary for the cell to continue through stopping points in the cell cycle termed "checkpoints." Checkpoints can serve to ensure sufficient cell size or appropriate environmental conditions before the cell continues, or they can stop the cell

cycle when damage occurs. Proteins that act to limit cell proliferation, and typically are involved in checkpoint regulation, are products of tumor suppressor genes (Hinds and Weinberg 1994). Many tumor suppressors have been identified, and mutations in their genes lead to increased incidence of cancer.

The gene product of one such suppressor, the retinoblastoma gene (RB), is intimately involved with the $\mathrm{G} 1 \rightarrow \mathrm{S}$ checkpoint. The $\mathrm{RB}$ gene product $(\mathrm{pRB})$ is also a site of action of other tumor suppressors, including p16, p21, and p53. pRB binds and inhibits both the transcription factor E2F and the tyrosine kinase c-abl, inhibiting progression from $\mathrm{G} 1$ to $\mathrm{S}$. Phosphorylation of $\mathrm{pRB}$ by the cdk4/cyclin $\mathrm{D}$ complex causes dissociation of the $\mathrm{pRB} / \mathrm{E} 2 \mathrm{~F}$ dimers and entry into $S$ phase.

Study of these cell cycle controls has been aided by the ability to obtain cells enriched in one stage of the cell cycle through various chemical and physical means. Chemical cell cycle inhibitors offer many options for point of cycle synchronization. 
Mimosine blocks cells in late G1; aphidicolin, thymidine and hydroxyurea inhibit DNA synthesis, blocking in S; and nocodazole stops mitosis at metaphase (reviewed in Krek and DeCaprio 1995). Removal of the blocking agent by addition of fresh cell culture medium allows cells to resume progression through the cycle in synchrony. Synchronous populations obtained by these methods are extremely useful for study of cycle-dependent processes. The population gradually becomes more asynchronous with each successive cycle, so this technique is less useful for long-term studies.

\section{AHR Ligands and Cell Cycle / Cell Proliferation}

Evidence for an effect of AHR ligands on the cell cycle and cell proliferation has come from a number of sources. Histopathology of tissues from various TCDD treated mammalian species show some general similarities (reviewed in Poland et al. 1982). Epithelial tissues are usually hyperplastic, while lymphoid tissues show hypoplasia or atrophy. Liver and cardiovascular lesions are also frequently observed. Gierthy and Crane (Gierthy and Crane 1984) first described an inhibition of proliferation by TCDD in cultured epithelial cells (contrast with hyperplasia in vivo). This effect has since been extended to MCF-7 breast cancer cells (Gierthy et al. 1993), rat H4IIE hepatoma cells (Gottlicher et al. 1990), rat livers (Fox et al. 1993) and primary rat hepatocytes (Hushka and Greenlee 1995).

Growth inhibition by TCDD in rat cells is due to an AHR-dependent delay in G1 $\rightarrow$ S progression (Wiebel et al. 1991; Weiss et al. 1996). This evidence is supported by a lengthened G1 stage in AHR-deficient HEPA-1 (mouse hepatoma) cells (Ma and Whitlock 1996). Transfection of an AHR-expressing vector restored the wild type G1 length, as well as several other characteristics. It is expected that the delay in $\mathrm{G} 1 \rightarrow \mathrm{S}$ progression is due to interactions between the AHR and control of the G1/S checkpoint, which was detailed above. A clue to the mechanism has come with the finding that the AHR associates with the retinoblastoma gene product, and that this association shows preference for the ligand-bound AHR (Ge and Elferink 1998). 
Growth inhibition by TCDD has not been observed in all studies. Inhibition of proliferation of murine Swiss $3 \mathrm{~T} 3$ cells was observed after treatment with $\mathrm{BaP}$, but not TCDD (Vaziri and Faller 1997). Stimulation of proliferation by TCDD has been observed in other cell culture experiments (Dickins et al. 1981; Busser and Lutz 1987; Wolfle et al. 1988; Lucier et al. 1991; Schrenk et al. 1992), and evidence suggests that proliferative effects are dependent on cell type and culture conditions.

While investigating the effect of actin microfilament and microtubule disrupters on CYP1A1 induction, Schöller et al. (1994) found that prolonged (20-24 hour) exposure to nocodazole inhibited CYP1A1 induction. However, this inhibition was due to cells being arrested in G2 or mitosis rather than disruption of the microtubule network. The AHR in these cells still binds TCDD, but it does not bind DNA as efficiently (Scholler et al. 1994). Other agents that block cells in $\mathrm{G} 2$ or $\mathrm{M}$ had similar effects. The cells resumed cycling once the nocodazole had been washed out, and CYP1A1 induction was restored coincident with progression to G1 (J. J. Reiners, Jr., personal communication).

These results taken together raise the possibility that AHR is involved in regulation of the cell cycle and that cell cycle progression can in turn affect AHR function. This tentative hypothesis clearly requires demonstration of the effects noted above in other systems as well as a more complete understanding of the mechanisms involved. It is possible that the AHR originally evolved to perform functions distinct from ligand binding and transcriptional regulation, and now has a multiple functions in later vertebrates. Such dual roles have recently come to light for several proteins involved in regulation of proliferation (Jacks and Weinberg 1998).

\section{AHR and Phosphorylation}

Effects of TCDD on cell proliferation may occur by modulating protein phosphorylation. TCDD stimulates tyrosine phosphorylation in mouse hepatocytes (Ma and Babish 1993). Similar effects have been observed in rainbow trout (Newsted and Giesy 1993). Phosphorylation is rapid and occurs in nucleus-free extracts, indicating that de novo protein synthesis is not required (Enan and Matsumura 1994; Enan and 
Matsumura 1995). The kinase src may mediate these effects (Enan and Matsumura 1996). These discoveries have led to speculation regarding a second pathway of AHR action distinct from transcriptional regulation (Matsumura 1994).

Phosphorylation of AHR and ARNT appears to be necessary for transcriptional regulation by their heterodimer. Tetradecanoyl phorbol acetate, which downregulates protein kinase $\mathrm{C}(\mathrm{PKC})$ at high concentrations, inhibits CYP1A1 induction by $\mathrm{AHR}$ ligands (Carrier et al. 1992; Okino et al. 1992), as do the inhibitor calphostin C and various phosphatases. Phosphatase treatment in vitro revealed that ARNT phosphorylation appears to be necessary for dimerization, while AHR phosphorylation is necessary for XRE binding (Berghard et al. 1993). Pre-activation of PKC enhances CYP1A1 induction by AHR ligands, and inhibition of PKC by staurosporine abolishes CYP1A1 induction (Chen and Tukey 1996). The AHR can be transformed in isolated cytosol in the presence of PKC inhibitors, suggesting that phosphorylation precedes ligand binding (Schafer et al. 1993).

AHR transformation also can modulate PKC activity. Treatment of cultured aortic smooth muscle cells with $\mathrm{BaP}$ or TCDD results in an initial decrease in PKC activity, followed by a marked increase (Weber et al. 1994). This effect is cell cycle dependent. Cells synchronized by serum starvation showed decreased levels and activities of PKC isoforms $\alpha, \beta 2$, and $\delta$ in G1, followed by increases in $\beta 2$ and $\delta$ after entry into S phase (Weber et al. 1997). Whether or not PKC activity affects AHR activity in these cells has yet to be determined, but it is possible that the two proteins are involved in a feedback loop of mutual regulation.

Murine fibroblasts grown in the absence of serum have been demonstrated to down regulate AhR expression (Vaziri et al. 1996). Expression could be induced by addition of growth factors whose receptors signal via tyrosine phosphorylation or by ectopic expression of $\mathrm{v}$-src, a constitutively active form of a protein downstream in the signaling pathway from some of those receptors. Experiments using a cell-cycle blocker showed that lack of AhR expression was not due simply to cell cycle arrest but rather was linked to tyrosine phosphorylation. 
Interactions between the AHR and other cell receptors have been characterized. In several studies decreased epidermal growth factor (EGF) binding by EGF receptor has been noted after treatment with TCDD (e.g. Sewall et al. 1993). Effects of TCDD on the estrogen (Wang et al. 1993) and progesterone receptors (Harper et al. 1994) also have been noted. Several cytokines have been implicated in modulation of AHR gene regulation (Abdel-Razzak et al. 1993).

\section{Receptor Pharmacology}

The actions of many therapeutic and toxic agents are mediated by receptors, cellular sites with relatively great affinity for the agent (or ligand) and an ability to produce a response following interaction with the ligand. Since the concept of specific receptors for different drugs and toxins was formulated early in the $20^{\text {th }}$ century, characterization and quantification of these interactions and responses have been continuing activities for pharmacologists and toxicologists. The AHR can be expected to conform to many, if not all, of the general aspects of receptor pharmacology as they are currently understood.

Clark (1937), first applied a mathematical model to the interaction between a drug and its receptor, borrowing an hyperbolic relationship from physical chemistry used to describe adsorption of small molecules to activated charcoal:

$$
\frac{[A R]}{\left[R_{T}\right]}=\frac{[A]}{[A]+K_{D}}
$$

where $[A],\left[R_{T}\right]$ and $[A R]$ are the concentration of ligand, receptor, and the ligandreceptor complex, respectively, and $\mathrm{K}_{\mathrm{D}}$ is the equilibrium dissociation constant. This equation is still the one commonly used to describe binding of a single molecule to a single receptor.

As measurements of response to ligands followed, it became obvious that response was not always simply proportional to the number of occupied receptors. Some ligands bound to the receptor, but produced no response, while some were less effective 
at producing a response once bound. Ariëns (1954) introduced the concept of "intrinsic activity" and defined response as:

$$
\frac{E_{a}}{E_{m}}=\frac{\alpha[A R]}{\left[R_{T}\right]}=\frac{\alpha \times[A]}{[A]+K_{D}}
$$

where $E_{a}$ and $E_{m}$ are the response at ligand concentration $[A]$ and the maximal response, and $\alpha$ is the intrinsic activity, which has a value between 0 and 1 for each ligand. Each ligand thus has two properties defining its interaction with the receptor, the affinity, governed by $K_{D}$, and the activity, $\alpha$. Compounds with $\alpha=1$ were termed full agonists, $\alpha=0$ antagonists, and $0<\alpha<1$ dualists, or partial agonists.

Later Stephenson (1956) would replace $\alpha$ with a function $e$ "efficacy" which did not assume a linear relationship between receptor occupation and response. Furchgott (1966) further revised this model to account for differences in receptor concentration by defining the "intrinsic efficacy" as the ability of a ligand to convert its receptor to a form capable of producing response. Intrinsic efficacy is therefore theoretically a property of the ligand and receptor, and is independent of tissue-specific effects, such as receptor concentration and coupling of the receptor to downstream events.

Stephenson's efficacy function was given definition by Black and Leff (1983), who upon study of several receptor systems proposed that response is often an hyperbolic function of receptor occupancy:

$$
\frac{E_{a}}{E_{m}}=\frac{[A R]}{K_{E}+[A R]}
$$

where $\mathrm{K}_{\mathrm{E}}$ is the concentration of ligand-receptor complex producing a half-maximal response. Combining equations 1 and 3 yields:

$$
\frac{E_{a}}{E_{m}}=\frac{\left[R_{T}\right] \times[A]}{K_{D} \times K_{E}+\left(\left[R_{T}\right]+K_{E}\right)[A]}
$$

which was termed the "operational model" of receptor action. The utility of this model lies in the ability to calculate $\mathrm{K}_{\mathrm{E}}$ once $\mathrm{K}_{\mathrm{D}}, \mathrm{R}_{\mathrm{T}}$, and dose-response data have been determined. $\mathrm{K}_{\mathrm{E}}$ also is a mathematical concept with a definite biological counterpart, 
rather than a nebulous fitting parameter. The drawback to this approach is that $\mathrm{K}_{\mathrm{E}}$ incorporates both ligand-specific and tissue-specific properties affecting efficacy.

These concepts have been introduced because they are important relationships that underlie the actions of receptors in general, and should apply to the AHR in particular. The concepts of affinity, intrinsic efficacy, and tissue coupling can be explored for their contributions to observed differences in $\mathrm{HAH}$ potency among compounds, species, strains, tissues, and endpoints. These principles have been underdeveloped in the field of AHR research beyond the measurement of binding affinities for a wide range of compounds. In particular, variations in intrinsic efficacies among $\mathrm{HAH}$ will lead to non-additive interactions in mixtures, and thereby create difficulties in applying the TEF concept.

\section{RATIONALE}

This research was conducted to further establish the Poeciliopsis lucida hepatocellular carcinoma (PLHC-1) cell line as a piscine model in AHR research and then use that model to address outstanding issues of HAH toxicity and AHR function. Chapter 2 describes the development and use of several techniques for the study of AHR function and interaction with the cell cycle. Chapter 3 explores the critical issue of conditions affecting exposure to and uptake of $\mathrm{HAH}$ in cultured-cell bioassays. Chapter 4 demonstrates the utility of a quantitative pharmacological approach to addressing mechanistic questions in AHR signal transduction. Chapter 5 reveals how models of receptor action can be used to predict the effects of perturbations to the signaling pathway.

A model piscine cell system is valuable to the field of AHR research for several reasons. First, the utility of cultured cells for rapid acquisition of data and exquisite control of experimental conditions has been demonstrated in mammalian systems. This is an obvious concept, but one slower to take hold in environmental biology. Second, fish are economically and agriculturally important organisms that are impacted by AHR- 
mediated toxicity in freshwater and coastal ecosystems. Understanding the mechanisms of toxicity and impacts of these compounds on fish populations have been recognized as significant issues by the international ecotoxicology community. Third, interspecies extrapolation is a technique commonly used to estimate the risk $\mathrm{HAH}$ pose to humans. Measuring effects in a broad range of organisms increases the data available for extrapolation and thereby improves human risk assessment. Last, fish are the earliestevolving animals known to express an AHR capable of binding HAH. Studying the structural and functional changes that led to this binding capability and subsequent response is necessary to understand the AHR's changing function(s). Furthermore, comparing the shared and distinct features of AHR signal transduction across a range of species will yield clues to the inceptive and current "endogenous" functions of this protein.

Given this need for a piscine cell model, the PLHC-1 cell line has many qualities to recommend it. These cells are of hepatocellular origin, facilitating comparison with liver responses in vivo and well-established cell models such as the mouse HEPA and rat H4IIE hepatocellular lines. In addition, PLHC-1 are derived from a fish that is adapted to warm environments, with maximum proliferation of the cells observed at $30^{\circ} \mathrm{C}$. The importance of this fact as regards ease of culture and increased rate of proliferation (and thus supply of cells for experiments) when compared to other piscine cell lines cannot be overemphasized. Finally, when this work was initiated several important aspects of AHR function in PLHC-1 had already been established. The cells express an AHR capable of binding ligand and inducing CYP1A in response (Hahn et al. 1993). Methods for assay of CYP1A protein and catalytic activity had been worked out (Bruschweiler et al. 1996a; Hahn et al. 1996b). All these factors combined to make the PLHC-1 cell line the obvious choice for further study.

Despite the preexisting base of knowledge, a substantial gap existed between the detail in which AHR function had been described in mammalian cell systems and PLHC1 cells. Some of this work (largely presented in Chapter 2 and Appendix B) was carried out to narrow that gap, but the focus of this thesis is to demonstrate the utility of this 
system for addressing unanswered questions regarding aspects of AHR signal transduction. To that end, the novel pharmacological approach developed in Chapter 4 was used to address the mechanism of reduced toxicity of ortho-substituted PCBs in fish. The resulting quantitative model is used to suggest a mechanism for the reduced CYP1A induction presented in Chapter 5. Similarly, the findings in Chapter 3 will apply individually to any cultured cell system used to study $\mathrm{HAH}$, but have perhaps the greatest impact on analysis of results among multiple systems.

The hopeful result of research in this field, as in any, is to move from a descriptive to a predictive mode of study, or from experiment to theory. Chapters 4 and 5 and Appendices C and D represent some of the first steps in that direction for AHR research. The ability to predict an outcome before the experiment is performed, rather than attempt to explain it afterward, is the hallmark of a maturing field. Doubtless, these early models will soon be regarded as crude and overly simplistic, but it is exciting to be a part of the effort to develop them nonetheless. 
Chapter 2: Characterization of Ah Receptor Expression, Proliferation and the Cell Cycle in PLHC-1 Cells

$\begin{array}{lc}\text { Abstract } & 39 \\ \text { Introduction } & 40 \\ \text { Materials and Methods } & 42 \\ \text { Results } & 47 \\ \text { Discussion } & 59\end{array}$




\begin{abstract}
Aryl hydrocarbon receptor ligands have been implicated in altered cell proliferation in many tissues in vivo and cell types in vitro. The mechanisms underlying these effects have not been explored in non-mammalian systems. This work establishes techniques for identifying and characterizing possible interactions between cell proliferation, the cell cycle, and AHR signal transduction in the piscine cell line PLHC-1. The doubling time of these cells was determined to be 22 hours, with cell cycle stage lengths of 13,3 , and 6 hours for $\mathrm{G} 1, \mathrm{~S}$ and $\mathrm{G} 2 / \mathrm{M}$, respectively. A minimum seeding density of $1.2 \times 10^{5}$ cells per $\mathrm{cm}^{2}$ in medium with $10 \%$ calf serum and $0.3 \times 10^{5}$ cells per $\mathrm{cm}^{2}$ in $10 \%$ fetal bovine serum was found to be required for subsequent proliferation. Of several cell cycle inhibitors tested, aphidicolin and nocodazole were the only ones effective for obtaining synchronous cell populations. Fluorescence activated cell sorting was used to identify cells responding to 2,3,7,8-tetrachlorodibenzo-p-dioxin (TCDD) on the basis of induced cytochrome P4501A protein or enzymatic activity. TCDD was found to inhibit PLHC-1 proliferation in a time- and dose-dependent manner in one subclone, but not in several others. Partial sequences for AHR and $\beta$-actin were obtained and used to design specific primers for RT-PCR measurement of AHR mRNA content. This technique was used with synchronous PLHC-1 cells to show that AHR expression does not vary during the cell cycle, and these results were confirmed at the level of AHR protein expression by measurement of specific binding of ${ }^{3} \mathrm{H}-\mathrm{TCDD}$. Taken together these results indicate that PLHC-1 are amenable to analysis of AHR-cell cycle interactions, but that heterogeneity of sub-clones may limit their usefulness for investigating AHR-mediated changes in proliferation.
\end{abstract}




\section{INTRODUCTION}

Altered cell proliferation is a hallmark of the toxicity of $2,3,7,8$ tetrachlorodibenzo-p-dioxin (TCDD) and related halogenated aromatic hydrocarbons (HAH). Carcinogenesis, epithelial proliferation, immunosupression, and teratogenesis are some of the known effects of these compounds (Poland et al. 1982). The toxic effects of HAH are mediated by the aryl hydrocarbon receptor (AHR), and mechanism(s) of altered proliferation are expected to involve the AHR. However, the pathway(s) linking AHR signaling and cell proliferation are not well understood.

Inhibition of proliferation in response to $\mathrm{HAH}$ treatment has been observed in vitro in a wide range of cell types, including epithelial cells (Gierthy et al. 1984), MCF-7 breast cancer cells (Gierthy et al. 1993), rat H4IIE hepatoma cells (Gottlicher et al. 1990), rat livers (Fox et al. 1993) and primary rat hepatocytes (Hushka et al. 1995). However, stimulation of proliferation by TCDD has been observed in other experiments (Dickins et al. 1981; Busser et al. 1987; Wolfle et al. 1988; Lucier et al. 1991; Schrenk et al. 1992), and evidence suggests that proliferative effects are dependent on cell type, time in culture and culture conditions.

Work in rodent hepatoma cells has provided the first clues of a mechanism for inhibition of proliferation by linking AHR signaling and the cell cycle. Inhibition by TCDD in rat cells is due to an AHR-dependent delay in G1 $\rightarrow$ S progression (Wiebel et al. 1991; Weiss et al. 1996), and a lengthened G1 stage has been observed in AHR-deficient HEPA-1 mouse hepatoma cells (Ma et al. 1996). The retinoblastoma gene product, which is involved in the G1/S checkpoint, interacts with the AHR (Ge et al. 1998), and it has been hypothesized that the delay in $\mathrm{Gl} \rightarrow \mathrm{S}$ progression is connected to this interaction.

Studies to date have focused on mammalian systems, but proliferative abnormalities have been noted in vivo in TCDD-treated fish (Spitsbergen et al. 1988). Effects of TCDD on cell proliferation have not been examined in cultured fish cells. A recent rise in use of cultured fish cells for a wide variety of in vitro toxicity studies (Baksi 
and Frazier 1990; Babich and Borenfreund 1991a; Bols and Lee 1991; Pesonen and Andersson 1997; Segner 1998), has made these systems available for use in studies of interactions between AHR signaling and cell proliferation. By extending knowledge of such effects beyond the mammalian class, the shared and distinct features among taxa can be used to build hypotheses of AHR evolution and function in cell proliferation.

The PLHC-1 cell line, derived from a 7,12-dimethylbenz(a)anthracene induced hepatocellular carcinoma of Poeciliopsis lucida (Hightower and Renfro 1988), was chosen for this study. These cells have been used for investigations of cytotoxicity (Babich et al. 1991b; Ryan and Hightower 1994; Bruschweiler et al. 1995; Huuskonen et al. 1998a; Fent and Batscher 2000) and effects of AHR ligands (Bruschweiler et al. 1996a; Bruschweiler et al. 1996b; Celander et al. 1996; Celander et al. 1997; Villeneuve et al. 1997; Huuskonen et al. 1998b; Huuskonen et al. 1998c; Smeets et al. 1999; Huuskonen et al. 2000). PLHC-1 cells show induction of CYP1A (an AHR-mediated response) in response to AHR agonists (Hahn et al. 1993; Hahn et al. 1996a; Hahn et al. 1996b; Hestermann et al. in press). These properties together with their relatively rapid proliferation led to the use of PLHC-1 cells here.

This study had the dual objectives of 1) characterizing proliferation and cell cycle in PLHC-1 cells and 2) developing techniques to study interactions between AHR signaling and cell proliferation. Cell cycle synchronization, flow cytometric analysis of induction of CYP1A protein and activity, the effect of TCDD on proliferation, and analysis of AHR mRNA and protein content were all performed in these cells. The results provide a basis for future studies of links between proliferation and AHR signal transduction in fish cells. 


\section{MATERIALS AND METHODS}

\section{Chemicals and solutions}

The 2,3,7,8-tetrachloro[1,6- $\left.{ }^{3} \mathrm{H}\right]$ dibenzo- $p$-dioxin $\left(\left[{ }^{3} \mathrm{H}\right] \mathrm{TCDD}\right.$, purity $\geq 97 \%$, specific activity $27 \mathrm{Ci} / \mathrm{mmol}$ ) was obtained from Chemsyn Science Laboratories (Lenexa, KS). TCDD and 2,3,7,8-tetrachlorodibenzofuran (TCDF) were obtained from Ultra Scientific (Kingston, RI). Oregon-Green conjugated goat anti-mouse IgG and methoxyfluorescein methyl ester (MFME) were from Molecular Probes (Eugene, OR). Restriction enzymes were from Promega (Madison, WI). All other reagents were obtained from Sigma (St. Louis, MO).

Saline GM is $0.8 \% \mathrm{NaCl}, 0.11 \%$ glucose, $0.04 \% \mathrm{KCl}, 0.039 \% \mathrm{Na}_{2} \mathrm{HPO}_{4}, 0.015 \%$ $\mathrm{KH}_{2} \mathrm{PO}_{4}, 0.5 \mathrm{mM}$ EDTA. Phosphate-buffered saline (PBS) is $0.8 \% \mathrm{NaCl}, 0.115 \%$ $\mathrm{Na}_{2} \mathrm{HPO}_{4}, 0.02 \% \mathrm{KCl}, 0.02 \% \mathrm{KH}_{2} \mathrm{PO}_{4}, \mathrm{pH}$ 7.4. Stock solutions of aphidicolin, nocodazole, TCDF and TCDD were prepared in dimethyl sulfoxide (DMSO) at 1000x the desired final concentration. Mimosine, thymidine and hydroxyurea were diluted in PBS. Concentrations of $\left[{ }^{3} \mathrm{H}\right] \mathrm{TCDD}$ solutions were verified by liquid scintillation counting (LSC) on a Beckman LS5000TD.

\section{Growth and Treatment of Cells}

PLHC-1 cells (Hightower et al. 1988), clone HC-16, were grown at $30^{\circ} \mathrm{C}$ in minimum essential medium (MEM) containing Earle's salts, nonessential amino acids, Lglutamine and $10 \%$ calf serum, as described previously (Hahn et al. 1993). Cells were seeded and treated in $25 \mathrm{~cm}^{2}$ flasks in $6 \mathrm{ml}$ medium. Unless noted otherwise, seeding density was $1.5 \times 10^{6} / \mathrm{ml}\left(2.4 \times 10^{5} / \mathrm{cm}^{2}\right)$. None of the chemical treatments used reduced cell viability, as determined by Trypan Blue exclusion.

Treatment of cells for synchronization with hydroxyurea, mimosine, nocodazole, and thymidine were performed as described (Krek et al. 1995). For all but nocodazole, 
PLHC-1 cells were treated with the indicated concentration of chemical for 24 hours, rinsed with prewarmed medium, given fresh medium, and sampled at subsequent intervals for DNA content analysis. Treatment with aphidicolin was by a method specifically for monolayer cultures (Sourlingas and Sekeri-Pataryas 1996), and both single- and double-block methods were employed. For double-block synchronization, cells were treated for 24 hours, rinsed and given fresh medium for 8-12 hours, and then treated again with aphidicolin for 16 hours. Nocodazole treatment was performed after a 16 hour pre-treatment with either thymidine or aphidicolin.

\section{Cell Cycle Analysis}

DNA staining for cell cycle analysis using propidium iodide (PI) was performed as described (Crissman and Hirons 1994). Cells were trypsinized, pelleted, and resuspended in one volume ice-cold saline GM. The suspension was gently vortexed during dropwise addition of three volumes ice-cold 95\% ethanol. Using cold reagents and gradual addition of ethanol reduced clumping of cells. Fixed cells were stored at $4^{\circ} \mathrm{C}$ until one day before analysis, and then were pelleted and resuspended in equal volumes $30 \mu \mathrm{g} / \mathrm{ml}$ PI and $100 \mu \mathrm{g} / \mathrm{ml}$ Rnase A, both in PBS. Stained cells were stored overnight at $4^{\circ} \mathrm{C}$, and protected from light until analysis. Flow cytometry was performed on a Becton Dickinson FacScan instrument at the MIT Cell Sorting Facility or a FacsCalibur at WHOI. Data from ten thousand ungated events were collected for each analysis. Modeling of cell cycle stages was performed using ModFit software (Verity). Coefficients of variation were typically $3-5 \%$.

\section{Analysis of CYP1A Protein and Activity}

Cells were analyzed for CYP1A protein or activity 24 hours after TCDD or DMSO treatment. CYP1A protein was measured by the method of Stauber et al (1995). Cells were trypsinized, pelleted, resuspended in $0.4 \%$ formalin, and incubated overnight at room temperature. Formalin-fixed cells were incubated in $0.05 \%$ Triton-X for 15 minutes on ice and then washed twice in $0.1 \%$ BSA in PBS. Cells were then incubated 
with $250 \mu$ mouse anti-scup CYP1A monoclonal antibody 1-12-3 (Park et al. 1986) or non-specific mouse $\operatorname{IgG}$ (both $1 \mu \mathrm{g} / \mathrm{ml}$ in PBS) for 15 minutes on ice and washed in goat serum and then twice in $0.1 \%$ BSA. They were then incubated in $250 \mu 1$ Oregon-Green conjugated goat anti-mouse $\operatorname{IgG}(1 \mu \mathrm{g} / \mathrm{ml}$ in PBS $)$ for 15 minutes on ice and washed twice in $0.1 \%$ BSA. Finally, the cells were resuspended in PBS and stored at $4^{\circ} \mathrm{C}$ in the dark until analysis.

CYP1A activity was measured as O-demethylation of MFME by a variation of a previosly established protocol (Miller and Whitlock 1981). Cells were trypsinized and resuspended to $10^{6} / \mathrm{ml}$ in MFME in PBS for 20 minutes prior to analysis of fluorescein production by flow cytometry. The suspension was protected from light until analysis.

\section{AHR Quantification by TCDD Binding}

Specific binding of $\left[{ }^{3} \mathrm{H}\right]$ TCDD in PLHC-1 cells was measured by a modification of the whole-cell filtration assay of Dold and Greenlee (1990). Cells were treated with 1 $\mathrm{nM}\left[{ }^{3} \mathrm{H}\right] \mathrm{TCDD}$ in the presence or absence of $200 \mathrm{nM}$ unlabeled TCDF and incubated 2 hours at $30^{\circ} \mathrm{C}$. This time was determined to be sufficient to achieve a steady state of bound radioligand (Appendix B). Cell densities were equal among treatments in order to minimize protein concentration effects on binding (Bradfield et al. 1988a). Following the incubation, tubes were vortexed briefly to assure even distribution of cells, and a $0.1 \mathrm{ml}$ aliquot was removed to determine final $\left[{ }^{3} \mathrm{H}\right] \mathrm{TCDD}$ concentration. Three, $0.45 \mathrm{ml}$ aliquots of cell suspension from each tube were then collected under vacuum on prewetted $25 \mathrm{~mm}$ Whatman GF/F filters. Filters were then washed three times with $2.5 \mathrm{ml}$ acetone that had been precooled to $-80^{\circ} \mathrm{C}$. The number of washes was determined empirically as that necessary to remove the free $\left[{ }^{3} \mathrm{H}\right]$ TCDD remaining on the filters (Appendix B). Replicates were processed in batches of twelve on a Millipore 1225 filter manifold. Radioactivity remaining on the filter was quantified by LSC. Cell protein was measured on separate aliquots by the bincinchinoic acid method of Smith (1985), using BSA as the standard and MEM as the blank. 
Cloning of AHR and $\beta$ actin cDNA Fragments

TCDD- and DMSO-treated cells were trypsinized, pelleted and resuspended in 1 ml RNA STAT-60 (Tel-Test, Friendswood, TX). RNA extraction continued according to the manufacturer's instructions. Poly $(\mathrm{A})^{+}$mRNA was isolated using mini-oligo(dT)cellulose spin columns ( 5 Prime $\rightarrow 3$ Prime, Boulder, CO). Reverse transcription coupled-PCR was performed using the Gene-AMP RNA-PCR kit (Perkin-Elmer) and a GeneAmp 2400 thermocycler. Reverse transcription was primed with random hexamers, and primer sets Qf/B1 and A1/B1 (Table 1) were used to amplify AHR, and F1/R1 $\beta$ actin. All primers were at $1 \mu \mathrm{M}$. PCR conditions were: $95^{\circ} \mathrm{C}, 1: 45 ; 35$ cycles of $\left(95^{\circ}\right.$, $\left.0: 15,50^{\circ}, 0: 30 ; 72^{\circ}, 1: 00\right) ; 72^{\circ}, 7: 00$.

Products of expected size were cloned into pGEM-T Easy (Promega). Twelve AHR clones were digested using 2 separate restriction enzymes, Pst1 and Sac1, and the sizes of the resulting fragments were compared to those predicted from previously obtained sequence for a PLHC-1 AHR2 (D. Franks and M. Hahn, unpublished results). Two AHR and two $\beta$-actin clones were sequenced by the University of Maine sequencing facility (Orono, ME).

\section{Measurement of $A H R m R N A$ by $R T-P C R$}

Cells were treated in $25 \mathrm{~cm}^{2}$ flasks, and total RNA was isolated as detailed above. cDNA was synthesized from $2 \mu \mathrm{g}$ of total RNA using Omniscript ${ }^{T M}$ Reverse Transcriptase (Qiagen, Valencia, CA) and random hexamers. One fifth of the reaction volume (equivalent to cDNA from 400 ng of RNA) was used for each PCR reaction. Specific primers used to amplify PLHC-1 AHR and $\beta$-actin are shown in Table 1. Primers were designed to cross mRNA splice sites (as predicted by alignment of the PLHC cDNA and Fundulus heteroclitus genomic AHR2 sequences) to eliminate amplification of AHR genomic DNA. The AHR and $\beta$-actin primers have nearly identical melting temperatures and amplify products of similar size, facilitating RT-PCR under the same conditions. PCR was performed using Amplitaq Gold (Perkin-Elmer) with: $95^{\circ} \mathrm{C}, 10: 00 ; 34$ cycles of $\left(95^{\circ}, 0: 15,60^{\circ}, 0: 30\right) ; 72^{\circ}, 7: 00$. The number of cycles 
used was within the range of exponential amplification for both AHR and $\beta$-actin products.

PCR products were separated by agarose gel electrophoresis and stained by soaking the gel in $1 \mu \mathrm{g} / \mathrm{ml}$ ethidium bromide for 30 minutes. Quantification of bands was performed with a Multilmage ${ }^{\top M}$ analysis system (Alpha Innotech, San Leandro, CA).

Integrated densities of AHR bands were normalized to integrated density of $\beta$-actin bands from the same samples, and these values were then normalized to those in untreated cells.

Table 1. PCR primer sequences.

\begin{tabular}{c|l} 
Primer name & \multicolumn{1}{|c}{ Sequence $\left(5^{\prime} \rightarrow 3^{\prime}\right)$} \\
\hline $\begin{array}{c}\text { Pegenerate } \\
\text { Al }\end{array}$ & \\
Qf & ARGCICTSAAYGGITT \\
B1 & AACCCITCIAAGMGICAYMG \\
F1 & CATICCRCTYTCICCIGTYTT \\
R1 & ACAACGGYTCSGGYATGTGC \\
Specific Primers & GAAGCAYTTGCGRTGWACRAT \\
AHRF & CAATCCCCTCAGATGCAGACCTCTCC \\
AHRR & ATAACCCAGGATTATCTTCCCCCTGC \\
ActinF & CCATTGGCAACGAGAGGTTCCGTTGC \\
Actin R & CTCATCGTACTCCTGCTTGCTGATCC
\end{tabular}




\section{RESULTS}

\section{PLHC-1 Growth Characteristics}

The proliferative rate for the PLHC-1 cells was measured by counting cells at increasing intervals following seeding in $25 \mathrm{~cm}^{2}$ flasks (Figure 1). Cells were in lag phase until 24 hours after seeding, and then proliferation proceeded exponentially for 30 hours before reaching a stationary plateau. A fit through the exponential growth stage predicts a population doubling time of 22 hours.

The short period of exponential growth was likely due to high seeding density $\left(2.4 \times 10^{5}\right.$ cells $\left./ \mathrm{cm}^{2}\right)$. At this density, the cells are $\sim 75 \%$ confluent after attachment. Previous evidence suggested that PLHC-1 do not proliferate at low densities (Hahn and Woodward, unpublished results). The minimum seeding density was determined in the standard medium (MEM $+10 \%$ calf serum; Figure $2 \mathrm{~A}$ ) and in MEM $+10 \%$ fetal bovine serum (Figure 2B). In 10\% calf serum, PLHC-1 proliferated at initial densities greater than or equal to $1.2 \times 10^{5}$ cells $/ \mathrm{cm}^{2}$, although proliferation was much slower below $2.4 \times 10^{5} \mathrm{cells} / \mathrm{cm}^{2}$. In contrast, $10 \% \mathrm{FBS}$ supported proliferation at densities as low as $3 \times 10^{4}$ cells $/ \mathrm{cm}^{2}$, although the lag phase was prolonged at lower densities.

\section{Cell Cycle Analysis and Synchronization}

Several flasks of PLHC-1 at different times in the log phase of growth were analyzed for DNA content by flow cytometry (an example is shown in Figure 3A). The percentages of cells in $\mathrm{G} 1, \mathrm{~S}$, and G2/M were determined, and these percentages were assumed to equal the fraction of time spent in each stage by an average cell. Multiplying by the doubling time yields estimates of 13,3 , and 6 hours for $\mathrm{G} 1, \mathrm{~S}$, and $\mathrm{G} 2 / \mathrm{M}$, respectively. These lengths have been confirmed by sampling parasynchronous (nearly synchronous) cells at increasing intervals after removal of aphidicolin. Attempts to label cells with bromodeoxyuridine in order to measure lengths of cycle stages more precisely were unsuccessful. 


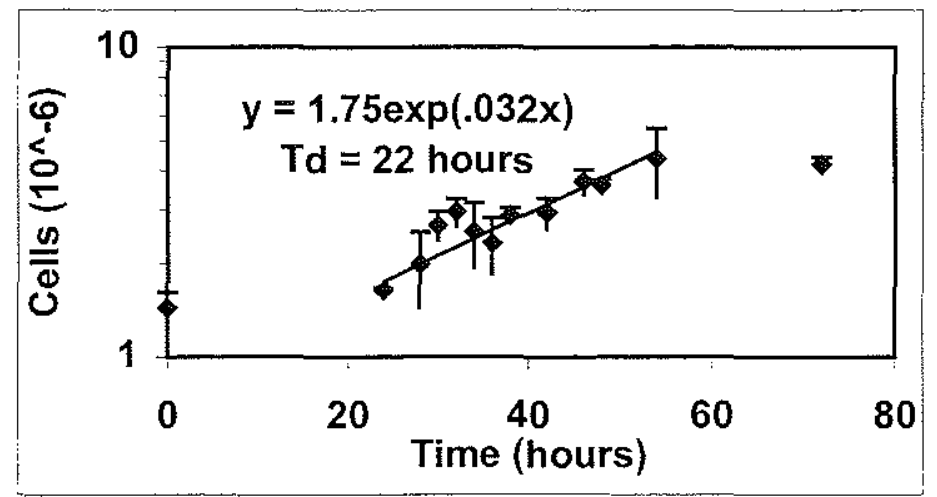

Figure 1. Proliferation in PLHC-1 cells. Cells were seeded in $25 \mathrm{~cm}^{2}$ flasks at $2.4 \times 10^{5}$ cells $/ \mathrm{cm}^{2}$ and subsequently counted at the indicated times using a hemacytometer. The best fit through the exponential growth phase is shown and predicts a population doubling time of 22 hours.
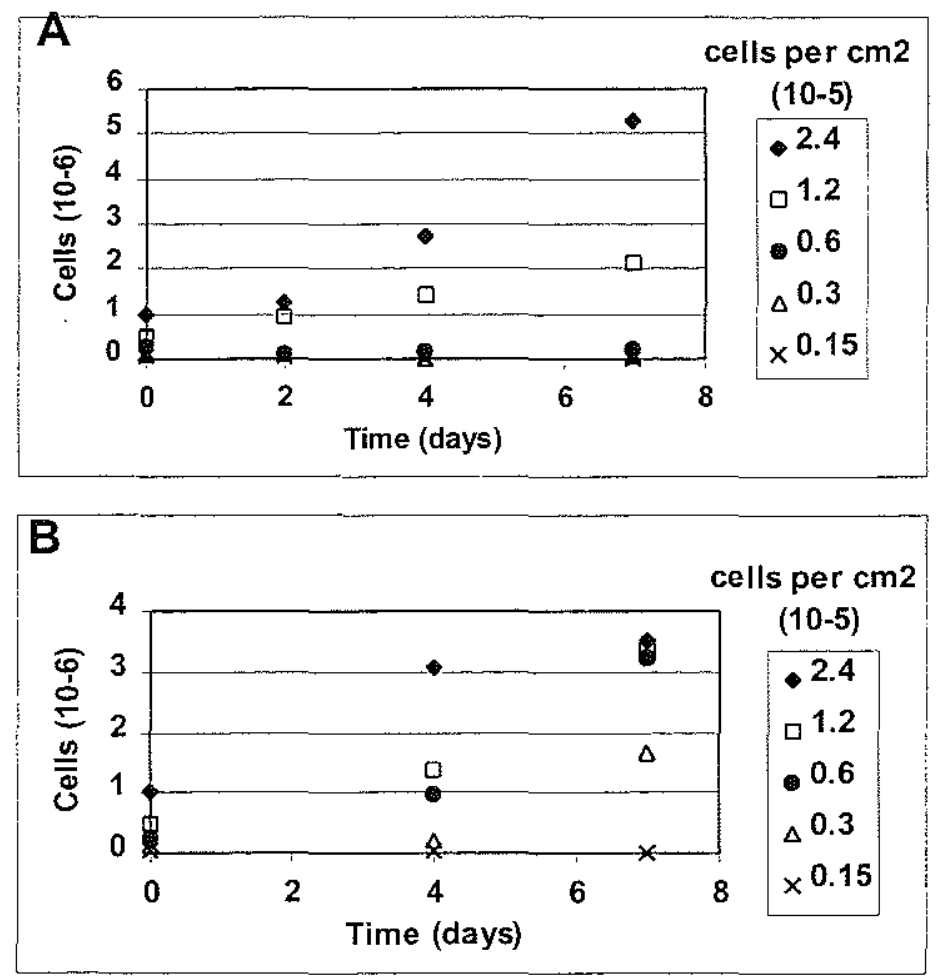

Figure 2. Determination of the minimum seeding density. Cells were seeded at the densities indicated in the legend and subsequently counted. (A) Cells cultured in MEM supplemented with $10 \%$ calf serum. (B) Cells cultured in MEM with $10 \%$ fetal bovine serum. 
A
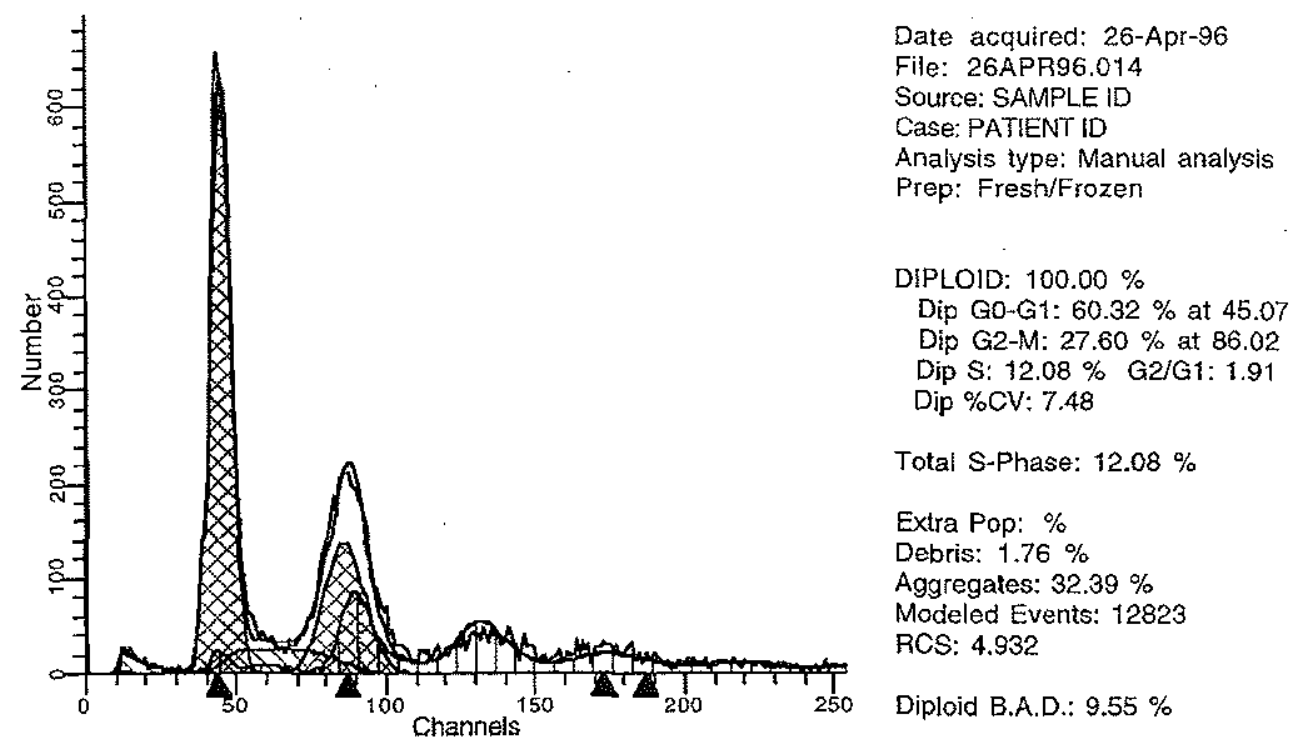

B

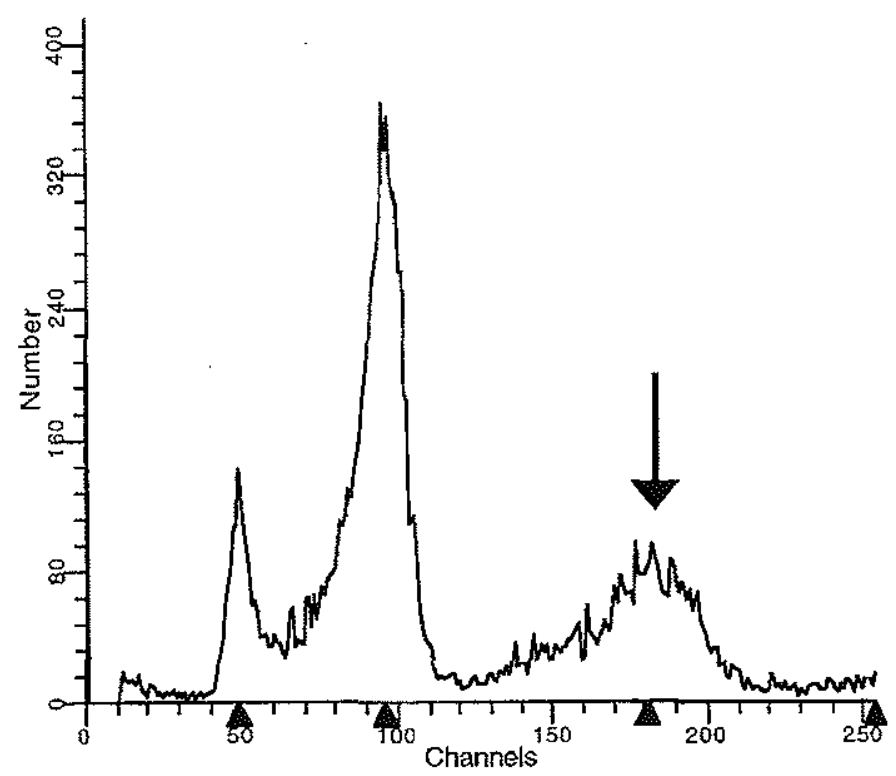

Figure 3. Flow cytometric analysis of DNA content in PLHC-1. Cells were fixed in ethanol and stained with PI as indicated in the Methods. (A) Exponentially growing cells were used to determine the fraction of cells in each stage of the cycle. (B) Cells treated with $5 \mu \mathrm{M}$ aphidicolin 8 hours after removal of the agent. The arrow indicates the population of cells with twice the expected DNA content. 
Table 2. Synchronization of PLHC-1 by chemical treatment.

"None" indicates no significant enrichment of a single cycle stage.

\begin{tabular}{c|c|c} 
Agent & Concentration(s) tested & Maximum synchrony \\
\hline Aphidicolin & 1.5 to $15 \mu \mathrm{M}(0.5-5 \mu \mathrm{g} / \mathrm{ml})$ & $80 \%$ \\
Hydroxyurea & $1 \mathrm{mM}$ & None \\
Mimosine & $0.2 \mathrm{mM}$ & None \\
Nocodazole & $500 \mathrm{ng} / \mathrm{mL}$ & $75 \%$ \\
Thymidine & $2 \mathrm{mM}$ & None
\end{tabular}

Several chemical treatments were tested for their ability to block cell cycle progression of PLHC-1 (Table 2). Only aphidicolin and nocodazole treatment resulted in populations enriched in one stage of the cycle. Treatment with aphidicolin consistently resulted in a population of cells with twice the expected DNA content ( $4 \mathrm{n}$ in G1, $8 \mathrm{n}$ in G2; Figure 3B), and this population persisted until the first mitosis following aphidicolin removal. Maximum synchrony with nocodazole was achieved using a pre-treatment with aphidicolin and shaking off mitotic cells following nocodazole treatment. Cell yields using this technique were substantially lower than with aphidicolin, and did not permit exponential growth following reattachment. This problem was also encountered when using fluorescence-activated cell sorting (FACS) with the vital DNA stain Hoechst 33342 to obtain a synchronous population (not shown).

A higher degree of synchrony was attained with greater cell densities (Figure 4). This is consistent with faster proliferation at these densities, since slower cell-cycle progression would lead to fewer cells accumulating in S phase during a 24-hour aphidicolin treatment. 

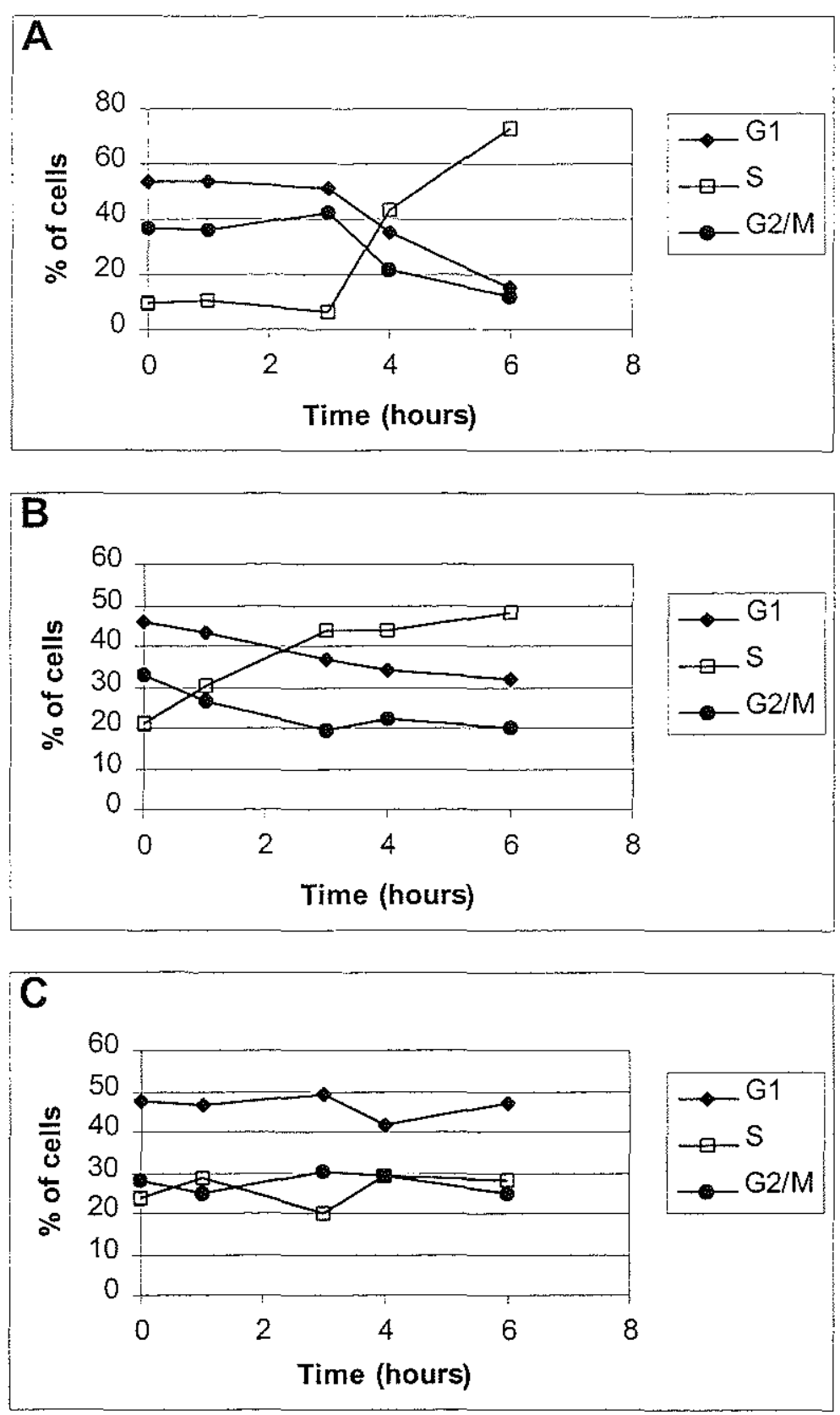

Figure 4. Density-dependence of synchronization efficiency. Cells were fixed at the indicated times following removal of $5 \mu \mathrm{M}$ aphidicolin. Analysis of cell cycle was performed as in Figure 3A. Seeding densities were (A) $3.6 \times 10^{5}$ cells $/ \mathrm{cm}^{2}$, (B) $2.4 \times 10^{5}$ cells $/ \mathrm{cm}^{2}$ and (C) $1.6 \times 10^{5}$ cells $/ \mathrm{cm}^{2}$. 

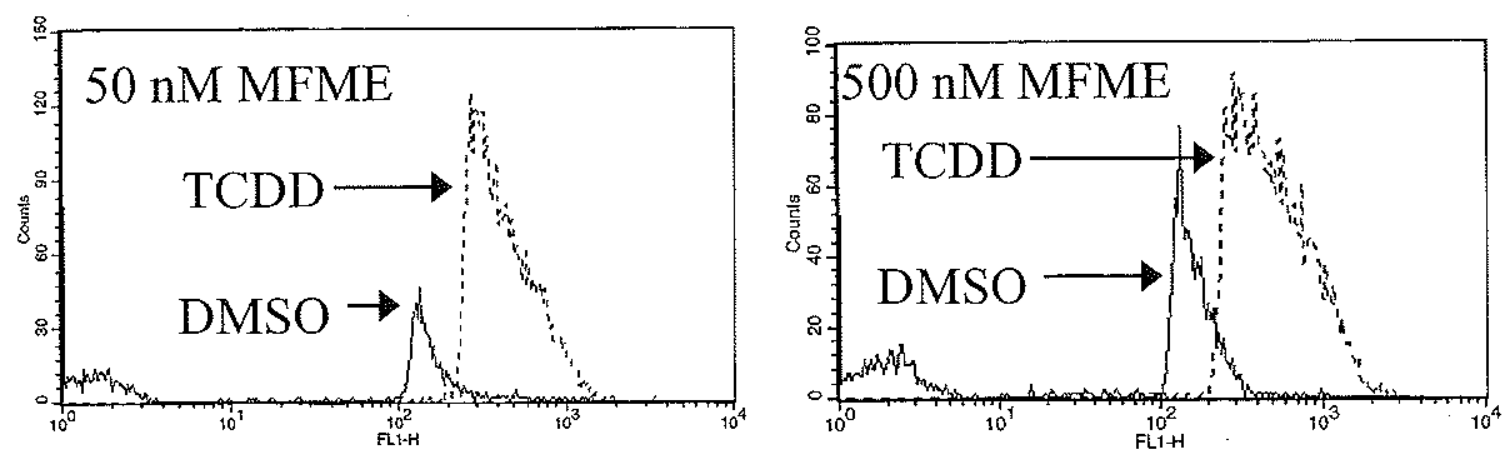

B

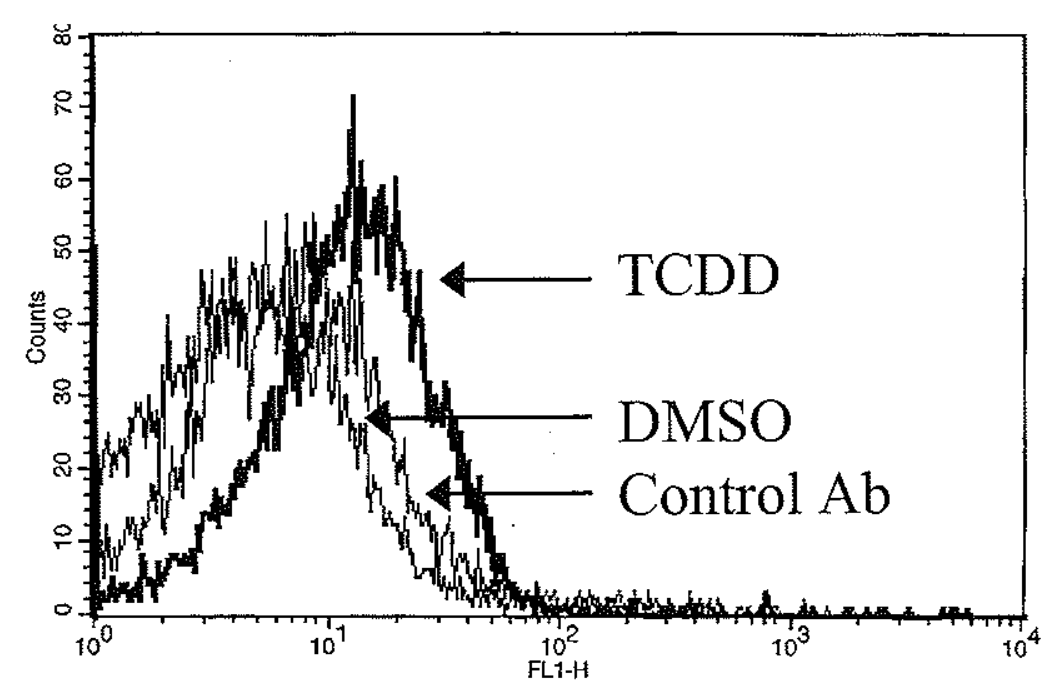

Figure 5. Flow cytometric analysis of CYP1A expression. Cells were treated with $2 \mathrm{nM}$ TCDD or $0.1 \%$ DMSO for 24 hours. (A) Cells were trypsinized and resuspended in the indicated concentration of MFME for 20 minutes prior to measurement of fluorescein fluorescence. (B) Cells were fixed and prepared for immunofluorescence as detailed in the Methods. TCDD-treated cells incubated with a non-specific primary antibody are included as a control. 


\section{Single-Cell CYP1A Analysis}

CYP1A expression was determined in individual cells in two ways: by immunostaining of fixed cells and measurement of MFME O-demethylation activity in viable cells (Figure 5). Both techniques are capable of distinguishing populations of cells treated with CYP1A inducers from uninduced controls; however, there was overlap between the signal determined for the two populations. The induced and control peaks were resolved better using MFME metabolism.

MFME concentrations between 50 and $500 \mathrm{nM}$ produced the best results. Concentrations lower than $50 \mathrm{nM}$ resulted in a high degree of overlap between control and induced populations, and concentrations higher than $500 \mathrm{nM}$ produced too much background fluorescence for the cytometer to distinguish individual events (i.e. cells). The 20-minute incubation time used was determined by a time course of fluorescein production. Fluorescence values shown for the induced population persisted for at least one hour, which facilitated counting and sorting of cells.

Immunodetection of CYP1A protein produced populations with a high degree of overlap (Fig. 5B). However, antibody concentrations and wash conditions were not optimized, so better resolution may be possible.

\section{TCDD Treatment and Proliferation}

The effect of TCDD on proliferation of PLHC-1 cells is shown in Figure 6. Cells were treated with $2 \mathrm{nM}$ TCDD or $0.1 \%$ DMSO one day after seeding and counted at subsequent intervals (Fig. 6A). The onset of proliferation was delayed between two and five days in TCDD treated cells, but by seven days post-treatment cell counts were equal to those in control cells. The dose-response relationship for this effect after two days indicates a significant decline in cell numbers at TCDD concentrations in excess of 0.06 nM (Fig. 6B). This delay in proliferation was consistently measured through several passages in this sub-clone of cells, but not in any of several subsequent ones. 

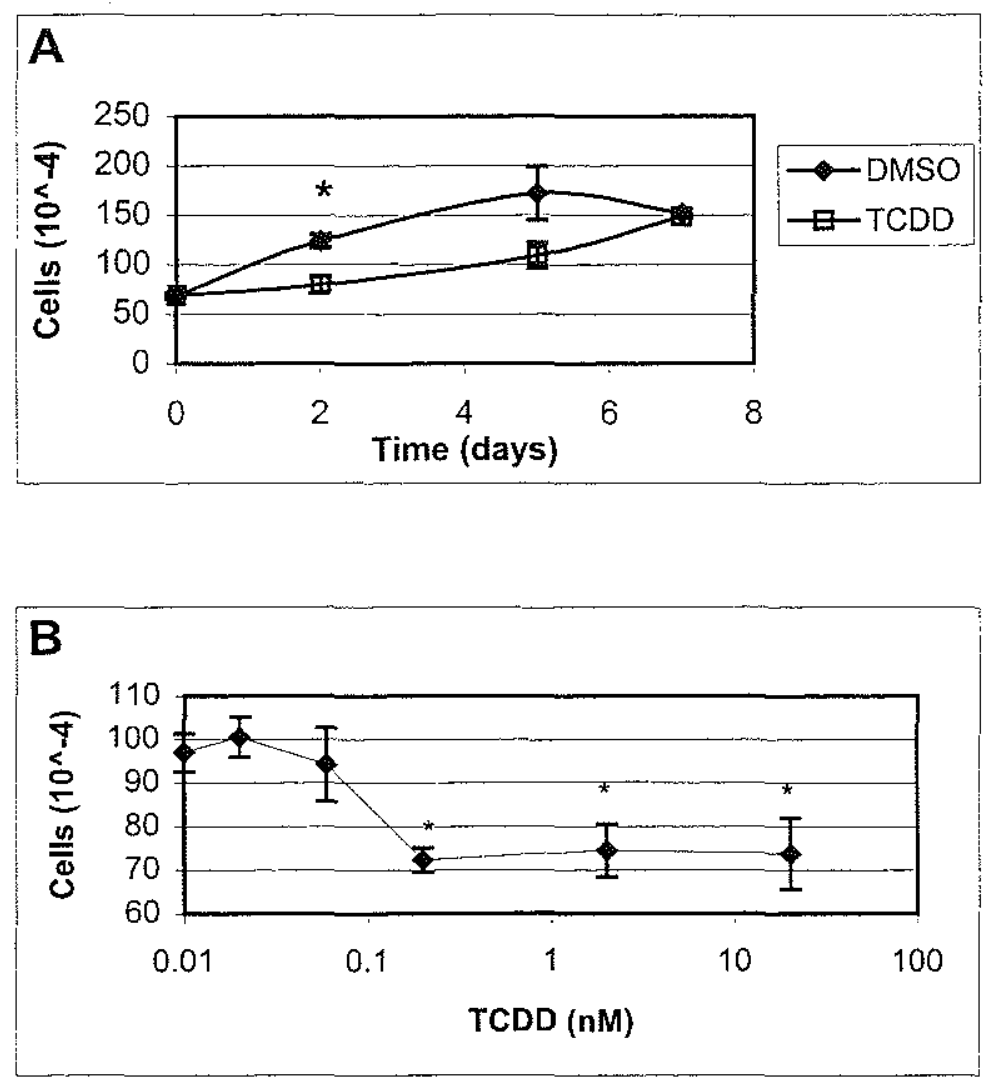

Figure 6. Effect of TCDD on PLHC-1 proliferation. Cells were seeded at $2.4 \times 10^{5}$ cells $/ \mathrm{cm}^{2}$, treated 24 hours later with the indicated concentrations of TCDD and counted at subsequent times. Points are means $\pm \mathrm{SE}$ of three replicates. * indicates significantly fewer cells in TCDD treatment. (A) Time course of proliferation. (B) Dose-response relationship. Cells were counted two days after treatment. The $0.01 \mathrm{nM}$ TCDD point indicates treatment with DMSO alone. 
Sequencing and Expression of AHR2 in PLHC-1

An AHR was cloned from PLHC-1 cells by harvesting RNA, isolating mRNA, and using RT-PCR with degenerate primers to amplify a portion of the gene. An AHR2 fragment had already been isolated from these cells (D. Franks et al, unpublished results), but expression of an AHR1 remained a possibility. Because AHR1 expression is very low in fish liver, but possibly inducible by AHR agonists (W. Powell, S. Karchner, and M. Hahn, unpublished results), RNA was isolated from TCDD- and DMSO-treated cells. The primer set Qf/B1 (which amplify both AHR1 and AHR2 in Fundulus heteroclitus) amplified a product of the expected size $(\sim 1000 \mathrm{bp}$; the $\sim 600 \mathrm{bp}$ product has been seen in other systems, and is not AHR), while A1/B1 did not (Figure 7A). Degenerate $\beta$-actin primers also successfully amplified a band of expected size. These products were cloned, and several AHR clones were chosen for further analysis. Six clones from DMSOtreated and 12 from TCDD-treated cells were digested with restriction enzymes that had only one recognition site in the previously determined partial AHR2 sequence. All but one of the clones produced restriction products of the expected size (not shown), and that clone as well as one other AHR and two actin clones were sequenced. The two AHR clones had nearly identical sequences (one contained a base change in the restriction site), and agreed with the sequence previously obtained (Figure 7B). The actin products were also nearly identical, and showed high identity (95.3\% nucleotide identity) with Fundulus heteroclitus $\beta$-actin (Figure $7 \mathrm{C}$ ). These sequences were used to generate specific PCR primers for use in semi-quantitative RT-PCR (Table 1, Figure 7B\&C).

Expression of the PLHC-1 AHR was measured in synchronized cells. After release from aphidicolin block, cells progressed from G1 into $S$ and G2 phases (Figure 8A). RT-PCR amplification of AHR and actin revealed no effect of cell cycle progression on expression of AHR mRNA (Figure 8B). Likewise, specific binding of TCDD by the AHR was not significantly altered (Figure 8C). 
A

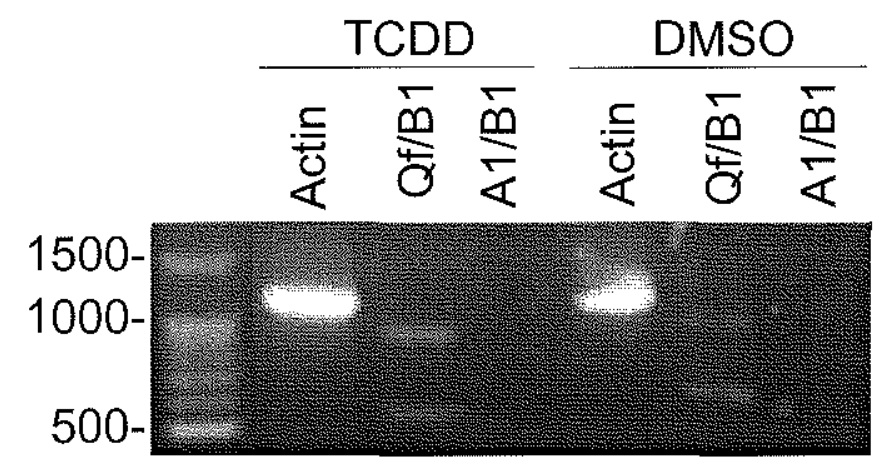

B

$\begin{array}{llllll}10 & 20 & 30 & 40 & 50 & 60\end{array}$

AACCCGTCGAAGAGGCATCGGGATCGGCTGAATGGGGAGCTGGACCGCTTGATGGAGCTGCTGCCTTTCCCTGATGAG $\begin{array}{llllllllllllllllllllllllll}N & P & S & K & R & H & R & D & R & L & N & G & E & L & D & R & L & M & E & L & L & P & F & P & D & E\end{array}$ $\begin{array}{lllllll}80 & 90 & 100 & 110 & 120 & 130 & 140\end{array}$ GTTCGCTCCAGCTTGGACAAGCTCTCTGTCCTGCGCCTGAGCGTGGGATACCTCAGGGTCAAGAGCTACTTTAAAACT $\begin{array}{lllllllllllllllllllllllllllll}V & R & S & S & L & D & K & L & S & V & L & R & L & S & V & G & Y & L & R & V & K & S & Y & E & K & T\end{array}$ $\begin{array}{lllllll}160 & 170 & 180 & 190 & 200 & 210 & 220\end{array}$ TCCATGAAGAATGGTAATGGCAGCCGGGTGCCTCTGGGGGTCAACGGGCAGAACATGGACTCTACTGGTTTCTCTGAA $\begin{array}{lllllllllllllllllllllllllll}S & M & K & N & G & N & G & S & R & V & P & L & G & V & N & G & Q & N & M & D & S & T & G & F & S & E\end{array}$

$\begin{array}{lllllll}240 & 250 & 260 & 270 & 280 & 290 & 300\end{array}$

GGAGAGCTGCTGCTGCAGGCGCTGAACGGCTTTGTGTTGGTGGTGACATCTGAAGGAATGGTGTTTTACACCTCCCCT

$\begin{array}{lllllllllllllllllllllllllll}G & E & L & L & L & Q & A & L & N & G & F & V & L & V & V & T & S & E & G & M & V & F & Y & T & S & P\end{array}$ $\begin{array}{lllllll}320 & 330 & 340 & 350 & 360 & 370 & 380\end{array}$

ACCATCAAAGACTACTTGGGCTTCCATCAGTCAGACGTGGTCCACCAGAGTGTGTTTGAGCTCATCCACACTGACGAC $\begin{array}{llllllllllllllllllllllllllllll}T & I & K & D & Y & \perp & G & F & H & Q & S & D & V & V & H & Q & S & V & F & E & L & I & H & T & D & D\end{array}$ $\begin{array}{llllll}400 & 410 & 420 & 430 & 440 & 450\end{array}$ CGAGCCATGTTCAGACAGCAGCTCCACTTTGCCTTAAACCCTCCTCCAATCCCCTCAGATGCAGACCTCTCCCAGAAC $\begin{array}{llllllllllllllllllllllllll}R & A & M & F & R & Q & Q & L & H & F & A & L & N & P & P & P & I & P & S & D & A & D & L & S & Q & N\end{array}$ $\begin{array}{llllll}480 & 490 & 500 & 510 & 520 & 530\end{array}$

TGTGAAAATGCAGTGATGTACAACCCAGAGCAGCTCCCCCCTGACAACTCCTCCTTCCTGGAGAGGAGCTTTTTCTGT $\begin{array}{llllllllllllllllllllllllllll}C & E & N & A & V & M & Y & N & P & E & Q & L & P & P & D & N & S & S & F & L & E & R & S & F & F & C\end{array}$ $\begin{array}{lllllll}550 & 560 & 570 & 580 & 590 & 600 & 610\end{array}$

CGCTTCCGATGTCTTTGGACAACTCCTCCGGCTTCCTGGCCCTGAAGTTCCATGGGCGCTTGAAGTACCTCCATGGT $\begin{array}{lllllllllllllllllllllllllll}R & F & R & C & L & L & D & N & S & S & G & F & L & A & L & K & F & H & G & R & L & K & Y & L & H & G\end{array}$
630
640
650
660
670
680
690
700

CAAAACTTTTCCAGGGACAGTGAGAGCTGTAAACGTATCCAGCTGGCPCTGTTTGCCATCGCTGTGCCTGTCCAGTCT

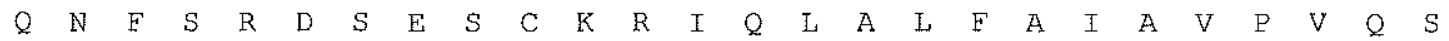

$\begin{array}{lllllll}710 & 720 & 730 & 740 & 750 & 760 & 770\end{array}$
CCGTCAATTGTGGAGATCAGAGCCAAAATGCTCCTCTTCCAGACAAGGCACAAGCTGGACTTCACACCCACTGGCGTT $\begin{array}{lllllllllllllllllllllllllllll}\mathrm{P} & \mathrm{S} & \mathrm{I} & \mathrm{V} & \mathrm{E} & \mathrm{I} & \mathrm{R} & \mathrm{A} & \mathrm{K} & \mathrm{M} & \mathrm{L} & \mathrm{L} & \mathrm{F} & \mathrm{Q} & \mathrm{T} & \mathrm{R} & \mathrm{H} & \mathrm{K} & \mathrm{L} & \mathrm{D} & \mathrm{F} & \mathrm{T} & \mathrm{P} & \mathrm{T} & \mathrm{G} & \mathrm{V}\end{array}$ $\begin{array}{lllllll}790 & 800 & 810 & 820 & 830 & 840 & 850\end{array}$

TGCAGCAGGGGGAAGATAATCCTGGGTTATTCTGAGACAGAGCTGTGTATGAAAGGCTCAGGATATCAGTTCATCCAT $\begin{array}{lllllllllllllllllllllllllll}C & S & R & G & K & I & I & L & G & Y & S & E & T & E & L & C & M & K & G & S & G & Y & Q & F & I & H\end{array}$ 570 880 890 900 910 920

GCTGCTGACATGATGTACTGCGCTGACAACCACATCCGCATGATTAAGACCGGCGAGAGTGGCATG $\begin{array}{lllllllllllllllllllllllllllllll}\text { A } & A & D & M & M & Y & C & A & D & N & H & I & R & M & I & K & T & G & E & S & G & M\end{array}$ 


\section{C}

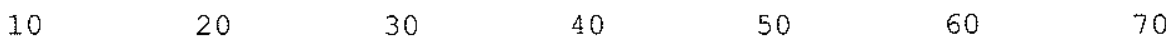

ATTCGATTGAATTCTGCAGACAACGGTTCCGGCATGTGCAAAGCCGGATTCGCCGGAGACGACGCCCCTCGTGCTGTC

$\begin{array}{lllllllllllllllllllllllllll}I & R & L & N & S & A & D & N & G & S & G & M & C & K & A & G & F & A & G & D & D & A & P & R & A & V\end{array}$

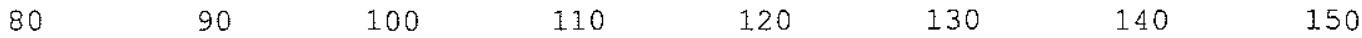

TTCCCATCCATCGTTGGTCGCCCAAGGCATCAGGGCGTGATGGTTGGTATGGGCCAGAAGGACAGCTATGTAGGTGAT

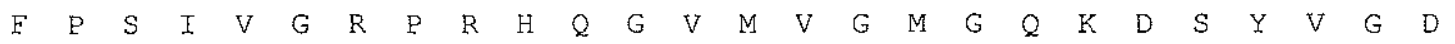

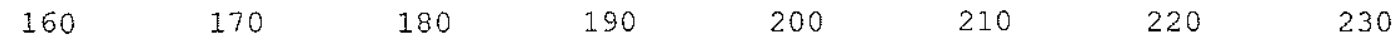

GAAGCCCAGAGCAAGAGAGGTATTCTGACCCTGAAGTACCCCATCGAGCACGGTATTGTGACCAACTGGGACGACATG

$\begin{array}{lllllllllllllllllllllllllll}E & A & \& & S & K & R & G & I & L & T & L & K & Y & P & I & E & H & G & I & V & T & N & W & D & D & M\end{array}$

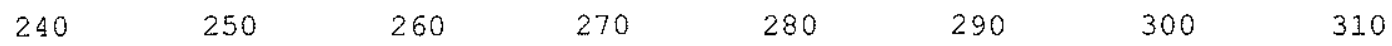

GAGAAGATCTGGCATCACACCTTCTACAACGAGCTGAGAGTTGCCCCTGAGGAGCACCCCGTCCTGCTCACAGAGGCC

$\begin{array}{lllllllllllllllllllllllllll}E & K & I & W & H & H & T & E & Y & N & E & L & R & V & A & P & E & E & H & P & V & L & L & T & E & A\end{array}$ $\begin{array}{lllllll}320 & 330 & 340 & 350 & 360 & 370 & 380\end{array}$

CCTCTGAACCCCAAAGCCAACAGGGAGAAGATGACCCAGATCATGTTTGAGACCTTCAACACCCCCGCCATGTACGTT

$\begin{array}{lllllllllllllllllllllllllll}\mathrm{P} & \mathrm{L} & \mathrm{N} & \mathrm{P} & \mathrm{K} & \mathrm{A} & \mathrm{N} & \mathrm{R} & \mathrm{E} & \mathrm{K} & \mathrm{M} & \mathrm{T} & \mathrm{Q} & \mathrm{I} & \mathrm{M} & \mathrm{F} & \mathrm{E} & \mathrm{T} & \mathrm{F} & \mathrm{N} & \mathrm{T} & \mathrm{P} & \mathrm{A} & \mathrm{M} & \mathrm{Y} & \mathrm{V}\end{array}$ $400 \quad 410 \quad 420 \quad 430 \quad 440 \quad 450 \quad 460$

GCCATCCAGGCCGTGCTGTCCCTGTACGCTTCTGGTCGTACCACTGGTATCGTCATGGACTCCGGTGATGGTGTGACC

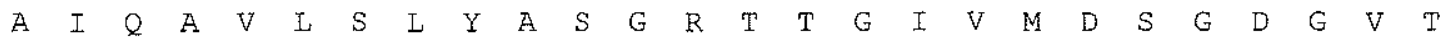
$480 \quad 490 \quad 500 \quad 510 \quad 520 \quad 530 \quad 540$

CACACAGTGCCCATCTATGAGGGTTACGCCCTGCCCCATGCCATCTTGCGTCTGGACTTGGCTGGCCGCGACCTCACA $\begin{array}{llllllllllllllllllllllllllllllll}H & T & V & P & I & Y & E & G & Y & A & L & P & H & A & I & L & R & L & D & L & A & G & R & D & L & T\end{array}$

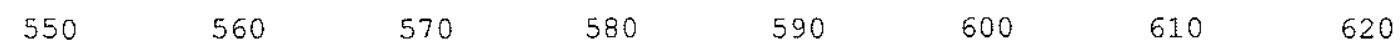
GACTACCTCATGAAGATCCTGACAGAGCGTGGCTACTCCTTCACCACCACAGCTGAGAGGGAAATTGTGCGCGACATC $\begin{array}{llllllllllllllllllllllllll}D & Y & L & M & K & I & L & T & E & R & G & Y & S & F & T & T & T & A & E & R & E & I & V & R & D & I\end{array}$

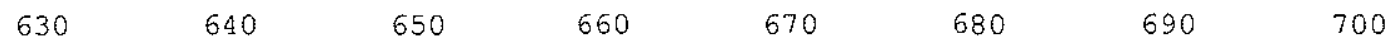
AAGGAGAAGCTGTGCTATGTCGCCCTGGACTTCGAGCAGGAGATGGGTACCGCTGCCTCTTCTTCATCCCTGGAGAAG $\begin{array}{llllllllllllllllllllllllll}K & E & K & L & C & Y & V & A & L & D & F & E & Q & E & M & G & T & A & A & S & S & S & S & L & E & K\end{array}$ $\begin{array}{llllllll}710 & 720 & 730 & 740 & 750 & 760 & 770 & 780\end{array}$ AGCTACGAACTCCCTGACGGACAGGTCATCACCATCGGCAATGAGAGGTTCCGTTGCCCAGAGGCCCTCTTCCAGCCT $\begin{array}{llllllllllllllllllllllllll}S & Y & E & L & P & D & G & Q & V & I & T & I & G & N & E & R & F & R & C & P & E & A & L & F & Q & P\end{array}$

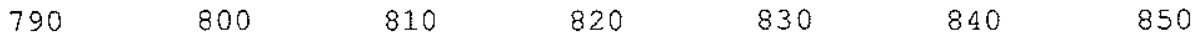

TCCTTCCTTGGTATGGAGTCCTGCGGAATCCACGAGACCACCTACAACAGCATCATGAAGTGCGACGTTGACATCCGT $\begin{array}{lllllllllllllllllllllllllll}S & F & L & G & M & E & S & C & G & I & H & E & T & T & Y & N & S & I & M & K & C & D & V & D & I & R\end{array}$ $\begin{array}{llllll}870 & 880 & 890 & 900 & 910 & 920\end{array}$ AAAGACCTGTACGCAAACACCGTGCTGTCTGGTGGTACCACCATGTACCCTGGCATTGCTGACAGGATGCAGAAGGAG $\begin{array}{llllllllllllllllllllllllllllllllllll}K & D & L & Y & A & N & T & V & L & S & G & G & T & T & M & Y & P & G & I & A & D & R & M & Q & K & E\end{array}$

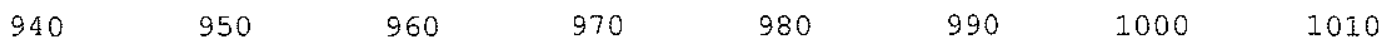
ATCACAGCCCTGGCCCCATCCACTATGAAGATCAAGATCATTGCCCCACCAGAGCGTAAATACTCTGTCTGGATCGGA $\begin{array}{lllllllllllllllllllllllllll}I & T & A & L & A & P & S & T & M & K & I & K & I & I & A & P & P & E & R & K & Y & S & V & W & I & G\end{array}$

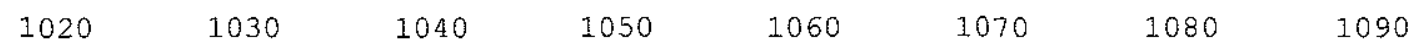
GGCTCCATCCTGGCCTCCCTGTCCACCTTCCAGCAGATGTGGATCAGCAAGCAGGAGTACGATGAGTCTGGCCCCTCC

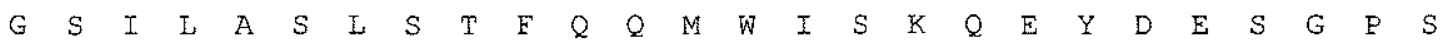
$1100 \quad 1110 \quad 1120$

ATCGTACATCGCAAGTGCTTCGGATCCTCGAATCAC

$\begin{array}{llllllllllllllllll}I & V & H & R & K & C & F & G & S & S & N & H\end{array}$

Figure 7. RT-PCR cloning of PLHC-1 AHR2 and $\beta$-actin. (A) Degenerate primers

(Table 1 ) were used to amplify cDNA prepared from DMSO- $(0.1 \%)$ and TCDD- $(2 \mathrm{nM})$ treated PLHC-1. (B) AHR2 sequence. (C) $\beta$-actin sequence. Sequences corresponding to the specific primers are indicated by bold face. 


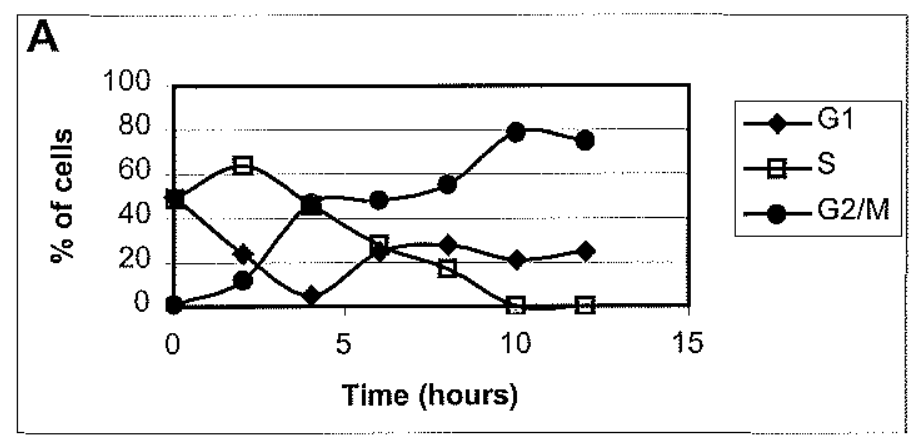

B
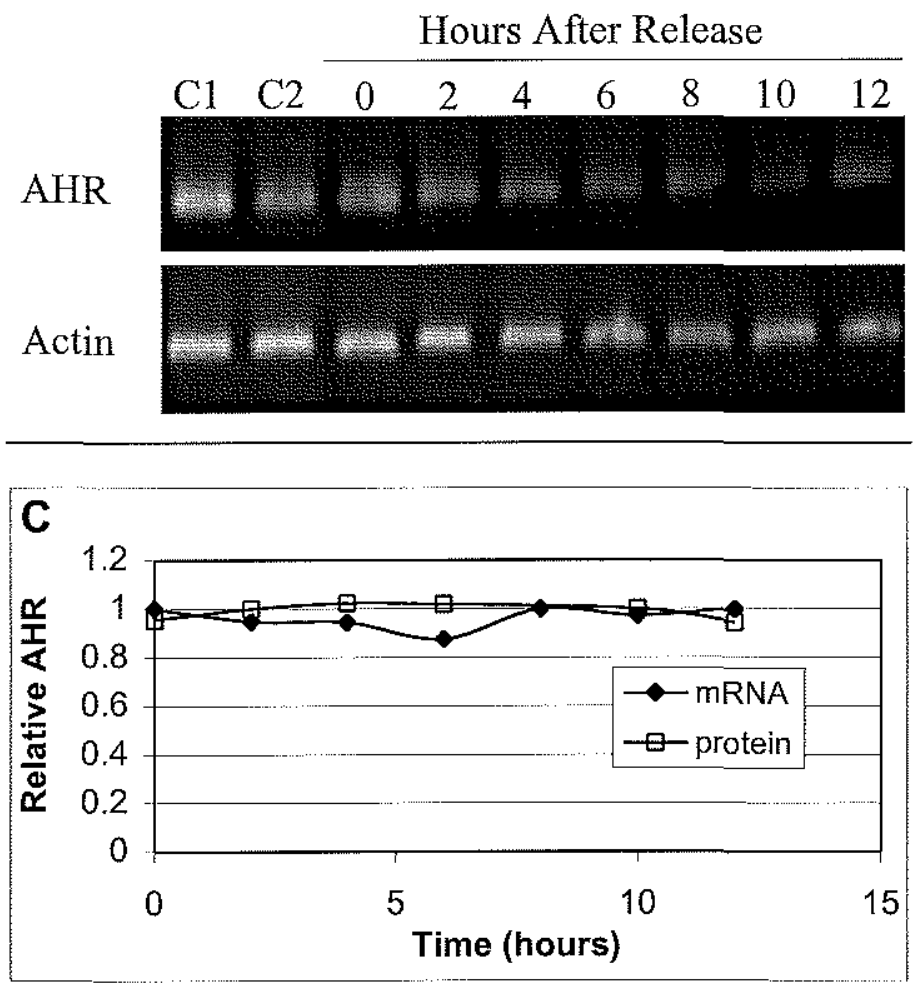

Figure 8. PLHC-1 AHR expression after cell cycle synchronization. (A) Cells were synchronized with a double block of aphidicolin and sampled at subsequent times after release. Cell cycle stages and AHR expression were assessed in sub-samples of the same cells. (B) AHR mRNA expression was assessed by RT-PCR following aphidicolin release. (C) AHR mRNA expression was normalized to $\beta$-actin expression and expression in randomly cycling cells harvested at the same time $(\mathrm{C} 1$ for $0-4$ hours, $\mathrm{C} 2$ for 6-12 hours). AHR protein expression was measured by TCDD specific binding in the presence of $1 \mathrm{nM}{ }^{3} \mathrm{H}$-TCDD. Specific binding was also normalized to time-matched, randomly cycling controls. Absolute values were $50 \pm 5 \mathrm{fmol} / \mathrm{mg}$ for all treatments. 


\section{DISCUSSION}

This work extends the usefulness of the PLHC-1 cell line in toxicological studies, particularly those involving HAH toxicity and cell cycle interactions. The rate of and optimal conditions for proliferation have been established, and the abilities of several chemicals to inhibit progression of the cell cycle have been evaluated. Interactions between AHR signaling and cell cycle progression were investigated, and techniques for future studies of such interactions have been developed.

\section{Proliferation of PLHC-1}

The doubling time measured here for PLHC-1 cells ( 22 hours) is similar to that of commonly used mammalian cell lines of hepatocellular origin (e.g. 17 and 19 hours for Hep2 and HEPA-1c1c7, respectively, Ma et al. 1996; Sourlingas et al. 1996), but shorter than published values for fish cells (e.g. 44 hours for RTG-2, Ackermann and Fent 1998). This is at least partially due to the lower temperature at which most other fish cells are maintained (typically $\leq 20^{\circ} \mathrm{C}$ vs. $30^{\circ} \mathrm{C}$ for PLHC-1), leading to slower metabolic rates.

Ackerman and Fent (1998) measured proliferation rates of PLHC-1 in different media, and reported a doubling time of 2 days in MEM with $10 \%$ FBS. However, the cells in that study were seeded at $1.6 \times 10^{5} / \mathrm{cm}^{2}$, a density near which we found an increased lag before onset of proliferation (Figure 2B). Our data at $1.2 \times 10^{5} / \mathrm{cm}^{2}$ in $10 \%$ FBS predict a doubling time of 2.5 days, so comparisons of proliferative rate should consider effects of initial seeding density as well as culture medium.

The longer lag time at low initial densities suggests that these cells release a relatively stable autocrine factor into the medium, and that a minimum concentration of that factor is required to support proliferation. Another possibility is that cell-cell contacts are required for proliferation, and a few isolated areas containing a higher local density of cells are proliferating at early time points. The ability of FBS to support proliferation at lower densities than calf serum supports the former hypothesis. 
TCDD inhibited proliferation in the particular sub-clone of PLHC-1 used in the experiments shown in Figure 6, but not in any subsequent sub-clones tested. This is likely due to heterogeneity in the cells themselves and is similar to results obtained for the loss of CYP1A inducibility following serum starvation (Chapter 5). The instability of these phenotypes suggests that the PLHC-1 cell line may not be suitable for some studies involving proliferative effects. This is a common problem with transformed cell lines, which lack some of the controls on proliferation (e.g. tumor supressor activity) present in vivo. Furthermore, the lack of consistent results regarding the effect of TCDD on cell proliferation reflects the confounding state of the field as a whole, where variable and sometimes contradictory results have been reported (Gierthy et al. 1984; Busser et al. 1987; Wolfle et al. 1988; Gottlicher et al. 1990; Lucier et al. 1991; Schrenk et al. 1992; Fox et al. 1993; Gierthy et al. 1993; Hushka et al. 1995).

\section{Cell Cycle and Synchronization}

Lengths of the cell cycle stages were evaluated and used to determine the lengths of incubations necessary to achieve synchrony with the inhibitors used. The plant amino acid mimosine, the ribonucleotide reductase inhibitor hydroxyurea, and the nucleotide analogue thymidine were all unsuccessful in inhibiting cell cycle progression. It is possible that the structures of molecules affected by these inhibitors are sufficiently different in fish to negate their effect. Another possibility is that the inadequacy of these compounds is confined to PLHC-1 cells. Results of attempts to synchronize other fish cells are required to distinguish between these possibilities.

The DNA polymerase inhibitor aphidicolin produced a high degree of synchrony, especially when a double-block strategy was used. Nocodazole, an inhibitor of microtubule polymerization, combined with a physical shake-off did yield cells highly synchronized in mitosis, but yields were too low to allow exponential growth following reattachment. Nocodazole alone or after an aphidicolin block produced cell populations less synchronous than with an aphidicolin double block. Therefore, the aphidicolin 
double block is presently the method of choice for synchronizing PLHC-1 cells, although the potential utility of several other methods has yet to be assessed.

\section{Measurement of CYPIA by Flow Cytometry}

FACS techniques have been used to investigate variability in CYP1A inducibility within cell populations. Miller and Whitlock (1981) measured benzo[a]pyrene (BaP) metabolism with a flow cytometer by following disappearance of the fluorescent substrate. This technique was used to isolate sub-populations of cells that were deficient in CYP1A inducibility. BaP requires UV excitation, which is not always available on cell sorters. This led to the development of ethoxyfluorescein ethyl ester (EFEE) as a suitable diagnostic substrate (Miller 1983), and the technique has been applied to populations of primary hepatocytes (Black et al. 1993).

EFEE is no longer available from the supplier (Molecular Probes), but we were able to obtain a supply of the structurally related MFME. Structural similarity to methoxyresorufin suggests that this may be a better substrate for CYP1A2 than CYP1A1, but since fish CYP1A shares sequence and metabolic characteristics of both mammalian CYP1As (Morrison et al. 1995; Woodin et al 1999) we expected that MFME would be metabolized by CYP1A in PLHC-1 cells. Figure 5A demonstrates that MFME metabolism is inducible by AHR agonists, and the small degree of overlap between the induced and control populations suggests that this technique may prove useful for future characterization of fish cell populations.

CYP1A immunofluorescence was less suitable for separating induced and control populations (Figure 5B). Furthermore, analysis by immunofluorescence requires fixation of the cells, so its applications are more limited (Mudzinski 1993; Stauber et al. 1995). However, complications present in CYP1A activity assays (e.g. inhibition by inducing compounds, see Chapters 3 and 4) are avoided by this technique. It may also prove useful for analysis of samples collected under conditions where immediate analysis is impossible. 


\section{AHR Cloning and Expression}

AHR2 had previously been cloned from PLHC-1 (preliminary results and phylogenetic analysis in Hahn 1998a), but no AHR1 isoforms were found in that effort. Recent evidence that AHR1 forms may be inducible by treatment with AHR agonists led us to clone AHRs from TCDD-treated cells and examine a greater number of clones in an attempt to isolate a PLHC-1 AHR1. None were found in treated or control cells, and the low expression of AHR1 in Fundulus heteroclitus livers (Karchner et al. 1999) suggests that AHR1 either is not present or is expressed at extremely low levels in PLHC-1 cells. AHR cloned from teleost species other than $F$. heteroclitus are all AHR2 forms (Karchner et al. 1999). For these reasons, measurement of AHR expression focused on the cloned AHR2 form.

AHR2 mRNA expression did not vary among stages of the cell cycle (Figure 8C). Thus, any cross-talk between the cell cycle and AHR signaling in PLHC-1 cells is likely to occur at the functional level. This is consistent with previous findings in HEPA-1c1c7 and Swiss 3 T3 cells (Scholler et al. 1994; Vaziri et al. 1996). In the former study, nocodazole treatment inhibited CYP1A induction by interfering with binding of the AHR to XREs; AHR expression was unaffected (Scholler et al. 1994). Growth arrest by serum withdrawal led to a reduction in AHR expression, but reintroduction of serum in the presence of a cell cycle inhibitor led to normal levels of AHR without cycle progression (Vaziri et al. 1996), demonstrating that control of AHR expression was not coupled to the cell cycle. In this context, it should be noted that PLHC-1 AHR2, like other AHR2 forms, contains a MYCAD protein sequence at the location where AHR1 forms, including those sequenced in mammals, have an $\mathrm{LXCXE}$ sequence predicted to be involved in association with pRb (Karchner et al. 1999).

These studies have established a foundation for future work investigating possible links between AHR function and the cell cycle. Studies of controls on cell proliferation should be performed in another system, since sub-clone heterogeneity and the transformed phenotype of these cells reduces their utility. However, other interactions 
may be preserved, and the base of knowledge regarding AHR sequence, expression and function in this cell line makes it the a valuable system in piscine AHR research. Future studies should use the tools developed here to focus on possible functional interactions between the AHR and cell cycle. 
Chapter 3: Cell Culture Serum Alters the Uptake and Relative Potencies of Halogenated Aromatic Hydrocarbons in PLHC-1 Cells
Abstract
65
Introduction
66
Materials and Methods
68
Results
72
Discussion
86 


\begin{abstract}
The effects of many chemicals on cellular processes are governed by their ability to enter the cell, which is in turn a function of the composition of the cell's external environment. To examine this relationship, the effect of serum in cell culture medium on the bioavailability of cytochrome P450 1A (CYP1A)-inducing compounds was determined in PLHC-1 cells. The presence of $10 \%$ calf serum in the medium increased the EC50 for induction of ethoxyresorufin $O$-deethylase (EROD) activity by $2,3,7,8$ tetrachlorodibenzo- $p$-dioxin (TCDD) 20-fold as compared to treatment in serum-free medium. Measurement of $\left[{ }^{3} \mathrm{H}\right]$ TCDD uptake and Ah receptor binding indicated that the apparent difference in potencies was a result of decreased bioavailability in the presence of serum, effectively reducing the concentration of TCDD within the cells. Induction of EROD and CYP1A protein in response to treatment with each of three coplanar polychlorinated biphenyls (PCB congeners 77, 126, and 169) was similarly affected by serum, although the magnitude varied among inducers and assays. Relative potencies (calculated as $\mathrm{EC} 50_{\mathrm{TCDD}} / \mathrm{EC} 50_{\mathrm{PCB}}$ ) for EROD induction by the three PCBs were significantly higher in the absence of serum. However, serum showed no significant effect on the relative potencies for CYP1A protein induction. These results demonstrate that measured inducing potencies, and relative potencies for EROD induction, by halogenated aromatic hydrocarbons are strongly dependent on the composition of culture medium, which can lead to artificial differences in comparisons among cell types.
\end{abstract}




\section{INTRODUCTION}

Cells in culture, both primary cultures and established cell lines, have become important systems for investigating toxic mechanisms and evaluating the potential toxicity of previously unstudied compounds. Establishing accurate concentrationresponse relationships in such systems is critical. The impact of artifacts introduced by

cultured-cell assays on the ability to compare responses among organisms, cell types, and individual compounds is poorly understood. One potential source of error introduced in such assays is the presence of serum in the culture medium. Serum is poorly defined, comes from diverse donor animals, and has substantial lot-to-lot variability in composition. In addition, cell lines have differing serum requirements, which introduce further variability when comparing responses among cell lines. Serum factors affect the proliferation rates of cells as well as a host of other metabolic processes.

The induction of cytochrome P450 1A (CYP1A) protein and catalytic activity in cultured cells is being used with increasing frequency to compare the sensitivities of a variety of organisms to the effects of halogenated aromatic hydrocarbons (HAH). Cells from mammals (Sawyer and Safe 1982; Safe 1987; Tillitt et al. 1991), birds (Kennedy et al. 1996a; Kennedy et al. 1996b) and fish (Clemons et al. 1996; Hahn et al. 1996b) have been used to study the mechanisms of HAH toxicity and, in the absence of in vivo data, to establish taxon-specific toxic equivalency factors (TEFs) for these compounds (van den Berg et al. 1998). Comparisons of these results can reveal mechanistic differences in the induction pathway of CYP1A among taxa. However, differences in CYP1A induction among cell culture systems can also reflect the culture conditions of the cells.

Serum is known to impact the effects of CYP1A inducers and CYP levels in cultured cells. For example, the presence of $10 \%$ fetal calf serum reduces the potency of TCDD and PCB126 for inhibiting aromatase (CYP19) activity in JEG-3 human choriocarcinoma cells (Drenth et al. 1998). Serum and other medium components can also alter the detectable levels of cytochromes P450 in rat hepatocytes (Turner and Pitot 1989; Hammond and Fry 1992) and HepG2 cells (Doostdar et al. 1988; Doostdar et al. 
1991). Despite these provocative findings, there has been no quantitative study of the effect of serum on CYP1A induction by HAH. Because these compounds are very hydrophobic and have limited aqueous solubilities, it can be expected that serum components, such as proteins and lipids, would have a significant effect on the bioavailability of HAH for cell uptake. Since entry into the cell is the first step in the toxic mechanism of these compounds, effects at this stage will be propagated (and perhaps multiplied) through subsequent cell responses.

Following entry of an inducer into the cell, CYP1A induction is controlled by the ligand-activated transcription factor, aryl hydrocarbon receptor (AHR). Binding of $\mathrm{HAH}$ to the AHR activates transcription of CYP1A and mediates the toxicity of the inducer. A compound's potency for CYP1A induction in vivo or in cultured cells is a strong predictor of its toxicity (Safe 1984). Use of cell culture systems for rapid analysis of the potential toxicity of individual compounds and environmental samples has increased with refinements in CYP1A measurement techniques. Levels of both the CYP1A protein (Bruschweiler et al. 1996a; Hahn et al. 1996b) and its ethoxyresorufin $O$-deethylase (EROD) activity (Kennedy et al. 1993) can be measured directly in the same multi-well plates used for growth of the cells and exposure to HAH.

The toxic equivalency approach utilizes these induction data to assess the toxic potential of individual compounds or mixtures relative to that of $2,3,7,8-$ tetrachlorodibenzo-p-dioxin (TCDD). The potency of a compound for eliciting a response can be compared to the potency of TCDD for the same response by calculating the ratio of their respective EC50s (concentration eliciting a 50\% maximal effect). Such relative potencies from several systems, including cultured cells, are then used to determine TEFs for individual taxa (van den Berg et al. 1998).

In previous reports we have established the conditions and methods for measuring EROD activity and CYP1A induction in PLHC-1 cells (Hahn et al. 1993; Hahn et al. 1996a; Hahn et al. 1996b), which are derived from a hepatocellular carcinoma of the topminnow Poeciliopsis lucida (Hightower et al. 1988). Here we make use of those findings to examine the role of serum in uptake of $\mathrm{HAH}$ from the culture medium by 
cells. This represents a first step in examining the complex interaction between these cells and their chemical milieu. The results provide compelling evidence that serum affects the potency of AHR ligands, and likely other hydrophobic compounds, in cells in culture.

\section{MATERIALS AND METHODS}

\section{Chemicals and solutions}

The 2,3,7,8-tetrachloro[1,6- $\left.{ }^{3} \mathrm{H}\right]$ dibenzo- $p$-dioxin $\left(\left[{ }^{3} \mathrm{H}\right] \mathrm{TCDD}\right.$, stated purity $\geq$ $97 \%$, specific activity $27 \mathrm{Ci} / \mathrm{mmol}$ ) was obtained from Chemsyn Science Laboratories (Lenexa, KS). Its radiochemical purity was $>91 \%$ as determined by HPLC immediately prior to use for uptake experiments and $>96 \%$ for specific binding determination. Unlabeled TCDD, 2,3,7,8-tetrachlorodibenzofuran (TCDF), PCB 77 (3,3',4,4'tetrachlorobiphenyl), PCB 126 (3,3',4,4',5-pentachlorobiphenyl) and PCB 169 $\left(3,3^{\prime}, 4,4^{\prime}, 5,5^{\prime}\right.$ - hexachlorobiphenyl) were all obtained from Ultra Scientific (Kingstown, RI). Resorufin, ethoxyresorufin and Amplex Red were obtained from Molecular Probes (Eugene, OR). Peroxidase conjugated goat anti-mouse antibody was from Pierce (Rockford, IL). All other reagents were obtained from Sigma (St. Louis, MO).

Phosphate-buffered saline (PBS) is $0.8 \% \mathrm{NaCl}, 0.115 \% \mathrm{Na}_{2} \mathrm{HPO}_{4}, 0.02 \% \mathrm{KCl}$, $0.02 \% \mathrm{KH}_{2} \mathrm{PO}_{4}$, $\mathrm{pH}$ 7.4. Phosphate buffer is $50 \mathrm{mM} \mathrm{Na}_{2} \mathrm{HPO}_{4}$ with $\mathrm{pH}$ adjusted to 8.0 with $50 \mathrm{mM} \mathrm{NaH}_{2} \mathrm{PO}_{4}$. TCDD, TCDF, and $\mathrm{PCB}$ solutions were prepared in dimethyl sulfoxide (DMSO) as described previously (Hahn et al. 1996b). Concentrations of $\left[{ }^{3} \mathrm{H}\right] \mathrm{TCDD}$ solutions were verified by liquid scintillation counting (LSC) on a Beckman LS5000TD.

Growth and Treatment of Cells

PLHC-1 cells (Hightower et al. 1988) were grown at $30^{\circ} \mathrm{C}$ in minimum essential medium (MEM) containing Earle's salts, nonessential amino acids, L-glutamine and 10\% 
calf serum (Sigma C6278, lot 106H4628), as described previously (Hahn et al. 1993). One day prior to dosing, cells were suspended to 0.5 to $1 \times 10^{6}$ per $\mathrm{ml}$ and seeded into 48 or 96-well plates (Costar; Cambridge, MA) at 0.5 or $0.2 \mathrm{ml}$ per well, respectively. One day later the medium was removed and replaced with fresh medium. Media used in the experiments include MEM without serum, with $5 \%$ serum, with $10 \%$ serum, with $10 \%$ delipidated, charcoal stripped calf serum (Sigma C1696), and with $10 \%$ fetal bovine serum (FBS; Gibco; Grand Island, NY). Serum-free MEM supplemented with bovine serum albumin (BSA) was also used. The cells were then treated by addition of solutions dissolved in DMSO or DMSO alone (2.5 or $1.0 \mu 1 /$ well). DMSO concentrations were $\leq$ $0.5 \%(\mathrm{v} / \mathrm{v})$ in all treatments. Following treatment, plates were incubated at $30^{\circ} \mathrm{C}$ for 24 hours unless otherwise indicated. For TCDD specific binding experiments, cells were seeded into 24-well plates (Corning; Corning, NY) at $2 \times 10^{6}$ cells in $1 \mathrm{ml}$ culture medium per well. With the exception of the delipidated serum and FBS, all serum used was from a single lot. None of the media or HAH treatments reduced cell viability, as assessed by Trypan Blue exclusion.

\section{EROD and protein assays}

EROD activity was measured using a multiwell fluorescence plate reader by a modification of the method of Kennedy et al (1995). Cells were rinsed once with $0.5 \mathrm{ml}$ room temperature $\mathrm{PBS}$, and the EROD reaction was then initiated with the addition of $2 \mu \mathrm{M} 7$-ethoxyresorufin in phosphate buffer $(200 \mu \mathrm{l} /$ well). The reaction was stopped after

eight minutes (resorufin production is linear with respect to time over this period; Hahn et al. 1996b) with the addition of $150 \mu \mathrm{l}$ ice-cold fluorescamine solution $(0.15 \mathrm{mg} / \mathrm{ml}$ in acetonitrile). After a fifteen minute incubation, resorufin and fluorescamine fluorescence were measured. Resorufin and protein concentrations were determined from standard curves prepared in the same plate. BSA was used for the protein standard curve. In some experiments, the EROD reaction was followed kinetically over eight minutes, as described previously (Hahn et al. 1996b). Protein was measured using fluorescamine as described above. 


\section{TCDD Uptake}

PLHC-1 cells were seeded in 48-well plates, grown for one day, and then fed media as indicated in figure legends. They were treated with $\left[{ }^{3} \mathrm{H}\right] \mathrm{TCDD}$ in DMSO as above and incubated at $30^{\circ} \mathrm{C}$. At $0.5,1,2,7$ and 24 hours post-treatment, the culture medium was transferred from each well to a separate vial. Cells were removed by sequential incubation with two, $0.2 \mathrm{ml}$ aliquots of $0.05 \%$ (w/v) trypsin, which were then combined in a single vial. Cell removal was verified by microscopy. TCDD retained on well surfaces was extracted with a single $1 \mathrm{ml}$ aliquot of hexane. TCDD associated with each fraction (medium, cells and well) was determined by LSC. Protein concentrations were determined using fluorescamine in duplicate wells fed each medium and treated with DMSO alone.

\section{TCDD Binding}

Specific binding of [ ${ }^{3}$ H]TCDD in PLHC-1 cells was measured by a whole-cell filtration assay (Dold et al. 1990). One day after seeding in 24-well plates, the cells were fed $0.5 \mathrm{ml}$ of the indicated media. Cells were treated with $0.18 \mathrm{nM}\left[{ }^{3} \mathrm{H}\right] \mathrm{TCDD}$ in the presence or absence of $40 \mathrm{nM}$ TCDF and incubated 2 hours at $30^{\circ} \mathrm{C}$. This time was determined to be sufficient to achieve a steady state of bound radioligand (not shown). Following the incubation, medium was removed, cells were rinsed with $0.5 \mathrm{ml}$ ice-cold PBS, and then detached with $0.5 \mathrm{ml}$ trypsin. The trypsin was inactivated by the addition of $0.5 \mathrm{ml}$ ice-cold culture medium (with 10\% serum), and cells from each well were collected under vacuum on a $25 \mathrm{~mm}$ Whatman GF/F filter that had been prewetted with PBS. Filters were then washed four times with $2.5 \mathrm{ml}$ acetone that had been precooled to $-80^{\circ} \mathrm{C}$. Replicates were processed in batches of twelve on a Millipore 1225 filter manifold. Radioactivity remaining on the filter was quantified by LSC. Specific binding was measured in triplicate as the difference of each of three total binding (without TCDF) replicates and the average of three nonspecific binding (with TCDF) replicates in each 
medium. Protein concentrations were determined in duplicate wells fed each medium and treated with DMSO alone.

\section{ELISA Assay}

Enzyme-linked immunosorbence assays to detect CYP1A were performed essentially as described (Bruschweiler et al. 1996a). One day after treatment in 96-well plates, cells were fixed in 50\% ethanol 15 minutes, in $75 \%$ ethanol 15 minutes, and in 95\% ethanol 30 minutes. After washing three times with PBS, non-specific antibody binding was blocked with $10 \%$ fetal bovine serum and $2 \%$ BSA in PBS for 1 hour. The primary antibody, mouse anti-scup CYP1A monoclonal antibody 1-12-3 $(10 \mu \mathrm{g} / \mathrm{ml}$; Park et al. 1986), was then added in $100 \mu \mathrm{l}$ blocking solution for 1 hour. After three washing steps with PBS, $100 \mu \mathrm{l}$ secondary antibody, peroxidase conjugated goat anti-mouse (1:1000 in blocking solution), was added for 1 hour. After another three washing steps with PBS, $100 \mu \mathrm{l}$ substrate solution (100 $\mu \mathrm{M}$ Amplex Red, $100 \mu \mathrm{M} \mathrm{H}_{2} \mathrm{O}_{2}$ in phosphate buffer, $\mathrm{pH}=7.0$ ) was added for 30 minutes. All incubations were performed at room temperature. Resorufin formation was measured in the fluorescence plate reader. For each treatment the background fluorescence, defined as the fluorescence detected in untreated cells, was subtracted, and all values were normalized to the maximum response measured. The assay was also performed on wells without cells or without the addition of primary antibody, and these controls yielded fluorescence values nearly identical to those in untreated cells, consistent with our earlier results detecting no CYP1A protein or EROD activity in untreated cells (Hahn et al. 1996b).

\section{Curve Fitting and Statistical Analysis}

For determination of dose-response relationships, EROD data were fit to a modified Gaussian function, and CYP1A induction data were fit to a logistic function. The rationale for use of these functions has been described previously (Kennedy et al. 1993; Hahn et al. 1996b). The Gaussian function properly reflects the biphasic nature of EROD induction, while a logistic function forms a plateau at higher inducer 
concentrations, consistent with CYP1A protein induction in these cells. Statistical analyses were performed with the aid of Excel (Microsoft; Redmond, WA) and JMP IN (SAS Institute, Inc.; Cary, NC) software.

\section{RESULTS}

\section{Culture Medium Composition Affects TCDD Uptake}

While investigating the effects of culture media composition on responses to TCDD in PLHC-1 cells, we found that TCDD was more potent in eliciting an EROD response when added to cells in serum-free medium $\left(\mathrm{S}_{0}\right)$ than in medium with $10 \%$ calf serum $\left(\mathrm{S}_{10} ;\right.$ Figure 1$)$. In this experiment, cells were grown in $\mathrm{S}_{10}$ that was replaced by either $\mathrm{S}_{0}$ or $\mathrm{S}_{10}$ immediately prior to treatment with TCDD. CYP1A-catalyzed EROD activity was measured 24 hours later. The dose of TCDD required to elicit a $50 \%$ maximal induction of EROD was about 20-fold less in cells treated in $\mathrm{S}_{0}$ than in cells treated in $\mathrm{S}_{10}$ (Table 1). A separate comparison of EROD induction in medium supplemented with $10 \%$ FBS showed that the EC50 was about 4-fold lower than in $\mathrm{S}_{10}$ and 5-fold higher than in $\mathrm{S}_{0}$ (not shown). Consistent with earlier results (Hahn et al. 1996b), there was no basal EROD activity in any of the media.

Table 1. Effect of medium on dose-response relationship parameters for EROD rates in PLHC-1 cells treated with TCDD.

\begin{tabular}{ccc}
\hline Medium & EC50 $(\mathrm{nM})^{a}$ & $\mathrm{EC100}^{a}(\mathrm{nM})^{a}$ \\
\hline $\mathrm{S}_{0}$ & 0.022 & 0.138 \\
$\mathrm{~S}_{10}$ & 0.474 & 2.590
\end{tabular}

Modified Gaussian functions were fit to data from Figure $1\left(\mathrm{~S}_{0}\right.$ and $\left.\mathrm{S}_{10}\right)$ to obtain these values.

a: EC50 and EC100 are nominal TCDD concentrations producing $50 \%$ and $100 \%$ of maximal EROD induction, respectively. 


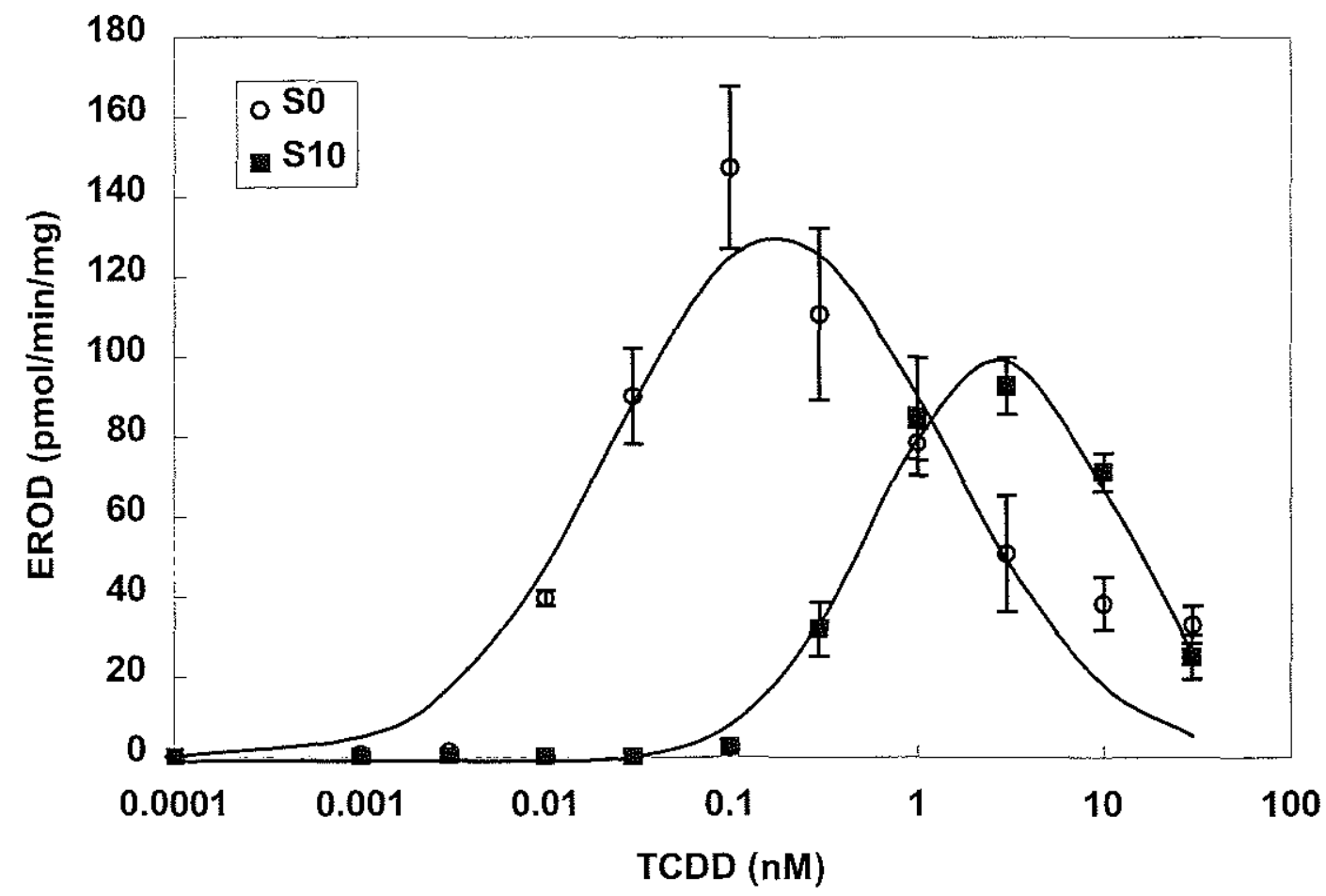

Figure 1. Effect of serum on potency of EROD induction by TCDD. Cells were fed culture medium with $\left(\mathrm{S}_{10}\right)$ or without $\left(\mathrm{S}_{0}\right) 10 \%$ calf serum immediately prior to treatment with TCDD. EROD activity (pmol of resorufin formed per minute per mg of cellular protein) was measured 24 hours later. The $0.0001 \mathrm{nM}$ TCDD concentration represents treatment with DMSO alone. Points are means $\pm \mathrm{SE}$ of four wells. The modified Gaussian fits to these data are plotted. 
In order to determine whether the culture medium affected partitioning of TCDD within the environment of a well, we measured the uptake of $\left[{ }^{3} \mathrm{H}\right] \mathrm{TCDD}$. Four different serum treatments were compared: $\mathrm{S}_{0}, \mathrm{~S}_{10}, 10 \%$ delipidated serum $\left(\mathrm{S}_{\mathrm{DL}}\right)$, and $5 \%$ calf serum $\left(\mathrm{S}_{5}\right)$. After growth in $\mathrm{S}_{10}, \mathrm{PLHC}-1$ cells were treated with $\left.1 \mathrm{nM} \mathrm{[}{ }^{3} \mathrm{H}\right] \mathrm{TCDD}$ in each of these media and sampled at subsequent times to determine the timing of TCDD uptake by the cells (Figure 2A). The TCDD associated with cells declined steadily from an early maximum and reached steady state between 2 and 7 hours post-treatment. TCDD was added directly to the medium overlying the cells in a DMSO solution, and the higher density of that solution accounts for the large early values of cell-associated TCDD in the adherent PLHC-1 cells. Once a steady state had been achieved, cellassociated TCDD was 2-3 fold greater in cells treated in $\mathrm{S}_{0}$ or $\mathrm{S}_{\mathrm{DL}}$ than in $\mathrm{S}_{5}$ or $\mathrm{S}_{10}$.

Having established the timing of TCDD uptake, it was possible to determine its partitioning in wells at different concentrations. Using the same four media, the fraction of total TCDD added that was associated with the cells was determined 24 hours posttreatment for four different concentrations of TCDD (Table 2 and Figure 2B). Again, the fraction of TCDD associated with the cells was highest in the cells treated in $\mathrm{S}_{0}$ and lowest in those treated in $\mathrm{S}_{10}$. The fraction of TCDD associated with cells was nearly constant between $0.01 \mathrm{nM}$ and $1 \mathrm{nM}$ within each medium treatment but declined at 10 $\mathrm{nM}$ (Figure 2B). The fraction of TCDD in the overlying medium was similar within each medium treatment at all concentrations of TCDD; at $10 \mathrm{nM}$ a greater fraction of TCDD was found associated with the polystyrene walls of the wells (Table 2).

Since the delipidation process may remove several serum constituents, it was necessary to determine which component(s) of serum was responsible for retaining TCDD in the medium. The effect of protein concentration on TCDD uptake was investigated. Cells were treated with $1 \mathrm{nM}$ TCDD as above, except that additional treatments consisting of $\mathrm{S}_{0}$ supplemented with increasing concentrations of BSA were added (Figure 2C). Protein at concentrations near those in $\mathrm{S}_{10}$ or $\mathrm{S}_{\mathrm{DL}}(5$ to $8 \mathrm{mg} / \mathrm{ml}$ according to the supplier) produced uptake identical to that in $\mathrm{S}_{\mathrm{DL}}$, indicating that protein and lipid both contribute to reduced uptake in the presence of serum. 
Table 2. Fractions of TCDD associated with culture medium, PLHC-1 cells, and well surfaces.

\begin{tabular}{ccccc}
\hline $\begin{array}{c}\text { Medium } \\
\text { treatment }\end{array}$ & $\begin{array}{c}\text { Nominal TCDD } \\
\text { concentration (nM) }\end{array}$ & Fraction of total TCDD associated with \\
\hline $\mathrm{S}_{0}$ & 0.01 & $37 \%$ & $36 \%(1.4)$ & Wells \\
& 0.1 & $33 \%$ & $47 \%(15)$ & $21 \%$ \\
& 1 & $33 \%$ & $44 \%(160)$ & $23 \%$ \\
& 10 & $28 \%$ & $16 \%(460)$ & $56 \%$ \\
\hline $\mathrm{S}_{\mathrm{DL}}$ & 0.01 & $72 \%$ & $14 \%(0.75)$ & $14 \%$ \\
& 0.1 & $71 \%$ & $18 \%(5.7)$ & $10 \%$ \\
& 1 & $71 \%$ & $19 \%(78)$ & $9 \%$ \\
& 10 & $59 \%$ & $9 \%(261)$ & $33 \%$ \\
\hline $\mathrm{S}_{5}$ & 0.01 & $74 \%$ & $15 \%(0.67)$ & $11 \%$ \\
& 0.1 & $83 \%$ & $12 \%(3.6)$ & $5 \%$ \\
& 1 & $78 \%$ & $17 \%(61)$ & $5 \%$ \\
& 10 & $74 \%$ & $6 \%(180)$ & $20 \%$ \\
\hline $\mathrm{S}_{10}$ & 0.01 & $79 \%$ & $11 \%(0.56)$ & $10 \%$ \\
& 0.1 & $90 \%$ & $7 \%(2.4)$ & $3 \%$ \\
& 1 & $86 \%$ & $12 \%(45)$ & $2 \%$ \\
& 10 & $79 \%$ & $5 \%(170)$ & $16 \%$ \\
\hline
\end{tabular}

PLHC-1 cells were grown in $S_{10}$ for 24 hours after subculture, fed the indicated medium, and treated with the indicated nominal concentration of $\left[{ }^{3} \mathrm{H}\right] \mathrm{TCDD}$. Partitioning of the $\left[{ }^{3} \mathrm{H}\right] \mathrm{TCDD}$ was determined after 24 hours as described in Materials and Methods. $a$ : average pmol of $\left[{ }^{3} \mathrm{H}\right] \mathrm{TCDD}$ associated with the cells in a well for each medium treatment and $\left[{ }^{3} \mathrm{H}\right] \mathrm{TCDD}$ concentration are indicated in parenthesis. 


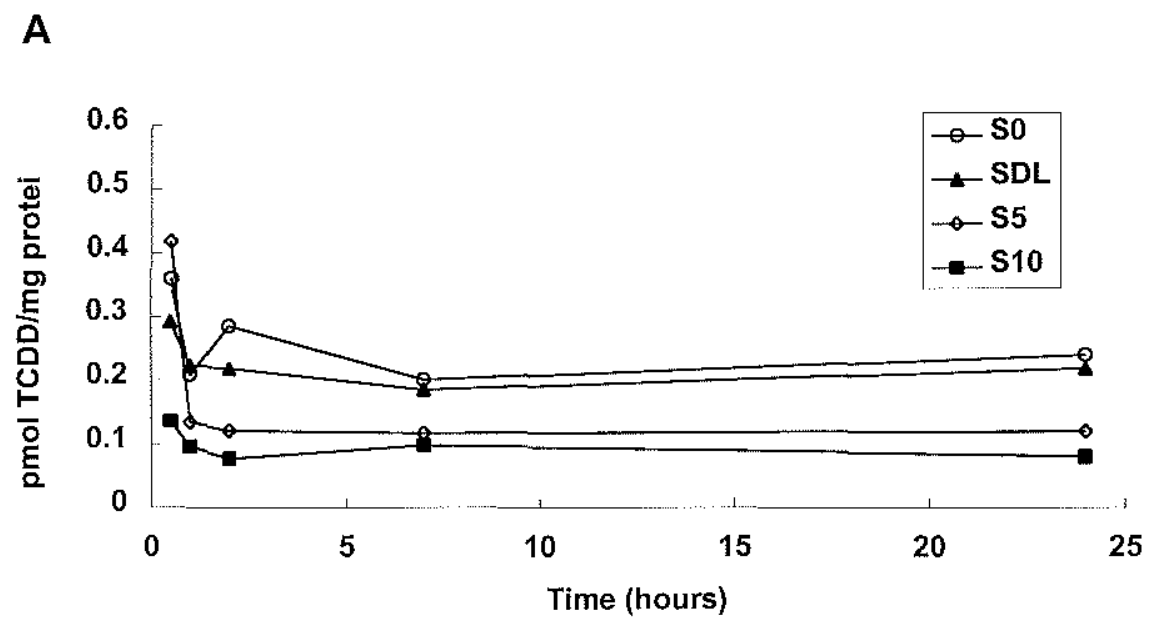

B

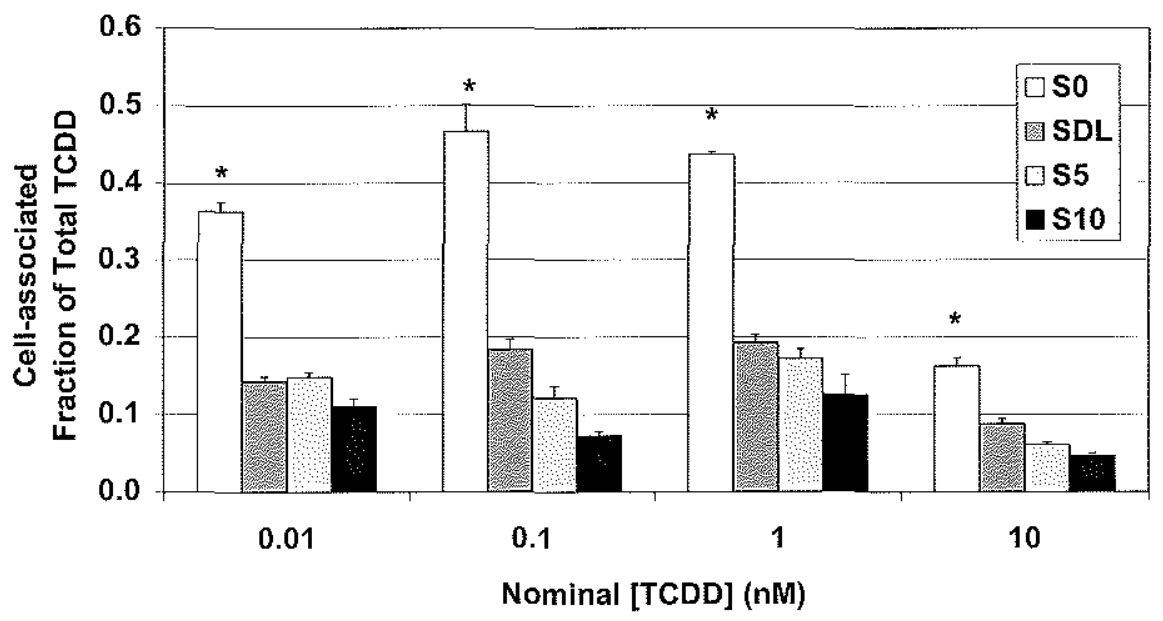




\section{C}

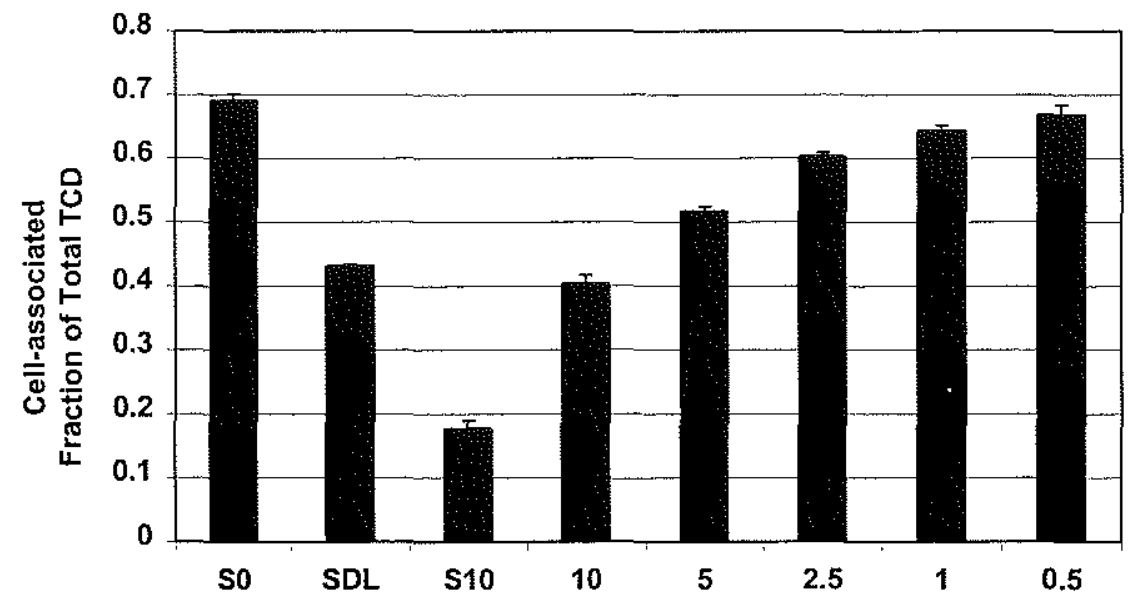

Figure 2. Effect of serum on TCDD uptake in PLHC-1 cells. Cells were fed culture medium with no serum, $10 \%$ delipidated calf serum $\left(\mathrm{S}_{\mathrm{DL}}\right), 5 \%$ calf serum $\left(\mathrm{S}_{5}\right), 10 \%$ calf serum, or increasing concentrations of BSA (numbers in $\mathrm{mg} / \mathrm{ml}$ ). (A) Cells were treated with $1 \mathrm{nM}\left[{ }^{3} \mathrm{H}\right] \mathrm{TCDD}$ and sampled at the indicated times to determine the amount of TCDD associated with the cells. Cell-associated TCDD was normalized to protein content to account for differences in cell number among the treatments. Points are means of duplicate wells. (B) Cells were treated with the indicated concentrations of $\left[{ }^{3} \mathrm{H}\right] \mathrm{TCDD}$ and collected after 24 hours. The ordinate represents the fraction of the total amount of TCDD recovered that was associated with the cells. * indicates significantly different from all other medium treatments ( $\mathrm{P}<0.05$, ANOVA). (C) As $\mathrm{B}$, except that $\mathrm{S}_{0}$ supplemented with $10,5,2.5,1$, and $0.5 \mathrm{mg} / \mathrm{ml} \mathrm{BSA}$ were also compared, and treatment was with $1 \mathrm{nM}$ TCDD. Points are means $\pm \mathrm{SE}$ of three wells. 
Differences in Uptake Affect TCDD Binding by the AH Receptor

The effect of medium composition on specific binding of TCDD by AHR in PLHC-1 cells was measured. Cells were grown in $\mathrm{S}_{10}$, fed one of the four media, treated with $0.18 \mathrm{nM}\left[{ }^{3} \mathrm{H}\right] \mathrm{TCDD}$ in the presence or absence of $40 \mathrm{nM}$ TCDF, and incubated for two hours. This concentration of TCDD was selected because it is near the value at which cells treated in $S_{0}$ or $S_{10}$ showed the greatest difference in EROD response (Figure 1). Binding of TCDD to the AHR was measured by a whole-cell filtration assay (Dold et al. 1990). The amount of TCDD bound was 3-4 fold higher in cells treated in $\mathrm{S}_{0}$, and showed the same relationship among medium treatments as the fraction of TCDD associated with the cells, i.e. $S_{0}>>S_{D L}>S_{5}>S_{10}$ (Figure 3). Thus, the differences in specific binding reflect the differing concentrations of TCDD within the cells among the treatments, as shown in Figure 2.

\section{Differences in EROD Response are Due to Differences in TCDD Uptake}

PLHC- 1 cells were fed the four media and treated with $0.01,0.1,1$ or $10 \mathrm{nM}$ $\left[{ }^{3} \mathrm{H}\right] \mathrm{TCDD}$ exactly as for the uptake experiment, except that after 24 hours the levels of CYP1A-catalyzed EROD activity were measured (Figure 4A). As expected from the results shown in Figures 1 and 3, a greater amount of TCDD bound by the AHR in $S_{0}$ led to a greater induction of EROD even though nominal TCDD concentrations were the same. For example, at $0.1 \mathrm{nM}$ TCDD, the magnitude of the EROD response among the medium treatments showed the same rank order as the magnitude of TCDD specific binding. Though the use of fewer concentrations of TCDD makes determination of a dose-response relationship less precise, the induction potencies in this assay were similar to those seen in the initial experiment (Figure 1).

When the dose-response curves are expressed in terms of cell-associated TCDD rather than nominal concentration in the medium, the points from the individual treatments align into a single biphasic induction curve typical of EROD induction by TCDD in PLHC-1 cells (Figure 4B). This relationship suggests that the difference in induction potency among media used for treatment of PLHC-1 cells is due solely to 


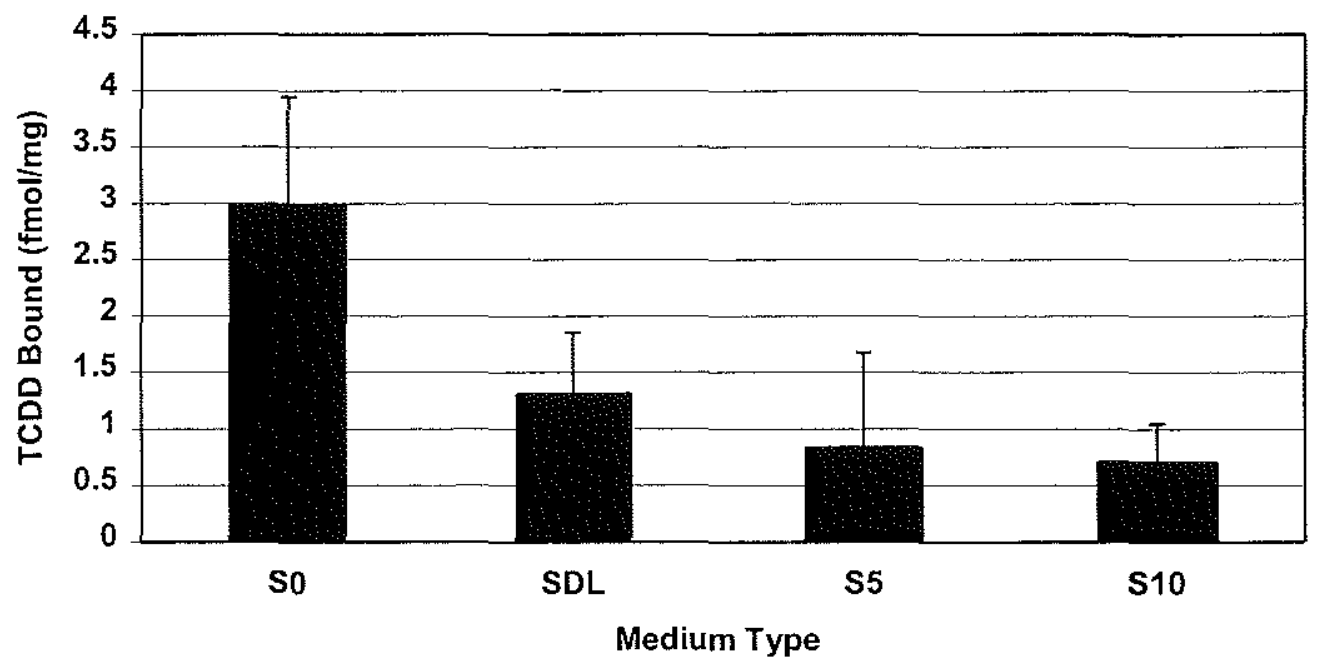

Figure 3. Effect of serum on specific binding of TCDD in PLHC-1 cells. Cells were fed the indicated medium immediately prior to treatment with $0.18 \mathrm{nM}\left[{ }^{3} \mathrm{H}\right] \mathrm{TCDD}$ in the presence or absence of 200-fold molar excess TCDF. Specific binding was determined by the whole-cell filtration assay of Dold and Greenlee (1990). Specific binding of TCDD is reported as fmol of TCDD per mg of total cellular protein. Points are means \pm SE of three specific binding determinations. 


\section{A}

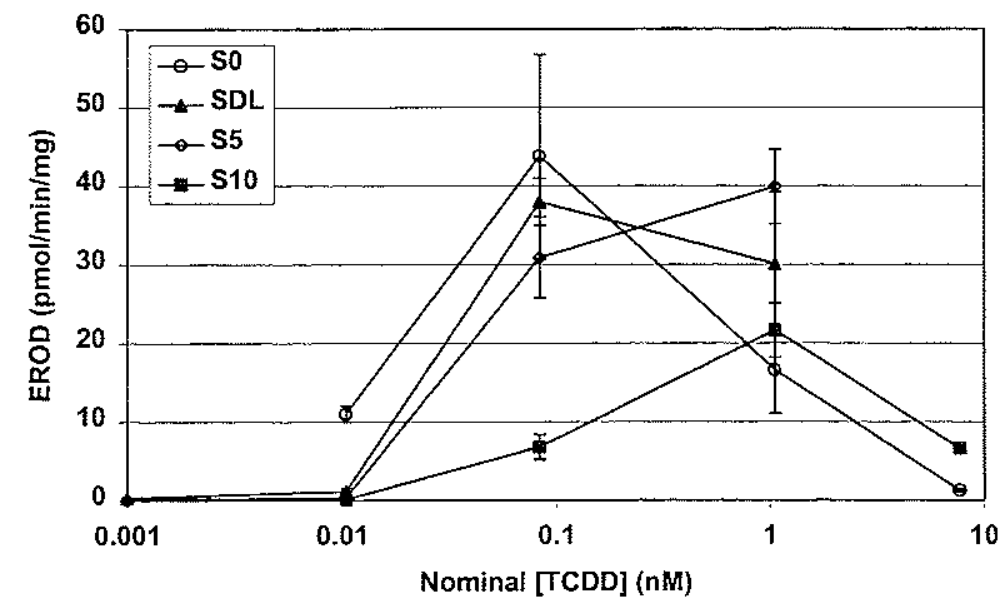

B

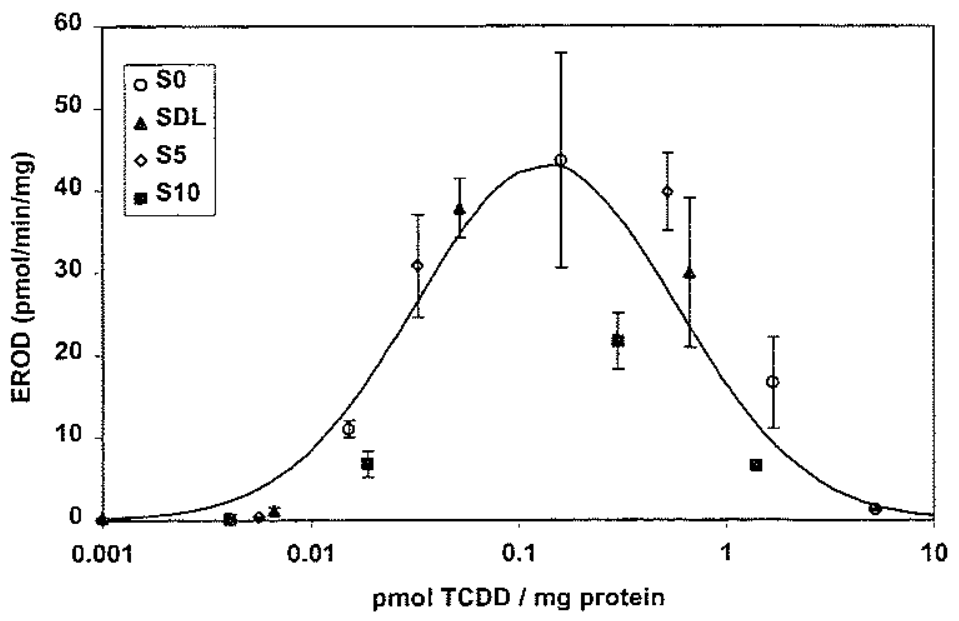

Figure 4. TCDD uptake and EROD induction. (A) EROD rates versus nominal TCDD concentration in medium. Cells were fed and treated as in Figure 2B. EROD activity was measured 24 hours later. The $0.001 \mathrm{nM}$ nominal TCDD concentration represents treatment with DMSO alone. Points are means $\pm \mathrm{SE}$ of four wells. (B) The EROD rates in (A) plotted against cell-associated TCDD determined as in Figure 2B. TCDD concentrations are expressed as pmol of cell-associated TCDD per average mg cellular protein for each treatment. Average cellular protein contents for the medium treatments were $92,116,116$ and $134 \mu \mathrm{g}$ per well for $\mathrm{S}_{0}, \mathrm{~S}_{\mathrm{DL}}, \mathrm{S}_{5}$, and $\mathrm{S}_{10}$, respectively. The Gaussian fit to the data is plotted (EC50 $=0.025 \mathrm{pmol} / \mathrm{mg}, \mathrm{EC} 100=0.135 \mathrm{pmol} / \mathrm{mg}$ ). 
differential partitioning of TCDD between the media and the cells. The concentrations of TCDD necessary to induce given EROD responses can be expressed in terms of pmol of TCDD per mg of cellular protein for comparison across all treatments (EC50 $=0.025$ $\mathrm{pmol} / \mathrm{mg}, \mathrm{EC} 100=0.135 \mathrm{pmol} / \mathrm{mg}$ ). Since protein content of the wells is linear with respect to cell number (Hahn et al. 1996b), TCDD doses shown are proportional to the dose per individual cell.

\section{Culture Medium Composition Alters the Relative Potency of HAH}

We wished to determine if serum reduces the uptake of other $\mathrm{HAH}$ to the same degree that it does TCDD. PLHC-1 cells were exposed to each of three coplanar PCBs in medium with or without serum, and EROD activity was assayed 24 hours later (Figure 5). The EC50 values for the responses are shown in Table 3. For each compound, the EC50 in $\mathrm{S}_{0}$ was lower than that in $\mathrm{S}_{10}$. The differences ranged from about 20 -fold for TCDD to about 2000-fold for PCB 77, although there is substantial uncertainty in the latter value, because a precise EC50 is difficult to obtain for this compound in $\mathrm{S}_{10}$ (e.g. Hahn et al. 1996b).

Since the potency of EROD induction by PCB 77 in PLHC-1 cells is quite variable and the efficacy of EROD induction was much lower for both PCBs 77 and 169, levels of CYP1A protein were analyzed more directly using an ELISA. Cells were treated as for the EROD assay, but were fixed and analyzed for CYP1A content using the monoclonal antibody 1-12-3, as described in Materials and Methods (Figure 6).

As with EROD induction, EC50 values for ELISA-measured CYP1A induction (Table 3) were consistently higher in $\mathrm{S}_{10}$. However, the magnitudes of the increases (the ratio in the final column of Table 3) were five- to ten-fold smaller with PCBs 77 and 169 for CYP1A protein as compared to EROD. The EC50 for induction of CYP1A protein was greater than the EC50 for EROD induction in all treatments, in agreement with our previous results (Hahn et al. 1996b).

The ELISA as performed provides only a relative measure of CYP1A protein content, but the range of values produced and the pattern of induction by TCDD in S $_{10}$ closely parallel those previously obtained by Western blot (Hahn et al. 1996b). This indicates that the 
A

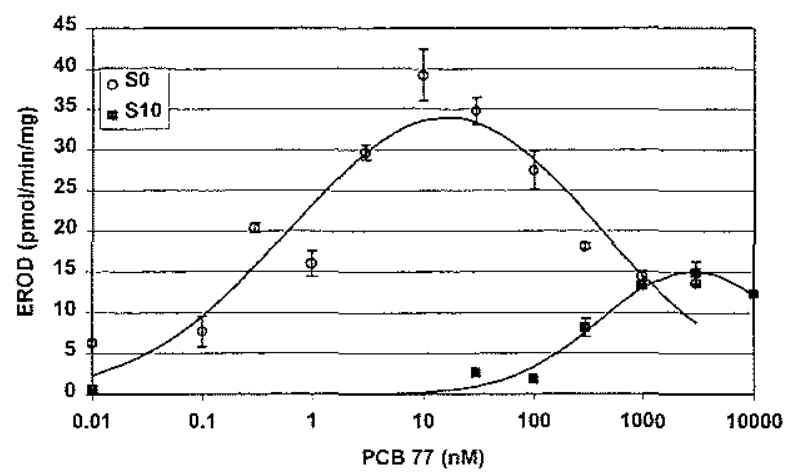

B

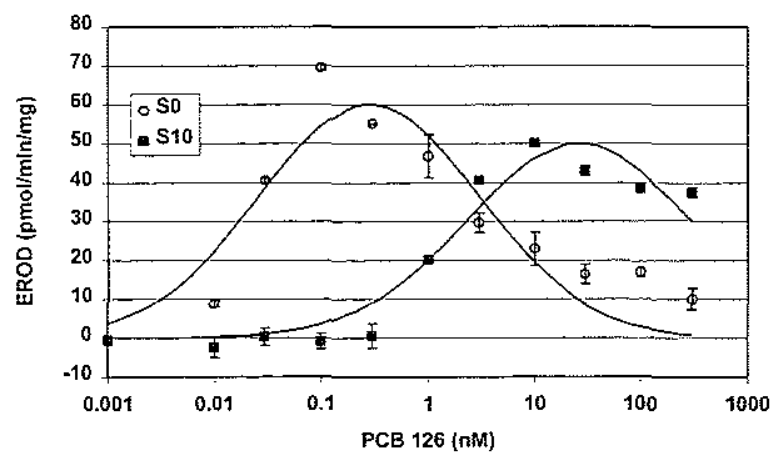

C

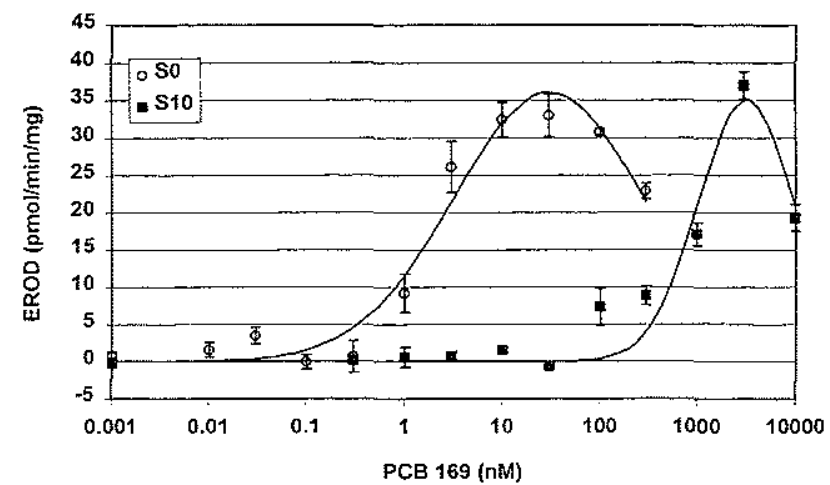

Figure 5. Effect of serum on potency for EROD induction by coplanar PCBs. Cells were treated and assayed as in Figure 1, except that treatment was with (A) PCB 77, (B) PCB 126, or (C) PCB 169. The lowest concentration in each panel represents treatment with DMSO alone. Points are means \pm SE of four wells. The modified Gaussian fits to these data are plotted. 
response as measured in this assay can be correlated with the values from a more quantitative approach. Furthermore, maximal levels of detected fluorescence from the ELISA assay were similar among all the treatments, indicating that the maximally induced level of CYP1A is similar among the four compounds, regardless of medium used.

The EC50s for the EROD and ELISA assays were used to calculate relative potencies for the four compounds within each medium treatment (Table 4). Relative potencies as determined by EROD assay for the three PCBs were significantly lower in $\mathrm{S}_{10}$ than in $\mathrm{S}_{0}$. In contrast, when CYP1A induction was measured by ELISA, there were neither consistent nor significant differences in relative potencies determined with cells in the two media.

Table 3. Effect of serum on CYP1A induction EC50s measured by EROD and ELISA for TCDD and three coplanar PCBs.

\begin{tabular}{|c|c|c|c|c|c|c|}
\hline & \multicolumn{2}{|c|}{ EROD EC50 (nM) $)^{a}$} & \multirow{2}{*}{$\begin{array}{l}\text { Ratio of } \\
\text { EC } 50 s^{b}\end{array}$} & \multicolumn{2}{|c|}{ ELISA EC50 (nM) } & \multirow{2}{*}{$\begin{array}{l}\text { Ratio of } \\
\text { EC } 50 \mathrm{~s}^{b}\end{array}$} \\
\hline & $\mathrm{S}_{0}$ & $\mathrm{~S}_{10}$ & & $\mathrm{~S}_{0}$ & $\mathrm{~S}_{10}$ & \\
\hline TCDD & $0.016 \pm 0.004$ & $0.33 \pm 0.10$ & 21 & $0.021 \pm 0.003$ & $1.2 \pm 0.3$ & 57 \\
\hline PCB 169 & $1.58 \pm 0.43$ & $246 \pm 102$ & 160 & $38 \pm 5$ & $1400 \pm 148$ & 37 \\
\hline PCB 126 & $0.029 \pm 0.004$ & $0.99 \pm 0.18$ & 35 & $0.24 \pm 12$ & $4.4 \pm 2.7$ & 19 \\
\hline PCB 77 & $0.73 \pm 0.30$ & $1500 \pm 550$ & 2000 & $13 \pm 5$ & $2200 \pm 82$ & 170 \\
\hline
\end{tabular}

a: EC50s were determined from modified Gaussian functions for EROD dose-responses and from logistic functions for ELISAs. Values are means \pm SE of 3 or 4 replicate determinations. Figures 1,5 and 6 are examples of one such replicate. $b:$ ratio $=\mathrm{EC} 50\left(\mathrm{~S}_{10}\right) / \mathrm{EC} 50\left(\mathrm{~S}_{0}\right)$ for each compound and assay 

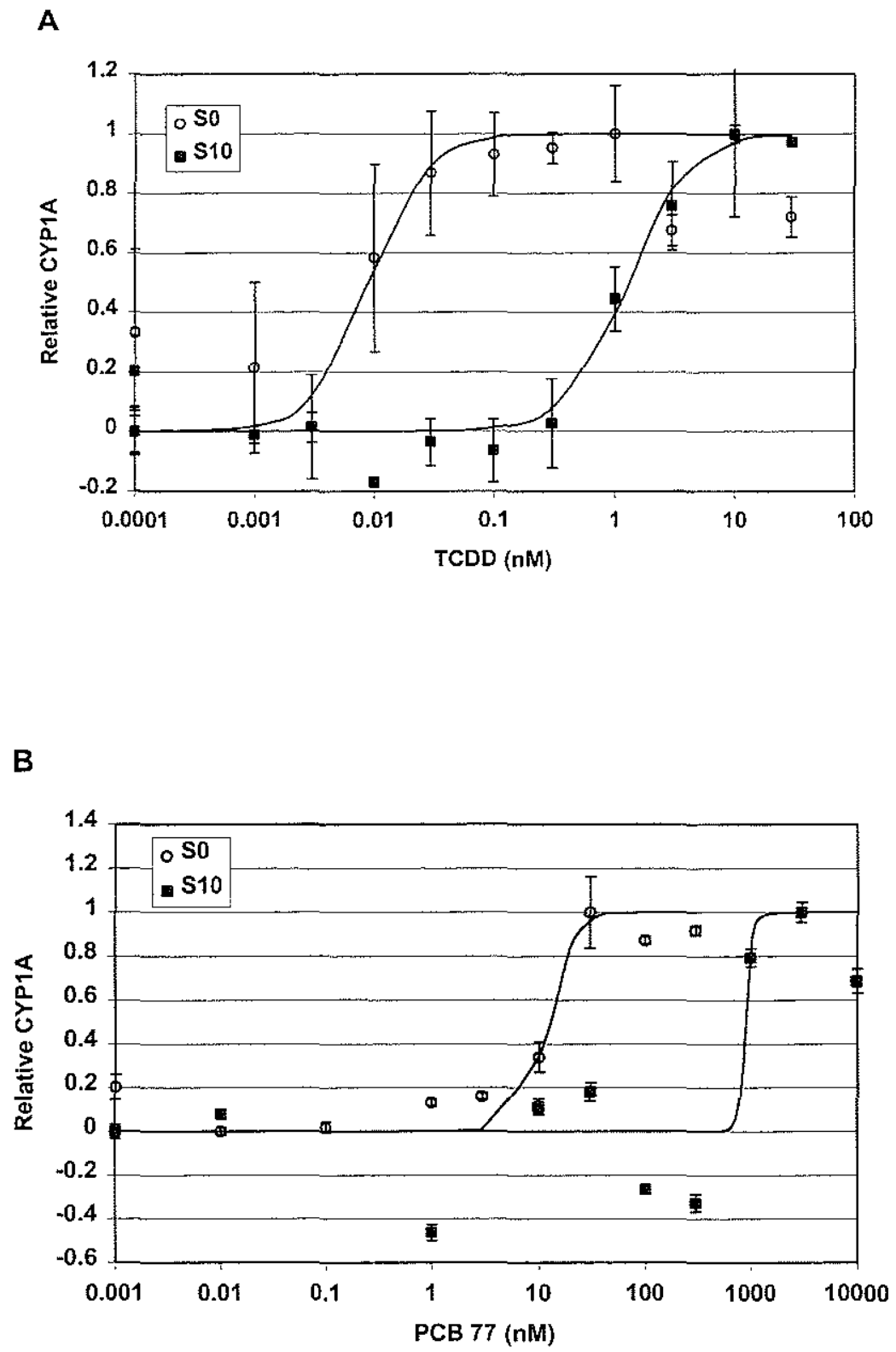

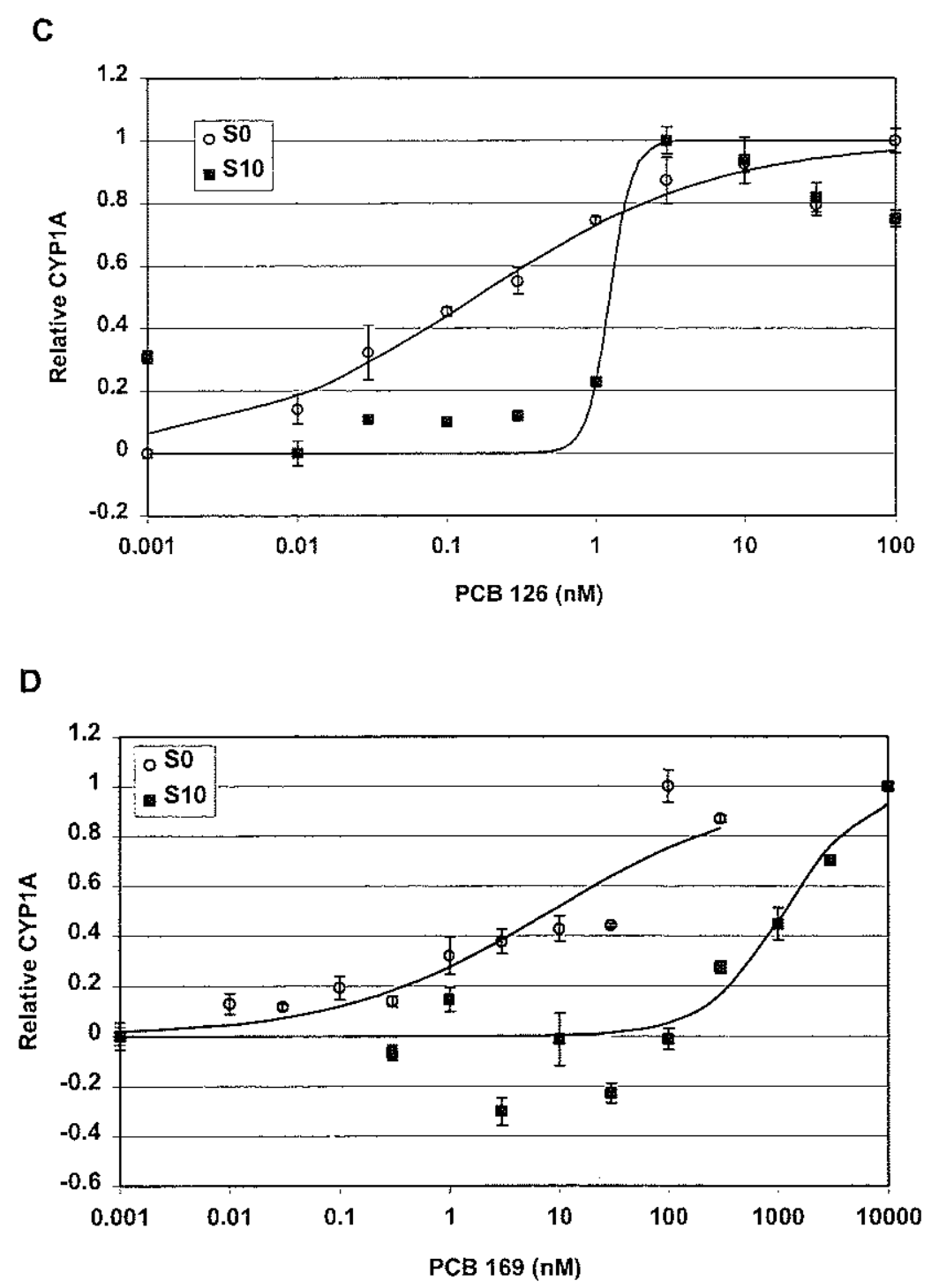

Figure 6. Effect of serum on potency of CYP1A induction by HAH. Cells were treated as in Figures 1 and 5. CYP1A content was measured 24 hours later by ELISA. The compounds used were (A) TCDD, (B) PCB 77, (C) PCB 126, or (D) PCB 169. The lowest concentration in each panel represents treatment with DMSO alone. Points are means \pm SE of four wells. The logistic fits to these data are plotted. 
Table 4. Effect of serum on determination of induction relative potencies.

\begin{tabular}{|c|c|c|c|c|c|c|}
\hline & \multicolumn{2}{|c|}{ EROD Relative Potency ${ }^{a}$} & \multirow[t]{2}{*}{ Ratio $^{b}$} & \multicolumn{2}{|c|}{ ELISA Relative Potency $^{a}$} & \multirow[t]{2}{*}{ Ratio $^{b}$} \\
\hline & $\mathrm{S}_{0}$ & $\overline{\mathrm{S}_{10}}$ & & $\mathrm{~S}_{0}$ & $\overline{\mathrm{S}_{10}}$ & \\
\hline TCDD & 1 & 1 & 1 & 1 & 1 & 1 \\
\hline \multirow[t]{2}{*}{ PCB 169} & 0.0075 & 0.0016 & $0.21^{c}$ & 0.0016 & 0.00049 & 0.31 \\
\hline & \pm 0.0018 & \pm 0.0010 & & \pm 0.0008 & \pm 0.00009 & \\
\hline \multirow[t]{2}{*}{ PCB 126} & 0.67 & 0.12 & $0.18^{c}$ & 0.031 & 0.075 & 2.4 \\
\hline & \pm 0.18 & \pm 0.02 & & \pm 0.004 & \pm 0.041 & \\
\hline \multirow[t]{2}{*}{ PCB 77} & 0.017 & 0.00040 & $0.02^{c}$ & 0.0016 & 0.00054 & 0.34 \\
\hline & \pm 0.005 & \pm 0.00013 & & \pm 0.0008 & \pm 0.00012 & \\
\hline
\end{tabular}

$a$ : Relative potencies were determined for each medium treatment and assay by dividing the EC50 for TCDD by the EC50 for each PCB. Values are means \pm SE of 3 or 4 replicate determinations.

$b:$ ratio $=$ relative potency $\left(S_{10}\right) /$ relative potency $\left(S_{0}\right)$ for each compound and assay

$c$ : Indicates relative potency in $10 \%$ serum is significantly lower than relative potency in $0 \%$ serum $(\mathrm{p}<0.05)$ by one-tailed paired t-test. Relative potencies from each experiment were paired for the analysis.

\section{DISCUSSION}

This series of experiments demonstrates a reduction in HAH uptake by PLHC-1 cells when bovine serum is included in the culture medium. This in turn leads to decreased occupancy of the AHR and an apparent decrease in the CYP1A induction potency of the compounds. Furthermore, the magnitude of this decrease is not the same among the HAH studied; this may lead to changes in relative potencies for EROD and 
CYP1A induction among the compounds. Serum will likely have a similar effect on the uptake of other hydrophobic chemicals.

\section{HAH Partitioning in a Multi-well Plate}

Our measurements of TCDD partitioning demonstrate that the majority of the compound remains in the medium when serum is present. Thus, small changes in medium composition could have significant effects on the amount of compound that enters the cells. The fraction of the total TCDD associated with the polystyrene wells was approximately equal to that found in the cells, suggesting that the composition of the chamber used for treatment also could affect the amount of compound that reaches the cells.

The percentage of total TCDD associated with the PLHC-1 cells was lowest at the highest nominal concentration of TCDD $(10 \mathrm{nM})$, regardless of the medium used for treatment (Table 2). Also, at $10 \mathrm{nM}$ TCDD the fraction associated with the well walls increased, perhaps because at this concentration the cells were saturated with TCDD, and the compound was diffusing through the basal membrane of the cells to the floor of the well. Reduced diffusion at low TCDD concentrations is consistent with the finding of Yu et al (1997) that H4IIE cells apparently reduced sorption of PCB 77 to the floor of culture plates. That same study also found that a majority of PCB $77(\sim 75 \%)$ remained in the medium, which was supplemented with $15 \%$ FBS. They found no effect of carrier (isooctane vs. DMSO) on the fraction of the compound associated with the cells, which was at most 5\%. Uptake studies with radiolabeled PCB77 have demonstrated similarly low levels associated with PLHC-1 cells (A. Patel and M.E. Hahn, unpublished results), suggesting that $\mathrm{HAH}$ partitioning is consistent between these two cell types and their media. In contrast, Schirmer et al (1997) found that the presence of $10 \% \mathrm{FBS}$ in culture medium greatly altered the solubility of fluoranthene, but did not significantly change the amount of that compound associated with cells from two fish lines. 
The magnitude of the effect of serum on AHR occupancy was nearly identical to the difference in uptake of TCDD by cells (compare Figure 3 and the $0.1 \mathrm{nM}$ TCDD group in Figure 2B). This supports a direct relationship between the amount of compound associated with the cells and the amount bound by the AHR when the concentration of TCDD is sufficiently below the amount required for receptor saturation. The latter condition is satisfied here, since the concentration used was less than the $\mathrm{K}_{\mathrm{D}}$ for TCDD binding to the AHR ( $\mathrm{K}_{\mathrm{D}}=0.8 \mathrm{nM}$ in $\mathrm{S}_{0}$; Hestermann et al., in preparation).

However, comparison of receptor occupancy and induction of EROD or CYP1A does not reveal a direct relationship like that occurring between TCDD uptake and receptor occupancy. There was a 4-fold increase in receptor occupancy in cells in $\mathrm{S}_{0}$ rather than $S_{10}$ medium, but a much larger increase in CYP1A content (compare Figure 3 with the $0.1 \mathrm{nM}$ nominal TCDD concentration in Figures 1 and 6A). This is most likely the result of a nonlinear occupancy-response relationship (also known as "spare receptors" or "receptor reserve"; Kenakin 1999) for TCDD and the AHR in these cells. Under such conditions, sub-maximal receptor occupancy will produce maximal cell response, so that small changes in occupancy would produce much larger changes in downstream responses. We are pursuing the precise nature of this relationship in the PLHC-1 cell line.

Relative potencies of the three coplanar PCBs determined in $\mathrm{S}_{0}$ were significantly higher than those determined in $\mathrm{S}_{10}$ for EROD response but not CYP1A protein induction. This suggests that the presence of serum has an effect on CYP1A catalytic activity that is separate from its induction via the AHR. The biphasic dose-response relationships typical of EROD induction are a result of the balance between CYP1A induction and competitive inhibition of catalytic activity by the inducer at higher concentrations (Gooch et al. 1989; Hahn et al. 1993; Petrulis and Bunce 1999). Inhibition lowers EROD induction EC50s relative to EC50s for induction of CYP1A protein, and thereby increases the apparent relative potency for the EROD response (Hahn et al. 1996b). It therefore seems likely that serum influences the inhibitory effect 
of the inducing compounds. Alternatively, there may be serum components that alter EROD activity in PLHC-1 cells by another mechanism.

\section{Implications of Reduced Uptake}

Perhaps the greatest potential for error in interpretation of in vitro bioassay data suggested by our results is in comparison of induction EC50s and relative potencies among cell lines. Cell lines vary widely in culture medium contents. Serum may be absent or present at concentrations of up to $20 \%$, and may come from a variety of animals and different developmental stages. Based on our results, such variations in media composition will affect cellular uptake of $\mathrm{HAH}$ and thus measured CYP1A induction potencies. Differences in potencies thus might incorrectly be attributed to mechanistic differences in CYP1A induction among the cell types and lead to false conclusions about relative sensitivities of the cells to the $\mathrm{HAH}$ in question.

One solution to this potential problem is to treat different cells in a single medium. Serum-free medium is the best candidate, since variations in composition among the chemically defined basal media (e.g. MEM, DMEM, RPMI-1640, F12) should have a negligible effect on bioavailability. Using serum-free medium also allows the greatest sensitivity in response to inducing compounds. The ability of each cell type to respond to HAH in serum-free medium should be determined, since serum withdrawal greatly reduces AHR content in Swiss 3T3 cells (Vaziri et al. 1996) and can abrogate CYP1A induction in PLHC-1 cells after 48 hours (Chapter 5). As noted previously, the presence of serum also affects the levels of cytochromes $\mathrm{P} 450$ in some cultured cells (Doostdar et al. 1988; Turner et al. 1989; Doostdar et al. 1991; Hammond et al. 1992).

PLHC-1 cells have recently been adapted to long-term culture in media with serum replacements (Ackermann et al. 1998), providing promise for their future use in a chemically defined medium. Such media should reduce the problems with lot-to-lot variability that can be encountered with serum; however, the serum replacements used still have a high protein and/or lipid content, which can be expected to reduce 
bioavailability as serum does. In addition, the ability of cells grown in these media to respond to $\mathrm{HAH}$ exposure has not been determined.

The effect of serum on bioavailability is also a concern for other assays involving uptake of hydrophobic compounds. The reduction in specific TCDD binding in the presence of $10 \%$ serum shown here is an example of such an assay. Serum composition also affects bioavailability of estrogenic compounds (Arnold et al. 1996; Nagel et al. 1997). This suggests that the effect of serum is a general one, and its magnitude should be determined for individual compounds. Comparisons of apparently anomalous results among assays performed in different laboratories or cell lines should take this factor into account, and previous conclusions regarding extrapolation from cultured cells may require reexamination.

This report continues our work of establishing the utility and optimal conditions for use of PLHC-1 cells in studying the mechanisms of $\mathrm{HAH}$ action. It also establishes a framework for measuring other effects of culture medium composition on AHR signal transduction in these cells. Through continued use of this model we hope to gain a better understanding of the molecular mechanisms that ultimately result in HAH toxicity. By comparing the shared and distinct features of AHR signal transduction in a variety of taxa we can also better approach questions of AHR function and evolution. 
Chapter 4: Stimulus-Response Relationships Demonstrate the Contributions of Affinity and Intrinsic Efficacy to Aryl Hydrocarbon Receptor Ligands Potency
Abstract
92
Introduction
93
Materials and Methods
95
Results
101
Discussion
114 


\begin{abstract}
Pharmacological models of receptor action have power for describing properties of ligand-receptor interaction and are necessary for mechanism-based risk assessment of receptor-mediated toxic effects. In order to build such a model for the aryl hydrocarbon receptor (AHR), binding affinities and CYP1A induction potencies were measured in PLHC-1 cells for ten halogenated aromatic hydrocarbons (HAH): 2,3,7,8tetrachlorodibenzo-p-dioxin (TCDD), 2,3,7,8-tetrachlorodibenzofuran (TCDF), and polychlorinated biphenyl (PCB) congeners 77, 81, 105, 118, 126, 128, 156 and 169. From these data an operational model of AHR action was used to determine intrinsic efficacies of these ligands. TCDD, TCDF, and non-ortho-substituted PCBs 77, 81, 126 and 169 behaved as full agonists and displayed high intrinsic efficacy. In contrast, the mono- and di-ortho substituted PCBs bound to the AHR but displayed lower or no intrinsic efficacy. PCB 156 was a full agonist, but with an intrinsic efficacy 10 - to 50 fold lower than non-ortho-substituted PCBs. PCB 118 was a very weak partial agonist. PCBs 105 and 128 were shown to be competitive antagonists in this system. When induction of CYP1A by mixtures of PCB 126, 128 or 156 with TCDD was measured, both PCB 156 (a low intrinsic-efficacy agonist) and PCB 128 (a competitive antagonist) inhibited the response to TCDD. The stimulus-response model predicts that only $1-2 \%$ of the receptors in the cell need be occupied to achieve $50 \%$ of maximal CYP1A induction by one of the high intrinsic efficacy agonists, demonstrating the existence of "spare" receptors in this system. These data show that the insensitivity of PLHC-1 cells to orthosubstituted PCBs is due to both reduced affinity and reduced intrinsic efficacy as compared to non-ortho-subsituted PCBs. More generally, separation of AHR ligand action into the properties of affinity and intrinsic efficacy allows for improved prediction of the behavior of complex mixtures of ligands, as well as mechanistic comparisons across species and toxic endpoints.
\end{abstract}




\section{INTRODUCTION}

The aryl hydrocarbon receptor (AHR) is a cytosolic receptor that mediates the toxicity of a variety of compounds, most notably 2,3,7,8-tetrachlorodibenzo- $p$-dioxin (TCDD) and structurally related halogenated aromatic hydrocarbons (HAH). The relationships among chemical structures and biological potencies of AHR ligands have been studied for decades in order to predict their toxicity both individually and in mixtures. As the mechanisms of action for the AHR have been elucidated, the need for application of pharmacological principles to describe these phenomena has become clear (Poland 1991; Poland 1996). A "Receptor Biology Roundtable" has called for quantitative assessment of ligand-receptor interactions to aid in mechanism-based risk assessment of environmental toxicants (Limbird and Taylor 1998). These quantitative pharmacological models have broad applicability, including extrapolation from model organisms to humans and expansion to other receptor-mediated toxicants, such as hormonally active compounds.

Downstream responses to receptor binding must be evaluated to categorize a ligand as a full agonist, partial agonist or antagonist ${ }^{1}$. The potency of the ligand for eliciting a response (i.e. the dose-response relationship) depends on the properties of affinity and efficacy. Affinity is the strength of the interaction, or binding, to the receptor, and efficacy is the ability of that ligand-receptor complex (or stimulus) to produce a response (Ariens 1954; Stephenson 1956). Affinity is a property of the ligand and receptor, while both ligand- and tissue-specific properties affect efficacy. Tissuespecific properties (often collectively termed "coupling") include the concentrations of receptors and other molecules required for transduction of the signal initiated by the ligand-receptor complex. Intrinsic efficacy of a ligand is the ability of that ligand to convert one receptor to an active form, and is independent of tissue coupling (Furchgott

\footnotetext{
'I have followed the definitions of these and other terms related to receptor pharmacology as outlined in reference (Jenkinson et al. 1995).
} 
1966) ${ }^{2}$. Thus, individual ligands can be characterized by their affinity for the receptor and by the intrinsic efficacy with which they activate the receptor.

The best-studied and most frequently used measure of response to AHR agonists is AHR-mediated cytochrome P4501A (CYP1A) induction. Following agonist binding, the AHR translocates to the nucleus, forms a heterodimer with ARNT, and interacts with enhancer elements (XREs) and transcriptional co-factors to activate transcription of several genes, including CYP1A1 (for review see Hankinson 1995; Schmidt et al. 1996). Levels of this enzyme may be quantified by immunoassay or by its ethoxyresorufin-Odeethylase (EROD) activity.

The properties of several AHR ligands have been evaluated by measuring response (typically CYP1A induction) following co-treatment with a known agonist (usually TCDD) and the compound of interest. These include partial agonists, such as 6methyl-1,3,8-trichlorodibenzo-p-dioxin and $\alpha$-naphthoflavone (Blank et al. 1987; Astroff et al. 1988; Merchant et al. 1992; Santostefano et al. 1992), and antagonists, including several substituted flavones ( $\mathrm{Lu}$ et al. 1995; Reiners et al. 1998; Ciolino et al. 1999; Henry et al. 1999) and di-ortho substituted polychlorinated biphenyls (PCBs) (Biegel et al. 1989; Aarts et al. 1995). In some instances AHR binding affinities and/or response inhibition IC50s were determined, but intrinsic efficacies of these ligands were not considered.

Here we report the characterization of AHR ligands in a system where stimulus (AHR binding) and response (CYP1A induction) were measured in whole-cell assays,

${ }^{2}$ It is important to note that a tissue with sufficient receptors and other required molecules will still produce a maximal response after treatment with a ligand that has comparatively low intrinsic efficacy. Thus, due to differential coupling the same compound can be a full agonist, partial agonist, or antagonist in different tissues in the same organism (Kenakin 1999). Here I will refer to high-intrinsic efficacy and lowintrinsic efficacy agonists to indicate properties of the ligand-receptor interaction that are independent of tissue. The terms full and partial agonist are used to describe agonists that are capable or incapable, respectively, of inducing the maximal tissue response. 
and these data were used to build a stimulus-response model for the cells of interest. The primary use of this model was to develop a pharmacological approach to distinguish the contributions of affinity and intrinsic efficacy to AHR ligand potency. The utility of this approach was demonstrated by using these data to determine the molecular basis for the relative insensitivity of fish to ortho-substituted PCBs. The reduced potency of these compounds was first suggested by in vivo studies of CYP1A induciblity (Gooch et al. 1989) and later supported by embryotoxicity (Walker et al. 1991). We chose the PLHC-1 cell line, derived from a hepatocellular carcinoma of the teleost Poeciliopsis lucida (Hightower et al. 1988), because these cells express AHR (Hahn et al. 1993; Hestermann et al. in press) and an inducible CYP1A (Hahn et al. 1993; Hahn et al. 1996a; Hahn et al. 1996b; Hestermann et al. in press). Ten HAH, including a representative dioxin (TCDD), furan (2,3,7,8-tetrachlorodibenzofuran; TCDF), and non-ortho-, mono-ortho-, and diortho-substituted PCBs were chosen to include known agonists as well as suspected partial agonists and antagonists. Stimulus-response relationships determined for these HAH broaden our understanding of the activities of these compounds and provide a framework for future studies of other organisms, tissues, AHR ligands and response endpoints.

\section{MATERIALS AND METHODS}

\section{Chemicals and solutions}

The 2,3,7,8-tetrachloro[ $\left[1,6-{ }^{3} \mathrm{H}\right]$ dibenzo-p-dioxin $\left(\left[{ }^{3} \mathrm{H}\right] \mathrm{TCDD}\right.$, purity $\geq 97 \%$, specific activity $27 \mathrm{Ci} / \mathrm{mmol}$ ) was obtained from Chemsyn Science Laboratories (Lenexa, KS). TCDD, 2,3,7,8-tetrachlorodibenzofuran (TCDF) and all PCBs (purity $>98 \%$ for all) were obtained from Ultra Scientific (Kingston, RI). Resorufin, ethoxyresorufin and Amplex Red were from Molecular Probes (Eugene, OR). Peroxidase conjugated goat anti-mouse antibody was from Pierce (Rockford, IL). All other reagents were obtained from Sigma (St. Louis, MO). 
Phosphate-buffered saline (PBS) is $0.8 \% \mathrm{NaCl}, 0.115 \% \mathrm{Na}_{2} \mathrm{HPO}_{4}, 0.02 \% \mathrm{KCl}$, $0.02 \% \mathrm{KH}_{2} \mathrm{PO}_{4}$, $\mathrm{pH}$ 7.4. Phosphate buffer is $50 \mathrm{mM} \mathrm{Na}_{2} \mathrm{HPO}_{4}$ with $\mathrm{pH}$ adjusted to 8.0 using $50 \mathrm{mM} \mathrm{NaH}_{2} \mathrm{PO}_{4}$. TCDD, TCDF and PCB solutions were prepared in dimethyl sulfoxide (DMSO) as described previously (Hahn et al. 1996b). Concentrations of $\left[{ }^{3} \mathrm{H}\right] \mathrm{TCDD}$ solutions were verified by liquid scintillation counting (LSC) on a Beckman LS5000TD.

\section{Growth and Treatment of Cells}

PLHC-1 cells (Hightower et al. 1988) were grown at $30^{\circ} \mathrm{C}$ in minimum essential medium (MEM) containing Earle's salts, nonessential amino acids, L-glutamine and 10\% calf serum, as described previously (Hahn et al. 1993). These cells express a single CYP1A isoform, which has no detectable constitutive expression (Hahn et al. 1996b). These cells also express only one AHR, an AHR2 form (Hahn 1998a; Chapter 2). For EROD and CYP1A ELISA assays, cells were seeded into 96-well plates (Costar; Cambridge, MA) at $2 \times 10^{5}$ cells in $0.2 \mathrm{ml}$ culture medium per well. One day later the medium was removed and replaced with $0.2 \mathrm{ml}$ serum-free MEM. The cells were then treated by addition of solutions dissolved in DMSO or DMSO alone ( $1 \mu \mathrm{l} /$ well). DMSO concentrations were $\leq 0.5 \%(\mathrm{v} / \mathrm{v})$ in all treatments, and did not affect cell viability. Following treatment, plates were incubated at $30^{\circ} \mathrm{C}$ for 24 hours. For TCDD specific binding experiments, $\left[{ }^{3} \mathrm{H}\right] \mathrm{TCDD}$ and competitors were dissolved at twice the desired concentration in $0.75 \mathrm{ml}$ serum-free MEM in glass tubes. Cells were trypsinized and resuspended at 2 to $4 \times 10^{6}$ cells per $\mathrm{ml}$ in serum-free medium, and $0.75 \mathrm{ml}$ cell suspension was added to each tube. Aliquots of cell suspension were reserved for protein determination.

\section{EROD and protein assays}

EROD activity was measured using a multiwell fluorescence plate reader by a modification of the method of Kennedy et al (1995). Cells were rinsed once with $0.2 \mathrm{ml}$ room temperature PBS, and the EROD reaction was then initiated with the addition of 
$2 \mu \mathrm{M}$ 7-ethoxyresorufin in phosphate buffer $(100 \mu \mathrm{l} /$ well). The reaction was stopped after eight minutes (resorufin production is linear with respect to time over this period; Hahn et al. 1996b) with the addition of $75 \mu \mathrm{l}$ ice-cold fluorescamine solution $(0.15 \mathrm{mg} / \mathrm{ml}$ in acetonitrile). After a fifteen-minute incubation, resorufin and fluorescamine fluorescence were measured. Resorufin and protein concentrations were determined from standard curves prepared on the same plate. BSA was used for the protein standard.

For the TCDD binding experiments, cell protein was measured by the bincinchinoic acid method of Smith (1985), using BSA as the standard and MEM as the blank.

\section{ELISA Assay}

Enzyme-linked immunosorbence assays to detect CYP1A were performed essentially as described by Brüschweiler et al (1996a). One day after treatment in 96-well plates, cells were fixed in 50\% ethanol 15 minutes, in 75\% ethanol 15 minutes, and in $95 \%$ ethanol 30 minutes. After washing with PBS, non-specific antibody binding was blocked with 10\% fetal bovine serum and 2\% BSA in PBS for 1 hour. The primary antibody, mouse anti-scup CYP1A monoclonal antibody 1-12-3 (10 $\mu \mathrm{g} / \mathrm{ml}$; Park et al. 1986), was then added in $100 \mu \mathrm{l}$ blocking solution for 1 hour. After three washing steps with PBS, $100 \mu 1$ secondary antibody, peroxidase conjugated goat anti-mouse (1:1000 in blocking solution), was added for 1 hour. After another three washing steps with PBS, $100 \mu 1$ substrate solution ( $100 \mu \mathrm{M}$ Amplex Red, $100 \mu \mathrm{M} \mathrm{H}_{2} \mathrm{O}_{2}$ in phosphate buffer, $\mathrm{pH}=7.0$ ) was added for 30 minutes. All incubations were performed at room temperature.

Resorufin formation was measured in the fluorescence plate reader. For each treatment the background fluorescence, defined as the fluorescence detected in untreated cells, was subtracted, and all values were normalized to the maximum response measured. The assay was also performed on wells without cells or without the addition of primary antibody, and these controls yielded fluorescence values nearly identical to those in untreated cells, consistent with our earlier results detecting no CYP1A protein or EROD activity in untreated cells (Hahn et al. 1996b). 
TCDD and Competitor Binding to the AHR

Specific binding of $\left[{ }^{3} \mathrm{H}\right] \mathrm{TCDD}$ in PLHC-1 cells was measured by a modification of the whole-cell filtration assay of Dold and Greenlee (1990). For determination of the equilibrium dissociation constant $\left(\mathrm{K}_{\mathrm{d}}\right)$ of TCDD binding to the AHR and the receptor content $\left(\mathrm{R}_{\mathrm{T}}\right)$ of PLHC-1, cells were treated with increasing concentrations of $\left[{ }^{3} \mathrm{H}\right] \mathrm{TCDD}$ in the presence or absence of 200-fold molar excess of unlabeled TCDF and incubated 2 hours at $30^{\circ} \mathrm{C}$. This time was determined to be sufficient to achieve a steady state of bound radioligand (Appendix B). For determination of binding inhibition constants $\left(\mathrm{K}_{\mathrm{i}}\right)$, 0.5 to $1 \mathrm{nM}\left[{ }^{3} \mathrm{H}\right] \mathrm{TCDD}$ and increasing concentrations of competitors (or a 200-fold excess TCDF treatment to measure non-specific binding) were dissolved in MEM. Cells suspended in MEM were subsequently added to ensure true competition, since off rates for AHR ligands can be extremely slow (Farrell and Safe 1987). Cell densities were equal among experiments in order to minimize protein concentration effects on binding (Bradfield et al. 1988a). Following the incubation, tubes were vortexed briefly to assure even distribution of cells, and a $0.1 \mathrm{ml}$ aliquot was removed to determine final $\left[{ }^{3} \mathrm{H}\right] \mathrm{TCDD}$ concentration. Three, $0.45 \mathrm{ml}$ aliquots of cell suspension from each tube were then collected under vacuum on prewetted $25 \mathrm{~mm}$ Whatman GF/F filters. In some cases cell aliquots were pelleted (200g, 10 minutes) and resuspended in PBS prior to application to filters. Filters were then washed three times with $2.5 \mathrm{ml}$ acetone that had been precooled to $-80^{\circ} \mathrm{C}$. The number of washes was determined empirically as that necessary to remove the free $\left.{ }^{3} \mathrm{H}\right] \mathrm{TCDD}$ remaining on the filters. Replicates were processed in batches of twelve on a Millipore 1225 filter manifold. Radioactivity remaining on the filter was quantified by LSC.

\section{Data Analysis and Theoretical Models}

EROD data were fit to a modified Gaussian function for determination of doseresponse relationships, as described previously (Kennedy et al. 1993; Hahn et al. 1996b). CYP1A induction data were fit to the Hill response function: 


$$
\frac{[C Y P 1 A]}{\left[C Y P 1 A_{\max }\right]}=\frac{[A]}{[A]+E C 50}
$$

where $C Y P 1 A$ and $C Y P 1 A_{\max }$ are the amount of CYP1A content measured at inducer concentration $[A]$ and with $10 \mathrm{nM}$ TCDD, respectively, and EC50 is the concentration of inducer required to elicit half-maximal CYP1A expression. A modified version of this equation that included a term allowing for non-zero background expression was used to fit data from the co-treatment experiment (Figure 6).

For AHR binding, total binding (without TCDF) and nonspecific binding (with TCDF) were measured as the average of three replicates at each $\left.{ }^{3} \mathrm{H}\right] \mathrm{TCDD}$ concentration. Because the $\left[{ }^{3} \mathrm{H}\right] \mathrm{TCDD}$ concentrations in the total and nonspecific binding treatments were not exactly equal, specific binding is shown as the difference of the total binding at a given concentration and the nonspecific binding at the same concentration as determined from a linear regression of the nonspecific binding data collected. These specific binding values were calculated for illustrative purposes only, and were not used for determination of $\mathrm{K}_{\mathrm{d}}$ and $\mathrm{R}_{\mathrm{T}}$. Those values were determined by simultaneous fitting of the data collected to equations describing total and nonspecific binding:

$$
\begin{aligned}
& T B=\frac{[A] \times\left[R_{T}\right]}{[A]+K_{d}}+m[A] \\
& N S B=m[A]
\end{aligned}
$$

where $T B$ is total binding, $[A]$ is the concentration of radioligand, NSB is nonspecific binding, and $m$ is the slope of the nonspecific binding curve. This method has significant advantages over others, such as Scatchard plots, which can place undue emphasis on a few points of the binding curve (Kenakin 1999). Specific binding curves were plotted using the Hill-Langmuir isotherm:

$$
[A \cdot R]=\frac{[A] \times\left[R_{T}\right]}{[A]+K_{d}}
$$

where $[A \cdot R]$ is the concentration of ligand-receptor complex (i.e. specifically bound ligand). The data were also fit to equations that did not assume a Hill coefficient of 1 
(i.e. a lack of cooperative binding), but these showed no statistical improvement, and the Hill coefficients were not significantly different from 1 .

Binding inhibition constants $\left(\mathrm{K}_{\mathrm{i}}\right)$ were determined by fitting inhibition data from at least three experiments to the Gaddum equation (Gaddum 1937):

$$
\frac{S B}{R_{T}}=\frac{[A]}{[A]+K_{d}\left(1+\frac{[I]}{K_{i}}\right)}
$$

where $S B$ is specific binding and $[I]$ is the concentration of competitor. Competitive inhibition of $\left[{ }^{3} \mathrm{H}\right] \mathrm{TCDD}$ binding by PCB 105 and antagonism of CYP1A induction by PCB 128 were shown by Schild analysis according to the following regression (Arunlakshana and Schild 1959):

$$
\log \left(\frac{\left[A^{\prime}\right]}{[A]}-1\right)=\log [I]-\log K_{i}
$$

where $\left[A^{\prime}\right]$ is the concentration of ligand required to achieve the same amount of specific binding (or response) in the presence of competitor $[I]$ that would be achieved by $[A]$ in the absence of competitor. The ratio $\left[A^{\prime}\right] /[A]$ is called the concentration ratio, and is also represented by $r$. A linear regression of $\log (r-1)$ on $\log [I]$ was performed. The regression supports (but does not prove) a mechanism of competitive antagonism if the slope $=1$, and in this case alone the intercept provides an estimate of $\mathrm{K}_{\mathrm{i}}$.

Stimulus-response coupling for individual AHR agonists was modeled using the operational model of Black and Leff (Black et al. 1983). This assumes a hyperbolic relationship between the amount of ligand-receptor complex and the observed response:

$$
\frac{E_{a}}{E_{m}}=\frac{[A \cdot R]}{K_{E}+[A \cdot R]}
$$

where $E_{a}$ is the response observed at agonist concentration $[A], E_{m}$ the maximal response, and $K_{E}$ the concentration of ligand-receptor complex that gives half-maximal response. Combining equations 4 and 7 yields:

$$
\frac{E_{a}}{E_{m}}=\frac{\left[R_{T}\right] \times[A]}{K_{d} \times K_{E}+\left(\left[R_{T}\right]+K_{E}\right)[A]}
$$


CYP1A induction (i.e. response) data for individual agonists were fit to equation 8 using experimentally determined values for $\mathrm{R}_{\mathrm{T}}$ and $\mathrm{K}_{\mathrm{d}}$ (assuming $\mathrm{K}_{\mathrm{i}}=\mathrm{K}_{\mathrm{d}}$ ) in order to determine the value of $\mathrm{K}_{\mathrm{E}}$.

Fitting and statistical analyses were performed with SigmaPlot (Jandel Scientific) and Jmp In (SAS Institute) software.

\section{RESULTS}

\section{CYPIA Response to HAH Exposure}

Induction of CYP1A by HAH was quantified by its EROD activity and by ELISA. Responses to TCDD, TCDF and eight PCBs (four non-ortho-, three monoortho-, and one di-ortho-substituted) were measured. CYP1A induction by TCDD and three of the non-ortho PCBs (IUPAC numbers 77, 126 and 169) has been measured and reported previously (Hestermann et al. in press). Those data are shown here in Figures 1A and 2A, with hyperbolic curves fitted for CYP1A protein induction. Representative induction curves for the other compounds are shown (Figures 1B and 2B), and the EC50s of induction for all ten compounds are in Table 1. TCDD, TCDF, all four non-ortho PCBs and one mono-ortho PCB (156) induced CYP1A protein and catalytic activity, while two other mono-ortho PCBs (105 and 118) and the one di-ortho PCB (128) induced little or no measurable CYP1A.

\section{AHR Binding Affinities}

Binding affinities for the ten compounds were measured by inhibition of $\left[{ }^{3} \mathrm{H}\right]$ TCDD binding to the AHR (Figure 3). Specific binding of $\left[{ }^{3} \mathrm{H}\right] \mathrm{TCDD}$ was measured by a whole-cell filtration method (Dold et al. 1990). The total, nonspecific and specific TCDD binding measured in the absence of competitor are shown in Figure 3A. Inhibition curves in Figure $3 \mathrm{~B}$ and $\mathrm{C}$ are shown as a fraction of binding in the absence of competitor. $\mathrm{K}_{\mathrm{i}}$ values for each compound (Table 1) were determined by simultaneous 

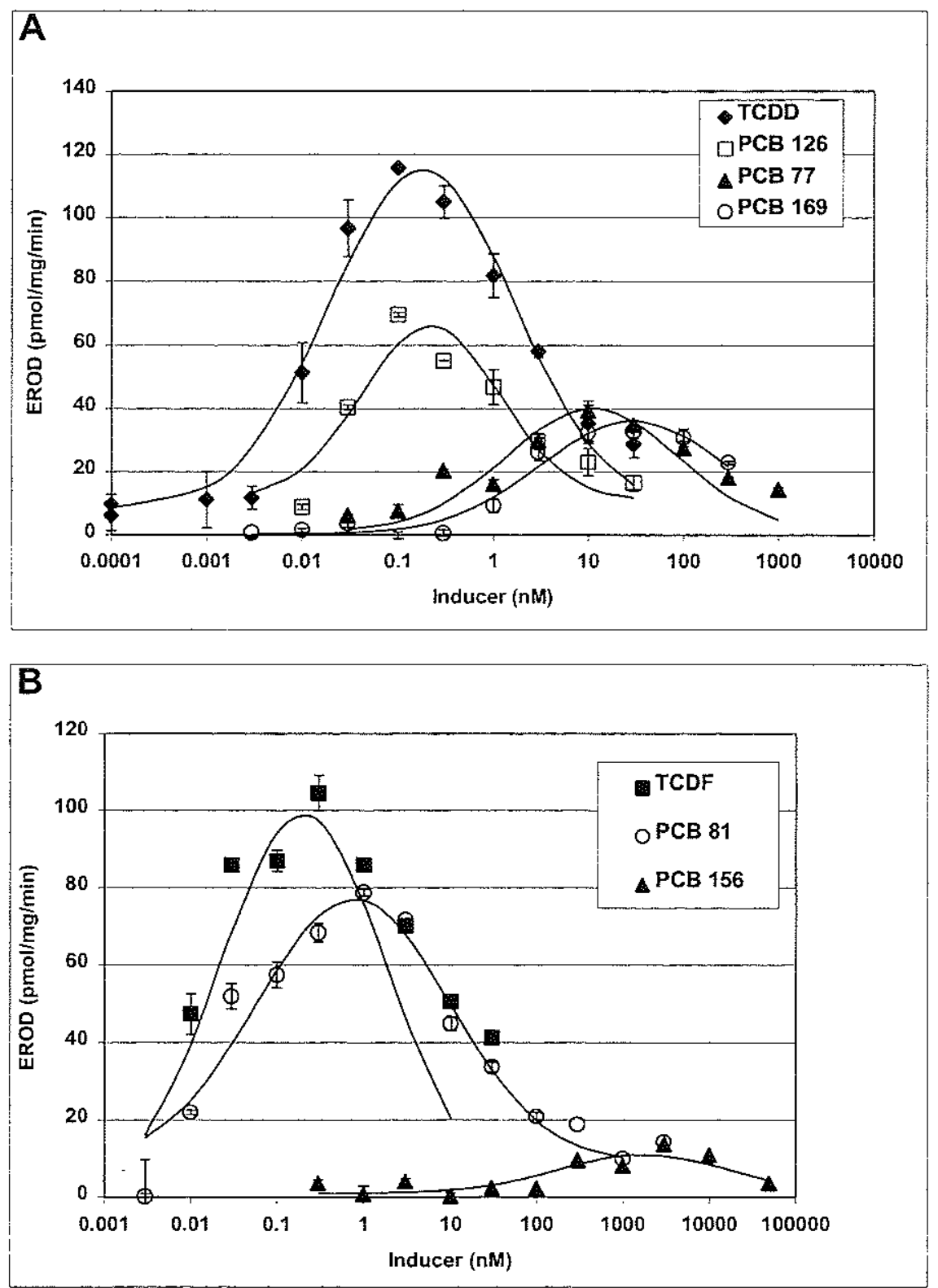

Figure 1. EROD induction by AHR agonists. Cells were treated with the indicated concentrations of inducer and EROD activity (pmol of resorufin formed per minute per mg of cellular protein) was assayed 24 hours later. For each compound, the lowest concentration represents treatment with DMSO alone. Points are means $\pm S E$ of three wells. The modified Gaussian fits to these data are plotted. (A) TCDD, PCB 77, PCB 126 and PCB 169 (B) TCDF, PCB 81 and PCB 156. PCBs 105, 118 and 128 were all inactive in inducing EROD. 

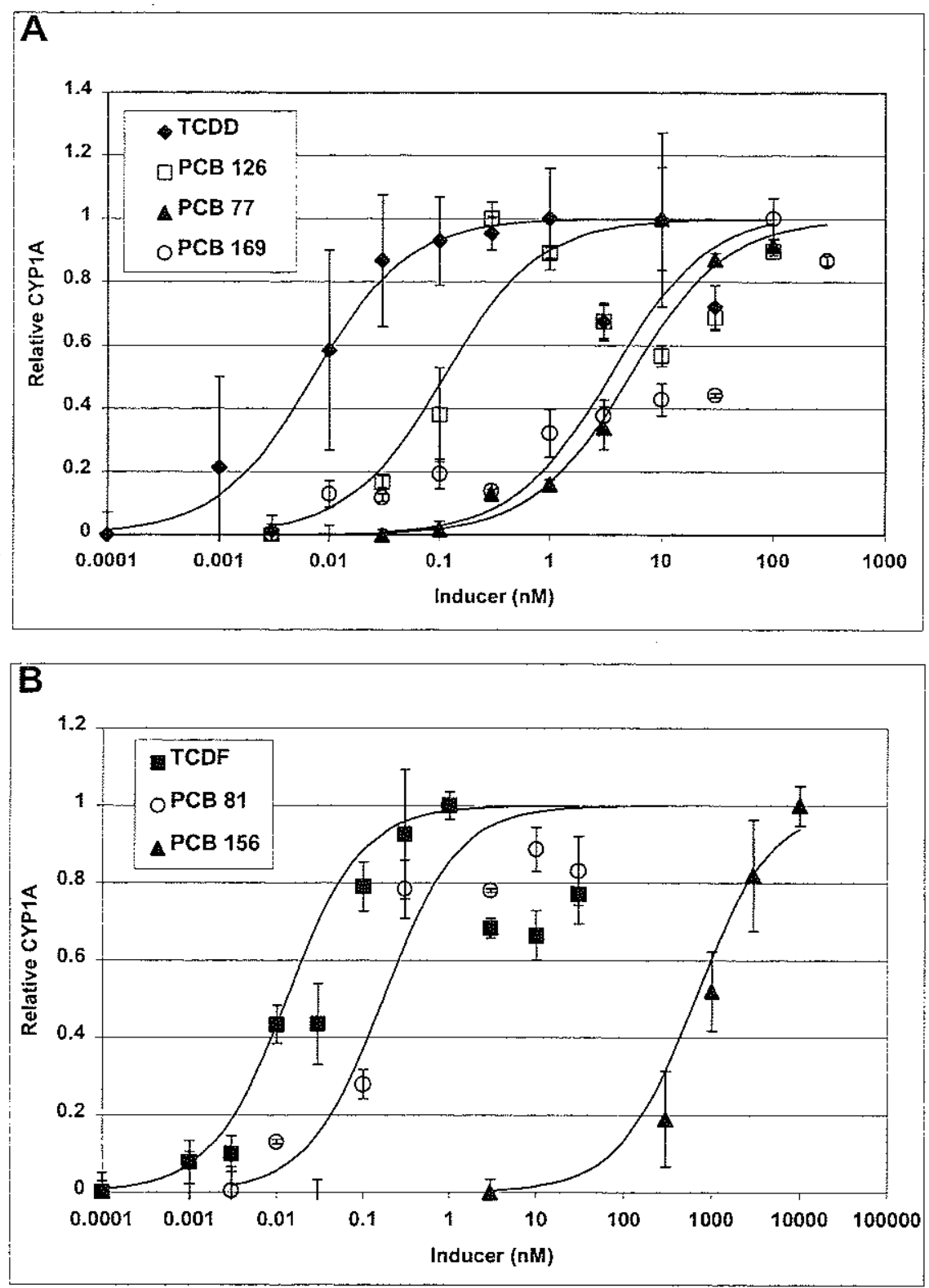

Figure 2. CYP1A induction by AHR agonists. Cells were treated as in Figure 1. ELISAdetected CYP1A protein content was assayed 24 hours later. For each compound, the lowest concentration represents treatment with DMSO alone. Points are means $\pm \mathrm{SE}$ of three wells. Values are normalized to induction with $10 \mathrm{nM}$ TCDD. The hyperbolic fits to these data are plotted. (A) TCDD, PCB 77, PCB 126 and PCB 169 (B) TCDF, PCB 81 and PCB 156. PCBs 105,118 and 128 were all nearly or totally inactive in inducing CYP1A. 

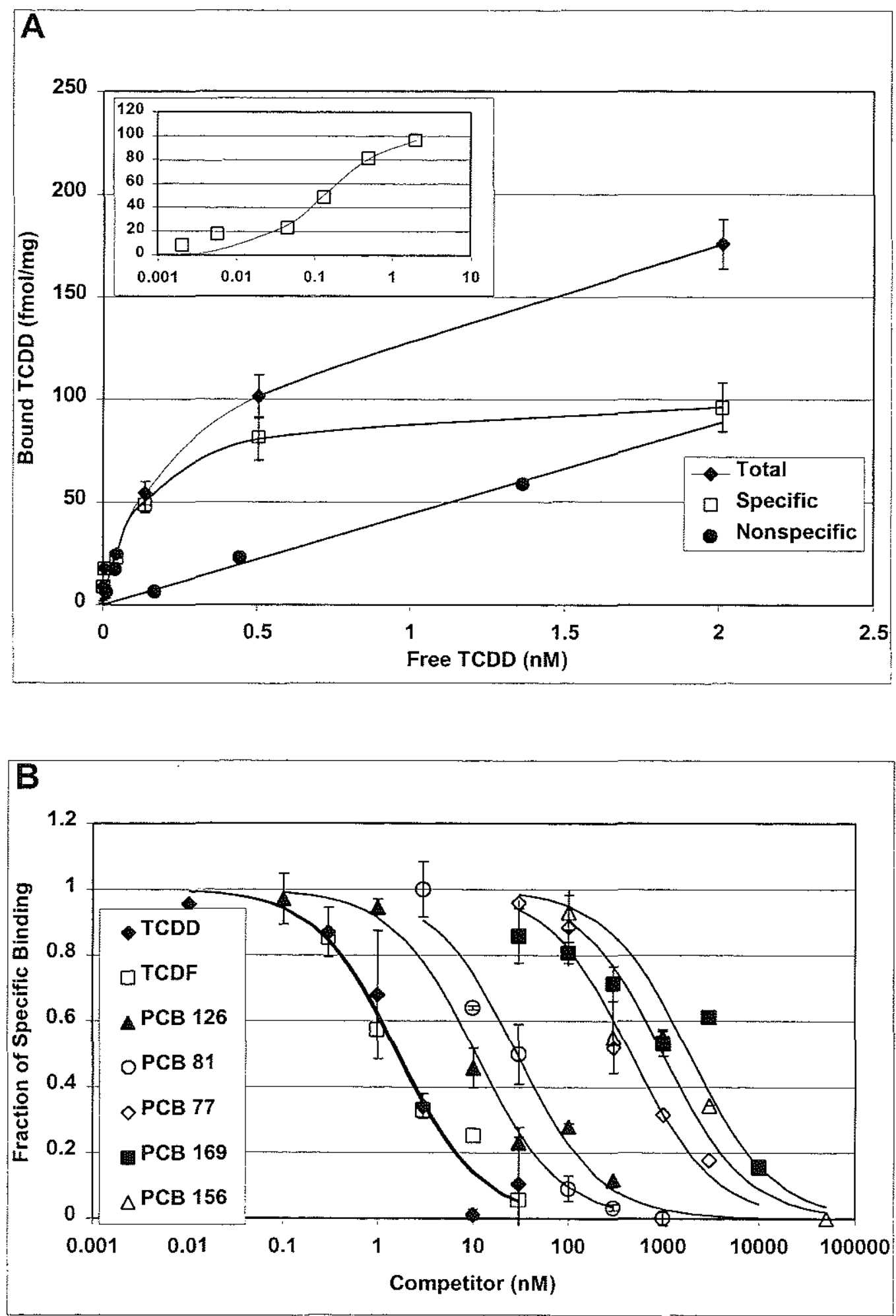


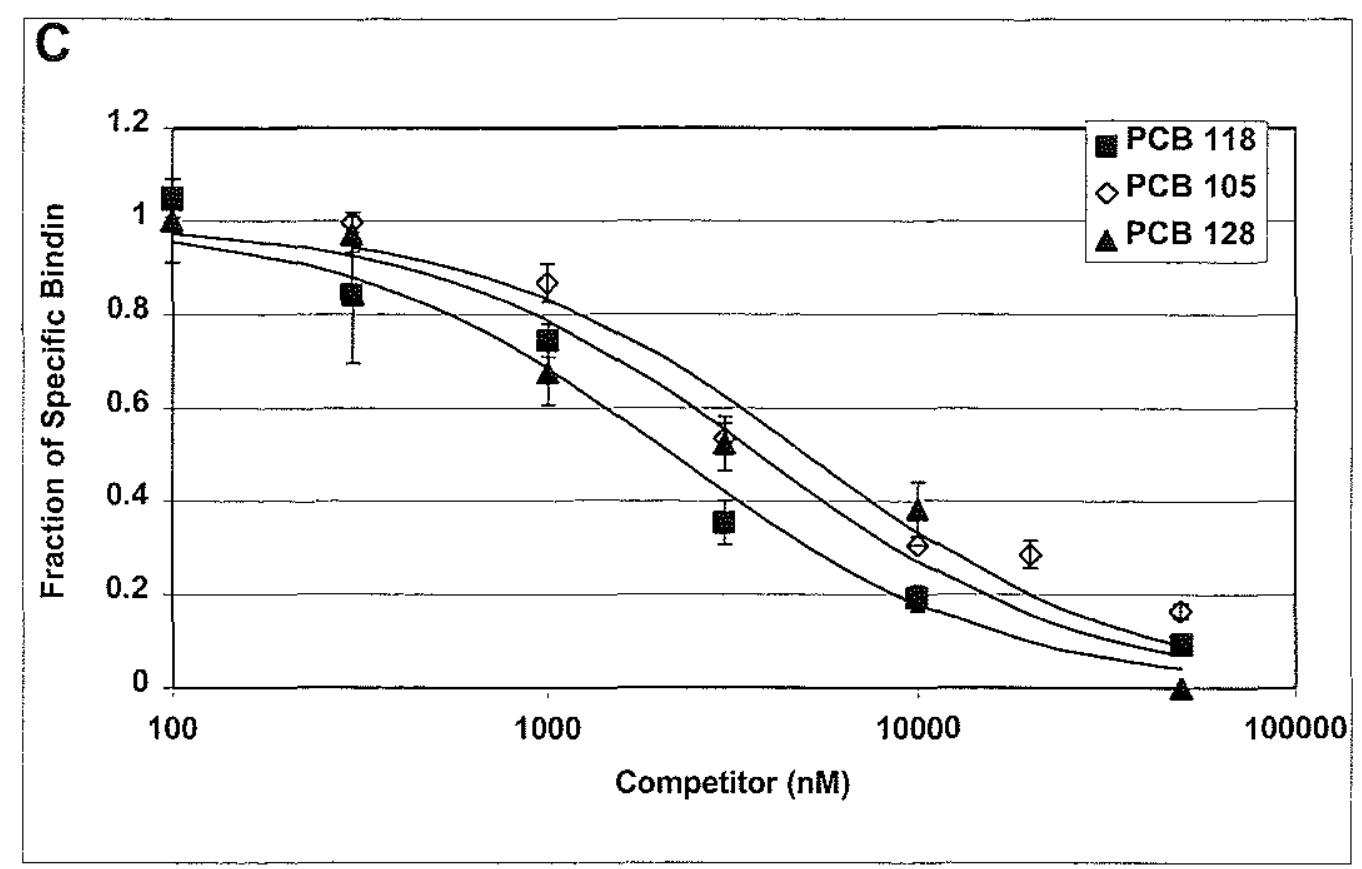

Figure 3. Inhibition of $\left.{ }^{3} \mathrm{H}\right] \mathrm{TCDD}$ binding by AHR ligands. Cells were treated with $\left[{ }^{3} \mathrm{H}\right] \mathrm{TCDD}$ in the presence or absence of increasing concentrations of competitors, including a 200 -fold excess TCDF treatment to measure non-specific binding. Specific binding of $\left[{ }^{3} \mathrm{H}\right] \mathrm{TCDD}$ was measured by a whole-cell filtration assay (Dold et al. 1990). (A) Binding curves for $\left[{ }^{3} \mathrm{H}\right] \mathrm{TCDD}$ in the absence of competitors. The plot through the specific binding points is from equation 4 , with $\mathrm{R}_{T}=103 \mathrm{fmol} / \mathrm{mg}$ and $\mathrm{K}_{d}=0.14 \mathrm{nM}$. Inset shows specific binding on a semi-logarithmic plot. Inhibition curves are shown for (B) full agonists and $(C)$ partial agonist and antagonists. Values are fractions of specific $\left[{ }^{3} \mathrm{H}\right] \mathrm{TCDD}$ binding measured in the absence of competitor. Points are means $\pm \mathrm{SE}$ of three replicates. 
fitting of 3-4 such curves from independent experiments, as described in the Methods. $\mathrm{K}_{\mathrm{i}}$ values for the agonists showed the same rank order potency as EROD and CYP1A EC50s (Table 1).

Table 1. Parameters for CYP1A and EROD activity induction and AHR binding for selected HAH.

\begin{tabular}{c|c|c|c} 
Compound & $\begin{array}{c}\text { EROD EC50 } \\
(\mathrm{nM})\end{array}$ & $\begin{array}{c}\text { CYP1A EC50 } \\
(\mathrm{nM})\end{array}$ & $\begin{array}{c}\mathrm{K}_{\mathrm{i}} \\
(\mathrm{nM})\end{array}$ \\
\hline TCDD & 0.016 & 0.015 & 0.76 \\
TCDF & 0.014 & 0.032 & 1.5 \\
PCB 126 & 0.029 & 0.12 & 16 \\
PCB 81 & 0.063 & 0.19 & 29 \\
PCB 77 & 0.73 & 14 & 860 \\
PCB 169 & 1.6 & 18 & 2200 \\
PCB 156 & 230 & 1900 & 2500 \\
PCB 118 & $>50000^{a}$ & $>50000^{a}$ & 2900 \\
PCB 105 & $\mathrm{ND}^{b}$ & $\mathrm{ND}$ & 4600 \\
PCB 128 & $\mathrm{ND}$ & $\mathrm{ND}$ & 6600 \\
& & &
\end{tabular}

EROD induction EC50s for TCDD, PCB 126, PCB 77 and PCB 169 are from (Hestermann et al. in press). EROD and CYP1A EC50s are means of at least three separate determinations, with one such determination shown in Figures 1 and $2 . \mathrm{K}_{\mathrm{i}}$ values are likewise determined from at least three separate binding inhibition experiments such as that shown in Figure 3.

a: minimal induction detected, but insufficient data for determining an EC50 $b: \mathrm{ND}=$ no induction detected 
Two compounds, PCBs 105 and 128, inhibited TCDD specific binding but failed to induce EROD or CYP1A, suggesting that they are antagonists in PLHC-1 cells over the range of concentrations used. In order to determine if antagonism by PCB 105 is competitive, binding inhibition was measured at three concentrations of TCDD (Figure 4A). The resulting Schild plot is shown in Figure 4B. The slope of the plot is not significantly different from unity, supporting the identification of PCB 105 as a competitive antagonist. The $\mathrm{K}_{\mathrm{j}}$ determined from the intercept of the plot with slope constrained to $1(2200 \mathrm{nM})$ is not significantly different from that determined from the data in Figure 3C (4600 nM).

\section{Stimulus-Response Coupling}

The logarithms of EC50 values are plotted against logarithms of $\mathrm{K}_{\mathrm{i}}$ values in Figure $5 \mathrm{~A}$, such that each point represents a single compound. The figure shows that EC50s for CYP1A protein induction increase in a 1:1 relationship with increases in binding affinities, with EC50s approximately 100 -fold lower than $\mathrm{K}_{\mathrm{i}} \mathrm{s}$ for each compound. This relationship does not hold for EC50s for EROD activity induction, where the slope of the line is significantly less than 1. This is in agreement with our previous results with a more limited set of compounds showing that EC50s based on EROD induction overestimate relative potencies as compared to CYP1A protein induction in the same cells (Hahn et al. 1996b; Hestermann et al. in press).

The ortho-substituted PCBs do not follow the trends seen with the other compounds. Figure 5A shows that the EC50s for CYP1A induction by PCB 156 are much higher than predicted from its $\mathrm{K}_{\mathrm{i}}$ and the relationships observed for the other compounds. Minimum EC50 values of $50 \mu \mathrm{M}$ for PCB 118 place it even farther from the observed relationships. The findings suggest that these compounds are less efficient at eliciting a response following receptor binding.

Since AHR binding (stimulus) and CYP1A induction (response) were measured in the same whole-cell system, it is possible to determine relationships between the two. This was done using an operational model (Black et al. 1983), as described in the 

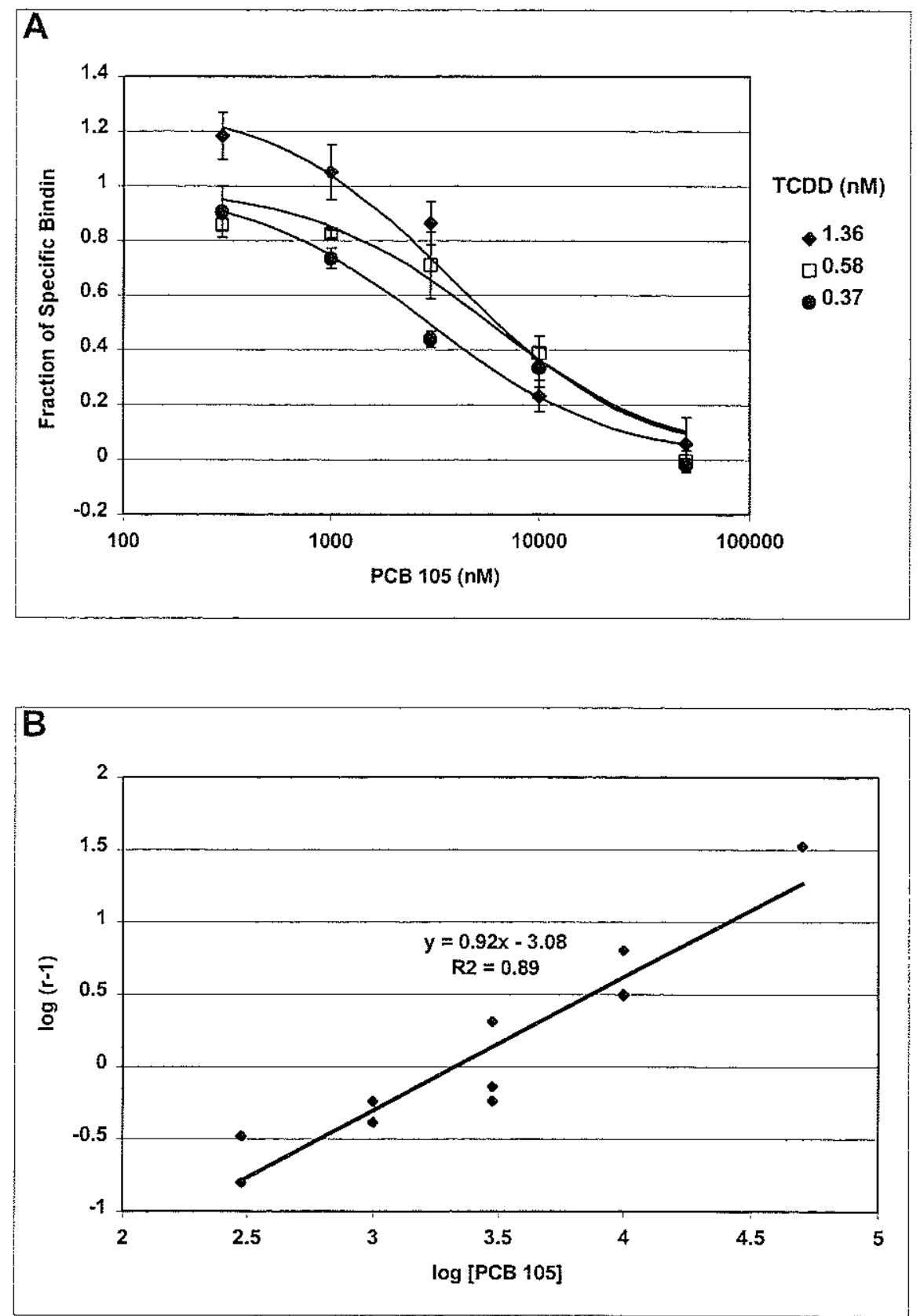

Figure 4. Competitive inhibition of $\left[{ }^{3} \mathrm{H}\right] \mathrm{TCDD}$ binding by PCB 105 . Cells were treated with $\left.{ }^{3} \mathrm{H}\right] \mathrm{TCDD}$ (concentrations in the legend) in the presence of PCB 105 (concentrations indicated on the abscissa). (A) Values are fractions of specific $\left[{ }^{3} \mathrm{H}\right] \mathrm{TCDD}$ binding measured in the absence of competitor and are means $\pm \mathrm{SE}$ of three replicates. (B) Schild regression of data from (A); see Methods for explanation. 

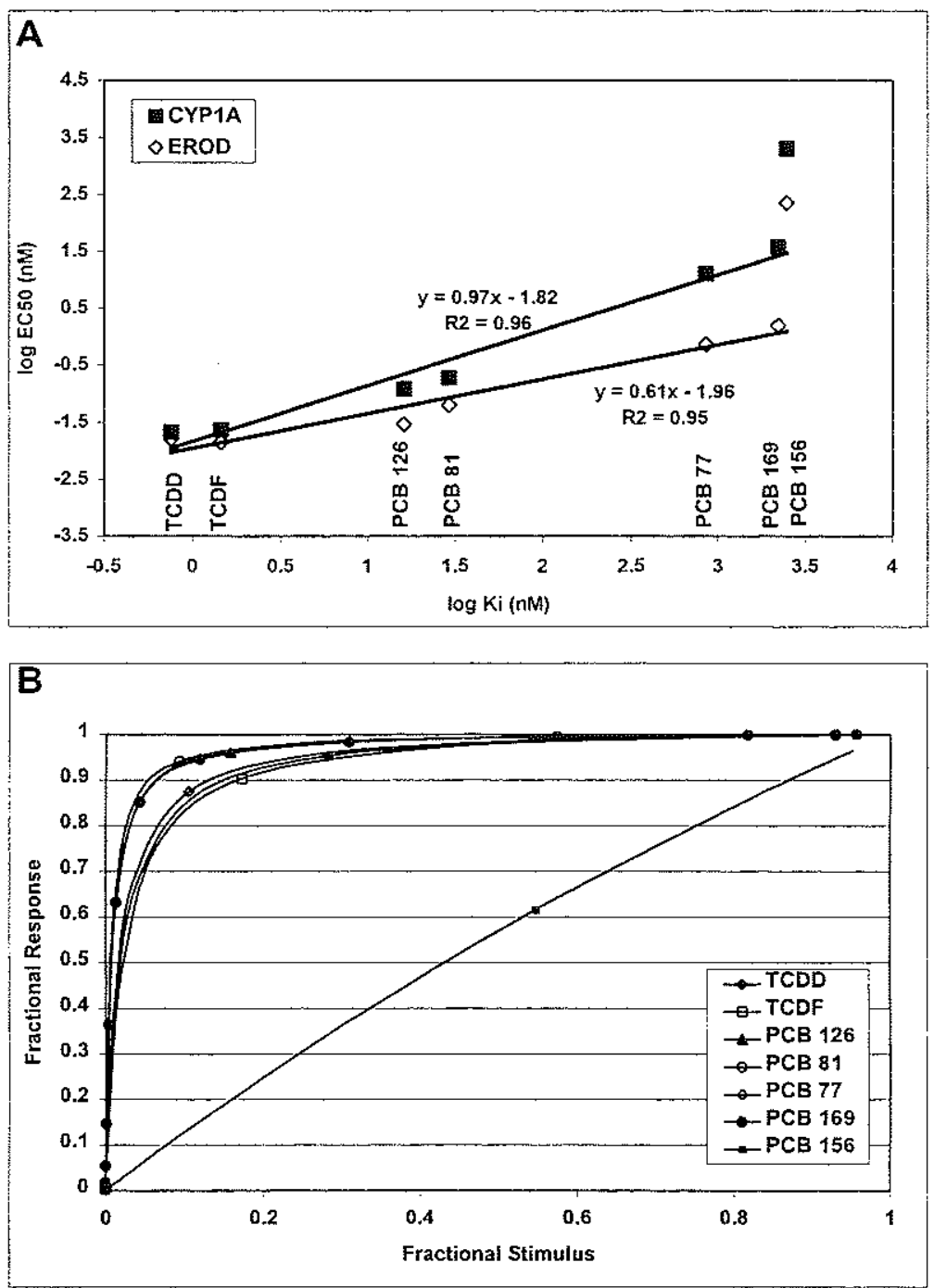

Figure 5. Stimulus-response coupling for AHR agonists. (A) EROD and CYP1A induction EC50s for each compound are plotted against their $\mathrm{K}_{\mathrm{i}}$ values on a log-log scale. The values are from Table 1, and individual compounds are identified. The least-squares fits shown exclude the values for PCB 156. The slope of the EROD regression is significantly less than 1 ( $p<0.01$; t-test). (B) Theoretical stimulus-response curves for the same seven compounds. Fractional stimulus (AHR binding) is on the abscissa and was calculated using Equation 4 and the $K_{i}$ values in Table 1. Fractional response (CYP1A induction) is on the ordinate, and was calculated using Equation 1 and the EC50 values in Table 1. 
Table 2. Stimulus-response coupling for AHR agonists.

\begin{tabular}{c|c|c|c} 
Compound & $\mathrm{K}_{\mathrm{E}}(\mathrm{fmol} / \mathrm{mg})^{a}$ & $\mathrm{R}_{50}(\%)^{b}$ & $\mathrm{R}_{95}(\%)^{b}$ \\
\hline TCDD & 2.0 & 1.9 & 27 \\
TCDF & 2.5 & 2.2 & 30 \\
PCB 126 & 1.0 & 0.75 & 13 \\
PCB 81 & 0.70 & 0.65 & 11 \\
PCB 77 & 3.1 & 1.7 & 24 \\
PCB 169 & 0.88 & 0.78 & 13 \\
PCB 156 & 39 & 45 & 94
\end{tabular}

$a$ : $\mathrm{K}_{\mathrm{E}}$ represents the amount of receptor-ligand complex required for half-maximal response. These values were determined from CYP1A induction data as described in the Methods (Equation 8).

$b: \mathrm{R}_{50}$ and $\mathrm{R}_{95}$ are the fraction of receptors (expressed as a percentage) that must be occupied by the indicated compound for $50 \%$ and $95 \%$ CYP1A induction, respectively.

Methods. The model assumed a hyperbolic stimulus-response relationship, which is consistent with data from other receptor systems and the mechanism of CYP1A induction. Fitted $K_{E}$ values for the agonists, as well as calculated $R_{50}$ and $R_{95}$ values, are shown in Table 2. $\mathrm{K}_{\mathrm{E}}$ represents the amount of receptor-ligand complex required for half-maximal response. These values are on the unit order of magnitude for all compounds except PCB 156, for which the $\mathrm{K}_{\mathrm{E}}$ is $\sim 10$ - to 50 -fold higher. The $\mathrm{R}_{50}$ and $\mathrm{R}_{95}$ values are the fraction of receptors that must be occupied to elicit a $50 \%$ and $95 \%$ response, respectively. Lower values indicate that fewer occupied receptors are necessary for response. Thus, fewer than $30 \%$ of the receptors need be occupied for a $95 \%$ response to TCDD, while about $94 \%$ must be occupied for the same response to PCB 156. 
The stimulus-response relationship is shown graphically in Figure 5B, where the fitted constants were used to draw theoretical stimulus-response curves for each agonist. Collectively, the stimulus-response relationships represented in Table 2 and Figure 5B demonstrate quantitatively what was earlier shown qualitatively, that PCB 156 is much less efficient in eliciting a response after binding to the AHR than the other compounds tested. Thus TCDD, TCDF, and the non-ortho-substituted PCBs are high-intrinsic efficacy agonists, and PCB 156 is a low-intrinsic efficacy agonist for the PLHC-1 AHR. Note that all are full agonists, as determined by maximal response, in this system.

\section{Demonstrating Ligand Character in a Mixture}

These data demonstrate that the compounds tested include representatives of three classes of receptor ligands: high-intrinsic efficacy agonists (TCDD, TCDF, PCBs 77, 81, 126 and 169), low-intrinsic efficacy agonists (PCB 156 and likely PCB 118) and antagonists (PCBs 105 and 128). Each class of compound should display unique properties when response is measured after co-treatment with a high-intrinsic efficacy agonist such as TCDD (Goldstein et al. 1974). A mixture of two high-intrinsic efficacy ligands should produce additive response. An antagonist should inhibit the response produced by the high-intrinsic efficacy ligand alone. Since a low-intrinsic efficacy agonist has properties of both an agonist and antagonist, it should exhibit concentrationdependent additive and inhibitory effects on the high-intrinsic efficacy ligand.

This co-treatment was done with PCBs 126, 128 and 156 as representatives of each class of ligand (Figure 6). Cells were treated with TCDD in the presence of increasing concentrations of each $\mathrm{PCB}$, and the EC50 for CYP1A induction by TCDD was measured. For each of the three mixtures, Schild regressions were produced using the fitted EC50s for TCDD at each concentration of PCB (Figure 7). In such a plot, a high-intrinsic efficacy agonist would be expected to show a slope of 0 , a competitive antagonist a slope of 1 , and a low-intrinsic efficacy agonist a slope between these two values. 

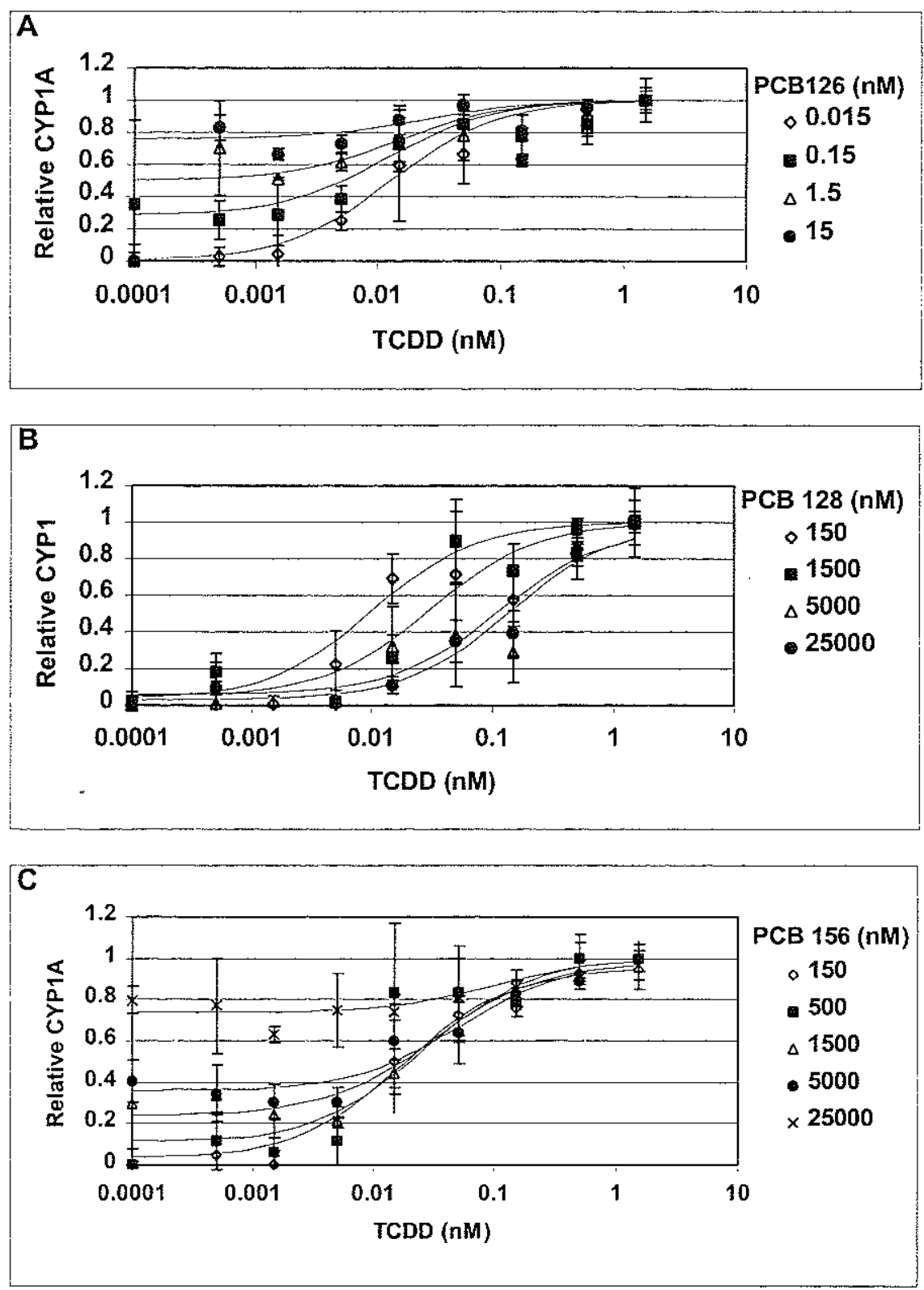

Figure 6. Demonstration of ligand intrinsic efficacy by co-treatment. Cells were cotreated with TCDD (concentrations indicated on the abscissa) and varying concentrations of PCB (concentrations indicated in the legend): (A) PCB 126, (B) PCB 128 or (C) PCB 156. The 0.0001 concentration of TCDD represents treatment with PCB alone. Points are means \pm SE of three wells. Values are normalized to induction with $10 \mathrm{nM}$ TCDD. The hyperbolic fits to these data are plotted. 


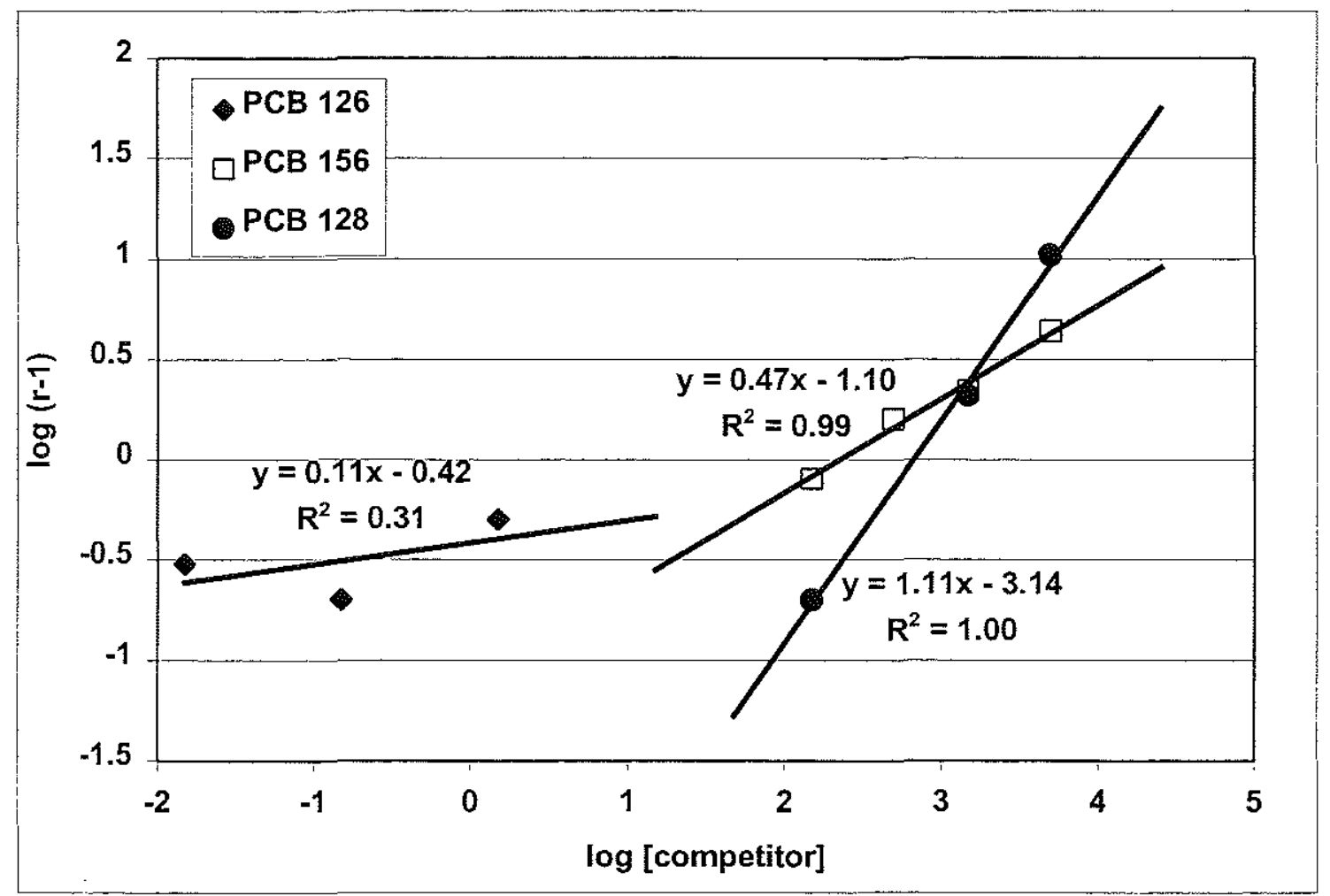

Figure 7. Schild regression for co-treatments. The EC50 values from the curves in Figure 6 were used for regressions. The EC50 value determined in the presence of the highest concentration of each PCB was excluded due to high baseline induction (PCBs 126 and 156) and/or limited solubility (PCBs 128 and 156). The slope of the PCB 126 regression is not significantly different from 0 , nor the slope of the PCB 128 regression significantly different from 1 , while the slope of the PCB 156 regression is significantly greater than 0 and less than $1(\mathrm{p}<0.01$ for all $)$. 
PCB 126 alone induced CYP1A, and in co-treatment caused only a slight increase in EC50s for CYP1A induction by TCDD (Figures 6A and 7). PCB 128 did not induce CYP1A, but did cause a progressive increase in EC50s for CYP1A induction by TCDD (Figures 6B and 7). PCB 156 induced CYP1A and increased EC50s for TCDD in cotreatment, although not to the same degree as $\mathrm{PCB} 128$ (Figures 6C and 7). As predicted, the Schild regression indicates that PCB126 is a high-intrinsic efficacy agonist (slope not significantly different from 0), PCB 156 is a low-intrinsic efficacy agonist (slope significantly different from both 0 and 1), and PCB 128 is a competitive antagonist (slope not significantly different from 1 ). The $y$-intercept for the PCB 128 regression predicts a $\mathrm{K}_{\mathrm{i}}$ that is not significantly different from that determined by ligand binding.

\section{DISCUSSION}

This set of experiments represents the first quantitative determination of stimulusresponse relationships for AHR ligands, in any system. Structure-activity relationships for both stimulus (receptor binding) and response (CYP1A induction) were determined in intact cells. From such assays, affinities and intrinsic efficacies of ligands can be evaluated, and the structural parameters that determine agonism can be determined separately for each of these properties of the ligand-receptor interaction. These data were also used to construct an operational model for AHR-ligand interactions, which has application for risk assessment as well as predicting effects of perturbations to the signaling pathway.

Interpreting CYP1A Induction and Competitive Binding Affinities

The data presented here demonstrate clearly a relationship between AHR binding affinities and CYP1A protein induction potencies. The regression shown in Figure 5a reveals that these values increase in a 1:1 relationship for the agonists studied. The 
correlation exists because TCDD, TCDF, and the non-ortho-substituted PCBs have similar intrinsic efficacies (Table 2), so that differences in AHR binding affinities account for the differences in CYP1A induction potencies among these compounds. Thus, knowledge of either the EC50 for induction of CYP1A or the $\mathrm{K}_{\mathrm{i}}$ for a high-intrinsic efficacy agonist allows for close estimation of the other value. However, this method would overestimate $\mathrm{K}_{\mathrm{i}} \mathrm{s}$ for lower intrinsic efficacy ligands such as PCBs 156 and 118 .

There was also a strong correlation between binding affinities and EC50s for CYP1A-catalyzed EROD induction, which is consistent with earlier studies comparing binding in rat hepatic cytosol and EROD response in vivo and in H4IIE cells (Safe 1990). However, the 1:1 relationship found here between EC50s for induction of CYP1A protein does not hold true with EC50s for EROD induction, which would underestimate the true value of the $\mathrm{K}_{\mathrm{i}}$ for less potent agonists. This almost certainly is due to inhibition of the enzyme activity by the inducing compounds (Gooch et al. 1989; Hahn et al. 1993), which lowers EC50s for EROD induction relative to EC50s for CYP1A protein induction (Hahn et al. 1996b). For this reason, subsequent analyses and conclusions were drawn from data for induction of CYP1A protein, rather than activity.

Agonistic activity is a de facto demonstration of binding to a particular receptor site, but what of antagonists? Competitive inhibition of TCDD binding to the AHR was shown here for the two antagonists, PCBs 105 and 128. Inhibition curves like those shown in Figure 3 are often mistakenly held to be evidence of binding competition, but they cannot distinguish true competitive inhibition from other types (e.g. allosteric inhibition or irreversible inactivation). Demonstrating competitive binding inhibition requires the measurement of binding or response with several concentrations of ligand and inhibitor, followed by analysis by Schild regression, as was done here, or by doublereciprocal plots analogous to those used in enzyme inhibition studies.

\section{Understanding the Mechanistic Basis of Structure-Activity Relationships}

Previous studies have shown that in fish, ortho-substituted PCBs are inactive or nearly so in terms of both CYP1A induction (Gooch et al. 1989; Newsted et al. 1995; 
Hahn et al. 1996a) and toxicity (Walker et al. 1991; Zabel et al. 1995). This has led to differences in recommended toxic equivalency factors (TEFs) for these compounds in fish and mammals (van den Berg et al. 1998). The data here indicate that the insensitivity of fish to ortho-substituted PCBs is a result of both reduced affinity and reduced intrinsic efficacy of these compounds. Receptor binding $\mathrm{K}_{\mathrm{i}} \mathrm{s}$ were 10-100 fold greater for the ortho-substituted PCBs than for their structurally related non-ortho-substituted counterparts (i.e. PCB 126 vs. 156, 81 vs. 118 and 77 vs. 105). Comparing EC50s for CYP1A induction among PCBs with similar binding affinities (PCBs 118, 156 and 169) reveals the reduced intrinsic efficacy of the ortho-substituted congeners. Our data provide a mechanistic explanation for previous studies that have noted less than additive interactions for CYP1A induction by mixtures of TCDD and ortho-substituted PCBs both in vivo (Newsted et al. 1995) and in cultured cells (Clemons et al. 1998).

The results of this work also have general applicability. Properties of ligandreceptor interactions and tissue coupling have a large effect on measured relative potencies. Potency depends on both affinity and efficacy, and the TEF concept as currently used does not allow for differences in intrinsic efficacy among compounds. Low-intrinsic efficacy compounds will yield less than additive responses in mixtures with high intrinsic efficacy agonists (Figure 6). Furthermore, relative potencies from different endpoints and tissues have been used to determine TEFs. Coupling between the receptor and response can be different for these endpoints and tissues, leading to variability among measured responses. A partial agonist for one response or tissue could be a full agonist or an antagonist for another. Therefore, relative potencies are tissue- and endpointspecific.

Intrinsic efficacy spans a continuum between full agonism and full antagonism. Ligands with intrinsic efficacies spanning this range were found in the set of compounds studied here. PCBs 118, 156, and 169 have similar AHR binding affinities (Table 1), but produce very different responses. Although there was insufficient response to PCB 118 in this cell type to quantify a stimulus-response relationship, it is clear that the intrinsic efficacy of PCB 118 is less than that of PCB 156, which in turn has a lower intrinsic 
efficacy than PCB 169. Given that PCBs 105 and 128 have even lower binding affinities, it is possible that they are partial agonists rather than true antagonists, and that solubility limitations obscure their nature. However, given that limitation, in this cell type PCBs 105 and 128 are antagonists in practice, if not in theory.

\section{Stimulus-response Modeling for the Ah Receptor}

AHR binding assays traditionally have been performed using isolated cytosol, a system that preserves only a few of the subsequent signaling events. Two previous studies have approached the question of AHR ligand intrinsic efficacy using such in vitro systems. AHR binding and XRE mobility shift in isolated cytosol both were measured in a recent study of substituted flavones (Henry et al. 1999). This system allowed the authors to characterize the compounds' agonistic and/or antagonistic properties for events up to and including XRE binding, and thereby determine properties of ligand structure that affect those steps. Similarly, a study of several dioxin and furan congeners revealed a 10-fold range in receptor binding affinities, but a 100-fold range in EC50 values for XRE mobility shift, suggesting differences in intrinsic efficacy among those compounds (Santostefano et al. 1992).

While useful for characterizing ligand-receptor interactions, such in vitro systems lack a full assessment of stimulus-response relationships and coupling in a particular tissue (see below). Cultured cell assays are ideal for addressing molecular mechanisms of AHR signal transduction in a system that retains several aspects of biological relevance. A combination of AHR binding affinities measured in vitro and responses measured in vivo or in cultured cells could potentially be used to classify a compound as an agonist, partial agonist, or antagonist. However, since the concentrations of ligand, receptor, and signaling cofactors vary among the assays, a quantitative stimulus-response model for the tissue cannot be constructed. Our use of whole-cell binding and response assays obviates these complications and thus allows for construction of such a model.

An operational stimulus-response model (Black et al. 1983) was chosen for this study because the value $\mathrm{K}_{\mathrm{E}}$ has a definition that is easily related to the mechanism of 
AHR signaling. It should be noted that $\mathrm{K}_{\mathrm{E}}$ includes both compound- and tissue-specific properties (as well as species-specific properties, for cross-species comparisons). It is a combination of the intrinsic efficacy of the ligand (the ability to activate the receptor to a form that induces a response) and the coupling properties of the cell. In the case of the AHR, the latter could include a host of factors, including ARNT concentration, affinity of ARNT for the AHR-ligand complex, affinity of the AHR-ARNT dimer for the XRE, concentration and affinities of transcriptional cofactors, etc. The intrinsic efficacies of the ligands do not change among tissues within an organism, but the tissue-specific properties can, and therefore so will $\mathrm{K}_{\mathrm{E}}$ values. This is an important consideration in future efforts to expand modeling to the level of the organism. In this study the compounds were compared in the same cell type, so tissue-specific properties were constant and differences in $\mathrm{K}_{\mathrm{E}}$ values are due solely to differences in the intrinsic efficacies of the ligands.

\section{AHR Expression and Tissue Response}

The value of the operational model lies in its power to predict the effect of perturbations to the tissue. For example, several treatments have been reported to affect expression of the AHR, including phenobarbital (Okey and Vella 1984), PCB 153 (Denomme et al. 1986), TCDD (Sloop and Lucier 1987), TGF- $\beta$ (Dohr et al. 1997b), serum withdrawal (Vaziri et al. 1996), and loss of a transcriptional regulator (Zhang et al. 1996). The effect of the changes on tissue response to AHR agonists has been determined in some of these cases, but not all. A stimulus-response model for the tissue in question should be able to accurately predict the effect of such changes, since receptor concentration, $\mathrm{R}_{\mathrm{T}}$, is an element in the model (see equation 8 in Methods).

This model also reveals important aspects of signaling in the absence of perturbation, including the presence of spare receptors. The potential for "spare" or "reserve" AHR has been proposed, beginning with the finding that only a small fraction of the agonist-occupied AHR accumulates in the nucleus (Greenlee and Poland 1979). The $\sim 100$-fold difference between EC50 and $\mathrm{K}_{\mathrm{i}}$ for high-intrinsic efficacy ligands 
demonstrates the presence of spare receptors in this system. Our finding that only $1-2 \%$ of the AHR molecules need be occupied by high-intrinsic efficacy agonists for $50 \%$ CYP1A induction (Table 2) shows that PLHC-1 cells have spare receptors for this response. Even after a 3-fold reduction in receptor content, these compounds could still induce the same maximal level of CYP1A ( $\mathrm{R}_{95}$ values are less than $33 \%$; Table 2), although higher agonist concentrations would be required. Conversely, there is no receptor reserve for a $95 \%$ maximal response to $\mathrm{PCB} 156$, and thus any reduction in AHR content would make this compound a partial agonist. Similarly, differences in coupling could change the fraction of occupied receptors required for another response, eliminating receptor reserve even for high-intrinsic efficacy agonists. The magnitude of receptor reserve is therefore dependent on the agonist, tissue and response of interest.

In summary, the potency of AHR ligands to induce a response was separated into the properties of affinity and intrinsic efficacy, and the resulting values were used to build a stimulus-response model for AHR signal transduction in PLHC-1 cells. This work represents the first time that intrinsic efficacies of AHR ligands have been quantitatively determined. Stimulus-response models provide useful insights for $\mathrm{HAH}$ risk assessment and mechanisms of toxicity across the many endpoints currently under investigation. Expansion of these analyses to other species, tissues and responses should prove fruitful in studying AHR function and evolution. 
Chapter 5: Serum Withdrawal Reduces CYP1A Induction by TCDD in PLHC-1 Cells: A Link Between AHR Expression and Response

$\begin{array}{ll}\text { Abstract } & 121 \\ \text { Introduction } & 122 \\ \text { Materials and Methods } & 123 \\ \text { Results } & 126 \\ \text { Discussion } & 133\end{array}$




\begin{abstract}
Changes in expression of the aryl hydrocarbon receptor (AHR) have been documented in several systems and in response to a variety of treatments. Due to a relative lack of data regarding the effect of such changes on response to AHR ligands, the significance of these findings is unclear. We tested the ability of changes in serum used in cell culture medium to alter expression of the AHR and the subsequent induction of cytochrome P4501A (CYP1A) in PLHC-1 teleost hepatoma cells. Growth in serum-free medium for two days led to a loss of CYP1A inducibility by 2,3,7,8-tetrachlorodibenzo$p$-dioxin (TCDD). In contrast, growth in $10 \%$ delipidated calf serum increased levels of both CYP1A protein and enzymatic activity relative to controls grown in $10 \%$ complete calf serum. These effects were consistent between 8 and 24 hours post-treatment, indicating that the kinetics of induction were unaffected. Measurement of induction of CYP1A in cells grown in serum-free medium for 1 and 2 days demonstrated a progressive loss of inducibility. This loss of response was paralleled a time-dependent loss of AHR protein, as measured by specific binding of ${ }^{3} \mathrm{H}-\mathrm{TCDD}$. Using an operational model for AHR action in PLHC-1 cells, the measured reduction in AHR could be shown to account for the changes in induction of CYP1A. Expression of AHR protein was unaffected by growth in 10\% delipidated serum. These phenotypes were found in only a limited subset of PLHC-1 cells, and only in early-passage cells. Expression of AHR protein in late-passage cells was unaffected by serum withdrawal and matched that in early-passage cells grown in $10 \%$ serum. Comparison of early- and late-passage cells revealed a 2 -fold greater rate of proliferation in the latter, suggesting a growth advantage is coincident with loss of serum-dependent expression of AHR. These results provide a quantitative link between changes in receptor expression and a downstream response, pointing the way for future studies of receptor expression and sensitivity to toxic responses in vitro and in vivo.
\end{abstract}




\section{INTRODUCTION}

The aryl hydrocarbon receptor (AHR) mediates the toxicity of 2,3,7,8tetrachlorodibenzo- $p$-dioxin and structurally related compounds. Several treatments have been reported to affect expression of the AHR, including phenobarbital (Okey et al. 1984), ortho-substituted PCBs (Denomme et al. 1986; [Landers, 1991 \#436]), TCDD (Sloop et al. 1987), TGF- $\beta$ (Dohr et al. 1997b), serum withdrawal (Vaziri et al. 1996), and loss of a transcriptional regulator (Zhang et al. 1996). The effect of changes in AHR expression on tissue response to AHR agonists has been determined in only a few of these cases, and in some is complicated by effects on the response that are not connected to AHR expression (Dohr and Abel 1997a). Determining factors affecting AHR expression is important, but alone such analyses are incomplete. The in vivo significance of altered AHR expression will ultimately depend on how responses, and thus the toxicity of AHR agonists, are impacted.

Serum withdrawal reduces AHR expression 4 to 10 -fold in Swiss $3 T 3$ murine fibroblasts (Vaziri et al. 1996), apparently by down-regulation of a tyrosine kinase. We wished to determine if such regulation of AHR expression was present in other cell types and to measure the impact of a decline in receptor on a downstream response. Induction of cytochrome P4501A (CYP1A) is a response to AHR agonists that is both well characterized and common throughout most of the vertebrate subphylum (Stegeman and Hahn 1994; Whitlock 1999), making it the logical choice for study.

In this study, receptor expression and induction of CYP1A were measured in PLHC-1 cells, derived from a hepatocellular carcinoma of the teleost Poeciliposis lucida (Hightower et al. 1988). Binding of TCDD to the AHR and induction of CYP1A have been measured in this cell line (Chapters 3 and 4), and a mathematical model of the stimulus-response relationship for this system has been developed. This allows receptor expression and consequent response to be modeled quantitatively, facilitating testing of hypotheses. 
We have also previously reported that serum in cell culture medium alters the uptake and apparent potencies of AHR ligands (Hestermann et al, in press). Another goal of this study was to determine the effects of longer-term growth in those serum treatments, and to separate the effect of serum on ligand uptake from effects on cell physiology. Therefore, in these experiments cells were grown in media containing different serum treatments but treated with ligands in a common medium in order to remove effects of serum on uptake.

We report that growth of PLHC-1 in serum-free medium results in a progressive decline of both AHR expression and CYP1A inducibility. In contrast, growth in medium containing $10 \%$ delipidated serum increased maximal levels of CYP1A without changing the potency of induction by TCDD. This increase was not correlated with a change in AHR expression. Both of these phenotypes were variable with regard to sub-clone and time in culture of the PLHC-1 cell line.

\section{MATERIALS AND METHODS}

\section{Chemicals and solutions}

The 2,3,7,8-tetrachloro[1,6- $\left.{ }^{3} \mathrm{H}\right]$ dibenzo- $p$-dioxin $\left(\left[{ }^{3} \mathrm{H}\right] \mathrm{TCDD}\right.$, purity $\geq 97 \%$, specific activity $27 \mathrm{Ci} / \mathrm{mmol}$ ) was obtained from Chemsyn Science Laboratories (Lenexa, KS). TCDD and 2,3,7,8-tetrachlorodibenzofuran (TCDF) were obtained from Ultra Scientific (Kingston, RI). Peroxidase conjugated goat anti-mouse IgG was from Schelicher and Schuell (Keene, NH). Luminescent peroxidase substrate was from Tropix (Bedford, MA). Resorufin and ethoxyresorufin were from Molecular Probes (Eugene, OR). All other reagents were obtained from Sigma (St. Louis, MO).

Phosphate-buffered saline (PBS) is $0.8 \% \mathrm{NaCl}, 0.115 \% \mathrm{Na}_{2} \mathrm{HPO}_{4}, 0.02 \% \mathrm{KCl}$, $0.02 \% \mathrm{KH}_{2} \mathrm{PO}_{4}$, $\mathrm{pH}$ 7.4. Phosphate buffer is $50 \mathrm{mM} \mathrm{Na}_{2} \mathrm{HPO}_{4}$ with $\mathrm{pH}$ adjusted to 8.0 with $50 \mathrm{mM} \mathrm{NaH}_{2} \mathrm{PO}_{4}$. Sample treatment buffer is $0.25 \mathrm{M}$ Tris-HCL, pH $6.8,40 \%(\mathrm{v} / \mathrm{v})$ glycerol, $4 \%(\mathrm{w} / \mathrm{v})$ sodium lauryl sulfate, $0.008 \%(\mathrm{w} / \mathrm{v})$ bromphenol blue, and $5 \%(\mathrm{v} / \mathrm{v})$ 
2-mercaptoethanol. TCDD, TCDF, and PCB solutions were prepared in dimethyl sulfoxide (DMSO) as described previously (Hahn et al. 1996b). Concentrations of $\left[{ }^{3} \mathrm{H}\right]$ TCDD solutions were verified by liquid scintillation counting (LSC) on a Beckman LS5000TD.

\section{Growth and Treatment of Cells}

PLHC-1 cells (Hightower et al. 1988) were grown at $30^{\circ} \mathrm{C}$ in minimum essential medium (MEM) containing Earle's salts, nonessential amino acids, L-glutamine and 10\% calf serum (Sigma C6278, lot 106H4628), as described previously (Hahn et al. 1993). One day prior to dosing, cells were suspended to 0.5 to $1 \times 10^{6}$ per $\mathrm{ml}$ and seeded into 48 or 96-well plates (Costar; Cambridge, MA) at 0.5 or $0.2 \mathrm{ml}$ per well, respectively. For TCDD specific binding experiments, cells were seeded into 24-well plates (Corning; Corning, NY) at $2 \times 10^{6}$ cells in $1 \mathrm{ml}$ culture medium per well. One day later the medium was removed and replaced with fresh medium. Media used in the experiments include MEM without serum, with $10 \%$ serum, with $10 \%$ delipidated, charcoal stripped calf serum (Sigma C1696), and with 10\% fetal bovine serum (FBS; Gibco; Grand Island, NY). After 2 days, the medium was changed to MEM $+10 \%$ calf serum and the cells were treated with TCDD dissolved in DMSO or DMSO alone $(2.5$ or $1.0 \mu 1 /$ well). DMSO concentrations were $\leq 0.5 \%(\mathrm{v} / \mathrm{v})$ in all treatments. Following treatment, plates were incubated at $30^{\circ} \mathrm{C}$ for 24 hours unless otherwise indicated. With the exception of the delipidated serum and FBS, all serum used was from a single lot. None of the treatments reduced cell viability, as assessed by Trypan Blue exclusion.

\section{EROD and protein assays}

EROD activity was measured using a multiwell fluorescence plate reader by a modification of the method of Kennedy et al (1995). Volumes given are for 48-well lates; halve for assays in 96-well plates. Cells were rinsed once with room temperature PBS and the EROD reaction was then initiated with the addition of $2 \mu \mathrm{M} 7$ ethoxyresorufin in phosphate buffer $(200 \mu 1 /$ well). The reaction was stopped after eight 
minutes (resorufin production is linear with respect to time over this period; Hahn et al. $1996 \mathrm{~b})$ with the addition of $150 \mu \mathrm{l}$ ice-cold fluorescamine solution $(0.15 \mathrm{mg} / \mathrm{ml}$ in acetonitrile). After a fifteen minute incubation, resorufin and fluorescamine fluorescence were measured. Resorufin and protein concentrations were determined from standard curves prepared in the same plate. BSA was used for the protein standard curve. In some experiments, the EROD reaction was followed kinetically over eight minutes, as described previously (Hahn et al. 1996b). Protein was measured using fluorescamine as described above.

\section{Measurement of CYP1A Protein}

CYP1A protein was measured by immunblotting of whole cell lysates, essentially as described (Hahn et al. 1996b). Cells grown and treated in 48-well plates were solubilized at $4^{\circ} \mathrm{C}$ for 15 minutes in $100 \mu 1$ sample treatment buffer, with gentle agitation. Lysates were transferred to tubes and boiled 5 minutes to complete solubilization and inactivate proteases.

Samples and CYP1A standards (purified CYP1A from scup, Stenotomus chrysops) were analyzed by denaturing gel electrophoresis on $8-12 \%$ acrylamide gradient minigels (Novex, San Diego, CA). $25 \mu$ of each sample (equivalent to $15 \mu \mathrm{g}$ protein) was used. Proteins were electrophoretically transferred onto $0.2 \mu \mathrm{m}$ nitrocellulose and incubated sequentially with blocking solution (Schleicher and Schuell), monoclonal antibody 1-12-3 (anti-scup CYP1A, Park et al. 1986) at $1 \mu \mathrm{g} / \mathrm{ml}$, and alkaline phosphatase conjugated goat anti-mouse IgG at 1:5000 dilution. Following each antibody incubation, membranes were 3 times each with tris-buffered saline and water. Color was developed by enhanced chemiluminescence as directed by the supplier (Tropix) using Kodak X-AR film. Images were acquired with a Kodak DCS200 digital camera and Adobe Photoshop, and band intensities were quantified by densitometry using NIH Image software. Values for CYP1A equivalents were determined from a standard curve using the scup CYP1A. 


\section{TCDD Binding}

Specific binding of $\left[{ }^{3} \mathrm{H}\right] \mathrm{TCDD}$ in PLHC-1 cells was measured by a whole-cell filtration assay (Dold et al. 1990). One day after seeding in 24-well plates, the cells were fed $1 \mathrm{ml}$ of the indicated media. Two days later the medium was changed to $0.5 \mathrm{ml}$ of $\mathrm{MEM}+10 \%$ calf serum, and cells were treated with $1 \mathrm{nM}\left[{ }^{3} \mathrm{H}\right] \mathrm{TCDD}$ in the presence or absence of $200 \mathrm{nM}$ TCDF and incubated 2 hours at $30^{\circ} \mathrm{C}$. This time was determined to be sufficient to achieve a steady state of bound radioligand (Appendix B). Following the incubation, medium was removed, cells were rinsed with $0.5 \mathrm{ml}$ ice-cold PBS, and then detached with $0.5 \mathrm{ml}$ trypsin. The trypsin was inactivated by the addition of $0.5 \mathrm{ml}$ icecold culture medium (with 10\% serum), and cells from each well were collected under vacuum on a $25 \mathrm{~mm}$ Whatman GF/F filter that had been prewetted with PBS. Filters were then washed four times with $2.5 \mathrm{ml}$ acetone that had been precooled to $-80^{\circ} \mathrm{C}$. Replicates were processed in batches of twelve on a Millipore 1225 filter manifold. Radioactivity remaining on the filter was quantified by LSC. Specific binding was measured in triplicate as the difference of each of three total binding (without TCDF) replicates and the average of three nonspecific binding (with TCDF) replicates in each medium. Protein concentrations were determined in duplicate wells fed each medium and treated with DMSO alone.

\section{RESULTS}

\section{Effect of Growth Medium on CYP1A Inducibility}

PLHC-1 cells were grown for two days in one of three media: serum-free MEM $\left(\mathrm{S}_{0}\right)$, MEM with $10 \%$ calf serum $\left(\mathrm{S}_{10}\right)$, or MEM with $10 \%$ delipidated calf serum $\left(\mathrm{S}_{\mathrm{DL}}\right)$. Then the medium was changed to $S_{10}$ (to insure equal kinetics of TCDD uptake Hestermann et al. in press) and the cells were treated with TCDD. EROD activity was assayed 24 hours later (Figure 1). Growth in $\mathrm{S}_{0}$ abolished induction of EROD by TCDD, 


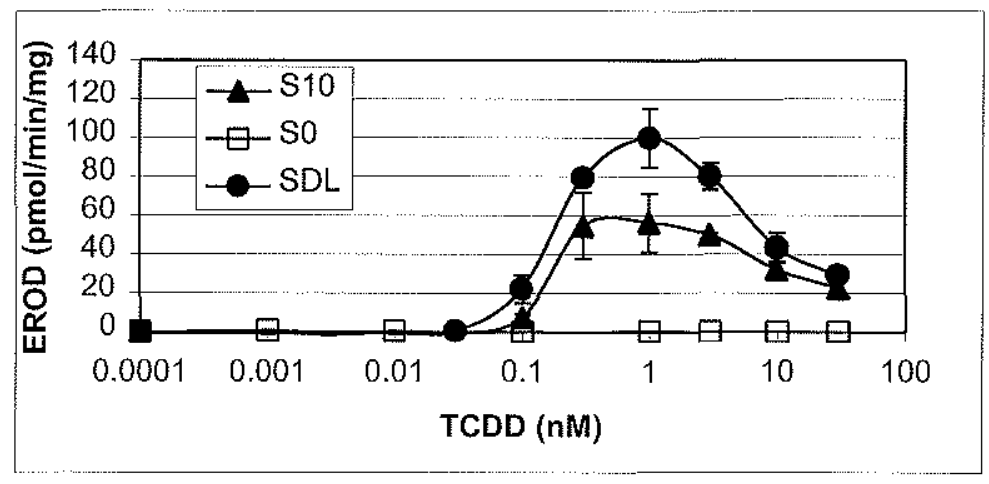

Figure 1. Effect of growth medium on EROD inducibility by TCDD. PLHC-1 were seeded in 48-well plates and grown for two days in the medium indicated in the legend. The medium was then changed to $S_{10}$, and cells were treated with TCDD. EROD activity was assayed 24 hours later. Points are means \pm standard error of triplicate wells.
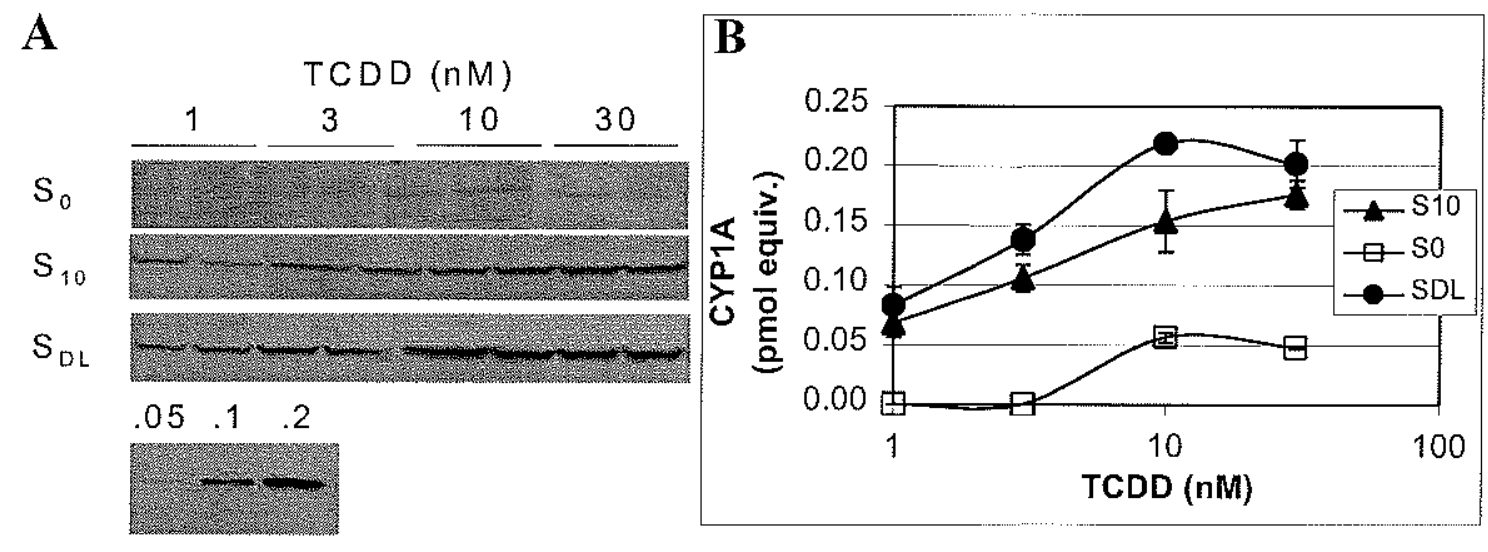

Figure 2. Effect of growth medium on CYP1A protein induction. Cells were grown and treated as in Figure 1. Cell lysates were harvested 24 hours after treatment with TCDD and analyzed by SDS-PAGE and immunoblotting with mAb 1-12-3. (A) Digital image of blot with medium and TCDD treatments indicated. The bottom row shows scup CYP1A standards with pmol amounts indicated. (B) Integrated densities of individual bands were converted to CYP1A equivalents. Points are mean \pm standard error of duplicate samples. 
and growth in $S_{D L}$ led to a significant increase in induction relative to $S_{10}$. Growth in $10 \%$ FBS led to similar increases over the activity seen in $10 \%$ calf serum (not shown).

These results were confirmed at the level of CYP1A protein expression by immunoblot (Figure 2). At doses of TCDD below $1 \mathrm{nM}$ the levels of CYP1A were undetectable by this method. At higher doses of TCDD the trend follows the results with EROD activity, i.e. greater induction with cells grown in $S_{D L}$ than in $S_{10}$, and little or no induction with cells grown in $\mathrm{S}_{0}$.

In order to determine if the different media were having an effect on the timing of CYP1A induction, EROD was measured from 8 to 24 hours after treatment (Figure 3). Induction of EROD was measurable by 8 hours in cells previously grown in $\mathrm{S}_{10}$ or $\mathrm{S}_{\mathrm{DL}}$, and rates continued to increase until 16-20 hours after treatment. Rates decreased slightly from this maximum at 24 hours. In contrast, no induction was measured in cells grown in $\mathrm{S}_{0}$ at any point up to 24 hours post-treatment.

\section{Timing and Mechanism of Loss of Inducibility}

Cells were grown in $\mathrm{S}_{10}, \mathrm{~S}_{0}$, or $\mathrm{S}_{\mathrm{DL}}$ for 1 or 2 days, changed to $\mathrm{S}_{10}$, and treated with TCDD. EROD activity was measured 20 hours later (Figure 4). After a single days' growth in $\mathrm{S}_{0}$, the EC50 for induction of EROD had increased about 10-fold as compared to cells in $S_{10}$, but the maximum level of induction was unchanged (Figue 4A). After two days, the EC50 increased further, and the maximal level of induction was lower than that observed after one day in $\mathrm{S}_{0}$. In contrast to previous results (Figure 1), a small amount of induction was observed after two days of growth in $\mathrm{S}_{0}$ (Figure $4 \mathrm{~B}$ ). Subsequent experiments showed similar subtle variability in the kinetics of loss of inducibility.

The progressive decline in inducibility could be due to a time-dependent loss of AHR protein or function. Levels of AHR protein were measured by specific binding of ${ }^{3} \mathrm{H}-\mathrm{TCDD}$ in PLHC-1 cells grown in the different media for 1 or 2 days (Figure 5). After two days, the amount of AHR in cells grown in $\mathrm{S}_{0}$ showed a significant decrease as compared to cells grown in $\mathrm{S}_{10}$ or $\mathrm{S}_{\mathrm{DL}}$ (Figure $5 \mathrm{~A}$ ). The decrease was time-dependent; a significant reduction was already present after one day of growth in $\mathrm{S}_{0}$. After two days, 


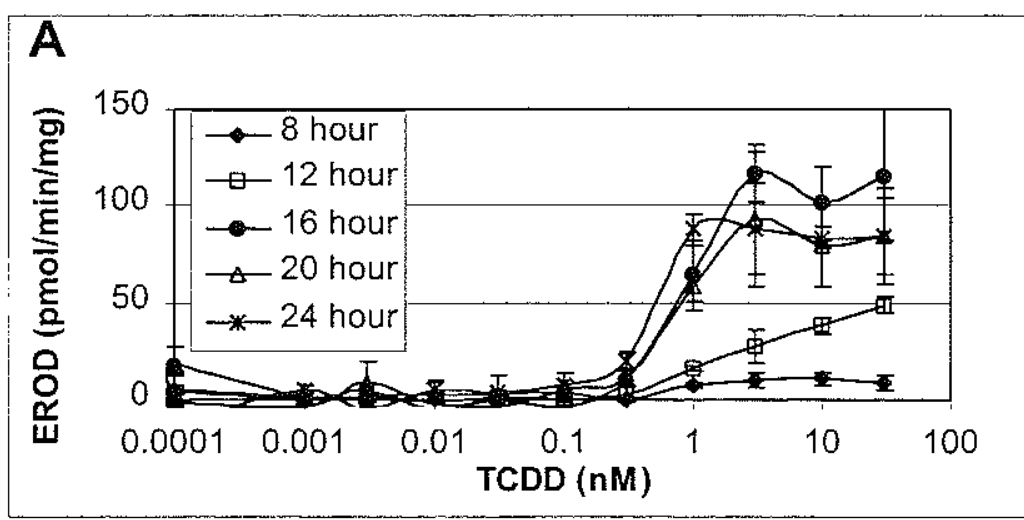

$\mathrm{S}_{10}$

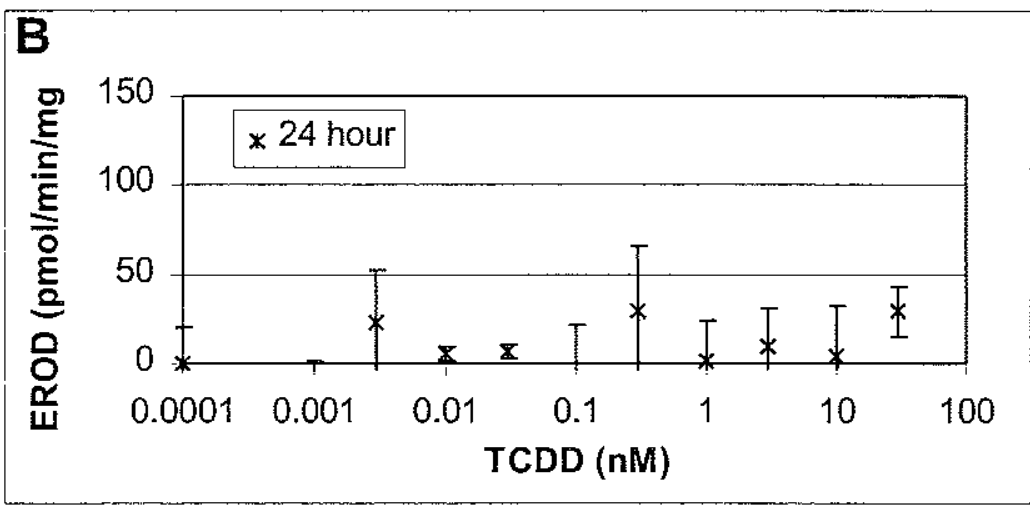

$\mathrm{S}_{0}$

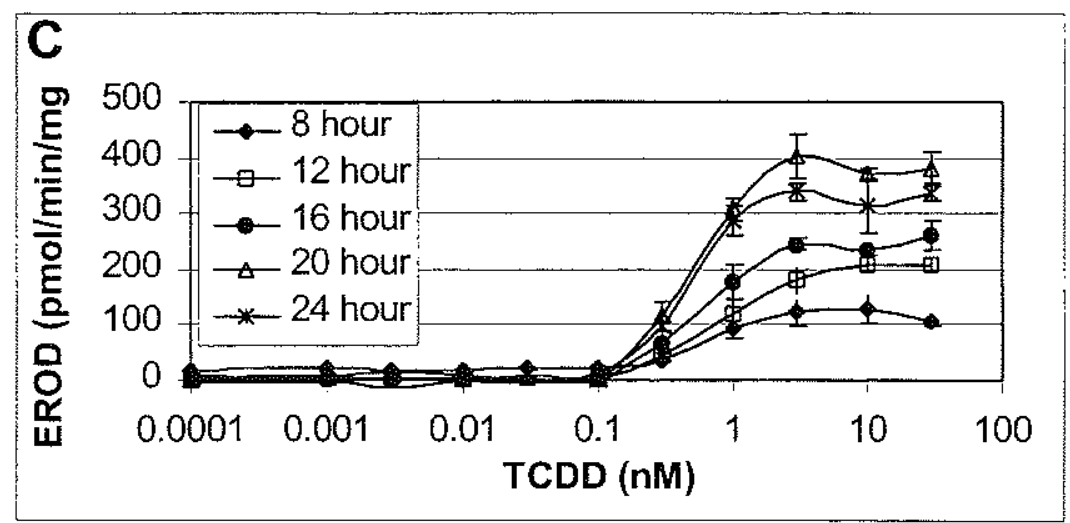

$\mathrm{S}_{\mathrm{DL}}$

Figure 3. Time course of induction of EROD activity. PLHC-1 cells were grown and treated as in Figure 1, and EROD activity was assayed at the indicated times after TCDD treatment. Points are means \pm standard error of triplicate wells. Cells were grown in (A) $\mathrm{S}_{10},(\mathrm{~B}) \mathrm{S}_{0}$ or $(\mathrm{C}) \mathrm{S}_{\mathrm{DL}}$. 

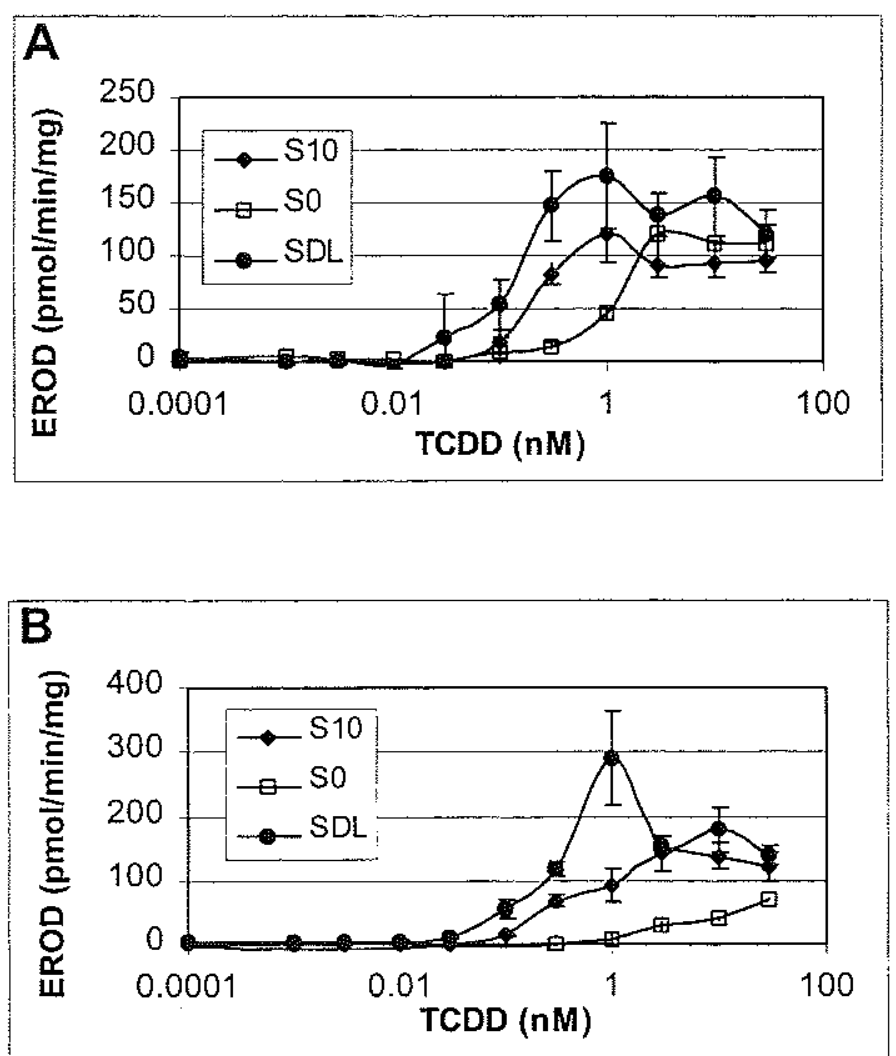

Figure 4. Effect of 1 or 2 days of growth in different media. Cells were grown, treated and assayed as in Figure 1, except that medium change and treatment took place after (A) one or (B) two days of growth in the indicated media. Points are means \pm standard error of triplicate wells. 

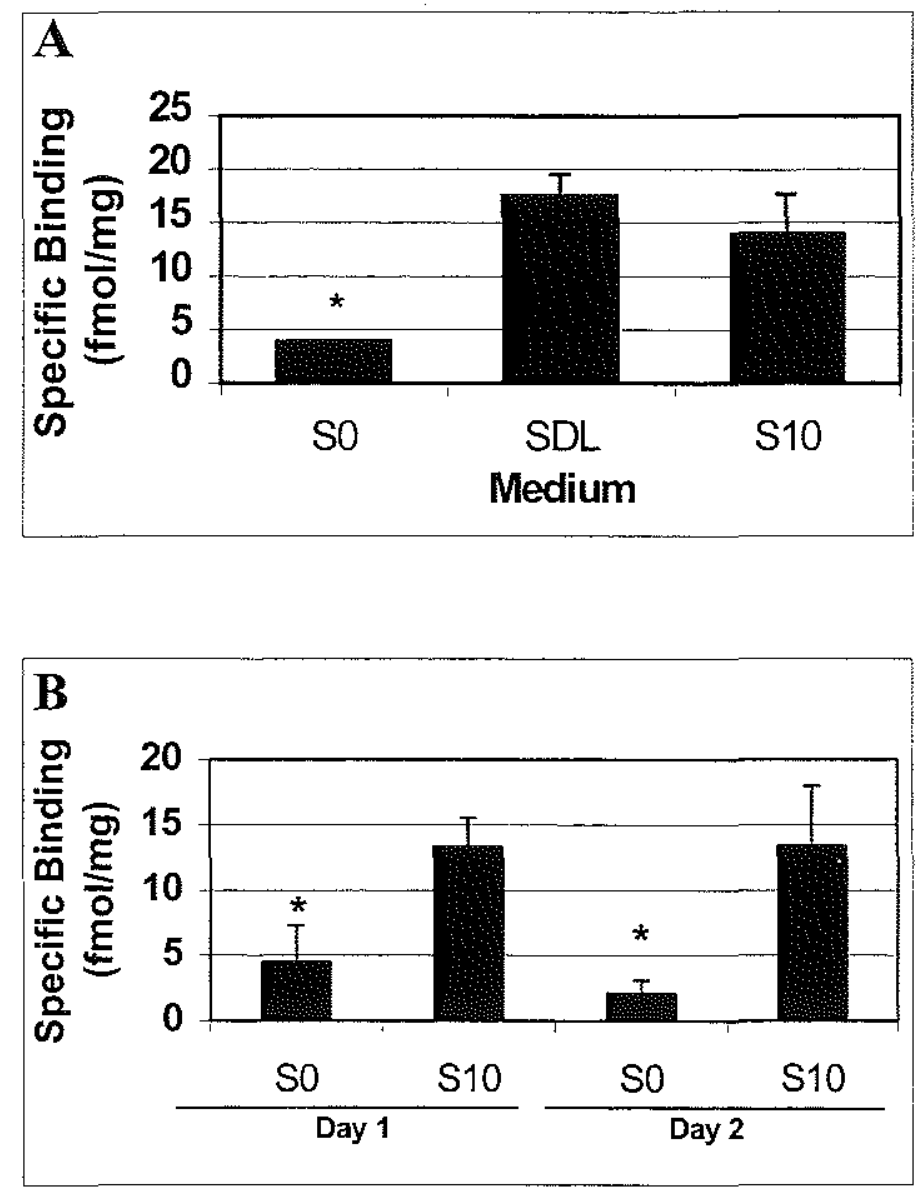

Figure 5. Effect of growth medium and time on AHR expression. PLHC-1 were grown in the indicated media, changed to $S_{10}$, and incubated with $1 \mathrm{nM}^{3} \mathrm{H}-\mathrm{TCDD}$ in the presence or absence of $200 \mathrm{nM}$ TCDF for two hours. ${ }^{3} \mathrm{H}$-TCDD binding was measured by a whole-cell filtration assay (Dold et al. 1990). Specific binding is shown as the average + standard error of three replicates. * indicates significantly less specific binding than cells in $S_{10}(p<0.01 ; t$-test $)$. (A) Cells were grown in the indicated media for two days prior to assay. (B) Cells were grown for one or two days. 

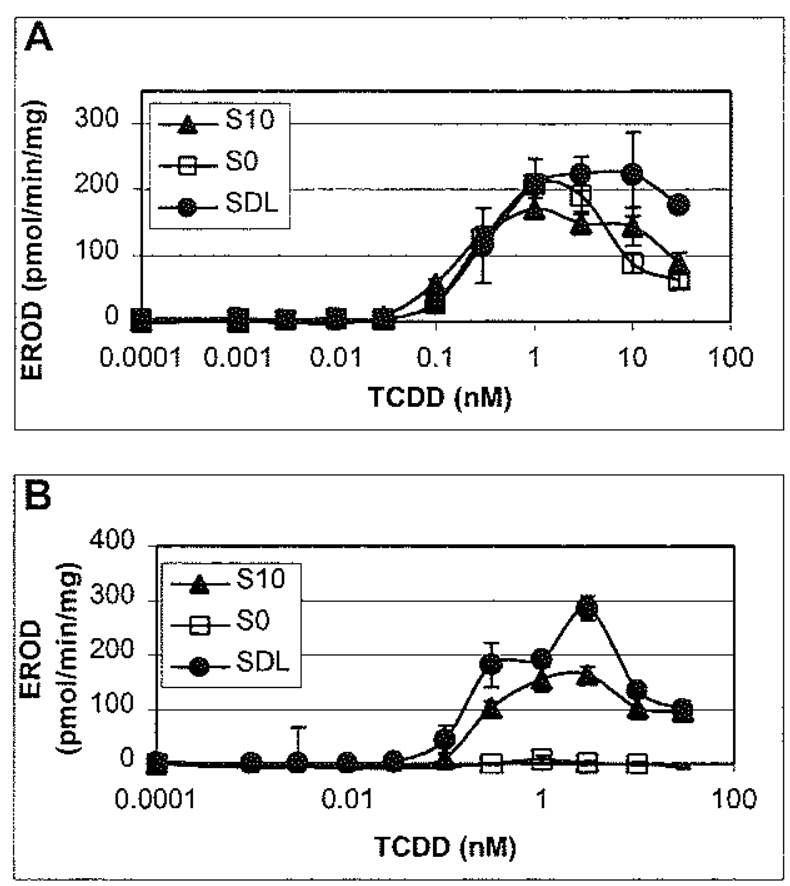

Figure 6. Response of early (15) and late (44) passage cells to growth medium. Cells were grown, treated and assayed as in Figure 1. (A) Late-passage cells. (B) Early passage cells.

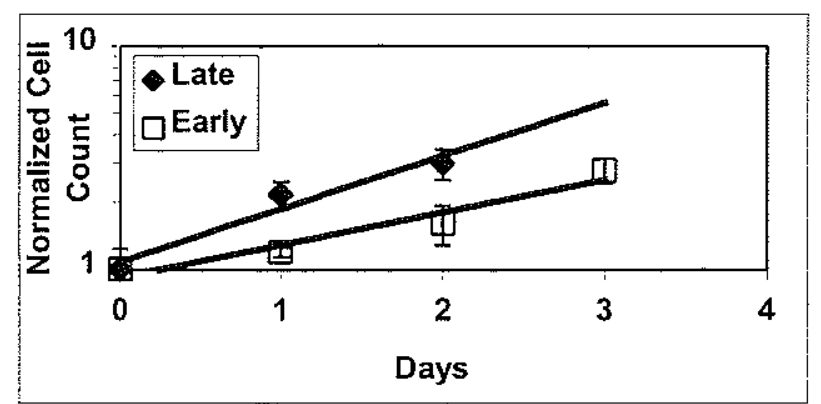

Figure 7. Proliferation in early- and late-passage cells. Early (15) and late (44) passage PLHC-1 cells were seeded in $25 \mathrm{~cm}^{2}$ flasks at $2.4 \times 10^{5} / \mathrm{cm}^{2}$ and grown in $\mathrm{S}_{10}$. Cells were counted at daily intervals with a hemacytometer. Counts were normalized to the value on day 0 , and are means \pm standard error for triplicate flasks. Exponential fits are shown (proliferation had stopped in late-passage cells by day 3 ), and the predicted doubling times are 30 and 50 hours for late- and early-passage cells, respectively. 
specific binding was barely detectable (Figure 5B). Interestingly, there was no difference between AHR content in cells grown in $\mathrm{S}_{10}$ and $\mathrm{S}_{\mathrm{DL}}$ (Figure 5A).

\section{Passage and Sub-clone Effects}

The phenomena of AHR down-regulation and loss of inducibility were detectable only in a limited set of PLHC-1 sub-clones, and did not persist beyond 30 passages. Later-passage cells treated and assayed with early-passage cells revealed no significant differences in induction of EROD, regardless of growth medium (Figure 6). The transition between the phenotypes depicted in Figure 6 (termed "early" and "late" passage) was abrupt; typically, only three passages separated the responses shown in the same sub-clone of cells. In order to address a possible mechanism for this change, rates of proliferation for early- and late-passage cells were determined (Figure 7). Latepassage cells proliferated at nearly twice the rate of early-passage cells.

\section{DISCUSSION}

This report explores the connection between AHR expression and cellular responses to AHR agonists. We have demonstrated a loss of inducibility of CYP1A in early-passage PLHC-1 grown in serum-free medium for two days. Cells grown in medium with $10 \%$ delipidated serum showed an increase in maximal level of induction over cells grown in the typical $10 \%$ calf serum. Neither the loss in $\mathrm{S}_{0}$ nor the increase in $\mathrm{S}_{\mathrm{DL}}$ was due to a change in the kinetics of induction. The loss of inducibility paralleled a loss of AHR over the same period. These effects were witnessed in early- but not latepassage PLHC-1.

The results presented also demonstrate that the effect of serum on ligand uptake (Hestermann et al, in press) can be separated from other effects on induction of CYP1A. Cells grown in $S_{0}$ or $S_{D L}$ and returned to $S_{10}$ for short-terms ( $\leq 24$ hours) of ligand exposure exhibited induction properties different from those of cells grown in $\mathrm{S}_{10}$. This 
suggests that the mechanisms of the observed effects involve changes in protein expression or another relatively slow (i.e. several hours to days) response, rather than changes in ion flux, enzyme activity, or similarly quick (i.e. minutes to hours) response.

\section{Loss of CYPIA Inducibility and Receptor Expression}

The loss of inducibility of EROD after two days in $\mathrm{S}_{0}$ was complete, but a small amount of CYP1A protein expression was still seen in cells treated with large doses of TCDD ( $\geq 10 \mathrm{nM}$; Figures 1 and 2). At high concentrations, the inducing compound will also act as an inhibitor of EROD (Gooch et al. 1989; Hahn et al. 1993; Petrulis et al. 1999), so the enzymatic activity of the small amount of CYP1A present would not be evident. Thus, it is possible that in other experiments (e.g. Figure 4B) greater amounts of CYP1A are present in the cells treated with high concentrations of TCDD than is apparent from the measured EROD activity. However, since the overall effect of inhibition is to decrease apparent EC50s relative to CYP1A protein induction, small losses in inducibility (which increase EC50; Figure 4) could be masked by inhibition.

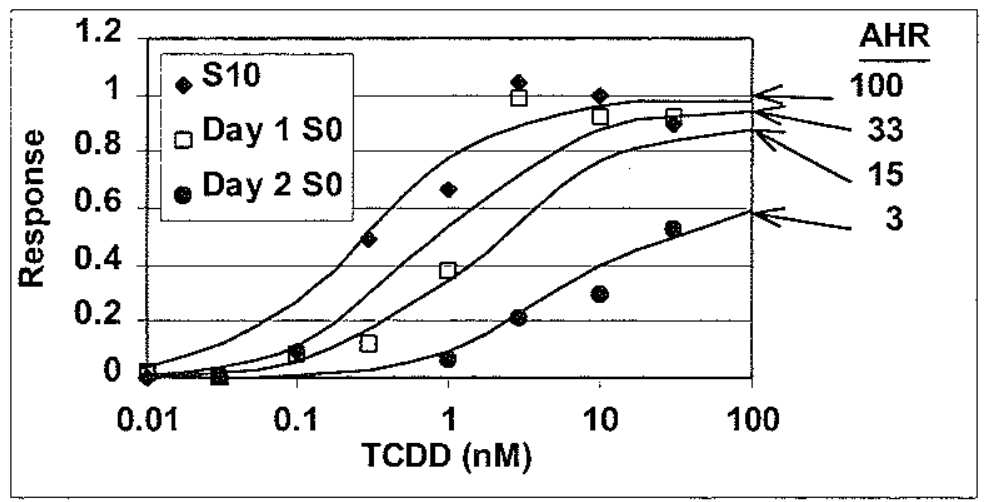

Figure 8. Influence of receptor number on induction of CYP1A. EROD data from Figure 4 (points) are shown with induction curves (lines) predicted at various levels of AHR expression. Predicted responses were calculated from the following equation, with $\mathrm{R}_{\mathrm{T}}=110 \mathrm{fmol} / \mathrm{mg}$ at $100 \% \mathrm{AHR}, \mathrm{K}_{\mathrm{D}}=15 \mathrm{nM}$ and $\mathrm{K}_{\mathrm{E}}=2 \mathrm{fmol} / \mathrm{mg}$ :

$$
\frac{E_{a}}{E_{m}}=\frac{\left[R_{T}\right] \times[A]}{K_{d} \times K_{E}+\left(\left[R_{T}\right]+K_{E}\right)[A]}
$$


The decline in inducibility of CYP1A protein and activity paralleled a decline in specific binding of ${ }^{3} \mathrm{H}$-TCDD, and presumably AHR protein expression. With the operational model of AHR function developed in the previous chapter, it is possible to predict the effects of changes in receptor content on measured responses. Figure 8 shows the EROD induction data from Figure 4 superimposed on predicted curves for different levels of AHR expression. The EROD activities have been normalized to the maximal values in cells grown in $\mathrm{S}_{10}$ for each day. The AHR content in cells grown in $\mathrm{S}_{0}$ was 33\% of that in cells grown in $\mathrm{S}_{10}$ after one day, and 15\% after two days (Figure 5).

Induction curves predicted by the model for full AHR expression and for a 3-fold reduction in AHR fit the induction data from $S_{10}$ and one day in $S_{0}$ very well. However, a $\sim 30$-fold decline in AHR is necessary to bring the predicted curve in alignment with the induction data from day 2. Because the receptor content measured after two days in $\mathrm{S}_{0}$ is near the limit of detection, a 30 -fold reduction is not significantly different from the measured value. Again, inhibition of EROD activity could also account for some of the difference seen between the actual induction and that predicted for $15 \%$ of normal AHR expression.

Another possibility is that a fraction of the AHR present is able to bind ligand but not competent to induce CYP1A. In this context, correlation of loss of inducibility with reduced AHR expression suggests a mechanism for the lack of induction of CYP1A, but does not exclude regulation after ligand binding. Nuclear translocation, ARNT dimerization, XRE binding, and recruitment of transcriptional co-activators remain as possible sites of regulation. Given this caveat, the most parsimonious explanation for the observed data remains a direct effect of loss of receptor protein on downstream responses.

This analysis provides a link between measured changes in AHR expression and function. Similar differences in response have been noted between wild type and reduced AHR mutants of HEPA-1 cells (Karenlampi et al. 1988; Zhang et al. 1996), where reductions in AHR content were correlated with increases in EC50 and reduced maximal induction of CYP1A1. The phenotype of one of the mutants was unstable (Karenlampi et 
al. 1988), and CYP1A1 inducibility increased over time in culture, which is also similar to the results seen here. The source of reduced AHR expression in that system was selection for mutants deficient in CYP1A1 inducibility rather than a transient treatment like that used here, so the mechanisms of reduced expression and changes in phenotype are likely different.

We have previously demonstrated the existence of "spare" receptors for induction of CYP1A by TCDD in PLHC-1 cells (Chapter 4). The presence of spare receptors implies that a small reduction in receptor content will increase the EC50 for the response, but not significantly decrease the maximal level of induction. A larger decrease in receptors will further increase the EC50 and reduce maximal response (Appendix C). This had not been demonstrated experimentally before the results presented here.

\section{Increased CYP1A Induction in PLHC-1 Cells Grown in Delipidated Serum}

No change in receptor expression was seen after growth in $S_{\mathrm{DL}}$ as opposed to $\mathrm{S}_{10}$ (Figure 5), and increases in receptor content would not be expected to increase the maximal level of response (Appendix C). Thus, the increased induction of CYP1A protein and activity after growth in $\mathrm{S}_{\mathrm{DL}}$ must be the result of another mechanism. Since the EC50 of induction was not changed by growth in $\mathrm{S}_{\mathrm{DL}}$, any proposed mechanism must affect signaling following binding of ligand to the AHR.

The increased induction of CYP1A observed here in cells grown in $\mathrm{S}_{\mathrm{DL}}$ is reminiscent of the potentiation of induction previously observed upon co-treatment of PLHC-1 cells with AHR agonists and glucocorticoid receptor (GR) agonists (Celander et al. 1996; Celander et al. 1997). The former study found increased expression of CYP1A when cells were treated with dexamethasone and TCDD versus TCDD alone. Potentiation was also observed with the hormonal GR agonists cortisol and prednisone, and was inhibited by GR antagonists. The potentiation of induction ranged from 2-20 fold, depending on doses of each compound used, and showed variability between experiments, as was seen here (compare maximal EROD rates for cells grown in $\mathrm{S}_{\mathrm{DL}}$ in Figures 1 and 3). Such potentiation has been shown to involve increased rate of CYP1A 
mRNA transcription, and has been hypothesized to involve binding of the GR to response elements in the CYP1A promoter (Mathis et al. 1989).

Another possible mechanism is the loss of transcriptional "squelching" in cells grown in $\mathrm{S}_{\mathrm{DL}}$. Squelching is the process in which activated receptors compete for a limited supply of co-activators (Prywes and Zhu 1992; Cahill et al. 1994), and is well established for steroid hormone receptors. According to the supplier (Sigma), their process for removal of lipids from serum does remove cholesterol, and likely steroid hormones as well. Thus, removal of steroid hormones would reduce activation of their receptors, leading to an increase in co-activators available for the AHR. The switch from $\mathrm{S}_{\mathrm{DL}}$ to $\mathrm{S}_{10}$ for AHR agonist exposure complicates this hypothesis, since steroid hormones would be reintroduced at the time of TCDD treatment. Thus, this hypothesis depends on the kinetics of activation of the various receptors.

\section{Effects of Passage Number and Sub-Clone}

The phenomena reported here did not occur in all of the sub-clones of PLHC-1 we studied, and did not persist beyond 30 passages in the sub-clones where they were present. Figure 7 shows that the late-passage cells have a growth advantage over earlypassage cells. Whether this is a transition that the entire population of cells makes or an increase in the relative numbers of a sub-population is unclear. If the latter hypothesis is true then this provides another link between cell proliferation and AHR function, because a sub-population of cells with faster proliferation also shows the loss of a control on AHR. expression.

The lack of differences in inducibility seen in some sub-clones even at very early passages (e.g. passage 10) suggests that heterogeneity may have existed in the parent line. The term sub-clone is even somewhat misleading for this cell line, because PLHC-1 cells do not proliferate at low densities, so no population is truly clonal. The apparent heterogeneity is consistent with earlier results (Chapter 2) showing differences in the effects of TCDD on cell proliferation. 
In summary, a lack of inducibility of CYP1A in cells grown in serum-free medium has been connected to a concurrent loss of AHR. The operational model of AHR signaling developed previously has been used to show that responses measured at intermediate points of AHR expression are consistent with our understanding of the relationship between receptor levels and downstream responses. Future work should focus on comparing several different responses to determine how changes in receptor expression and tissue coupling may influence sensitivity to AHR ligands. 
Chapter 6: Conclusions and Future Directions 
This work demonstrates the power and utility of PLHC-1 cells for addressing questions of Ah receptor function. Several methods and tools have been developed for use in future studies, enabling the reported studies to unlock the potential of these cells. Cross-talk between AHR and other signaling pathways previously demonstrated in mammals were extended to a new class of organisms, and aspects of AHR function that were previously unexplored in any system have been elucidated. In this chapter those individual results will be placed into a wider context, and future work toward which they point will be proposed.

\section{Interactions between AHR Signaling and Cell Proliferation}

The early goals of this research revolved around exploring interactions among signal transduction pathways involving the AHR, progression through the cell cycle, and cell proliferation. As was discussed in the Introduction, there are several provocative hints indicating that interactions among these pathways occur at the molecular level, but a clear understanding is lacking. If these interactions are a crucial aspect of AHR function, then it can be expected that they have been maintained through much, if not all, of the evolutionary history of this receptor. By comparing the shared and distinct features of such interactions among organisms, it will be possible to formulate hypotheses regarding that history.

PLHC-1 cells were evaluated as a teleost model for exploring such interactions. Several pieces of information necessary for these studies initially were lacking, including knowledge of the proliferation rate and cell cycle characteristics, optimum growth density, response to serum withdrawal and cell cycle inhibitors, and characteristics of AHR(s) expressed in the cells. After addressing these deficiencies, it was possible to ask what effect(s) AHR ligands have on cell proliferation, and in turn how proliferation and cell cycle progression influence AHR function.

Following several reports of inhibition of proliferation by TCDD in cells of hepatic origin, this possible effect was measured in PLHC-1 cells. Dose- and timedependent inhibition of proliferation was observed in a sub-clone of these cells, but not in 
any of several others examined. The EC50 for this effect, $60 \mathrm{pM}$, is consistent with the potency of TCDD for producing other responses via the AHR (e.g. EC50 for CYP1A activity induction is $330 \mathrm{pM}$ in that medium). The inhibition was also transitory; TCDDtreated cells resumed proliferation 4-5 days following treatment. This effect was reminiscent of the lag before proliferation when PLHC-1 cells were seeded at lower densities, suggesting that perhaps TCDD interferes with the mechanism for committing to proliferation.

The inability to replicate this finding in other sub-clones implies heterogeneity within the PLHC-1 cell line. This is a very real possibility, since these cells have not been established from a single clone at any point in their history in culture. Furthermore, a loss of the ability of TCDD to inhibit proliferation suggests that some control on this process has been lost in most of the PLHC-1 cells. This is consistent with the observation in Chapter 5 that late-passage cells proliferate at a greater rate and have lost a serum-dependent control on AHR expression. Whether these two phenomena (i.e. TCDD inhibition of proliferation and serum-dependent AHR expression) are connected remains unclear.

Expression of AHR mRNA and protein was found to remain constant throughout the cell cycle. However, serum withdrawal, a treatment known to block cell cycle progression at the G0/G1 transition, led to a decrease in AHR protein. PLHC-1 cells do proliferate in serum-free medium for at least a week (not shown), so the absence of serum is not blocking the cell cycle. This effect of serum on AHR expression independently of changes in cell cycle progression is consistent with findings in 3T3 fibroblasts (Vaziri et al. 1996), and suggests a control on AHR expression that has been conserved throughout much of vertebrate evolution.

Whereas these effects were measured successfully in PLHC-1 cells, heterogeneity of response makes this cell line less than perfect as a model for studying such interactions. A great deal of time and effort was expended in studies of cells that turned out to be non-responsive for the types of effects described above. A survey to determine responses of other piscine cell lines to such treatments is warranted, as a more 
appropriate model may exist. Such a survey will benefit from the knowledge and techniques developed here. However, until a better model is found the PLHC-1 cells remain the only piscine model capable of supporting further research in interactions among the AHR and other signal transduction pathways.

\section{AHR Ligand Treatment and Response}

The other major thrust of this thesis was to improve our understanding of AHR signal transduction and responses to AHR ligands. The sort of scheme shown in Figure 2 of the Introduction is common in the field of AHR research, but what is lacking in large part are numbers associated with the arrows. Equilibrium conditions of some of the steps are known, but a thorough understanding requires rates of each step to be determined. In addition, since much of the previous work has been performed in a number of different systems, differences between them must be considered when building a comprehensive model.

\section{Toward an Accurate Assessment of Ligand Concentration}

The effect of serum on potencies of induction detailed in Chapter 3 was first observed as a complicating factor in the experiments shown in Chapter 5. PLHC-1 cells were grown and treated in medium with or without serum, and differences in both ligand potency (i.e. EC50) and efficacy (i.e. maximal response) were observed. The effect on potency grew from a nuisance to an interesting study of its own when a survey of the literature revealed the expanding use of cultured cells in risk assessment for AHR ligands. Such studies are attractive to regulatory agencies because of their relative ease of use and lower cost when compared with in vivo tests. Our results demonstrated the potential for increased sensitivity within a cell system and confounding results when comparing among systems.

Entry of compound into the cell and subsequent availability for binding is a step in the pathway to toxicity that has been under-appreciated in this field. Toxicokinetic studies in an organism typically end at the level of concentration in a tissue, and 
mechanistic studies in cells pick up with binding of ligand to the AHR. Some recent work has begun to address the routes and kinetics of HAH entry into cells (Dulfer et al. 1996; Dulfer 1998), but this step remains perhaps the subject of the least understanding and greatest number of assumptions in the pathway of $\mathrm{HAH}$ toxicity. The relationship between the amount of compound applied to cells and the concentration available for binding is largely a mystery.

The results in Chapter 3 address one component of this issue by examining factors controlling the fraction of compound that is associated with the cell. This fraction is dependent on time, external environment, and dose. Subsequent collaborative work has shown that even two laboratories ostensibly following the same protocol for treatment of cells will measure widely different results simply based on these controllable factors. Given the number and magnitude of decisions that are being made on the basis of data collected in cell bioassays, such discrepancies should be addressed as early as possible.

One question not addressed by the studies in Chapter 3 is the location of HAH within the cell after it enters from the medium. The extremely hydrophobic nature of these compounds suggests that much of it will associate with lipid membranes and perhaps hydrophobic interiors of lipid or protein aggregates. The concentration of ligand in the cytosol and available for receptor binding depends on such factors. In fact, it has been suggested that the difference in AHR binding affinities among some PCBs (e.g. PCBs 77 and 169) is not due to an actual difference in affinity, but rather to differences in their cytosolic concentration that result from differences in hydrophobicity (P. Sinclair, personal communication). Studies of binding affinity in increasingly purified preparations of AHR suggest that such miscalculation of the "free" concentration of ligand can lead to an $\sim 1000$-fold difference in measured $\mathrm{K}_{\mathrm{D}} \mathrm{s}$ (Bradfield et al. 1988b). However, whether such a mechanism accounts for apparent differences in affinity among compounds is not known. 


\section{Stimulus-Response Relationships}

Our understanding of events subsequent to ligand binding also suffers from a lack of quantitative measurement of the kinetics and controlling factors for receptor transformation. Although the existence of AHR partial agonists and antagonists has been recognized for a decade, a simplistic model of binding leading to transformation, which in turn leads to response, continues to pervade much of the published literature. The separation of ligand potency into the properties of affinity and intrinsic efficacy, reported in Chapter 5, begins to move in the direction of considering differences in ligand properties other than binding affinities. Together with recent efforts to explore the structural bases for ligand intrinsic efficacy (Henry et al. 1999), hopefully these studies will garner a larger appreciation for the myriad factors linking binding and response.

One current limitation of the analysis performed in Chapter 5 is the restriction to cultured cell systems. This analysis requires measurements of binding and response too numerous to perform in vivo, and only recently possible in cultured cells. Reliable protocols for rapid, large-scale analysis of binding to the AHR and induction of CYP1A protein and activity were adapted to the PLHC-1 cell system. Transfer of such assays to other cell lines to analyze species- and tissue-specific effects should be relatively straightforward. However, expansion to the level of the organism will require carefully targeted studies to assess factors upstream of ligand entry into the cell and downstream of cellular response.

Moving down in level of organization, assays performed using isolated cell fractions lose the ability to analyze several of the relevant steps leading to response. However, such assays are valuable for careful analysis of the steps that are retained (e.g. ligand binding, interactions with ARNT and other proteins, DNA binding, and possibly initiation of transcription). The number of events falling under the term "efficacy" is large, and no assessment has been made of which are constant within a tissue (i.e. tissue coupling) and which are in some part variable, depending on the identity of the ligand. For example, recent studies of estrogen receptor structure suggest that antagonists induce a different receptor conformation than agonists, and that the antagonist occupied estrogen 
receptor does not interact with transcriptional coactivators (Brzozowski et al. 1997; Norris et al. 1998). Such conformational changes could effect steps in the AHR signal transduction pathway that involve interactions with other molecules (e.g. ARNT, DNA, co-activators; Lees and Whitelaw 1999).

The separation of ligand action into the terms affinity and efficacy is just a first step in developing this understanding. Further separation of efficacy into ligand- and tissue-specific properties may obscure the likelihood that some processes are dependent on both. We now have the tools to determine the molecular mechanisms of differences in efficacy. This should allow a conjunction of classical pharmacology and molecular endocrinology to approach a compelete understanding of ligand-receptor interactions.

Even with the limitations discussed above, I am excited about the prospects of this understanding of AHR action for driving future research. The sort of analysis performed in Chapter 5 can be applied to a wide variety of ligands, cell types and responses to build a more complete model of AHR function. Several candidates for endogenous AHR ligands have been proposed, and it will be interesting to see how their affinities and intrinsic efficacies compare to xenobiotics.

Another immediate application lies in the area of interspecies extrapolation. Rodent toxicity data is often used to estimate human health risks, and knowledge of the differences in affinities and intrinsic efficacies for binding to the human and rodent AHRs will improve such estimates. Furthermore, tissue coupling will vary among organisms for various responses, and determination of these values will aid our understanding of why some organisms show resistance to certain toxic endpoints but not others (Birnbaum 1991).

Obviously, similar arguments apply to wildlife toxicity. As model organisms are developed and used for different taxa it will be important to know how responses in the model organisms differ from others of interest. Some of this work already is being done in measuring potencies of induction of CYP1A and, in more limited cases, AHR binding affinities for compounds of interest. However, collection and analysis of such data will 
be most effective when it is driven by a need to understand mechanistic differences and to construct valid stimulus-response models.

The need to work within a pharmacologically sound framework is pointed out by the limitations of the currently used TEF approach. As was discussed in Chapter 4, AHR ligands in mixtures are assumed to have solely additive interactions, which does not take into account ligands with lower intrinsic efficacies. Thus, TEF-derived toxic potencies are almost certain to be overestimates when the contributions of individual compounds are summed. Working from known concentrations of compounds toward estimating toxic effects will require adjustment for low-intrinsic efficacy compounds.

Conversely, bioassay-derived potencies will tend to underestimate the concentrations of AHR ligands. CYP1A activity, a common bioassay, is inhibited by many of the inducing compounds themselves, further complicating its use in such analyses. Despite these complications, the concept of using bioassays to predict toxicity of HAH mixtures is extremely useful. Bioassay-derived potencies do correlate well with a variety of toxic endpoints. However, this approach has been applied when the underlying correlations are not well established.

Finally, it is satisfying to be able to build quantitative models and predict outcomes that can be tested by experiment. As more numbers are added to the arrows in that general AHR signal transduction scheme, these models will become more pervasive, more accurate, and more useful. The few interactions quantified here are simply a start. Science is useful primarily because it improves our ability to predict future outcomes. This field is moving into a stage where that promise will be fulfilled. 


\section{Appendix A: A Primer on Radio-Ligand Binding Assays}

following Kenakin, T. (1999) Pharmacologic Analysis of Drug-Receptor Interaction, $3^{\text {rd }}$ ed. Raven Press.

The goal of any ligand binding assay is twofold. First, free ligand must be separated from bound ligand. Second, ligand bound with a relatively higher affinity must be separated from that bound with a relatively lower affinity. Several assays have been devised to achieve the first goal. To achieve the second goal, radio-ligand binding assays assume that lower affinity binding is unsaturable in the range of ligand concentrations used. Thus, labeled ligand can be displaced from higher affinity, but not lower affinity, binding sites by an excess of unlabeled ligand. Therefore the definition of high-affinity binding sites is binding sites which are saturable within the concentrations of ligand used. High-affinity binding is determined by subtracting the amount of ligand bound in the presence of competitor from the amount of ligand bound in the absence of competitor.

Therefore, actual data collected from an experiment consists of two binding curves, a "total binding" curve measuring binding at several ligand concentrations in the absence of competitor, and a "non-specific binding" curve determined in the presence of competitor. The "specific binding" curve is simply the difference between these two. It is important to note that specific binding is not a directly determined value, but a derived one. Nevertheless, the total amount and affinity of specific binding are the values of interest, so we begin by considering the interaction between receptor and ligand.

The specific interaction of a ligand and its receptor is reversible, with rate constants for the association and dissociation of the ligand with the receptor:

$$
[A]+[R] \underset{k_{2}}{\stackrel{k_{1}}{\rightleftarrows}}[A R]
$$

Where $[\mathrm{A}],[\mathrm{R}]$, and $[\mathrm{AR}]$ are the concentrations of ligand, receptor and ligand-receptor complex, respectively, and $\mathrm{k}_{1}$ and $\mathrm{k}_{2}$ are the association and dissociation rate constants. At equilibrium, association and dissociation occur at an equal rate, and 


$$
k_{1}[A][R]=k_{2}[A R]
$$

The amount of receptor competent to bind ligand is divided into two pools, with and without ligand bound:

$$
R_{T}=R+A R
$$

Where $\mathrm{R}_{\mathrm{T}}$ is the total receptor pool. Substituting this relationship into equation 2 and rearranging produces:

$$
[A] \times\left(\left[R_{T}\right]-[A R]\right)=\frac{k_{2}}{k_{1}}[A R]
$$

And now if a single equilibrium dissociation constant, $\mathrm{K}_{\mathrm{D}}$ is defined to replace the rate constants:

$$
K_{D}=\frac{k_{2}}{k_{1}}
$$

and this is substituted in equation 4, we arrive at the following expression relating ligand concentration and the fraction of receptor that is occupied by ligand:

$$
\frac{[A R]}{\left[R_{T}\right]}=\frac{[A]}{[A]+K_{D}}
$$

This relationship is known as the Langmuir binding isotherm.

Equation 6 relates binding to free ligand concentration; if total ligand concentration is measured, the amount bound must be subtracted. In addition, the 
relationship expressed by equation 6 involves several assumptions about the nature of the association. The most important ones to remember are:

1) The system must have reached equilibrium, i.e. association and dissociation are occurring at equal rates when binding is measured.

2) Binding of one ligand molecule does not effect binding of another, which includes two major components:

A) Removal of a ligand molecule from the available pool by binding does not alter the concentration of free ligand, i.e. the fraction of total ligand that is bound to the receptor is relatively small.

B) Binding is not cooperative.

Deviation from any of these assumptions requires modification of equation 6 in order for it to be useful. For example, cooperative binding can be modeled by adding an exponent (the Hill coefficient) to the free ligand concentrations:

$$
[A R]=\frac{[A]^{n} \times\left[R_{T}\right]}{[A]^{n}+K_{D}}
$$

Possessing both a method to determine specific binding and a theoretical relationship to describe it, it should be possible to fit data to the relationship. By measuring the amount of receptor occupied at several different free ligand concentrations, the values of $R_{T}$ and $K_{D}$ can be determined.

First it is necessary to determine whether sufficient data have been collected to perform a proper binding analysis. The data should include several points at concentrations of free ligand above the $K_{D}$. This can be assessed visually by plotting specific binding versus free ligand concentration on a semi-log plot, but not with a linear scale of free ligand, which can be misleading. The figures below show an idealized specific binding curve. The data on the left are plotted with a linear $\mathrm{x}$ axis and seem to indicate that the last few points are beyond the inflection point (i.e. the $\mathrm{K}_{\mathrm{D}}$ ) of the curve, and that a saturating ligand concentration is being approached. However, the semi-log 
plot on the right reveals that the inflection point has not been reached, and $R_{\Upsilon}$ and $K_{D}$ (hereafter collectively called the binding constants) cannot be estimated properly (Klotz 1982).
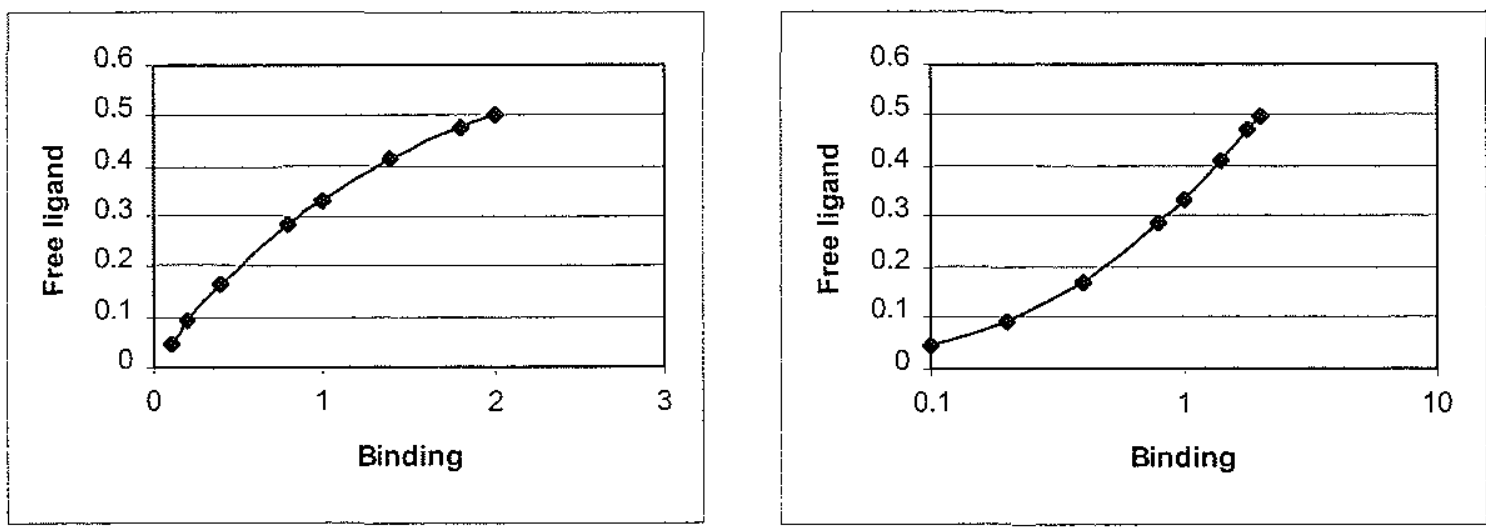

Figure 1. Linear and semi-log plots of binding.

Once sufficient data have been collected, the binding constants can be determined. The classic method for estimating these values, and one still in use, is the Scatchard plot. Since equation 6 describes a nonlinear function of ligand concentration, a transformation that yields a linear relationship would be both visually satisfying and simpler to fit. By cross multiplying the terms of equation 6 and dividing throughout by $[\mathrm{A}]^{*} \mathrm{~K}_{\mathrm{D}}$ such a linear relationship is established:

$$
\frac{[A R]}{[A]}=-\frac{[A R]}{K_{D}}+\frac{\left[R_{T}\right]}{K_{D}}
$$

A plot of bound ligand (or receptor) concentration divided by free ligand concentration on the ordinate and bound ligand concentration on the abscissa yields a line with a slope of $-1 / \mathrm{K}_{\mathrm{D}}$ and an $\mathrm{x}$-intercept of $\mathrm{R}_{\mathrm{T}}$. An obviously nonlinear relationship for data plotted in this fashion is a sign that one of the assumptions listed for equation 6 is false.

While the Scatchard plot is a useful tool for visually assessing the nature of the binding interaction and easily computing $\mathrm{R}_{\Upsilon}$ and $\mathrm{K}_{\mathrm{D}}$, it does have its drawbacks. The 
transformation necessary to achieve the linear relationship includes both independent (ligand concentration) and dependent (binding) variables in the y axis. Therefore data points from different ligand concentrations are weighted unequally, with points at the highest and lowest ligand concentrations receiving greater relative weight in the determination of the binding constants. This typically leads to overestimation of both $\mathrm{R}_{\mathrm{T}}$ and $\mathrm{K}_{\mathrm{D}}$.

With the advent of computer software for performing nonlinear curve fits, it is possible to fit data directly to the Langmuir isotherm without transformation. This produces more accurate estimates of the binding constants. However, the specific binding values are not calculated from primary data, so this approach is still somewhat removed from the ideal of determining binding directly from measured quantities.

Since "non-specific binding" is by definition unsaturable within the range of ligand concentrations used, it increases as a linear function of ligand concentration:

$$
N S B=m[A]
$$

and total binding should simply be the sum of the specific and non-specific binding:

$$
T B=\frac{[A] \times\left[R_{Y}\right]}{[A]+K_{D}}+m[A]
$$

Therefore the data collected for the total binding curve can be fit to equation $10 \mathrm{in}$ order to determine the binding constants and the slope of the non-specific binding line.

Theoretically, even more accurate estimates of the binding constants can be achieved by simultaneously fitting the total binding data to equation 10 and the non-specific binding data to equation 9 ; however, if the quality of the total binding data is good, then the two estimates should be identical. 


\section{Example}

What follows is an example comparing methods for determining binding. The data is ${ }^{3} \mathrm{H}-\mathrm{TCDD}$ binding in PLHC-1 cells, where free ligand has been separated from bound by a filtration assay. The total, specific and non-specific binding numbers and free ligand concentrations are listed below, with free TCDD concentrations in $\mathrm{nM}$ and binding in $\mathrm{fmol} / \mathrm{mg}$ protein.

Table 1. Binding data for ${ }^{3} \mathrm{H}-\mathrm{TCDD}$ in PLHC-1 cells.

\begin{tabular}{r|r|rr|r}
{$[$ TCDD] } & Total & Specific & [TCDD] & NS \\
\hline 0.092 & 7.27 & 3.61 & 0.077 & 3.39 \\
0.101 & 15.21 & 14.29 & 0.080 & 8.31 \\
0.145 & 18.04 & 16.77 & 0.102 & 14.33 \\
0.174 & 19.10 & 16.45 & 0.187 & 7.42 \\
0.237 & 13.73 & 9.02 & 0.192 & 8.78 \\
0.355 & 22.32 & 17.55 & 0.318 & 9.73 \\
0.439 & 20.24 & 14.33 & 0.324 & 13.74 \\
0.580 & 31.79 & 24.06 & 0.503 & 11.46 \\
0.817 & 47.93 & 38.85 & 0.673 & 25.97 \\
0.972 & 31.36 & 19.70 & 0.793 & 17.96 \\
1.172 & 57.85 & 42.35 & 0.987 & 33.88 \\
1.519 & 60.20 & 43.96 & 1.459 & 47.58 \\
2.236 & 97.95 & 68.17 & 1.876 & 42.31 \\
3.352 & 54.42 & 48.29 & 2.876 & 24.08 \\
4.559 & 109.01 & 69.09 & 4.061 & 81.34 \\
4.870 & 122.24 & 55.10 & 4.174 & 60.20
\end{tabular}

Since free ligand concentrations for the total and non-specific binding determinations don't match, specific binding was determined by fitting a line to the nonspecific binding and using that regression to determine non-specific binding at the free ligand concentrations present in the total binding determinations: 


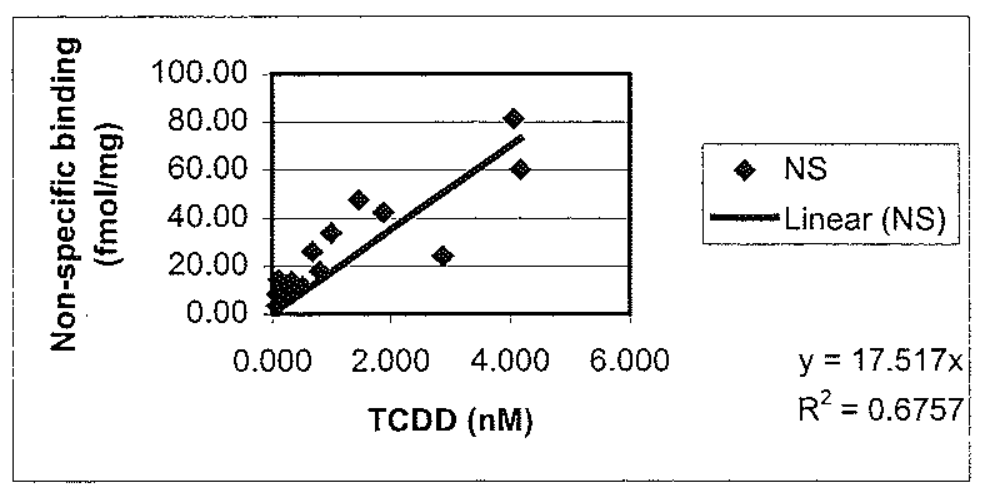

Figure 2. Non-specific binding.

Therefore specific binding is: TB $-17.517 *[\mathrm{TCDD}]$

First the specific binding values were transformed and plotted by the method of Scatchard:

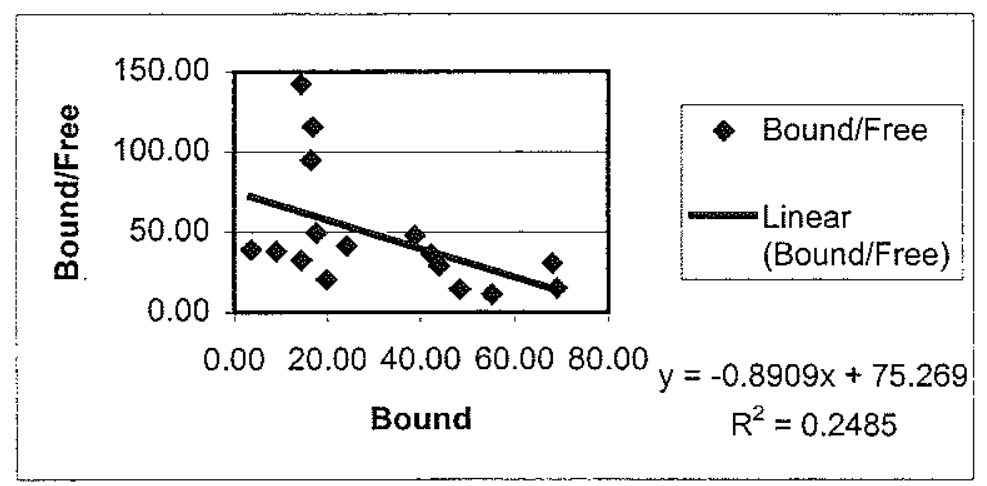

Figure 3. Scatchard plot.

This yields values of $1.22 \mathrm{nM}(1 / 0.8909)$ and $84(75.269 / 0.8909) \mathrm{fmol} / \mathrm{mg}$ for $\mathrm{K}_{d}$ and $\mathrm{R}_{\mathrm{T}}$, respectively.

Next specific binding was fit to the Langmuir isotherm. Since the linear fit of these points in the Scatchard plot wasn't very good, the possibility that some form of cooperative binding was taking place was investigated. The data were fit to both equations 6 and 7 to see how much better equation 7 fit the data. The coefficients determined by these fits are shown in Table 2 . 


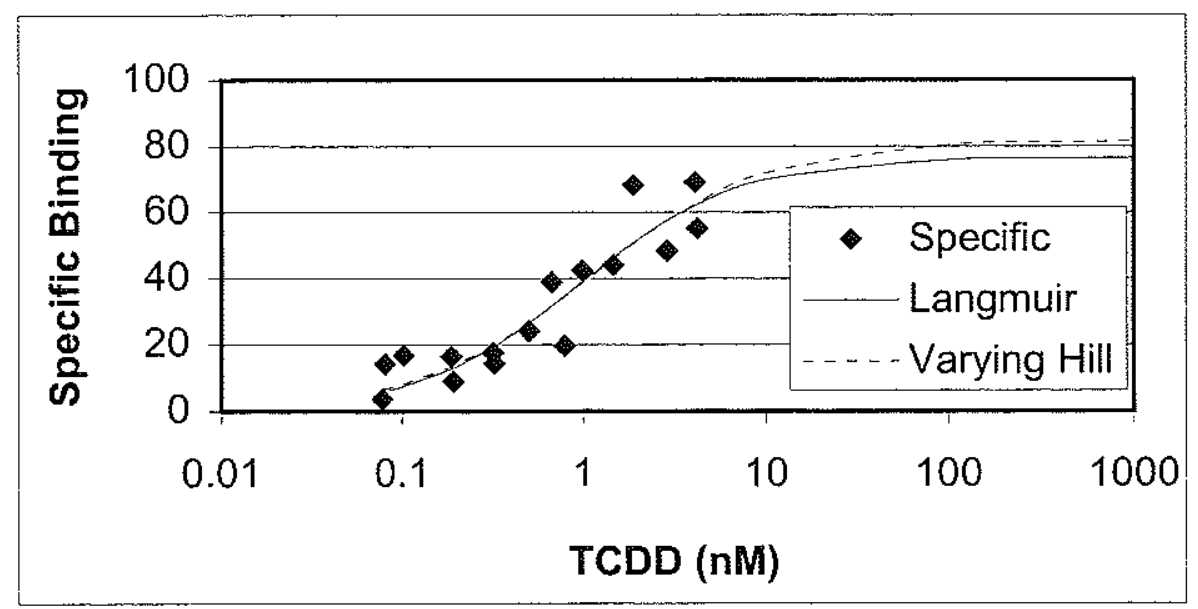

Figure 4. Varying Hill coefficient and binding data fit.

Table 2. Binding coefficients.

\begin{tabular}{c|c|c} 
Coefficient & Langmuir & Varying Hill \\
\hline $\mathrm{n}$ & 1 & 0.913 \\
$\mathrm{~K}_{\mathrm{D}}(\mathrm{nM})$ & 0.954 & 1.11 \\
$\mathrm{R}_{\mathrm{T}}(\mathrm{fmol} / \mathrm{mg})$ & 76.53 & 81.69
\end{tabular}

The values for $K_{D}$ and $R_{T}$ are similar for the two methods, $n$ is not significantly different from 1 in the second fit, and that equation does not provide a significantly better fit of the points by F-test (not shown), so a Hill coefficient of 1 will be used from here on.

Next the total binding was fit to equation 10 :

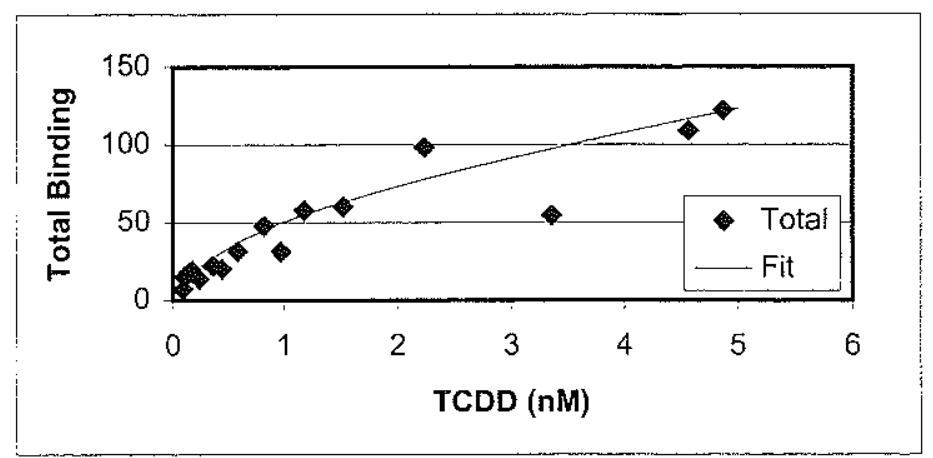

Figure 5. Total binding determination. 
The values of $\mathrm{K}_{\mathrm{D}}$ and $\mathrm{R}_{\mathrm{T}}$ determined by this method were $0.80 \mathrm{nM}$ and $65.8 \mathrm{fmol} / \mathrm{mg}$. The specific binding curve using these values is shown below.

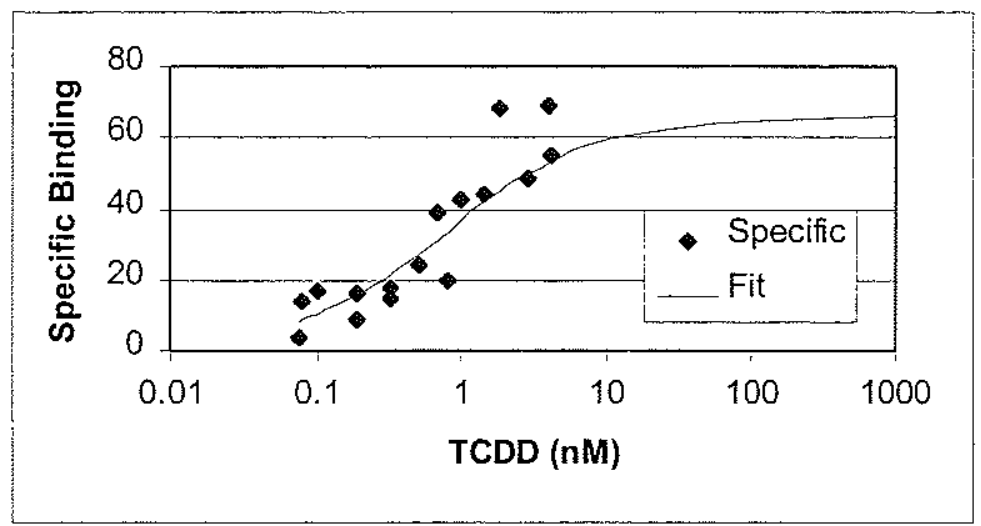

Figure 6. Fit of curve predicted from total binding.

Finally, non-specific and total binding data were fit simultaneously to equations 9 and 10 .

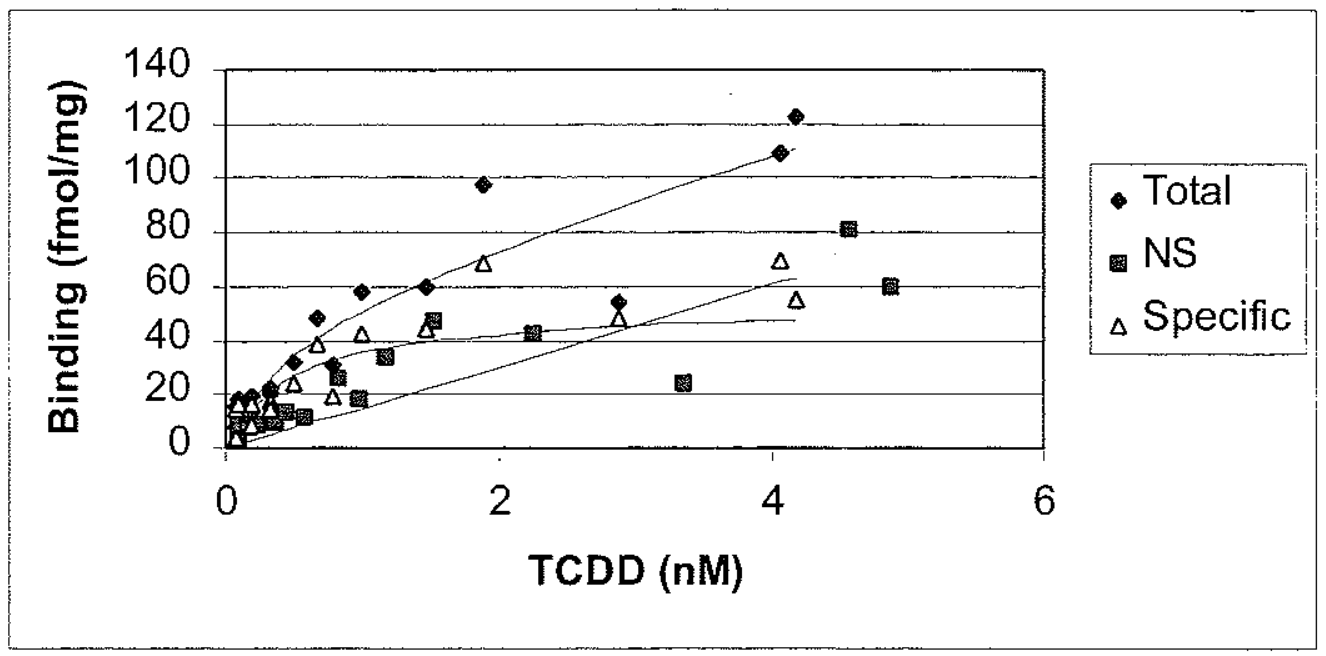

Figure 7. Simultaneous fitting of specific and non-specific binding.

This yields binding constants of $K_{D}=0.50 \mathrm{nM}$ and $R_{T}=53 \mathrm{fmol} / \mathrm{mg}$. The corresponding specific binding curve is also shown in the figure above. 
Shown in the table below are the constants determined for the various curve fits.

Table 3. Binding constants for different fitting methods.

\begin{tabular}{c|cccc} 
& $\mathbf{N}$ & $\mathbf{K}_{\mathbf{D}}$ & $\mathbf{R}_{\mathbf{T}}$ & $\mathbf{m}$ \\
\hline Scatchard & 1 & 1.22 & 84 & \\
Varying Hill & 0.913 & 1.11 & 82 & \\
Langmuir & 1 & 0.95 & 77 & \\
Total & 1 & 0.8 & 66 & 14 \\
Simultaneous & 1 & 0.5 & 53 & 15
\end{tabular}

Notice that as the theoretical appropriateness of the fits increases (moving down the table), the $K_{D}$ and $R_{T}$ decrease. Overestimation of the $R_{T}$ is common when a few points with higher specific binding skew the fit, as the two points near $70 \mathrm{fmol} / \mathrm{mg}$ of specific binding do in these data. The fits determined with the last four methods are plotted against specific binding below. The fitted lines have been extrapolated beyond the data to demonstrate the leveling of the curves.

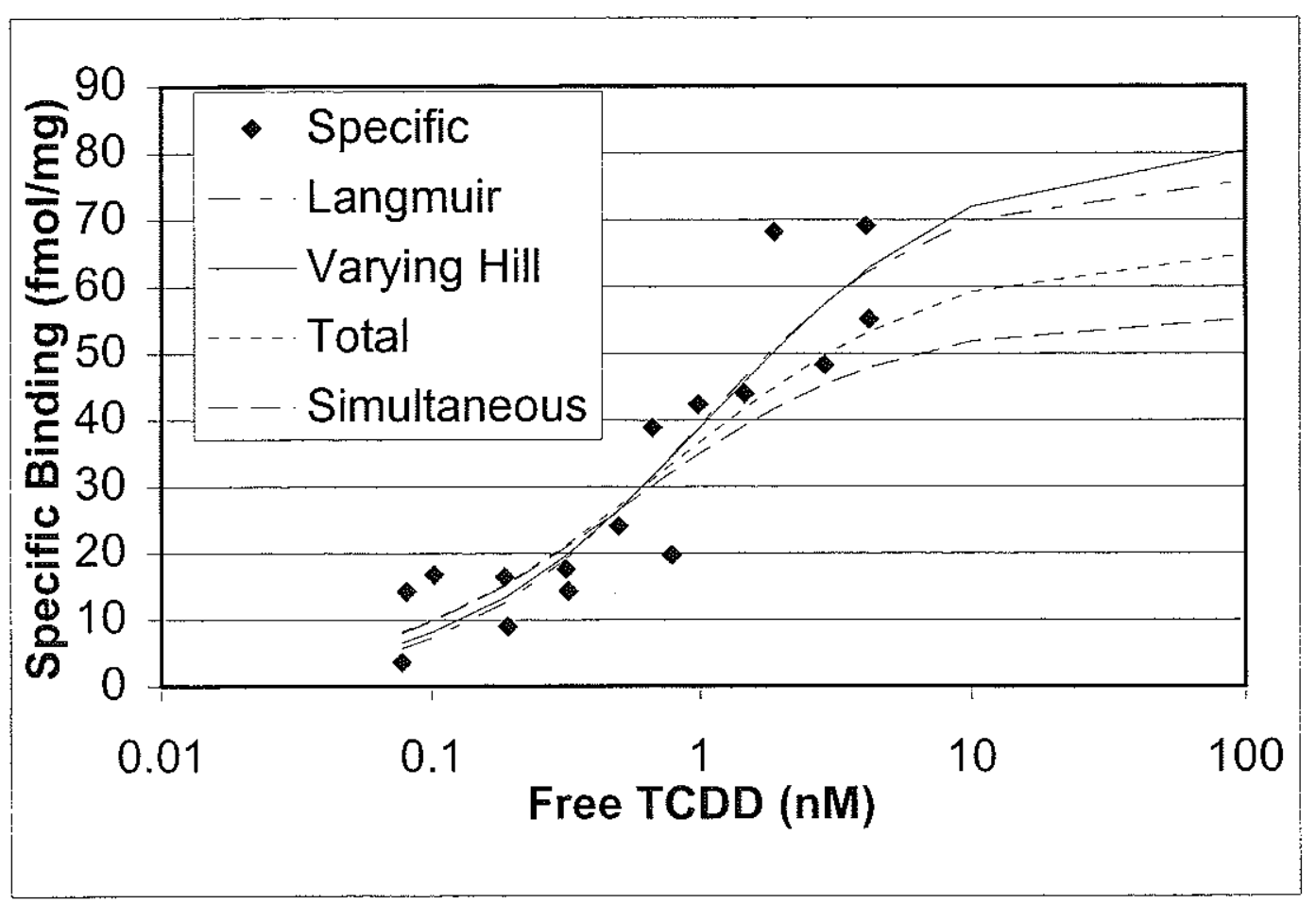

Figure 8 . Fits to specific binding using various methods. 


\section{Appendix B: Development of an AHR Binding Assay for PLHC-1 Cells}

I recognized at the beginning of this thesis project that a dependable, highthroughput assay for measuring binding of ligands to the AHR was required to complete the objectives. This has proven true; every data chapter includes at least one ligand binding assay. The lack of an antibody that reliably detects fish AHRs has increased this assay's value, because it can be used to measure AHR expression as well as ligand binding affinities.

Previous, mostly unpublished, work by Mark Hahn had attempted to refine previously described assays used with isolated cytosol to measure binding to the PLHC-1 AHR. This was greatly complicated by the fact that fish AHRs are generally less stable and therefore more difficult to isolate than their mammalian counterparts (Denison et al. 1986; Heilmann et al. 1988; Lorenzen et al. 1990). Furthermore, charcoal-coated dextran, which is commonly used to remove excess unbound ligand, also strips ligand from the AHR (Lorenzen et al. 1990). Nevertheless, some success was obtained with sucrose-density gradient (not a high-throughput assay), protamine sulfate (Denison et al. 1984) and hydroxylapatite (Gasiewicz and Neal 1982) assays (summarized in Hahn 1998a).

I decided to focus on the whole-cell filtration assay (Dold et al. 1990) for several reasons:

1. It is rapid, with time investment relative to results equal to other batch assays.

2. It had been developed for use with cultured hepatoma cells (HEPA-1).

3. Exposure to ligands takes place in intact cells. The importance of this in regard to comparison with response data is highlighted in Chapter 4 , but another advantage is that this avoids degradation of AHR during isolation of cytosol (Swanson and Perdew 1991).

Initial efforts focused on finding the best combination of equipment and conditions, and the published protocol was followed exactly. One study showed a modest, but reproducible, increase in specific binding when GF/F filters were used 


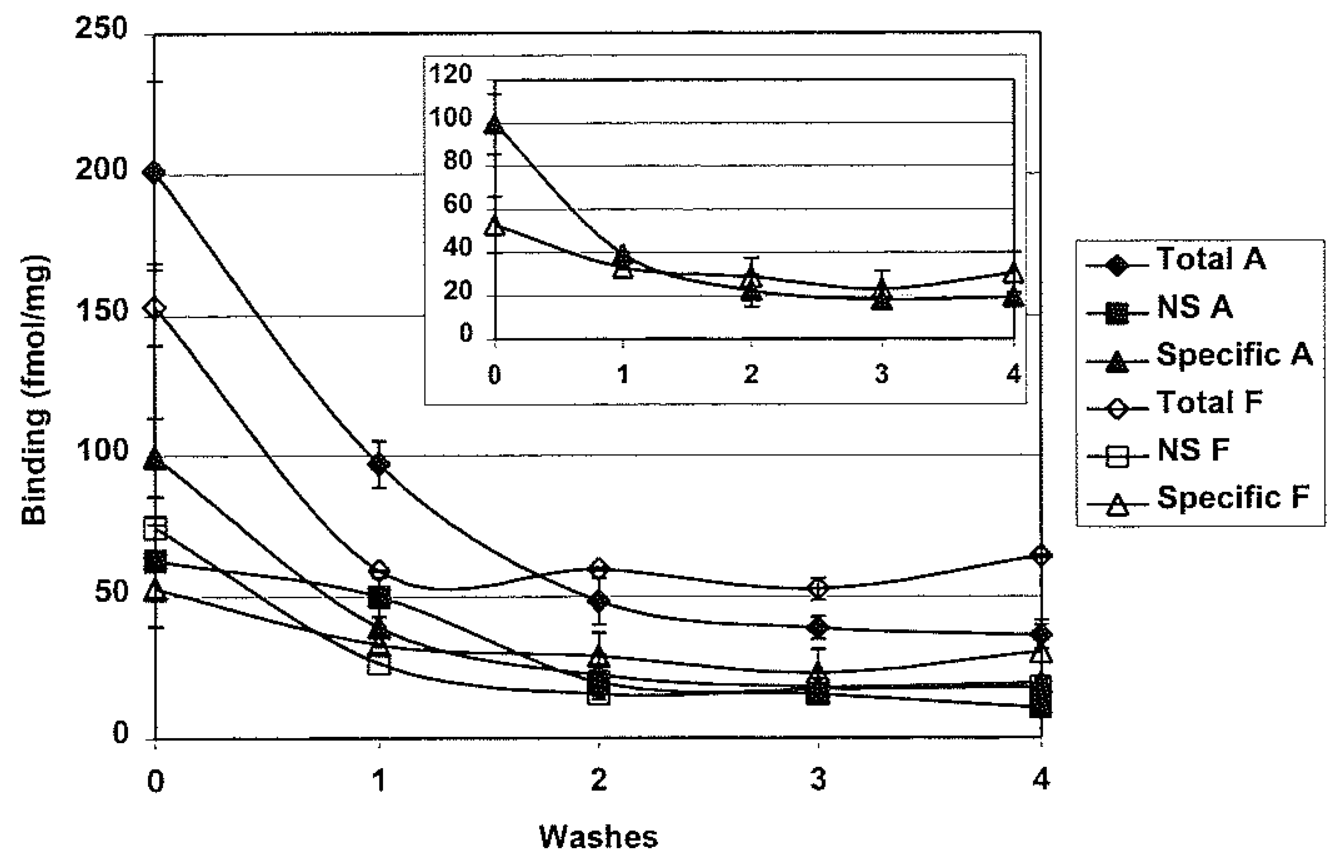

Figure 1. Binding measured by filtration on $\mathrm{GF} / \mathrm{A}$ or $\mathrm{GF} / \mathrm{F}$ filters. HEPA-1 were exposed to $0.5 \mathrm{nM}{ }^{3} \mathrm{H}-\mathrm{TCDD}$ with or without $200 \mathrm{nM}$ TCDF for two hours. The assay was performed as described in Chapter 2. Total, non-specific (NS) and specific binding are shown using GF/A (A) or GF/F (F) filters. The $\mathrm{x}$-axis is the number of acetone washes. The inset shows specific binding alone. Error bars are SE of three replicates.

instead of GF/A (Figure 1). The GF/F filters have smaller pore size and faster flow rate, so cells should be retained better but the acetone flows through faster.

Another change to the published protocol involved exposure in suspended, rather than attached cells. This adjustment was made because of high variability in cell number and thus protein content among replicate wells in the 24-well plates originally used. The protocol using attached cells was employed for binding assays in Chapters 2, 3, and 5, but they required several attempts before reproducible results were obtained. By suspending 


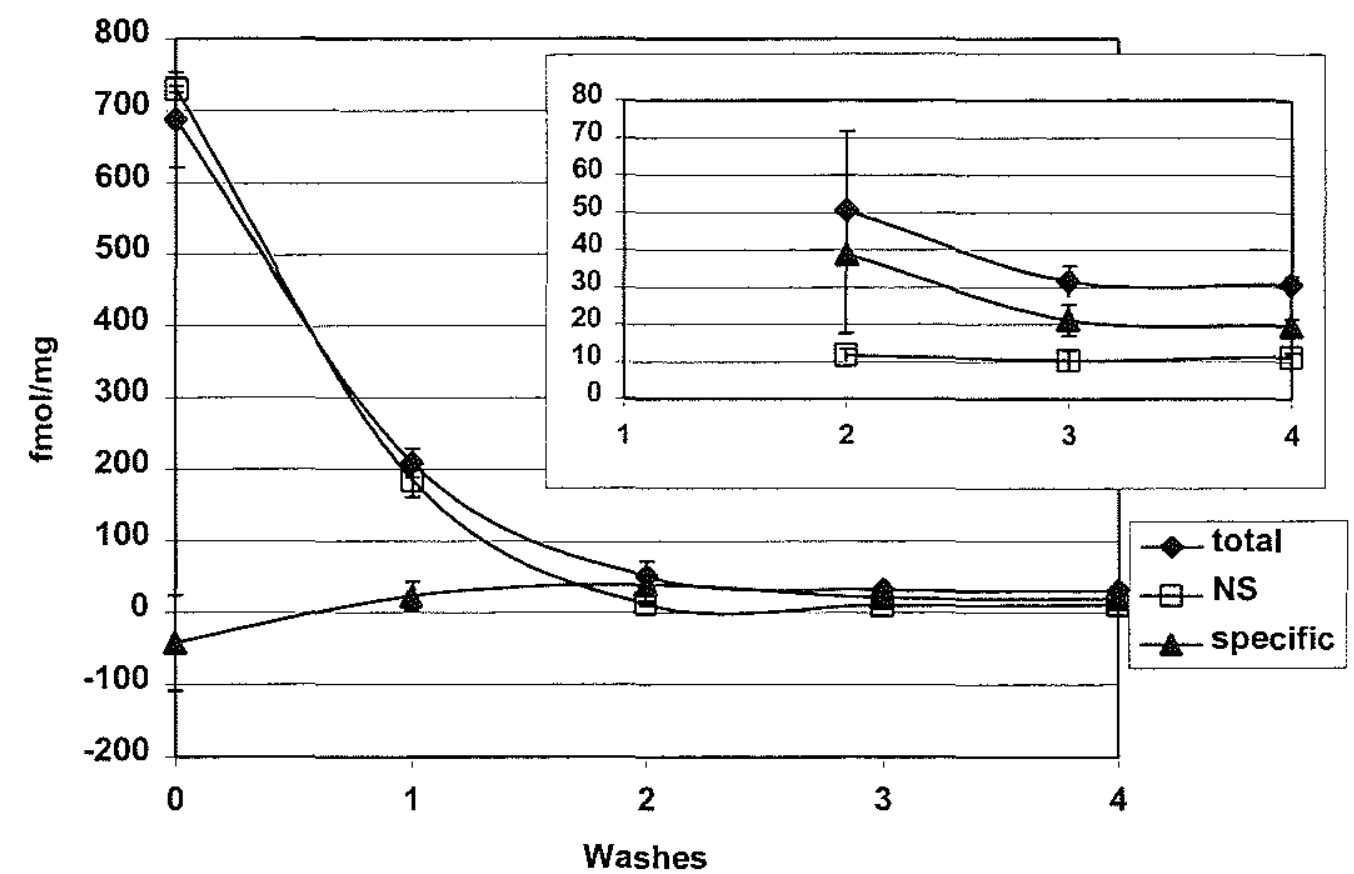

Figure 2. Binding measured after exposure in suspended cells. The incubation conditions are as in Figure 1, except that PLHC-1 cells have been exposed to ${ }^{3} \mathrm{H}-\mathrm{TCDD}$ and TCDF in suspension in MEM $+10 \%$ calf serum. The inset shows only the last three washes on a smaller scale for comparison.

the cells prior to incubation, even distribution of cell aliquots to replicate binding tubes was assured. This method also makes simultaneous addition of competitors easier. One disadvantage is that the cells are not washed before being applied to the filter, so a much larger amount of unbound TCDD must be removed. This requires a greater number of washes (Figure 2), and prohibits use of the assay at ${ }^{3} \mathrm{H}-\mathrm{TCDD}$ concentrations exceeding 5 $\mathrm{nM}$.

Fortunately, PLHC-1 cells do not attach to glass substrates during the two hour incubation. In addition, they do show equal amounts of receptor content whether the incubation is performed in medium with or without serum. Limited experiments with 
H4IIE and HEPA-1 cells revealed a tendency to clump in serum free medium and attach in medium with serum. The former problem made removal of free TCDD difficult, and the latter removed the advantage gained over assays with adherent cells.

The kinetics of binding were followed to insure that the two hour incubation was sufficient to achieve equilibrium (Figure 3). Specific binding was not significantly different between 90 minutes and 4 hours, so 2 hours is sufficient. Binding was also measured at several protein concentrations to insure that binding to individual sites (AHR and others) was independent (i.e. [free TCDD]»[bound TCDD]) across the protein amounts used in the several studies (Figure 4). The linear relationship shown demonstrates that TCDD concentration is not limiting binding at these protein concentrations, but the positive $Y$-intercept indicates that free TCDD may not be totally removed from filters. This will not affect specific binding values, since TCDD will remain on filters used to determine non-specific binding as well.

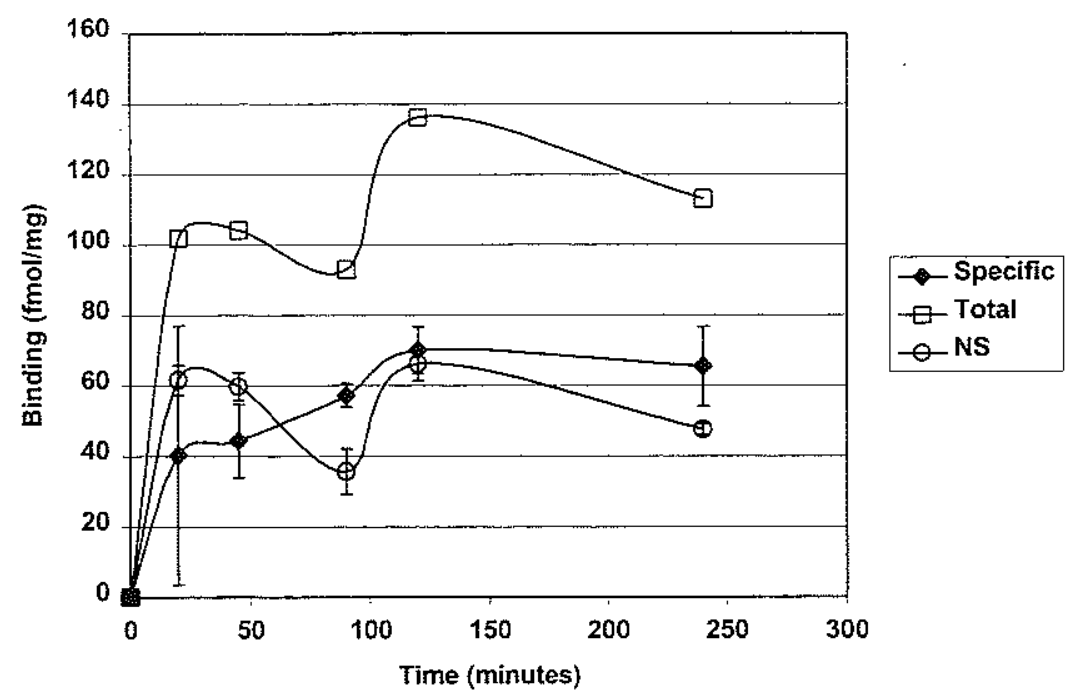

Figure 3. Time course of binding in PLHC-1 cells. Cells were incubated with $1 \mathrm{nM}{ }^{3} \mathrm{H}-$ TCDD with or without $200 \mathrm{nM}$ TCDF as in Figure 2, except that exposure was in serumfree medium, and aliquots were removed from the tubes at the indicated times for analysis. 


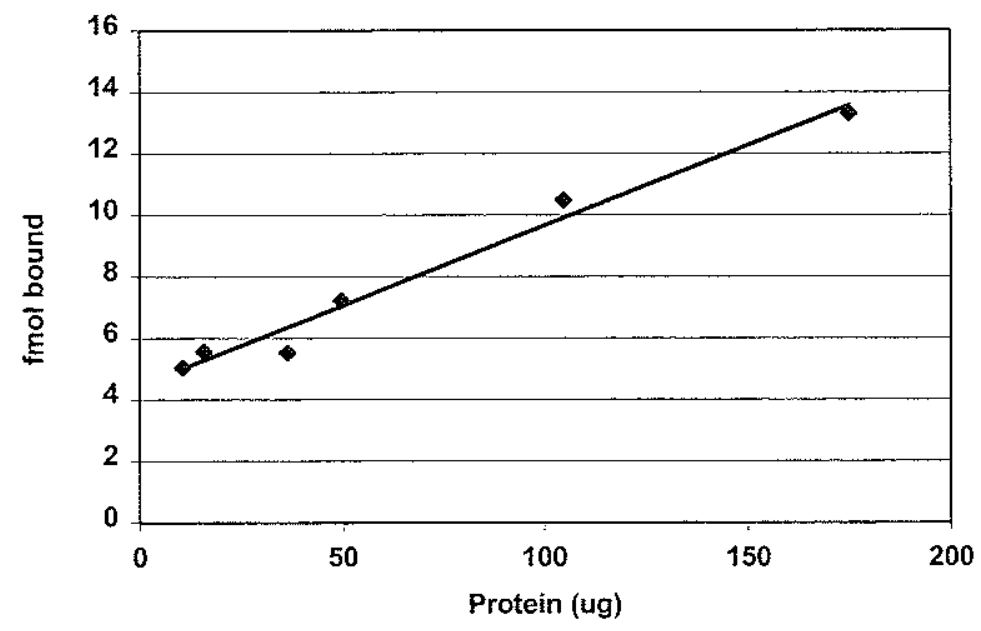

Figure 4. Binding with increasing cell protein. Serial dilutions of PLHC-1 were exposed to ${ }^{3} \mathrm{H}-\mathrm{TCDD}$ as in Figure 3 for 2 hours. Total binding was measured. 


\section{Appendix C: Modeling the Effects of Changes in AHR Expression on Responses}

This appendix will present mathematical modeling of the effects that changes in receptor expression have on response in PLHC-1 cells as well as some primary data showing a lack of AHR induction by compounds shown to induce in other systems. As was noted in Chapters 4 and 5, several factors affecting AHR expression have been reported, leaving open the question of what effect such changes would have on downstream responses. The models presented here attempt to address this issue.

\section{Neither TCDD nor PB Induce AHR in PLHC-1}

PLHC-1 cells were treated with TCDD and phenobarbital, two compounds reported to induce expression of AHR in other systems (Okey et al. 1979; Sloop et al. 1987). Cells were exposed for 24 hours before harvesting RNA and performing semiquantitative RT-PCR, according to the method in Chapter 2 (Figure 1). Neither of these compounds induced expression of AHR mRNA in PLHC-1 cells, although a slight, dosedependent decline may have occurred with $\mathrm{PB}$. Therefore, it was not possible to show CYP1A induction data from cells with increased receptor content.

\section{Predicting Effects of Changes in AHR Expression}

In Chapter 5, Equation 4 from the Introduction was used to predict the effects of progressive reductions in receptor content on CYP1A expression. A more complete set of such curves is shown in Figure 2A. The EC50s and maximal responses are shown in Table 1. A reduction in receptor expression as great as 10 -fold would still allow nearmaximal induction of CYP1A by TCDD, albeit with a 9-fold increase in the EC50. Greater reductions in receptor content lead to steady declines in maximal level of induction, but even with a 500-fold lower level of receptor, induction would still be measurable. 

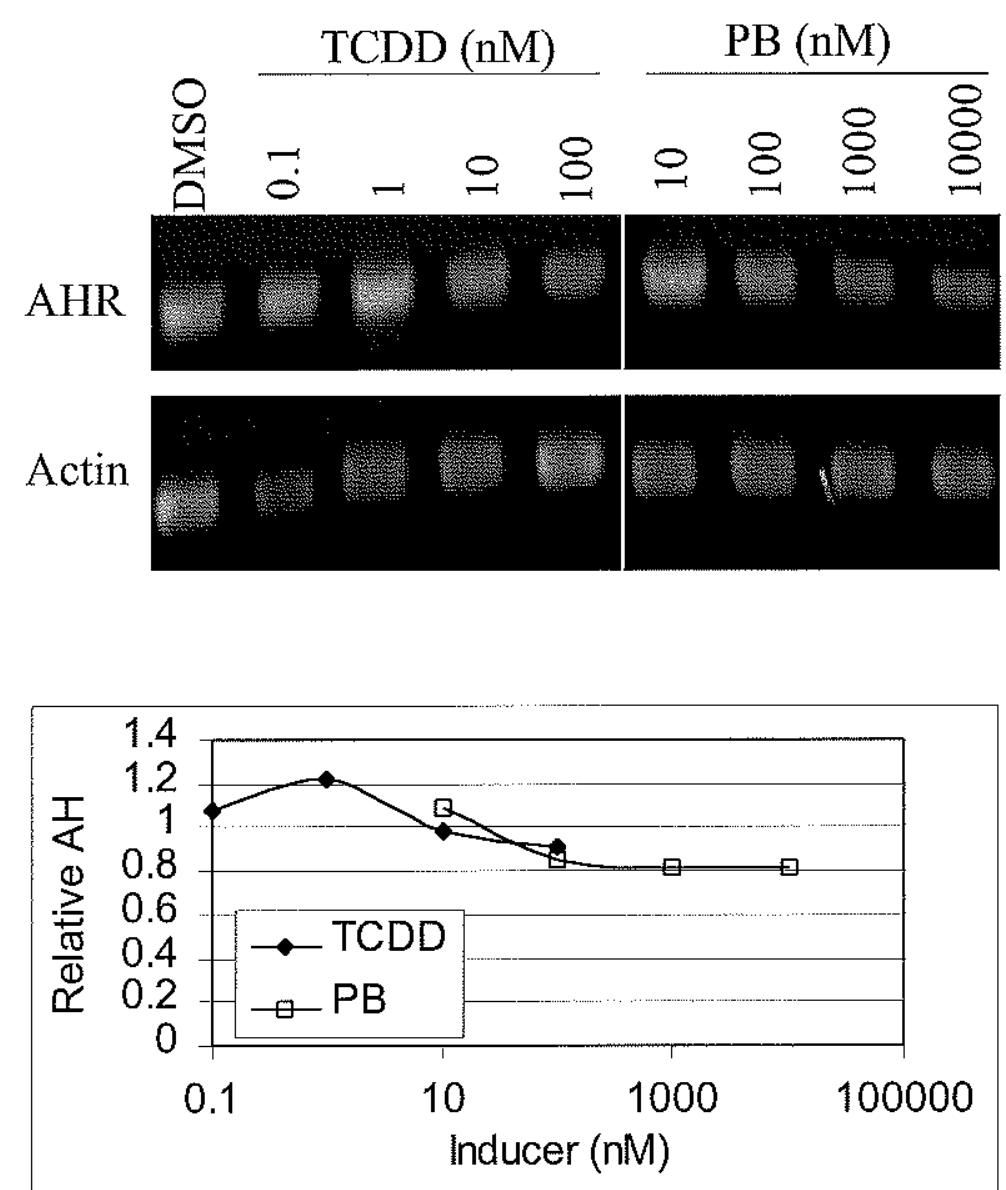

Figure 1. Effect of TCDD and PB on AHR expression. PLHC-1 cells were treated with TCDD or PB at the indicated concentrations for 24 hours and then harvested. RNA was isolated and used to amplify AHR and $\beta$-actin products by RT-PCR as detailed in the Methods section of Chapter 2. AHR expression was normalized to actin expression for each treatment and then normalized to the DMSO control. A value of 1 indicates an AHR/actin ratio equal to that in the control. 
Predicted effects of increases in AHR expression are shown in Figure 2B, with EC50 and maximal induction values in Table 1. A series of 2-fold increases in receptor expression lead to no change in maximal induction, but do produce 2-fold decreases in EC50s. Thus, a doubling of receptor content (which is the magnitude of many of the reported induction values) should halve the EC50 for response. This small change is not likely to be resolved using even sensitive and precise measurement techniques.

Note that these predicted curves use $\mathrm{K}_{\mathrm{D}}, \mathrm{K}_{\mathrm{E}}$ and $\mathrm{R}_{\mathrm{T}}$ values from CYP1A induction by TCDD in PLHC-1 cells. This response has a large receptor reserve (Chapter 4). It is possible that another response with less efficient tissue coupling (and thus a greater $\mathrm{K}_{\mathrm{E}}$ ) would show a more pronounced effect of reduction in receptor number on response. Equivalently, the effect of reducing AHR content on CYP1A response to a low-intrinsic efficacy agonist would be greater. As stated in Chapter 4, decreases in AHR content would render PCB 156 a partial agonist for induction of CYP1A, since there is no reserve for that ligand and response.

Since an increase in $\mathrm{K}_{\mathrm{E}}$ or decrease in $\mathrm{R}_{\mathrm{T}}$ have the same effect on the doseresponse curve (see equations for Table 1), such conditions can be pictured by using the curves in Figures 2A, but assuming a different starting concentration of receptors. For example, if these were curves for a response with 10 -fold greater $\mathrm{K}_{\mathrm{E}}$, the 10 -fold lower $\mathrm{R}_{\mathrm{T}}$ curve in Figure 1 represents response at $100 \%$ receptor expression. A 5-fold decrease in receptor content (to the 50 -fold reduction curve) would cause a $30 \%$ decline in maximal response and a 3-fold increase in EC50. In contrast, for induction of CYP1A, such a decline in AHR (from 1 to 5 -fold reduction) would result in a 5-fold increase in EC50, with only a slight reduction in maximal response. If our hypothetical response with the higher $\mathrm{K}_{\mathrm{E}}$ were lethality or incidence of tumors, the potential significance of the change in receptor content becomes much greater.

These calculations reveal the importance of determining intrinsic efficacies for different ligands and tissue coupling for the various responses of interest. Biomarkers such as CYP1A induction will be most useful when the differences in tissue coupling 
among responses are known. Without such knowledge, the impact of perturbations to the signaling pathway is impossible to predict.
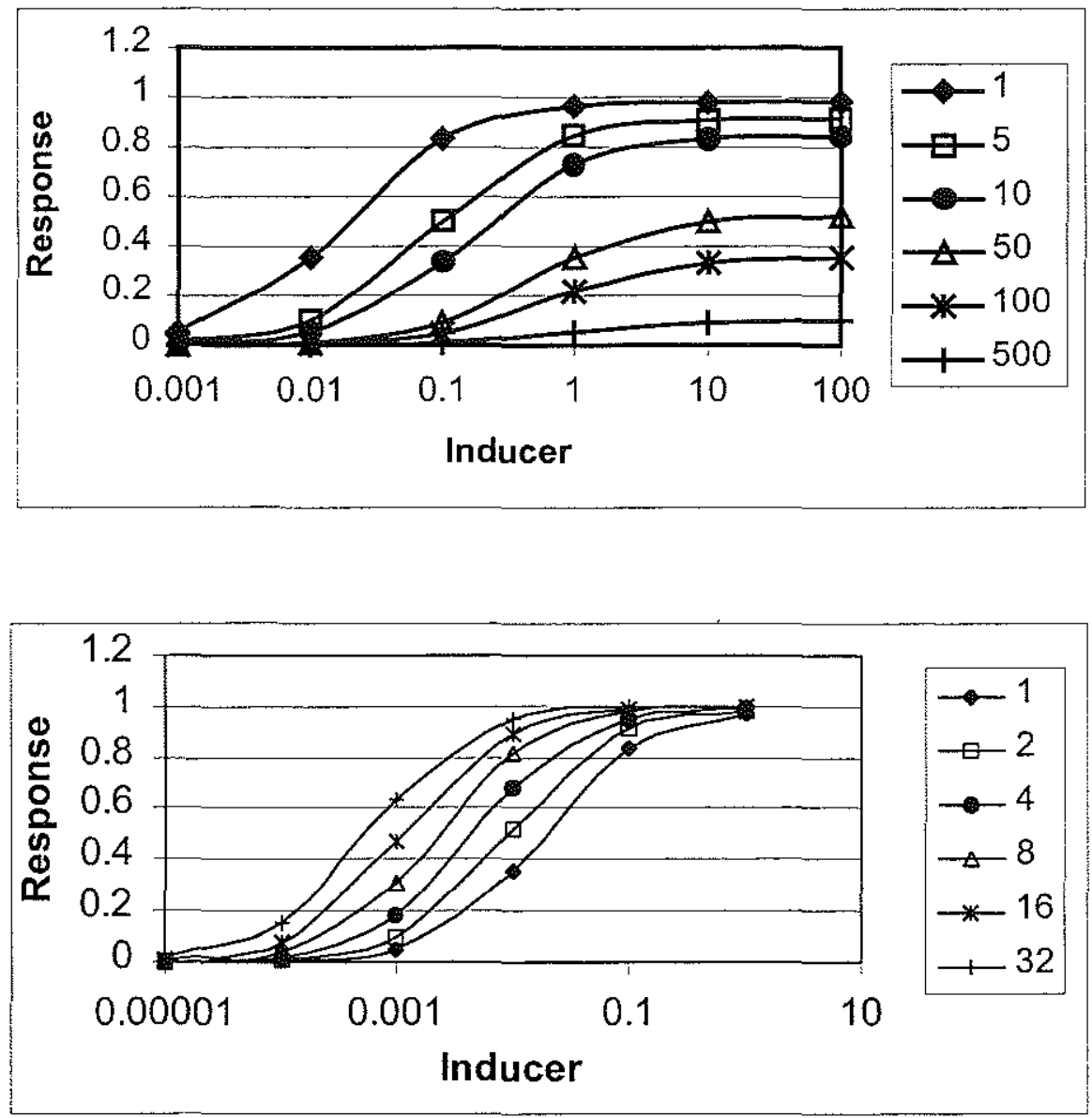

Figure 2. Effect of receptor number on response. Curves were generated using Equation 4 from the Introduction, using $K_{D}=1, K_{E}=2$, and an initial $R_{T}=110$. These numbers are consistent with induction of CYP1A by TCDD in PLHC-1 cells. (A) Effect of reduction in receptor number. The numbers in the legend indicate fold reduction in receptor. (B) Effect of increase in receptor number. The numbers in the legend indicate fold increase in receptor. 
Table 1. Effect of receptor number on EC50 and maximum response.

\begin{tabular}{|c|l|c|}
\hline $\begin{array}{c}\text { Fold Induction } \\
\text { or (Reduction) }\end{array}$ & EC50 & $\begin{array}{c}\text { Maximal } \\
\text { response }\end{array}$ \\
\hline$(500)$ & 0.90 & 0.10 \\
\hline$(100)$ & 0.65 & 0.35 \\
\hline$(50)$ & 0.48 & 0.52 \\
\hline$(10)$ & 0.15 & 0.85 \\
\hline$(5)$ & 0.083 & 0.92 \\
\hline 1 & 0.018 & 0.98 \\
\hline 2 & 0.0090 & 0.99 \\
\hline 4 & 0.0045 & 1.00 \\
\hline 8 & 0.0023 & 1.00 \\
\hline 16 & 0.0011 & 1.00 \\
\hline 32 & 0.00057 & 1.00 \\
\hline & & \\
\hline
\end{tabular}

Values calculated as follows:

$$
\begin{gathered}
\text { Maximal response }=\frac{R_{T} / K_{E}}{1+\left(R_{T} / K_{E}\right)} \\
\mathrm{EC} 50=\frac{K_{D}}{1+\left(R_{T} / K_{E}\right)}
\end{gathered}
$$




\section{Appendix D: Predicting AHR Ligand Intrinsic Efficacy in H4IIE}

AHR binding affinities and CYP1A induction potencies have been determined in a variety of systems, but not under conditions that allow direct comparison of the resulting $K_{D S}$ and EC50s as appears in Chapter 4. Therefore, intrinsic efficacies cannot be calculated for those compounds. However, it is possible to calculate relative efficacies by normalizing results to a standard compound, such as TCDD, and then comparing $\mathrm{K}_{\mathrm{D}} \mathrm{s}$ and EC50s.

This analysis was performed for 5 HAH in H4IIE rat hepatoma cells (Table 1). AHR binding affinities in rat cytosol (Bandiera et al. 1982) were normalized to the affinity of TCDD, and relative potencies of induction of CYP1A activity (AHH or EROD) were calculated from both new data and published results (Sawyer et al. 1982; Tillitt et al. 1991). Induction relative potencies were divided by relative affinities in order to express relative efficacies of the compounds (RE, column 5 of Table 1). RE determined from induction data here were compared to those calculated from two previous studies (Columns 5-7 of Table 1).

The results from the three studies are somewhat different, but a few trends emerge. PCBs 77, 105 and 156 consistently have lower efficacy than TCDD in H4IIE cells, whereas the efficacy of PCB 126 is similar to that for TCDD. Since CYP1A activity assays were used, inhibition obscures determination of maximal response levels, and thus characterization of these ligands as full or partial agonists. If any of the lowerintrinsic efficacy PCBs are full agonists, then that implies a receptor reserve for CYP1A induction in this cell type.

The preliminary assignment of PCB 77 (a non-ortho-substituted congener) as a low-intrinsic efficacy agonist in H4IIE suggests that structure-efficacy, and thus structure-activity, relationships vary among species. Relative efficacies were calculated for PLHC-1 from data in Chapter 4 (final column of Table 1). PCB 77 has lower relative efficacy in H4IIE than in PLHC-1, while the values between the two cell types are similar for the two ortho-substituted PCBs, 105 and 156. 
The striking differences between potencies for ortho- and non-ortho-substituted PCBs observed in fish is not seen in mammals, although most of the comparisons performed use PCBs 77 and 105 as representatives of those two classes of compounds. Relative efficacies of these two compounds were quite similar to one another in data from the two published studies (although there are large differences between the studies), indicating that the difference in affinities between them accounts for differences in response potencies. The reduced relative efficacy of PCB 77 in H4IIE suggests that not all non-ortho-subsituted PCBs are high-intrinsic efficacy ligands as in PLHC-1, narrowing the gap between intrinsic efficacies of ortho- and non-ortho-substituted PCBs in the mammalian system. Careful analyses of the sort performed in Chapter 4 are required in more systems in order to test this hypothesis.

Table 1. Calculating relative efficacies in the rat from relative receptor affinities measured in rat cytosol and induction potencies measured in H4IIE cells.

\begin{tabular}{|c|c|c|c|c|c|c|c|}
\hline \multirow[b]{2}{*}{ Compound } & \multirow[b]{2}{*}{$\mathrm{K}_{\mathrm{D}}(\mathrm{nM})^{\mathrm{a}}$} & \multicolumn{2}{|c|}{ Relative } & \multicolumn{3}{|c|}{ RE in H4IIE } & \multirow{2}{*}{$\begin{array}{l}\text { RE in } \\
\text { PLHC- } 1\end{array}$} \\
\hline & & Affinity & Potency & This study & Tillitt $^{\mathrm{b}}$ & Sawyer & \\
\hline TCDD & 10 & 1 & 1 & 1 & 1 & 1 & 1 \\
\hline PCB 126 & 130 & 0.077 & 0.13 & 1.7 & 0.28 & 4.2 & 0.43 \\
\hline РCB 77 & 710 & 0.014 & 0.0022 & 0.15 & 0.0013 & 0.064 & 1.2 \\
\hline PCB 105 & 4300 & 0.0023 & 0 & 0 & 0.0033 & 0.29 & 0 \\
\hline PCB 156 & 7100 & 0.0014 & 0.000081 & 0.057 & 0.039 & 0.063 & 0.02 \\
\hline
\end{tabular}

Published binding affinities were normalized to that for TCDD (Column 3). Relative potencies of CYP1A induction measured here (Column 4) were then divided by normalized binding affinities to determine relative efficacies (RE, Column 5). For comparison, similar calculations were performed from published induction EC50s (Columns 6 and 7).

a: Binding affinities from (Bandiera et al. 1982)

b: Calculated from EC50s for induction of CYP1A from (Tillitt et al. 1991)

c: Calculated from EC50s for induction of CYP1A from (Sawyer et al. 1982) 


\section{References}

Aarts, J. M., Denison, M. S., Cox, M. A., Schalk, M. A., Garrison, P. M., Tullis, K., de Haan, L. H. and Brouwer, A. (1995). Species-specific antagonism of Ah receptor action by $2,2^{\prime}, 5,5^{\prime}$ - tetrachloro- and $2,2^{\prime}, 3,3^{\prime} 4,4^{\prime}$-hexachlorobiphenyl. Eur J Pharmacol 293(4): 463-74.

Abbott, B. D., Birnbaum, L. S. and Perdew, G. H. (1995a). Developmental expression of two members of a new class of transcription factors .1. Expression of aryl hydrocarbon receptor in the C57BL/6N mouse embryo. Develop Dynam 204(2): 133-143.

Abbott, B. D. and Probst, M. R. (1995b). Developmental expression of two members of a new class of transcription factors .2. Expression of aryl hydrocarbon receptor nuclear translocator in the C57BL/6N mouse embryo. Develop Dynam 204(2): 144-155.

Abdel-Razzak, Z., Loyer, P., Fautrel, A., Gautier, J.-C., Corcos, L., Turlin, B., Beaune, P. and Guillouzo, A. (1993). Cytokines down-regulate expression of major cytochrome P-450 enzymes in adult human hepatocytes in primary culture. Mol. Pharm. 44: 707-715.

Abnet, C. C., Tanguay, R. L., Hahn, M. E., Heideman, W. and Peterson, R. E. (1999). Two forms of aryl hydrocarbon receptor type 2 in rainbow trout (Oncorhynchus mykiss): Evidence for differential expression and enhancer specificity. J. Biol. Chem. 274(21): 15159-15166.

Ackermann, G. E. and Fent, K. (1998). The adaptation of the permanent fish cell lines PLHC-1 and RTG-2 to FCS-free media results in similar growth rates compared to FCS-containing conditions. Mar. Environ. Res. 46(1-5): 363-367.

Ariens, E. J. (1954). Affinity and intrinsic activity in the theory of competitive inhibition. Arch. Int. Pharmacodyn. Ther. 99: 32-49.

Amold, S. F., Collins, B. M., Robinson, M. K., Guillette, L. J. J. and McLachlan, J. A. (1996). Differential interaction of natural and synthetic estrogens with extracellular binding proteins in a yeast estrogen screen. Steroids 61: 642-6. 
Arunlakshana, O. and Schild, H. O. (1959). Some quantitative uses of drug antagonists.

Br. J. Pharmacol. 14: 48-58.

Astroff, B., Zacharewski, T., Safe, S., Arlotto, M. P., Parkinson, A., Thomas, P. and Levin, W. (1988). 6-Methyl-1,2,8-trichlorodibenzofuran as a 2,3,7,8tetrachlorodibeno-p-dioxin antagonist: inhibition of the induction of rat cytochrome P-450 isozymes and related monooxygenase activities. Mol. Pharmacol. 33: 231-236.

Babich, H. and Borenfreund, E. (1991a). Cytotoxicity and genotoxicity assays with cultured fish cells: a review. Toxic. in Vitro 5: 91-100.

Babich, H., Rosenberg, D. W. and Borenfreund, E. (1991b). In vitro cytotoxicity studies with fish hepatoma cell line, PLHC-1 (Poeciliopsis lucida). Ecotoxicol. Environ. Safe. 21: 327-336.

Baksi, S. M. and Frazier, J. M. (1990). Isolated fish hepatocytes - model systems for toxicology research. Aquat. Toxicol. 16: 229-256.

Bandiera, S., Safe, S. and Okey, A. B. (1982). Binding of polychlorinated biphenyls classified as either phenobarbitone-, 3-methylcholanthrene- or mixed-type inducers to cytosolic Ah receptor. Chem.-Biol. Inter. 39: 259-277.

Berghard, A., Gradin, K., Pongratz, I., Whitelaw, M. and Poellinger, L. (1993). CrossCoupling of Signal Transduction Pathways - The Dioxin Receptor Mediates Induction of Cytochrome P-450IA1 Expression via a Protein Kinase-C-Dependent Mechanism. Mol Cell Biol 13(1): 677-689.

Biegel, L., Harris, M., Davis, D., Rosengren, R., Safe, L. and Safe, S. (1989). 2,2',4,4',5,5'-Hexachlorobiphenyl as a 2,3,7,8-tetrachlorodibenzo-p-dioxin antagonist in C57BL/6J mice. Toxicol. Appl. Pharmacol. 97: 561-571.

Birnbaum, L. S. (1991). Developmental toxicity of TCDD and related compounds: species sensitivities and differences. Banbury Report 35: Biological Basis for Risk Assessment of Dioxins and Related Compounds. M. A. Gallo, R. J. Scheuplein and K. A. V. d. Heijden, Cold Spring Harbor Press: 51-67. 
Black, J. W. and Leff, P. (1983). Operational models of pharmacological agonist. Proc. R. Soc. Lond. [Biol.] 220: 141-162.

Black, K. A., Novicki, D. L., Vincent, J. L. and Smith, G. J. (1993). Flow Cytometric Analysis of Xenobiotic Metabolism Activity in Isolated Rat Hepatocytes. Cytometry 14(3): 334-338.

Blank, J. A., Tucker, A. N., Sweatlock, J., Gasiewicz, T. A. and Luster, M. I. (1987). $\alpha-$ Naphthoflavone antagonism of 2,3,7,8-tetrachlorodibenzo-p-dioxin-induced murine lymphocyte ethoxyresorufin O-deethylase activity and immunosuppression. Mol. Pharmacol, 32: 168-172.

Bols, N. C. and Lee, L. E. J. (1991). Technology and uses of cell cultures from the tissues and organs of bony fish. Cytotechnology 6: 163-187.

Bradfield, C. A., Glover, E. and Poland, A. (1991). Purification and N-terminal amino acid sequence of the Ah receptor from the C57BL/6J mouse. Mol. Pharmacol. 39: 13-19.

Bradfield, C. A., Kende, A. S. and Poland, A. (1988a). Kinetic and equilibrium studies of Ah receptor-ligand binding: use of [ $\left.{ }^{125} \mathrm{I}\right] 2$-iodo-7,8-dibromodibenzo-p-dioxin. Mol. Pharmacol. 34: 229-237.

Bradfield, C. A. and Poland, A. (1988b). A competitive binding assay for 2,3,7,8tetrachlorodibenzo-p-dioxin and related ligands of the Ah receptor. $\underline{\text { Mol. }}$ Pharmacol. 34: 682-688.

Bruschweiler, B. J., Wurgler, F. E. and Fent, K. (1995). Cytotoxicity in vitro of organotin compounds to fish hepatoma cells PLHC-1 (Poeciliopsis lucida). Aquatic Tox. 32(2-3): 143-160.

Bruschweiler, B. J., Wurgler, F. E. and Fent, K. (1996a). An ELISA assay for cytochrome P4501A in fish liver cells. Environ. Toxicol. Chem. 15(4): 592-596.

Bruschweiler, B. J., Wurgler, F. E. and Fent, K. (1996b). Inhibitory effects of heavy metals on cytochrome P4501A induction in permanent fish hepatoma cells. Arch Environ Contam Toxicol 31(4): 475-82. 
Brzozowski, A. M., Pike, A. C., Dauter, Z., Hubbard, R. E., Bonn, T., Engstrom, O., Ohman, L., Greene, G. L., Gustafsson, J. A. and Carlquist, M. (1997). Molecular basis of agonism and antagonism in the oestrogen receptor. Nature 389(6652): 753-8.

Burbach, K. M., Poland, A. and Bradfield, C. A. (1992). Cloning of the Ah receptor cDNA reveals a distinctive ligand-activated transcription factor. Proc. Natl. Acad. Sci. U.S.A. 89: 8185-8189.

Busser, M. T. and Lutz, W. K. (1987). Stimulation of DNA synthesis in rat and mouse liver by various tumor promoters. Carcinogenesis 8(10): 1433-7.

Cahill, M. A., Emst, W. H., Janknecht, R. and Nordheim, A. (1994). Regulatory squelching. FEBS Lett 344(2-3): 105-8.

Carrier, F., Owens, R. A., Nebert, D. W. and Puga, A. (1992). Dioxin-dependent activation of murine Cyplal gene transcription requires protein kinase $\mathrm{C}$ dependent phosphorylation. Mol. Cell. Biol. 12(4): 1856-1863.

Carver, L. A. and Bradfield, C. A. (1997). Ligand-dependent interaction of the aryl hydrocarbon receptor with a novel immunophilin homolog in vivo. J. Biol. Chem. 272(17): 11452-11456.

Celander, M., Bremer, J., Hahn, M. E. and Stegeman, J. J. (1997). Glucocorticoidxenobiotic interactions: Dexamethasone potentiation of cytochrome P4501A induction by b-naphthoflavone in a fish hepatoma cell line (PLHC-1). Environ. Toxicol. Chem. 16(5): 900-907.

Celander, M., Hahn, M. E. and Stegeman, J. J. (1996). Cytochromes P450 (CYP) in the Poeciliopsis lucida hepatocellular carcinoma cell line (PLHC-1): Dose- and timedependent glucocorticoid potentiation of CYP1A induction without induction of CYP3A. Arch. Biochem. Biophys. 329(1): 113-122.

Chan, W. K., Yao, G., Gu, Y.-Z. and Bradfield, C. A. (1999). Cross-talk between the aryl hydrocarbon receptor and hypoxia inducible factor signaling pathways. Demonstration of competition and compensation. J Biol Chem 274: 12115-12123. 
Chen, Y. H. and Tukey, R. H. (1996). Protein kinase C modulates regulation of the CYP1A1 gene by the aryl hydrocarbon receptor. J Biol Chem 271(42): 26261-6.

Ciolino, H. P., Daschner, P. J. and Yeh, G. C. (1999). Dietary flavonols quercetin and kaempferol are ligands of the aryl hydrocarbon receptor that affect CYP1A! transcription differently. Biochem. J. 340: 715-722.

Clark, A. J. (1937). General Pharmacology. Heffner's Handbuch der experimentellen Pharmacologie Ergaenzungsband, Band 4. Berlin, Springer: 38-51.

Clemons, J. H., Lee, L. E. J., Myers, C. R., Dixon, D. G. and Bols, N. C. (1996). Cytochrome P4501A1 induction by polychlorinated biphenyls (PCBs) in liver cell lines from rat and trout and the derivation of toxic equivalency factors (TEFs). Can. J. Fish. Aquat. Sci. 53: 1177-1185.

Clemons, J. H., Myers, C. R., Lee, L. E. J., Dixon, D. G. and Bols, N. C. (1998). Induction of cytochrome P4501A by binary mixtures of polychlorinated biphenyls (PCBs) and 2,3,7,8-tetrachlorodibenzo-p-dioxin (TCDD) in liver cell lines from rate and trout. Aquat. Toxicol. 43: 179-194.

Crissman, H. A. and Hirons, G. T. (1994). Staining of DNA in live and fixed cells. Meth. Cell Biol. 41: 195-208.

Denison, M. S., Fine, J. and Wilkinson, C. F. (1984). Protamine sulfate precipitation: a new assay for the Ah receptor. Anal. Biochem. 142: 28-36.

Denison, M. S., Fisher, J. M. and Whitlock, J. P. (1988). The DNA recognition site for the dioxin-Ah receptor complex. J. Biol. Chem. 263: 17221-17224.

Denison, M. S., Wilkinson, C. F. and Okey, A. B. (1986). Ah receptor for 2,3,7,8tetrachlorodibenzo-p-dioxin: comparative studies in mammalian and nonmammalian species. Chemosphere 15: 1665-1672.

Denomme, M. A., Leece, B., Li, A., Towner, R. and Safe, S. (1986). Elevation of 2,3,7,8tetrachlorodibenzo-p-dioxin (TCDD) rat hepatic receptor levels by polychlorinated biphenyls. Structure-activity relationships. Biochem. Pharm. 35: $277-282$. 
Dickins, M., Seefeld, M. D. and Peterson, R. E. (1981). Toxicol. Appl. Pharmacol. 58: 389-398.

Dohr, O. and Abel, J. (1997a). Transforming growth factor- $\beta_{1}$ coregulates mRNA expression of aryl hydrocarbon receptor and cell-cycle-regulating genes in human cancer cell lines. Biochem. Biophys. Res. Comm. 241: 86-91.

Dohr, O., Sinning, R., Vogel, C., Munzel, P. and Abel, J. (1997b). Effect of transforming growth factor- $\beta 1$ on expression of aryl hydrocarbon receptor and genes of $\mathrm{Ah}$ gene battery: clues for independent down-regulation in A549 cells. Mol. Pharmacol. 51: 703-710.

Dold, K. M. and Greenlee, W. F. (1990). Filtration assay for quantitation of 2,3,7,8tetrachlorodibenzo-p-dioxin (TCDD) specific binding to whole cells in culture. Anal. Biochem. 184: 67-73.

Dolwick, K. M., Swanson, H. I. and Bradfield, C. A. (1993). In vitro analysis of Ah receptor domains involved in ligand-activated DNA recognition. Proc. Natl. Acad. Sci. U.S.A. 90: 8566-8570.

Doostdar, H., Burke, M. D., Melvin, W. T. and Grant, M. H. (1991). The effects of dimethylsulphoxide and 5-aminolaevulinic acid on the activities of cytochrome P450-dependent mixed function oxidase and UDP-glucuronosyl transferase activities in human Hep G2 hepatoma cells. Biochem. Pharmacol. 42: 1307-1313.

Doostdar, H., Duthie, S. J., Burke, M. D., Melvin, W. T. and Grant, M. H. (1988). The influence of culture medium composition on drug metabolising enzyme activities of the human liver derived Hep G2 cell line. FEBS Lett. 241(1,2): 15-18.

Drenth, H. J., Bouwman, C. A., Seinen, W. and Van den Berg, M. (1998). Effects of some persistent halogenated environmental contaminants on aromatase (CYP19) activity in the human choriocarcinoma cell line JEG-3. Toxicol. Appl. Pharmacol. 148(1): $50-5$.

Dulfer (1998). Kinetics and Conductivity Parameters of Uptake and Transport of Polychlorinated Biphenyls in the CACO-2 Intestinal Cell Line Model. Environmental Toxicology and Chemistry 17(3): 493-501. 
Dulfer, W. J., Groten, J. P. and Govers, H. A. J. (1996). Effect of fatty acids and the aqueous diffusion barrier on the uptake and transport of polychlorinated biphenyls in Caco-2 cells. Journal of Lipid Research 37: 950-961.

Duncan, D. M., Burgess, E. A. and Duncan, I. (1998). Control of distal antennal identity and tarsal development in Drosophila by spineless-aristapedia, a homolog of the mammalian dioxin receptor. Genes Dev. 12: 1290-1303.

Elferink, C. J., Gasiewicz, T. A. and Whitlock, J. P. (1990). Protein-DNA interactions at a dioxin-responsive enhancer. Evidence that the transformed Ah receptor is heteromeric. J. Biol. Chem. 265: 20708-20712.

Ema, M., Sogawa, K., Watanabe, N., Chujoh, Y., Matsushita, N., Gotoh, O., Funae, Y. and Fujii-Kuriyama, Y. (1992). cDNA cloning and structure of mouse putative Ah receptor. Biochemical and Biophysical Research Communications 184: 246-253.

Enan, E. and Matsumura, F. (1994). 2,3,7,8-tetrachlorodibenzo-p-dioxin (TCDD)Induced changes in glucose transporting activity in guinea pigs, mice, and rats in vivo and in vitro. J Biochem Toxicol 9(2): 97-106.

Enan, E. and Matsumura, F. (1995). Evidence for a second pathway in the action mechanism of 2,3,7,8-Tetrachlorodibenzo-p-dioxin (TCDD) - Significance of Ahreceptor mediated activation of protein kinase under cell-free conditions. Biochem Pharmacol 49(2): 249-261.

Enan, E. and Matsumura, F. (1996). Identification of c-Src as the integral component of the cytosolic Ah receptor complex, transducing the signal of 2,3,7,8Tetrachlorodibenzo-p-dioxin (TCDD) through the protein phosphorylation pathway. Biochem Pharmacol 52: 1599-1612.

Ernst, W., Goerke, H., Eder, G. and Schaefer, R. G. (1976). Bull. Environ. Contam. Toxicol. 15: 55.

Farrell, K. and Safe, S. (1987). Absence of positive co-operativity in the binding of 2,3,7,8-tetrachlorodibenzo-p-dioxin to its cytosolic receptor protein. Biochem. J. 244: $539-546$. 
Favreau, L. V. and Pickett, C. B. (1991). Transcriptional regulation of the rat NAD(P)H: quinone reductase gene. Journal of Biological Chemistry 266: 4556-4561.

Fent, K. and Batscher, R. (2000). Cyochrome P4501A induction potencies of polycyclic aromatic hydrocarbons in a fish hepatoma cell line: demonstration of additive interactions and an induction equivalency concept. Env. Tox. Chem.

Fernandez-Salguero, P., Hilbert, D. M., Rudikoff, S., Ward, J. M. and Gonzalez, F. J. (1996). Aryl-hydrocarbon receptor-deficient mice are resistant to 2,3,7,8tetrachlorodibenzo-p-dioxin-induced toxicity. Toxicology and Applied Pharmacology 140: 173-179.

Fox, T. R., Best, L. L., Goldsworthy, S. M., Mills, J. J. and Goldsworthy, T. L. (1993). Gene expression and cell proliferation in rat liver after 2,3,7,8-tetrachlorodibenzop-dioxin exposure. Cancer Res. 53: 2265-2271.

Furchgott, R. F. (1966). The use of beta-haloalkylamines in the differentiation of receptors and in the determination of dissociation constantsof receptor-agonist complexes. Adv. Drug Res. 3: 21-25.

Gaddum, J. H. (1937). The quantitative aspects of antagonistic drugs. J. Physiol. (Lond.) 89: 7P.

Gaido, K. W., Maness, S. C., Leonard, L. S. and Greenlee, W. F. (1992). 2,3,7,8Tetrachlorodibenzo-p-dioxin-dependent regulation of transforming growth factors-a and -b2 expression in a human keratinocyte cell line involves both transcriptional and post-transcriptional control. Journal of Biological Chemistry 34: 24591-24595.

Gasiewicz, T. A. and Neal, R. A. (1982). The examination and quantitation of tissue cytosolic receptors for 2,3,7,8-tetrachlorodibenzo-p-dioxin using hydroxylapatite. Anal. Biochem. 124: 1-11.

Ge, N. L. and Elferink, C. J. (1998). A direct interaction between the aryl hydrocarbon receptor and retinoblastoma protein - Linking dioxin signaling to the cell cycle. $\underline{\mathrm{J}}$ Biol Chem 273(35): 22708-22713. 
Gierthy, J. F., Bennett, J. A., Bradley, L. M. and Cutler, D. S. (1993). Correlation of in vitro and in vivo growth suppression of MCF-7 human breast cancer by $2,3.7,8$ tetrachlorodibenzo-p-dioxin. Cancer Research 53: 3149-3153.

Gierthy, J. F. and Crane, D. (1984). Reversible inhibition of in vitro epithelial cell proliferation by 2,3,7,8-tetrachlorodibenzo-p-dioxin. Toxicology and Applied Pharmacology 74: $91-98$.

Goldstein, A., Aronow, L. and Kalman, S. M. (1974). Principles of Drug Action: The Basis of Pharmacology, 2nd Edition, Wiley.

Gooch, J. W., Elskus, A. A., Kloepper-Sams, P. J., Hahn, M. E. and Stegeman, J. J. (1989). Effects of ortho and non-ortho substituted polychlorinated biphenyl congeners on the hepatic monooxygenase system in scup (Stenotomus chrysops). Toxicol. Appl. Pharmacol. 98: 422-433.

Gottlicher, M., Cikryt, P. and Wiebel, F. J. (1990). Inhibition of growth by 2,3,7,8tetrachlorodibenzo-p-dioxin in $5 \mathrm{~L}$ rat hepatoma cells is associated with the presence of Ah receptor. Carcinogenesis 11: 2205-2210.

Gradin, K., McGuire, J., Wenger, R. H., Kvietikova, I., Whitelaw, M. L., Toftgard, R., Tora, L., Gassmann, M. and Poellinger, L. (1996). Functional interference between hypoxia and dioxin signal transduction pathways: competition for recruitment of the Arnt transcription factor. Molecular and Cellular Biology 16(10): 5221-5231.

Greenlee, W. F. and Poland, A. (1979). Nuclear uptake of 2,3,7,8-tetrachlorodibenzo-pdioxin in $\mathrm{C} 57 \mathrm{BL} / 6 \mathrm{~J}$ and DBA/2J mice - role of the hepatic cytosolic receptor protein. J. Biol. Chem. 254: 9814-9821.

Hahn, M. E. (1998a). The Aryl Hydrocarbon Receptor: A Comparative Perspective. Comparative Biochemistry and Physiology 121 C(1-3): 23-53.

Hahn, M. E. (1998b). Mechanisms of innate and acquired resistance to dioxin-like compounds. Reviews in Toxicology. Series B - Environmental Toxicology 2(5,6): 395-443. 
Hahn, M. E. and Chandran, K. (1996a). Uroporphyrin accumulation associated with cytochrome $\mathrm{P} 4501 \mathrm{~A}$ induction in fish hepatoma cells exposed to Ah receptor agonists, including 2,3,7,8-tetrachlorodibenzo-p-dioxin and planar chlorobiphenyls. Arch. Biochem. Biophys. 329(2): 163-174.

Hahn, M. E. and Karchner, S. I. (1995). Evolutionary conservation of the vertebrate Ah (dioxin) receptor: Amplification and sequencing of the PAS domain of a teleost Ah receptor cDNA. Biochemical Journal 310(2): 383-387.

Hahn, M. E., Karchner, S. I., Shapiro, M. A. and Perera, S. A. (1997). Molecular evolution of two vertebrate aryl hydrocarbon (dioxin) receptors (AHR1 and AHR2) and the PAS family. Proceedings of the National Academy of Sciences U.S.A. 94(25): 13743-13748.

Hahn, M. E., Lamb, T. M., Schultz, M. E., Smolowitz, R. M. and Stegeman, J. J. (1993). Cytochrome P4501A induction and inhibition by 3,3',4,4'-tetrachlorobiphenyl in an Ah receptor-containing fish hepatoma cell line (PLHC-1). Aquat. Toxicol. 26: 185-208.

Hahn, M. E., Poland, A., Glover, E. and Stegeman, J. J. (1994). Photoaffinity labeling of the Ah receptor: Phylogenetic survey of diverse vertebrate and invertebrate species. Arch. Biochem. Biophys. 310(1): 218-228.

Hahn, M. E., Woodward, B. L., Stegeman, J. J. and Kennedy, S. W. (1996b). Rapid assessment of induced cytochrome P4501A (CYP1A) protein and catalytic activity in fish hepatoma cells grown in multi-well plates: Response to TCDD, TCDF, and two planar PCBs. Environ. Toxicol. Chem. 15(4): 582-591.

Hammond, A. H. and Fry, J. R. (1992). Effect of serum-free medium on cytochrome P450-dependent metabolism and toxicity in rat cultured hepatocytes. Biochem. Pharmacol. 44(7): 1461-1464.

Hankinson, O. (1993). Research on the Aryl Hydrocarbon (Dioxin) Receptor is Primed to Take Off. Archives of Biochemistry and Biophysics 300(1): 1-5.

Hankinson, O. (1995). The aryl hydrocarbon receptor complex. Annual Review of Pharmacology and Toxicology 35: 307-340. 
Harper, N., Wang, X., Liu, H. and Safe, S. (1994). Inhibition of estrogen-induced progesterone receptor in MCF-7 human breast cancer cells by aryl hydrocarbon (Ah) receptor agonists. Mol Cell Endocrinol 104(1): 47-55.

Heilmann, L. J., Sheen, Y. Y., Bigelow, S. W. and Nebert, D. W. (1988). The trout P450IA1: cDNA and deduced protein sequence, expression in liver, and evolutionary significance. DNA 7: 379-387.

Henry, E. C., Kende, A. S., Rucci, G., Totleben, M. J., Willey, J. J., Dertinger, S. D., Pollenz, R. S., Jones, J. P. and Gasiewicz, T. A. (1999). Flavone antagonists bind competitively with 2,3,7,8-tetrachlorodibenzo- $p$-dioxin (TCDD) to the aryl hydrocarbon receptor but inhibit nuclear uptake and transformation. Molecular Pharmacology 55: 716-725.

Hestermann, E. V., Stegeman, J. J. and Hahn, M. E. (in press). Serum alters the uptake and relative potencies of halogenated aromatic hydrocarbons in cell culture bioassays. Tox. Sci.

Hightower, L. E. and Renfro, J. L. (1988). Recent applications of fish cell culture to biomedical research. J. Exper. Zool. 248: 290-302.

Hinds, P. W. and Weinberg, R. A. (1994). Tumor suppressor genes. Curr Opin Genet Dev 4(1): $135-41$.

Hoffer, A., Chang, C. Y. and Puga, A. (1996). Dioxin induces transcription of fos and jun genes by Ah receptor-dependent and -independent pathways. Toxicol Appl Pharmacol 141(1): 238-247.

Hoffman, E. C., Reyes, H., Chu, F.-F., Sander, F., Conley, L. H., Brooks, B. A. and Hankinson, O. (1991). Cloning of a factor required for activity of the Ah (dioxin) receptor. Science 252: 954-958.

Huff, J., Lucier, G. and Tritscher, A. (1994). Carcinogenicity of TCDD - Experimental, Mechanistic, and Epidemiologic Evidence. Annu Rev Pharmacol Toxicol 34: 343-372.

Huggett, R. J. (1992). Biomarkers for Chemical Contamination, CRC Press. 
Hushka, D. R. and Greenlee, W. F. (1995). 2.3.7,8-Tetrachlorodibenso-p-dioxin inhibits DNA synthesis in rat primary hepatocytes. Mutation Research 333: 89-99.

Huuskonen, S. E., Hahn, M. E. and Lindstrom-Seppa, P. E. (1998a). A fish hepatoma cell line (PLHC-1) as a tool to study cytotoxicity and CYP1A induction properties of cellulose and wood chip extracts. Chemosphere 36(14): 2921-2932.

Huuskonen, S. E., Koponen, K., Ritola, O., Hahn, M. and Lindstrom-Seppa, P. E. (1998b). Induction of CYP1A and porphyrin accumulation in fish hepatoma cells (PLHC-1) exposed to sediment or water from a PCB-contaminated lake (Lake Kernaala, Finland). Marine Environmental Research 46(1-5): 379-384.

Huuskonen, S. E., Ristola, T. E., Tuvikene, A., Hahn, M. E., Kukkonen, J. V. K. and Lindstrom-Seppa, P. E. (1998c). Comparison of two bioassays, a fish liver cell line (PLHC-1) and a midge (Chironomus riparius), in monitoring freshwater sediments. Aquatic Toxicology 44: 47-67.

Huuskonen, S. E., Tuvikene, A., Trapido, M. and Hahn, M. E. (2000). CYP1A induction and porphyrin accumulation in PLHC-1 fish cells exposed to sediment and oil shale extracts. Archives of Environmental Contamination and Toxicology 38: 5969.

Israel, D. and J.P. Whitlock, J. (1984). Regulation of cytochrome P1450 gene transcription by 2,3,7,8-tetrachlorodibenzo-p-dioxin in wild type and variant mouse hepatoma cells. J. Biol. Chem. 259: 5400-5402.

Jacks, T. and Weinberg, R. A. (1998). The expanding role of cell cycle regulators. Science 280: 1035-1072.

Jenkinson, D. H., Barnard, E. A., Hoyer, D., Humphrey, P. P. A., Leff, P. and Shankley, N. P. (1995). International Union of Pharmacology Committee on Receptor Nomenclature and Drug Classification. IX. Recommendations on Terms and Symbols in Quantitative Pharmacology. Pharmacological Reviews 47: 255-266. Jones, P. B. C., Durrin, L. K., Fisher, J. M. and Whitlock, J. P. (1986). Control of gene expression by 2,3,7,8-tetrachlorodibenzo-p-dioxin. Multiple dioxin-responsive domains 5'-ward of the cytochrome $\mathrm{P}_{1}-450$ gene. J. Biol. Chem. 261: 6647-6650. 
Kalmaz, E. V. and Kalmaz, G. D. (1979). Ecol. Model. 6: 223.

Karchner, S. I., Powell, W. H. and Hahn, M. E. (1999). Identification and functional characterization of two highly divergent aryl hydrocarbon receptors (AHRI and AHR2) in the teleost Fundulus heteroclitus. J. Biol. Chem. 274(47): 3381433824 .

Karenlampi, S. O., Legraverend, C., Gudas, J. M., Carramanzana, N. and Hankinson, O. (1988). A third genetic locus affecting the Ah (dioxin) receptor. J. Biol. Chem. 263: 10111-10117.

Kenakin, T. (1999). Pharmacologic Analysis of Drug-Receptor Interactions. New York, CRC/Raven Press.

Kennedy, S. W., Jones, S. P. and Bastien, L. J. (1995). Efficient analysis of cytochrome P4501A catalytic activity, porphyrins, and total proteins in chicken embryo hepatocyte cultures with a fluorescence plate reader. Anal. Biochem. 226: 362370.

Kennedy, S. W., Lorenzen, A., James, C. A. and Collins, B. T. (1993). EthoxyresorufinO-deethylase and porphyrin analysis in chicken embryo hepatocyte cultures with a fluorescence multi-well plate reader. Anal. Biochem. 211: 102-112.

Kennedy, S. W., Lorenzen, A., Jones, S. P., Hahn, M. E. and Stegeman, J. J. (1996a). Cytochrome P4501A induction in avian hepatocyte cultures: a promising approach for predicting the sensitivity of avian species to toxic effects of halogenated aromatic hydrocarbons. Toxicol. Appl. Pharmacol. 141: 214-230.

Kennedy, S. W., Lorenzen, A. and Norstrom, R. J. (1996b). Chicken embryo hepatocyte bioassay for measuring cytochrome P4501A-based 2,3,7,8-tetrachlorodibenzo-pdioxin equivalent concentrations in environmental samples. Environ. Sci. Technol. 30: 706-715.

Klotz, I. M. (1982). Numbers of receptor sites from scatchard graphs: facts and fantasies. Science 217: 1247-1249.

Kociba, R. (1991). Rodent bioassays for assessing chronic toxicity and carcinogenic potential of TCDD. Banbury report 35: biological basis for risk assessment of 
dioxins and related compounds. M. A. Gallo, R. J. Scheuplein and K. A. van der Heiden. Plainview, NY, Cold Spring Harbor Laboratory Press.

Kociba, R. J. and Schwetz, B. A. (1982). Toxicity of 2, 3, 7, 8-tetrachlorodibenzo-pdioxin (TCDD). Drug Metab Rev 13(3): 387-406.

Krek, W. and DeCaprio, J. A. (1995). Cell synchronization. Meth. Enzymol. 254: 114124.

Lees, M. J. and Whitelaw, M. L. (1999). Multiple roles of ligand in transforming the dioxin receptor to an active basic helix-loop-helix/PAS transcription factor complex with the nuclear protein Arnt. Mol Cell Biol 19(8): 5811-22.

Limbird, L. E. and Taylor, P. (1998). Endocrine disruptors signal the need for receptor models and mechanisms to inform policy. Cell 93: 157-163.

Lorenzen, A. and Okey, A. B. (1990). Detection and characterization of $\left[{ }^{3} \mathrm{H}\right] 2,3,7,8-$ tetrachlorodibenzo- $p$-dioxin binding to Ah receptor in a rainbow trout hepatoma cell line. Toxicol. Appl. Pharmacol. 106: 53-62.

Lu, Y. F., Santostefano, M., Cunningham, B. D. M., Threadgill, M. D. and Safe, S. (1995). Identification of 3'-methoxy-4'-nitroflavone as a pure aryl hydrocarbon (Ah) receptor antagonist and evidence for more than one form of the nuclear Ah receptor in MCF-7 human breast cancer cells. Arch Biochem Biophys 316(1): 470-477.

Lucier, G. W., Tritscher, A., Goldsworthy, T., Foley, J., Clark, G., Goldstein, J. and Maronpot, R. (1991). Ovarian hormones enhance 2,3,7,8-tetachlorodibenzo-pdioxin-mediated increases in cell proliferation and preneoplastic foci in a twostage model for rat hepatocarcinogenesis. Cancer Res. 51: 1391-1397.

Lusska, A., Shen, E. and Whitlock, J. P. (1993). Protein-DNA Interactions at a DioxinResponsive Enhancer - Analysis of 6 Bona-Fide DNA-Binding Sites for the Liganded Ah Receptor. J Biol Chem 268(9): 6575-6580.

Ma, Q. and Whitlock, J. P. (1996). The aromatic hydrocarbon receptor modulates the Hepa 1c1c7 cell cycle and differentiated state independently of dioxin. Molecular and Cellular Biology 16(5): 2144-2150. 
Ma, Q. and Whitlock, J. P. (1997). A novel cytoplasmic protein that interacts with the Ah receptor, contains tetratricopeptide repeat motifs, and augments the transcriptional response to 2,3,7,8-tetrachlorodibenzo-p-dioxin. Joumal of Biological Chemistry 272(14): 8878-8884.

Ma, X. F. and Babish, J. G. (1993). Acute 2,3,7,8-Tetrachlorodibenzo-p-dioxin Exposure Results in Enhanced Tyrosylphosphorylation and Expression of Murine Hepatic Cyclin Dependent Kinases. Biochem Biophys Res Commun 197(3): 1070-1077.

Mathis, J. M., Houser, W. H., Bresnick, E., Cidlowski, J. A., Hines, R. N., Prough, R. A. and Simpson, E. R. (1989). Glucocorticoid regulation of the rat cytochrome P450c (P450IA1) gene: Receptor binding within intron 1. Arch. Biochem. Biophys. 269: 93-105.

Matsumura, F. (1994). How important is the protein phosphorylation pathway in the toxic expression of dioxin-type chemicals? Commentary. Biochem Pharmacol 48(2): 215-224.

McGuire, J., Whitelaw, M. L., Pongratz, I., Gustafsson, J. A. and Poellinger, L. (1994). A Cellular Factor Stimulates Ligand-Dependent Release of hsp90 from the Basic Helix-Loop-Helix Dioxin Receptor. Mol Cell Biol 14(4): 2438-2446.

Merchant, M., Morrison, V., Santostefano, M. and Safe, S. (1992). Mechanism of action of aryl hydrocarbon receptor antagonists: Inhibition of 2,3,7,8tetrachlorodibenzo-p-dioxin-induced CYP1A1 gene expression. Arch. Biochem. Biophys. 298: 389-394.

Meyer, B. K., Pray-Grant, M. F., vanden Heuvel, J. P. and Perdew, G. H. (1998). Hepatitis B virus $\mathrm{X}$-associated protein 2 is a subunit of the unliganded aryl hydrocarbon receptor core complex and exhibits transcriptional enhancer activity. Molecular and Cellular Biology 18(2): 978-988.

Miller, A. G. (1983). Ethylated fluoresceins: Assay of cytochrome P-450 activity and application to measurements in single cells by flow cytometry. Analytical Biochemistry 133: 46-57. 
Miller, A. G. and Whitlock, J. P. J. (1981). Novel variants in benzo(a)pyrene metabolism. The Journal of Biological Chemistry 256(5): 2433-2437.

Morrison, H. G., Oleksiak, M. F., Cornell, N. W., Sogin, M. L. and Stegeman, J. J. (1995). Identification of cytochrome P-450 1A (CYP1A) genes from two teleost fish, toadfish (Opsanus tau) and scup (Stenotomus chrysops), and phylogenetic analysis of CYP1A genes. Biochemical Journal 308: 97-104.

Mudzinski, S. P. (1993). Effects of Benzo[a]pyrene on concanavalin A-stimulated human peripheral blood mononuclear cells in vitro: inhibition of proliferation but no effect on parameters related to the $G_{1}$ phase of the cell cycle. Toxicol Appl Pharmacol 119: 166-174.

Murray, A. and Hunt, T. (1994). The cell cycle: an introduction. New York, W. H. Freemen \& Co.

Nagel, S. C., vom Saal, F. S., Thayer, K. A., Dhar, M. G., Boechler, M. and Welshons, W. V. (1997). Relative binding affinity-serum modified access (RBA-SMA) assay predicts the relative in vivo bioactivity of the xenoestrogens bisphenol $\mathrm{A}$ and octylphenol. Environ. Health Perspect. 105: 70-76.

Nebert, D. W., Goujon, F. M. and Gielen, J. E. (1972). Aryl hydrocarbon hydroxylase induction by polycyclic hydrocarbons: simple autosomal trait in the mouse. Nature New Biol. 236: 107-110.

Newsted, J. L. and Giesy, J. P. (1993). Effect of 2,3,7,8-tetrachlorodibenzo-p-dioxin (TCDD) on the epidermal growth factor receptor in hepatic plasma membranes of rainbow trout. Toxicology and Applied Pharmacology 118: 119-130.

Newsted, J. L., Giesy, J. P., Ankley, G. T., Tillitt, D. E., Crawford, R. A., Gooch, J. W., Jones, P. D. and Denison, M. S. (1995). Development of toxic equivalency factors for PCB congeners and the assessment of TCDD and PCB mixtures in rainbow trout. Environmental Toxicology and Chemistry 14(5): 861-871.

Norris, J. D., Fan, D., Stallcup, M. R. and McDonnell, D. P. (1998). Enhancement of estrogen receptor transcriptional activity by the coactivator GRIP-1 highlights the 
role of activation function 2 in determining estrogen receptor pharmacology. Biol Chem 273(12): 6679-88.

Okey, A. and Vella, L. (1984). Elevated binding of 2,3,7,8-tetrachlorodibenzo-p-dioxin and 3-methylcholanthrene to the Ah receptor in hepatic cytosols from phenobarbital-treated rats and mice. Biochem. Pharm. 33: 531-538.

Okey, A. B., Bondy, G. P., Mason, M. E., Kahl, G. F., Eisen, H. J., Guenthner, T. M. and Nebert, D. W. (1979). Regulatory gene product of the Ah locus. Characterization of the cytosolic inducer-receptor complex and evidence for its nuclear translocation. J. Biol. Chem. 254: 11636-11648.

Okino, S. T., Pendurthi, U. R. and Tukey, R. H. (1992). Phorbol Esters Inhibit the Dioxin Receptor-Mediated Transcriptional Activation of the Mouse Cyp1a-1 and Cyp1a2 Genes by 2,3,7,8-Tetrachlorodibenzo-p-dioxin. J Biol Chem 267(10): 69916998.

Park, S. S., Miller, H., Klotz, A. V., Kloepper-Sams, P. J., Stegeman, J. J. and Gelboin, H. V. (1986). Monoclonal antibodies to liver microsomal cytochrome P-450E of the marine fish Stenotomus chrysops (scup): Cross-reactivity with 3methylcholanthrene induced rat cytochrome P-450. Arch. Biochem. Biophys. 249: 339-350.

Pasco, D. S., Boyum, K. W., Elbi, C., Siu, C. S. and Fagan, J. B. (1993). Inducerdependent transcriptional activation of the P4501A2 gene in vivo and in isolated hepatocytes. Journal of Biological Chemistry 268: 1053-1057.

Peakall, D. B. (1975). Crit. Rev. Environ. Control. 5: 469.

Perdew, G. H. (1988). Association of the Ah receptor with the $90-\mathrm{kDa}$ heat shock protein. J. Biol. Chem. 263: 13802-13805.

Pesonen, M. and Andersson, T. B. (1997). Fish primary hepatocyte culture; an important model for xenobiotic metabolism and toxicity studies. Aquatic Toxicology 37: 253-267. 
Petrulis, J. R. and Bunce, N. J. (1999). Competitive inhibition by inducer as a confounding factor in the use of the ethoxyresorufin-O-deethylase (EROD) assay to estimate exposure to dioxin-like compounds. Toxicol. Lett. 105(3): 251-60.

Poland, A. (1991). Receptor-mediated toxicity: relfections on a quantitative model for risk assessment. Banbury Report 35: Biological Basis for Risk Assessment of Dioxins and Related Compounds. M. A. Gallo, R. J. Scheuplein and K. A. V. d. Heijden, Cold Spring Harbor Press: 417-426.

Poland, A. (1996). Meeting Report: Receptor-acting xenobiotics and their risk assessment. Drug Metab Dispos 24(12): 1385-1388.

Poland, A. and Glover, E. (1973). Chlorinated dibenzo-p-dioxins: potent inducers of delta-aminolevulinic acid synthetase and aryl hydrocarbon hydroxylase. II. A study of the structure-activity relationship. Mol. Pharmacol. 9: 736-747.

Poland, A. and Glover, E. (1974). Comparison of 2,3,7,8-tetrachlorodibenzo-p-dioxin, a potent inducer of aryl hydrocarbon hydroxylase, with 3-methyl-cholanthrene. Mol. Pharmacol. 10: 349-359.

Poland, A. and Glover, E. (1975). Genetic expression of aryl hydrocarbon hydroxylase by 2,3,7,8-tetrachlorodibenzo-p-dioxin: evidence for a receptor mutation in genetically non-responsive mice. Molecular Pharmacology 11: 389-398.

Poland, A., Glover, E. and Kende, A. S. (1976). Stereospecific, high-affinity binding of 2,3,7,8-tetrachlorodibenzo-p-dioxin by hepatic cytosol. J. Biol. Chem. 251: 49364946.

Poland, A. and Knutson, J. C. (1982). 2,3,7,8-Tetrachlorodibenzo-p-dioxin and related halogenated aromatic hydrocarbons: examination of the mechanism of toxicity. Annual Reviews of Pharmacology and Toxicology 22: 517-554.

Pollenz, R. S., Sattler, C. A. and Poland, A. (1994). The aryl hydrocarbon receptor and aryl hydrocarbon receptor nuclear translocator protein show distinct subcellular localizations in Hepa 1c1c7 cells by immunofluorescence. Molecular Pharmacology 45: 428-438. 
Powell-Coffman, J. A., Bradfield, C. A. and Wood, W. B. (1998). Caenorhabditis elegans orthologs of the aryl hydrocarbon receptor and its heterodimerization partner the aryl hydorcarbon nuclear translocator. Proc. Natl. Acad. Sci. USA 95: 2844-2849.

Prywes, R. and Zhu, H. (1992). In vitro squelching of activated transcription by serum response factor: evidence for a common coactivator used by multiple transcriptional activators. Nucleic Acids Res 20(3): 513-20.

Puga, A., Nebert, D. W. and Carrier, F. (1992). Dioxin induces expression of c-fos and cjun proto-oncogenes and a large increase in transcription factor AP-1. DNA Cell Biol. 11(4): 269-281.

Reiners, J. J., Lee, J. Y., Clift, R. E., Dudley, D. T. and Myrand, S. P. (1998). PD98059 is an equipotent antagonist of the aryl hydrocarbon receptor and inhibitor of mitogen-activated protein kinase kinase. Mol Pharmacol 53(3): 438-445.

Reisz-Porszasz, S., Probst, M. R., Fukunaga, B. N. and Hankinson, O. (1994). Identification of functional domains of the aryl hydrocarbon receptor nuclear translocator protein (ARNT). Mol. Cell. Biol. 14: 6075-6086.

Rushmore, T. H. and Pickett, C. B. (1990). Transcriptional regulation of rat glutathione stransferase ya subunit gene. Journal of Biological Chemistry 265: 14648-14653.

Ryan, J. A. and Hightower, L. E. (1994). Evaluation of heavy-metal ion toxicity in fish cells using a combined stress protein and cytotoxicity assay. Environmental Toxicology and Chemistry 13(8): 1231-1240.

Safe, S. (1984). Polychlorinated biphenyls (PCBs) and polybrominated biphenyls (PBBs): biochemistry, toxicology, and mechanism of action. CRC Crit. Rev. Toxicol. 13: 319-395.

Safe, S. (1987). Determination of 2,3,7,8-TCDD toxic equivalent factors (TEFs): support for the use of in the vitro AHH induction assay. Chemosphere 16: 791-802.

Safe, S. (1990). Polychlorinated biphenyls (PCBs), dibenzo-p-dioxins (PCDDs), dibenzofurans (PCDFs), and related compounds: environmental and mechanistic 
considerations which support the development of toxic equivalency factors (TEFs). CRC Crit. Rev. Toxicol. 21(1): 51-88.

Santostefano, M., Piskorska-Pliszczynska, J., Morrison, V. and Safe, S. (1992). Effects of ligand structure on the in vitro transformation of the rat cytosolic aryl hydrocarbon receptor. Archives of Biochemistry and Biophysics 297: 73-79.

Sawyer, T. and Safe, S. (1982). PCB isomers and congeners: induction of aryl hydrocarbon hydroxylase and ethoxyresorufin O-deethylase enzyme activities in rat hepatoma cells. Toxicol. Lett. 13: 87-94.

Schafer, M. W., Madhukar, B. V., Swanson, H. I., Tullis, K. and Denison, M. S. (1993). Protein Kinase-C Is Not Involved in Ah Receptor Transformation and DNA Binding. Arch Biochem Biophys 307(2): 267-271.

Schenkman, J. B. and Greim, H., Eds. (1992). Cytochrome P450. Handbook of Experimental Pharmacology.

Schirmer, K., Chan, A. G. J., Greenberg, B. M., Dixon, D. G. and Bols, N. C. (1997). Methodology for demonstrating and measuring the phototoxicity of fluoranthene to fish cells in culture. Toxicol. In Vitro 11: 107-119.

Schlezinger, J. J., White, R. D. and Stegeman, J. J. (1999). Oxidative inactivation of cytochrome P-450 1A (CYP1A) stimulated by 3,3',4,4'-tetrachlorobiphenyl: production of reactive oxygen by vertebrate CYP1As. Mol Pharmacol 56(3): 58897.

Schmidt, J. V. and Bradfield, C. A. (1996). Ah receptor signaling pathways. Annual Review of Cell and Developmental Biology 12: 55-89.

Scholler, A., Hong, N. J., Bischer, P. and Reiners, J. J. (1994). Short and long term effects of cytoskeleton-disrupting drugs on cytochrome P450 Cyp1a-1 induction in murine hepatoma 1c1c7 cells: Suppression by the microtubule inhibitor nocodazole. Mol Pharmacol 45(5): 944-954.

Schrenk, D., Karger, A., Lipp, H.-P. and Bock, K. W. (1992). 2,3,7,8Tetrachlorodibenzo-p-dioxin and ethinylestradiol as co-mitogens in cultured rat hepatocytes. Carcinogenesis 13: 453-456. 
Segner, H. (1998). Fish cell lines as a tool in aquatic toxicology. Fish Ecotoxicology. T. Braunbeck, D. E. Hinton and B. Streit. Basel, Switzerland, Birkhauser Verlag.

Sewall, C. H., Lucier, G. W., Tritscher, A. M. and Clark, G. C. (1993). TCDD-Mediated Changes in Hepatic Epidermal Growth Factor Receptor May Be a Critical Event in the Hepatocarcinogenic Action of TCDD. Carcinogenesis 14(9): 1885-1893.

Sloop, T. C. and Lucier, G. W. (1987). Dose-dependent elevation of Ah receptor binding by TCDD in rat liver. Toxicology and Applied Pharmacology 88: 329-337.

Smeets, J. M. W., Voormolen, A., Tillitt, D. E., Everaarts, J. M., Seinen, W. and van den Berg, M. (1999). Cytochrome P4501A Induction, Benzo[a]pyrene Metabolism, and Nucleotide Adduct Formation in Fish Hepatoma Cells; Effect of Preexposure to 3,3'4,4',5 Pentachlorobiphenyl. Environmental Toxicology and Chemistry 18(3): 474-480.

Smith, P. K., Krohn, R. I., Hermanson, G. T., Mallia, A. K., Gartner, F. H., Provenzano, M. D., Fujimoto, E. K., Goeke, N. M., Olson, B. J. and Klenk, D. C. (1985). Measurement of protein using bicinchoninic acid. Anal. Biochem. 150: 76-85.

Sourlingas, T. G. and Sekeri-Pataryas, K. E. (1996). Aphidicolin large-scale synchronization of rapidly dividing cell monolayers and the analysis of total histone and histone variant biosynthesis during the $\mathrm{S}$ and $\mathrm{G} 2$ phases of the HEp-2 cell cycle. Analytical Biochemistry 234: 104-107.

Spitsbergen, J. M., Kleeman, J. M. and Peterson, R. E. (1988). Morphologic lesions and acute toxicity in rainbow trout (Salmo gairneri) treated with 2,3,7,8tetrachlorodibenzo-p-dioxin. J. Toxicol. Environ. Health 23: 333-358.

Stauber, K. L., Laskin, J. D., Yurkow, E. J., Thomas, P. E., Laskin, D. L. and Conney, A. H. (1995). Flow cytometry reveals subpopulations of murine epidermal cells that are refractory to induction of cytochrome P-4501A1 by beta-naphthoflavone. $\underline{\mathrm{J}}$ Pharmacol Exp Ther 273(2): 967-976.

Stegeman, J. J. and Hahn, M. E. (1994). Biochemistry and molecular biology of monooxygenases: Current perspectives on forms, functions, and regulation of cytochrome P450 in aquatic species. Aquatic Toxicology: Molecular, 
Biochemical and Cellular Perspectives. D. C. Malins and G. K. Ostrander. Boca Raton, CRC/Lewis: 87-206.

Stephenson, R. P. (1956). A modification of receptor theory. Br. J. Pharmacol. 11: 379393.

Sutter, T. R., Guzman, K., Dold, K. M. and Greenlee, W. F. (1991). Targets for dioxin: genes for plasminogen activator inhibitor- 2 and interleukin-1 $\beta$. Science $254: 415$ 418.

Swanson, H. I. and Perdew, G. H. (1991). Detection of the Ah receptor in rainbow trout. Use of 2-azido-3-[125I]iodo-7,8-dibromodibenzo-p-dioxin in cell culture. Toxicology Letters 58(1): 85-95.

Swanson, H. I., Tullis, K. and Denison, M. S. (1993). Binding of Transformed Ah Receptor Complex to a Dioxin Responsive Transcriptional Enhancer - Evidence for Two Distinct Heteromeric DNA-Binding Forms. Biochemistry 32(47): 1284112849 .

Takimoto, K., Lindahl, R., Dunn, T. J. and Pitot, H. C. (1994). Structure of the 5 ' flanking region of class 3 aldehyde dehydrogenase in the rat. Arch Biochem Biophys 312(2): 539-546.

Tanguay, R. L., Abnet, C. C., Heideman, W. and Peterson, R. E. (1998). Cloning and characterization of the zebrafish (Danio rerio) aryl hydrocarbon receptor. $\mathrm{Bba}$ Gene Struct Express 1444(1): 35-48.

Tillitt, D. E., Giesy, J. P. and Ankley, G. T. (1991). Characterization of the H4IIE rat hepatoma cell bioassay as a tool for assessing toxic potency of planar halogenated hydrocarbons in environmental samples. Environ. Sci. Technol. 25(1): 87-92.

Tumer, N. A. and Pitot, H. C. (1989). Dependence of the induction of cytochrome P-450 by phenobarbitol in primary cultures of adult rat hepatocytes on the composition of the culture medium. Biochem. Pharmacol. 38(14): 2247-2251.

van den Berg, M., Birnbaum, L., Bosveld, B. T. C., Brunström, B., Cook, P., Feeley, M., et al. (1998). Toxic Equivalency Factors (TEFs) for PCBs, PCDDs, and PCDFs for humans and wildlife. Environ. Health Perspect. 106: 775-792. 
Vanden Heuvel, J. P. and Lucier, G. (1993). Environmental toxicology of polychlorinated dibenzo-p-dioxins and polychlorinated dibenzofurans. Environ Health Perspect 100: $189-200$.

Vasiliou, V., Reuter, S. F., Kozak, C. A. and Nebert, D. W. (1993). Mouse DioxinInducible Cytosolic Aldehyde Dehydrogenase-3 - AHD4 cDNA Sequence, Genetic Mapping, and Differences in Messenger ma Levels. Pharmacogenetics 3(6): 281-290.

Vaziri, C. and Faller, D. V. (1997). A benzo[a]pyrene-induced cell cycle checkpoint resulting in p53-independent $\mathrm{G}_{1}$ arrest in $3 \mathrm{~T} 3$ fibroblassts. The Joumal of Biological Chemistry 272(5): 2762-2769.

Vaziri, C., Schneider, A., Sherr, D. H. and Faller, D. V. (1996). Expression of the aryl hydrocarbon receptor is regulated by serum and mitogenic growth factors in murine 3T3 fibroblasts. J. Biol. Chem. 271(42): 25921-25927.

Villeneuve, D. L., Crunkilton, R. L. and DeVita, W. M. (1997). Aryl hydrocarbon receptor-mediated toxic potency of dissolved lipophilic organic contaminants collected from Lincoln Creek, Milwaukee, Wisconsin, USA, to PLHC-1 (Poeciliopsis lucida) fish hepatoma cells. Environmental Toxicology and Chemistry 16(5): 977-984.

Walker, M. K. and Peterson, R. E. (1991). Potencies of polychlorinated dibenzo-p-dioxin, dibenzofuran, and biphenyl congeners, relative to 2,3,7,8-tetrachlorodibenzo-pdioxin, for producing early life stage mortality in rainbow trout (Oncorhynchus mykiss). Aquat. Toxicol. 21: 219-238.

Wang, X., Porter, W., Krishnan, V., Narasimhan, T. R. and Safe, S. (1993). Mechanism of 2,3,7,8-tetrachlorodibenzo-p-dioxin (TCDD)-Mediated Decrease of the Nuclear Estrogen Receptor in MCF-7 Human Breast Cancer Cells. Mol Cell Endocrinol 96(1-2): 159-166.

Wassermann, M., Wassermann, D., Cucos, S. and Miller, H. J. (1979). World PCBs map: storage and effects in man and his biologic environment in the 1970s. Ann NY Acad Sci 320: 69-124. 
Weber, T. J., Fan, Y. Y., Chapkin, R. S. and Ramos, K. S. (1997). Growth-related signaling in vascular smooth muscle cells is deregulated by TCDD during the $\mathrm{G}(0) / \mathrm{G}(1)$ transition. J Toxicol Environ Health 51(4): 369-386.

Weber, T. J., Ou, X. L., Merchant, M., Wang, X. H., Safe, S. H. and Ramos, K. S. (1994). Biphasic Modulation of Protein Kinase C (PKC) Activity by Polychlorinated Dibenzo-P-Dioxins (PCDDs) in Serum-Deprived Rat Aortic Smooth Muscle Cells. J Biochem Toxicol 9(3): 113-120.

Weiss, C., Kolluri, S. K., Kiefer, F. and Gottlicher, M. (1996). Complementation of Ah receptor deficiency in hepatoma cells: Negative feedback regulation and cell cycle control by the Ah receptor. Exp Cell Res 226(1): 154-163.

Whitelaw, M., Gustafsson, J. A. and Poellinger, L. (1994). Identification of transactivation and repression functions of the dioxin receptor and its basic helixloop-helix/PAS partner factor ARNT: Inducible versus constitutive modes of regulation. Mol. Cell. Biol. 14: 8343-8355.

Whitelaw, M. L., McGuire, J., Picard, D., Gustafsson, J.-A. and Poellinger, L. (1995). Heat shock protein hsp90 regulates dioxin receptor function in vivo. Proceedings of the National Academy of Sciences U.S.A. 92: 4437-4441.

Whitlock, J. P. (1999). Induction of cytochrome P4501A1. Annual Review of Pharmacology and Toxicology 39: 103-125.

WHO (1976). Environmental health criteria II: polychlorinated biphenyls and terphenyls. Geneva, World Health Organization.

Wiebel, F. J., Klose, U. and Kiefer, F. (1991). Toxicol. Lett. 55(161-169).

Wolfle, D., Munzel, P., Fischer, G. and Bock, K. W. (1988). Altered growth control of rat hepatocytes after treatment with 3,4,3',4'-tetrachlorobiphenyl in vivo and in vitro. Carcinogenesis 9: 919-924.

Yu, K. O., Fisher, J. W., Burton, G. A. and Tillitt, D. E. (1997). Carrier Effects of Dosing the H4IIE Cells with 3,3',4,4'-tetrachlorobiphenyl (PCB77) in dimethylsulfoxide or isooctane. Chemosphere 35(4): 895-904. 